Portland State University

PDXScholar

$11-4-1976$

\title{
A Numerical Solution For The Ultimate Strength of Tubular Beam-Columns
}

Arnold L. Wagner

Portland State University

Follow this and additional works at: https://pdxscholar.library.pdx.edu/open_access_etds

Part of the Civil and Environmental Engineering Commons, Engineering Education Commons, and the Science and Mathematics Education Commons

Let us know how access to this document benefits you.

\section{Recommended Citation}

Wagner, Arnold L., "A Numerical Solution For The Ultimate Strength of Tubular Beam-Columns" (1976). Dissertations and Theses. Paper 2437.

https://doi.org/10.15760/etd.2436

This Thesis is brought to you for free and open access. It has been accepted for inclusion in Dissertations and Theses by an authorized administrator of PDXScholar. Please contact us if we can make this document more accessible: pdxscholar@pdx.edu. 
AN ABSTRACT OF THE THESIS OF Arnold L. Wagner for the Master of Sclence In Applied Sclence presented November 4, 1976.

Title: A Numerical Solution For The Ultimate Strength of Tubular Beam-Columns.

APPROVED BY MEMBERS OF THE THESIS COMMITTEE:

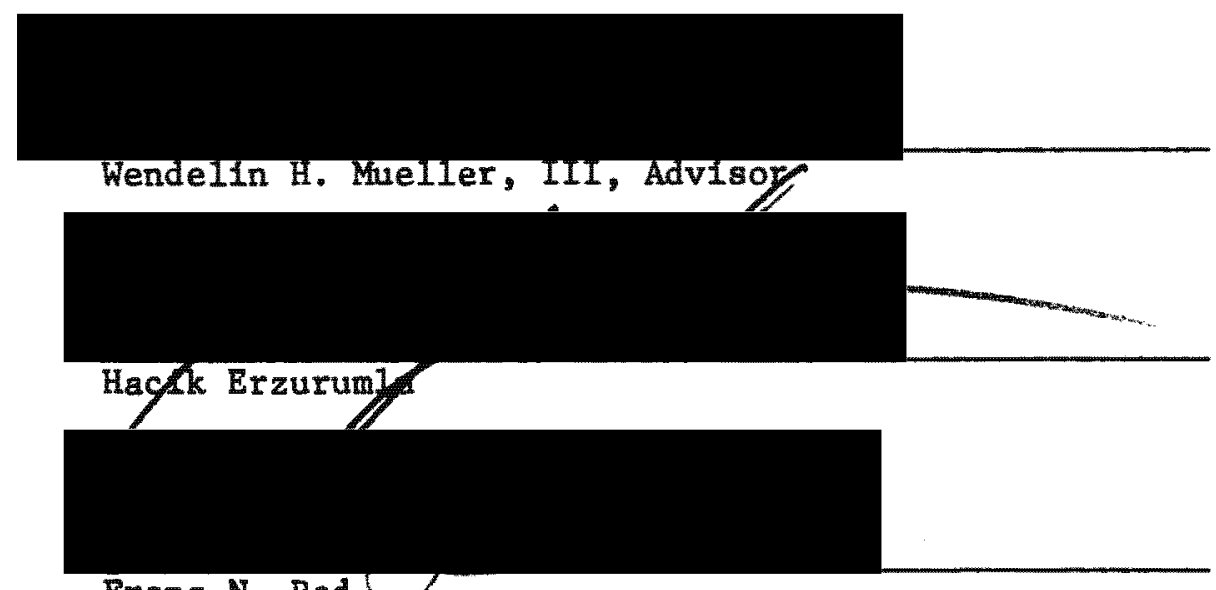

Franz N. Rad $\longrightarrow$
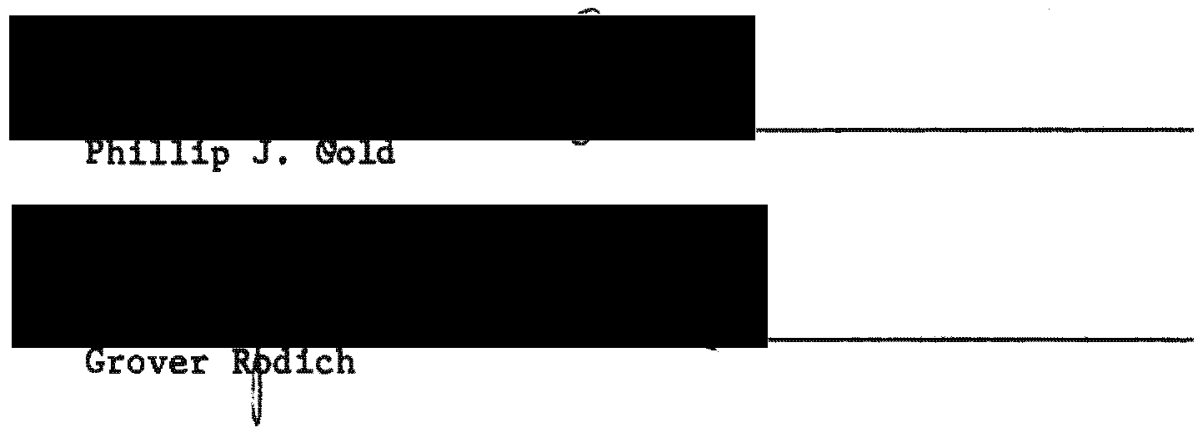

To provide a basis for the development of interaction curves for tubular beam-columns of annular cross section, a general purpose beam-column computer program is developed, and used to determine ultImate load capacities. The paper presents the analytical model and the computer method. The analytical results are compared with pub- 
1ished test data as well as experimental data obtained as part of this profect. 


\title{
A NUMERICAL SOLUTION FOR THE \\ ULTIMATE STRENGTH OF TUBULAR \\ BEAM-COLUMNS
}

by

ARNOLD L. WAGNER

A thesis submitted in partial fulfillment of the requirements for the degree of

\author{
MASTER OF SCIENCE \\ in \\ APPLIED SCIENCE
}

Portland State UnIveralty

1976 
TO THE OFFICE OF GRADUATE STUDIES AND RESEARCH:

The members of the Commttee approve the thesis of

Arnold L. Wagner presented November 4, 1976.

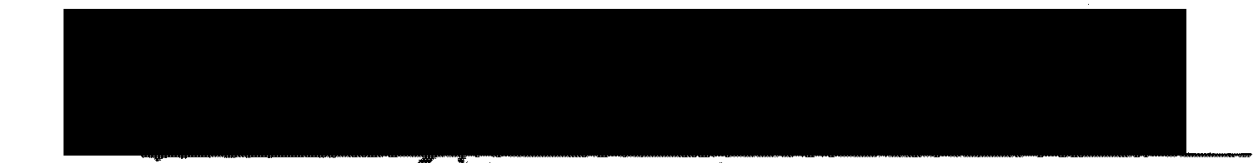

Wendelin H. Meller, III, Advisor

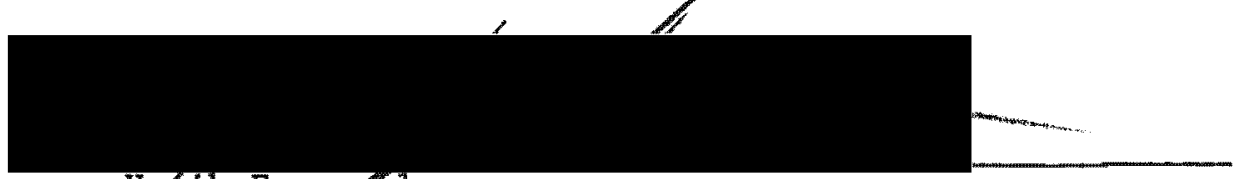

Hgcik Erzurganlu
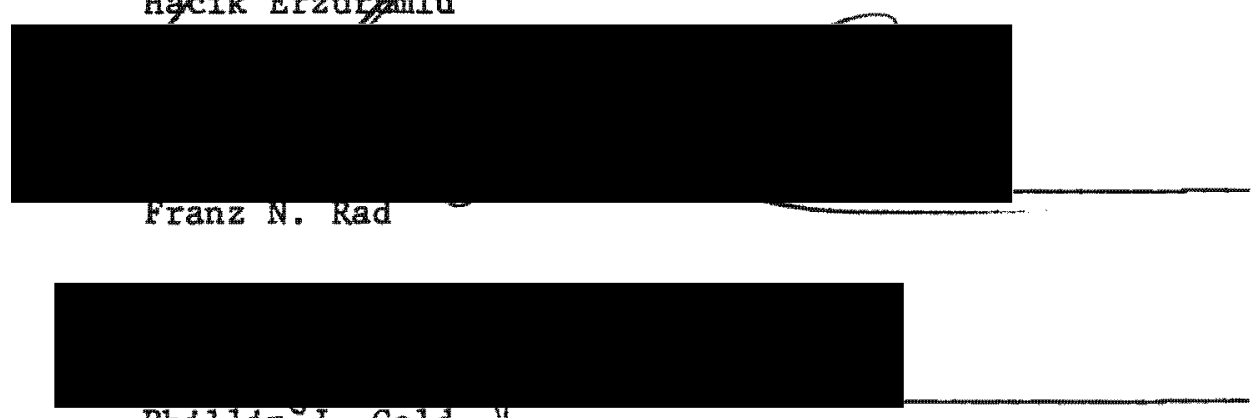

Phillip J. Gold v

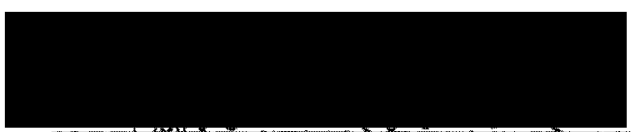

Grover Rodlch

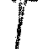

APPROVED :

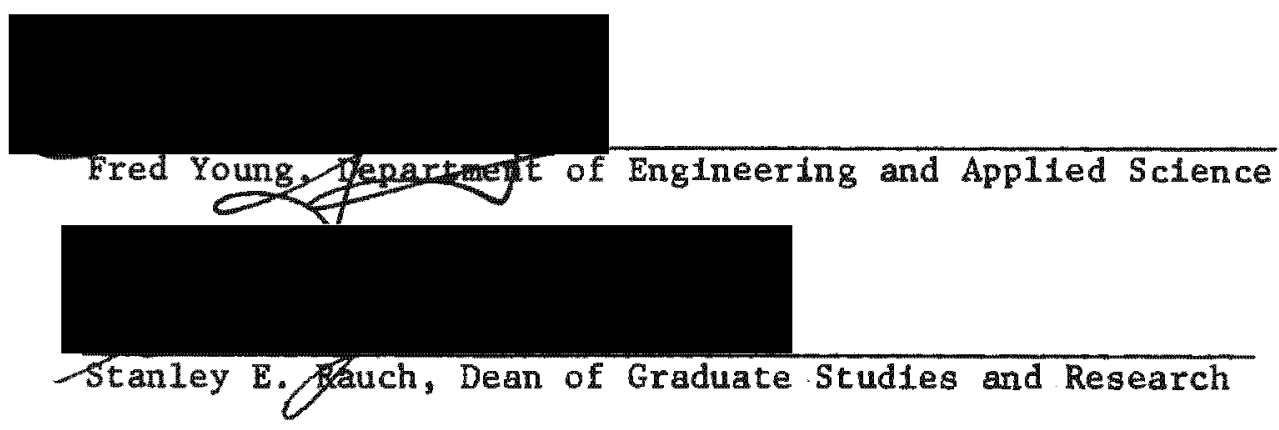




\section{ACKNOWLEDGMENTS}

The author is deeply grateful to Dr. Wendelin H. Mueller for his guidance, help and encouragement throughout the course of study. Gratitude is also expressed to Dr. Hacik Erzurumlu for his criticism and comments. A special thanks to Mr. Steve Rinella for his technical assistance in the testing phase of the project.

Financial assistance in the form of a feliowship from the American Institute of Steel Construction and a research grant from Portland State University are gratefully acknowledged. The author would also like to thank Fought \& Co. Steel Fabricators for material donations and the Portland State University Computer Center for their cooperation in running the programs. Finally, a spectal thanks to Swan Wooster Engineering for assistance in typing this thesis. 
TABLE OF CONTENTS

PAGE

\begin{tabular}{|c|c|c|c|c|c|c|c|c|c|c|c|c|c|c|c|c|c|c|c|c|c|}
\hline ACKN & OWLI & EDGMENTS & . & • & . & - & - & & . & . & . & & & - & $\cdot$ & • & & & & . & 11 \\
\hline LIST & OF & TABLES & - & - & $\cdot$ & - & - & & - & & ${ }^{\circ}$ & & & $\cdot$ & . & 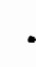 & & & • & . & \\
\hline IST & OF & FIGURES & . & . & • & - & - & & - & & 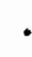 & & & $\cdot$ & • & 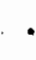 & & & • & . & \\
\hline IST & $c$ & SYMBOLS & & . & • & 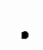 & • & & • & & & & & & . & & & & & & \\
\hline
\end{tabular}

CHAPTER

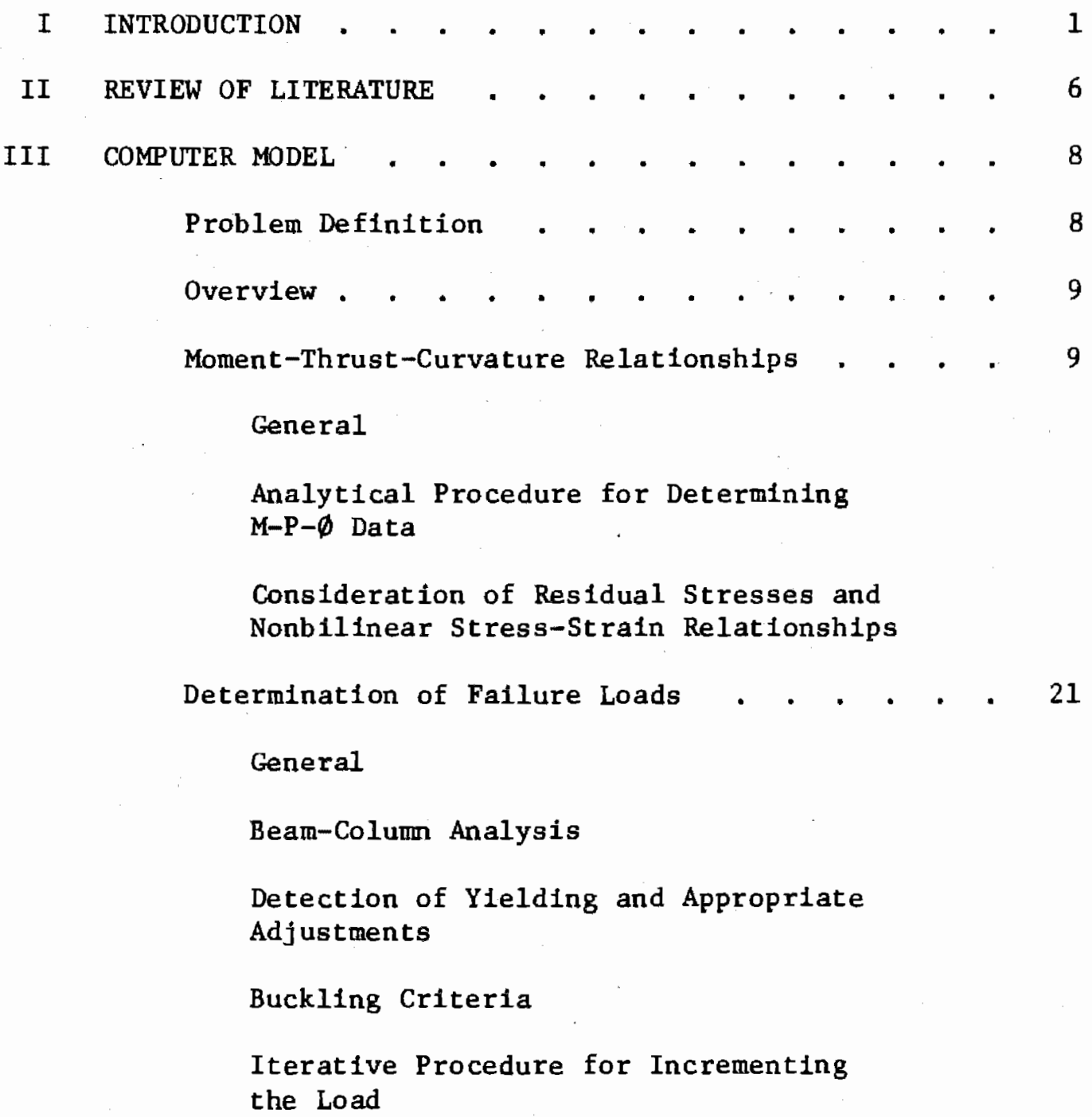


II COMPUTER MODEL (Cont'd)

Design Applications . . . . . . . . . 29

Comparison wlth Published Test Results . . . 35

IV EXPERIMENTAL PROGRAM • • • • • . . . • • • . 39

Overview . . . . . . . . . . . 39

Experimental Setup . . . . . . . . . . 39

Description of Models . . . . . . . . 43

Instrumentation . . . . . . . . . 45

Steel Properties and Coupon Tests . . . . 45

Moment-Thrust-Curvature Data . . . . . . . 47

Comparison of Experimental and Analytical

Results . . . . . . . . . . 47

Test $1 \mathrm{~T} 2$

Test 1 T3

Test 2 T 3

Test $3 \mathrm{~T} 3$

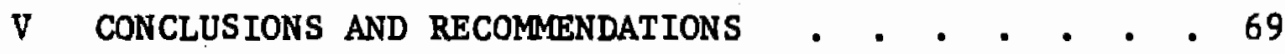
Referenceg . . . . . . . . . . . . 71 APPENDIX I . . . . . . . . . . . . . . 73 APPENDIX II . . . . . . . . . . . . 90 APPENDIX III . . . . . . . . . . . . . 93 APPENDIX IV • • • • • • • • . • • • • 96 VITA • • . . • . . . . . . . • • • . 184 


\section{LIST OF TABLES}

TABLE

PAGE

1 Results of Coupon Tests . . . . . . . . 46

2 Comparison of Predicted and Measured Ul1tmate Load Values. . . . . . . . . 65 


\section{LIST OF FIGURES}

FIGURE

PAGE

1 Block Diagram of the Computer Mode1 . . . . . . 3

2 Qualitative Interaction Dlagram . . . . . . . 4

3 Element configuration and assumed residual

stress distribution . . . . . . . . . . . 11

4 Flow diagram for calculation of M-P- $\emptyset$ data . . 13

5 Moment-thrust-curvature relationship . . . . . 15

6 Moment-thrust-curvature relatlonship . . . . . 18

7 Stress-strain relationship . . . . . . . . . 19

8 Moment-thrust-curvature relationsh1p . . . . . 20

9 Physical beam-column model . . . . . . . . 24

10 Stiffness adfustment . . . . . . . . . . . 24

11 Load vs. lateral deflection . . . . . . . 26

12 Stabllity criteria . . . . . . . . . . . 28

13 Flow diagram for determination of fallure load . 30

14 Interaction diagram . . . . . . . . . . . 32

15 Interaction diagram . . . . . . . . . . 33

16 Interaction diagram . . . . . . . . . 34

17 Moment-thrust-curvature relationship . . . . . 36

18 Interaction curves . . . . . . . . . . 37

19 Loading configuration . . . . . . . . . 40

20 Experimental setup . . . . . . . . . . . 41

21 Actuator supports . . . . . . . . . . 42 
22 Schematic of experimental setup . . . . . . . 44

23 Stress-straln relationship for 2.00 in

O.D. tube . . . . . . . . . . . . . . . 48

24 Stress-strain relationshlp for 3.00 in

O.D. tube . . . . . . . . . . . . . . 49

25 Moment-thrust-curvature relationsh1p;

2.00 1n 0.D. tube . . . . . . . . . . 50

26 Moment-thrust-curvature relationship;

3.00 In 0.D. tube . . . . . . . . . . . 51

27 Test $1 \mathrm{~T} 2$. . . . . . . . . . . . . . 52

28 Test 1 T 3 . . . . . . . . . . . . . . 52

29 Load vs. maximum deflection - Test 1T2 . . . . 54

30 Load vs, end rotation - Test 1T2 . . . . . . 55

31 Load vs, curvature - Test 1T2 • . . . . . 56

32 Load vs, maximum deflection - Test 1T3 . . . . . 57

33 Load vs, end rotation - Test 1T3 . . . . . . 58

34 Load vs. curvature - Test $1 \mathrm{~T} 3$. . . . . . . 59

35 Load vs. maximum deflection - Test 2T3 . . . . . 61

36 Load vs, end rotation - Test 2T3 . . . . . . 62

37 Load vs, curvature - Test 2T3 . . . . . . 63

38 Test 3T3 • • • • . . • . • . • . • . 64

39 Load vs. maximum deflection - Test 3T3 . . . . 66

40 Load vs. end rotation - Test 3T3 . . . . . . . 67

41 Load vs. curvature - Test 3T3 . . . . . . 68

42 Beam of variable stiffness subjected to

general loading condition . . . . . . . . 74 
43. Infinitesimal beam Increment . . . . . . . 75

44 Couple acting to set the slope at station 1. . . 83

45 Example problem - net load check . . . . . . . 88

46 Example problen - net load check . . . . . . . 89

47 Calculation of net load . . . . . . . . . 90

48 Interpolation on the M-P- data . . . . . . . .93

49 Assumed residual stress distribution . . . . . . 95 


\section{LIST OF SYMBOLS}

$A=$ Cross section area

$d^{2} y / d x^{2}=$ Differential expression for curvature

$E=$ Modulus of elasticity

$\mathrm{e}=$ Eccentricity of load $\mathrm{P}$

$F=$ Total force on the cross section

$F_{y}=$ Yield stress

$I=$ Moment of inertia

$1=$ Station number along the beam-column

$L=$ Length

$M=$ Bending moment

${ }_{\text {CAL }}=$ Bending moment calculated by the recursive technique

$M_{I N T}=$ Bending moment interpolated from the $\mathrm{M}-\mathrm{P}-\phi$ curves

$M_{0}=$ Applied end moment

$M_{p}=$ Plastic bending moment

$M_{y}=$ Bending moment at first yield

OD = Outside diameter

$\mathbf{P}=$ Axial load

$P_{u}=$ Ultimate value of axial load

$P_{y}=$ Axial load causing complete yielding of the cross section

$\Delta P=$ Axial load increment

$\mathbf{r}=$ Radius of gyration

$\mathrm{t}=$ Thickness

$\beta=$ Ratio of smaller to larger end moment

$\varepsilon_{a}=$ Strain due to axial load 
$\varepsilon_{r}=$ Strain due to residual stresses

$\varepsilon_{\phi}=$ Strain due to applied curvature

$\varepsilon_{t}=$ Total strain value

$\theta=$ End rotation

$\phi, \phi_{y}=$ Curvature and curvature at first yield, respectively 
CHAPTER I

INTRODUCTION

The analysis and design of structures has advanced greatly in recent years, due in large part to the use of digltal computers. Problems requiring complex derivations for their solution may now be handled relatively easily using numerical methods in an iterative (trial and error) form. In an iteration procedure a trial solution is made and then checked for correctness. If the solution is not correct an error exists and the problem must be solved again with changed parameters. If the iteration is to converge, each successive solution must be closer to the correct solution. Th1s process is continued unt1l the error is acceptable. The procedure fust described Is referred to as the open form approach, and is commonly used by computer programs for the analysis of non-linear structural systems. The primary goal of this project was the determination of the ultimate load capacity of a clrcular steel tube loaded as a beam-column, 1.e., a loading condition consisting of both axial load and flexure. Methods for calculating the combination of axial load and bending moment at fallure in wide-flange members have been developed (11) and are currently employed in design pract1ce. Previous 1nvest1gators $(4,6,16$, 17) have shown that tubular members exhibit structural characteristics markedly different than wide-flange shapes when subjected to loads causing stresses above the elastic range. Since a systematic technique to determine the ultimate strength of tubular members is so far not 
avallable, an Investigation was launched to develop an analytic tool in the form of a computer program which could be used to gener : $_{+}$ load displacement histories and calculate fallure loads for circular steel tubes.

The computer model Involves two separate phases of calculations, Figure 1. First, the moment-thrust-curvature (M-P- $\emptyset$ ) relationship for the member cross section is obtained. Using this as input, the ultimate strength of the beam-column is determined for a selected pattern of loading. The computer model is capable of accounting for the effects of residual stresses during the generation of the $M-P-\emptyset$ relationship. The inclusion of any configuration of stress-strain relationship may be accomplished by providing appropriate input data in tabular form. It should be noted that while this investigation includes the determination of $M-P-\emptyset$ data, those provided by other investigators may also be used. The calculation of fallure loads is accomplished by a numerical technique which increases the load by a varlable step incrementing procedure until no further load can be supported. At this polnt the beam-colum is considered to have reached fallure.

The major use of the computer model in this investigation is the development of curves giving combinations of axial load and end moments which cause fallure. These curves are commonly referred to as interaction diagrams, Figure 2. Interaction diagrams for wideflange members are avallable and design equations based on these have been developed (3), however, it is generally belleved that they give excessively conservative results when applied to tubular members. 
PHASE I

Determination of Moment-Thrust-Curvature (M-P- ) Relationships for Member Cross Section

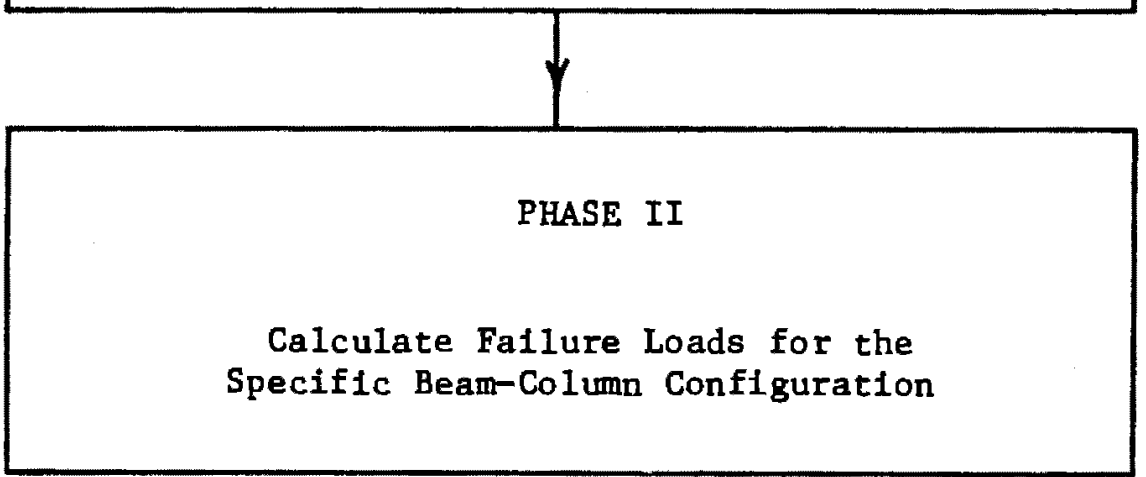

F1gure 1 Block diagram of the computer mode1 


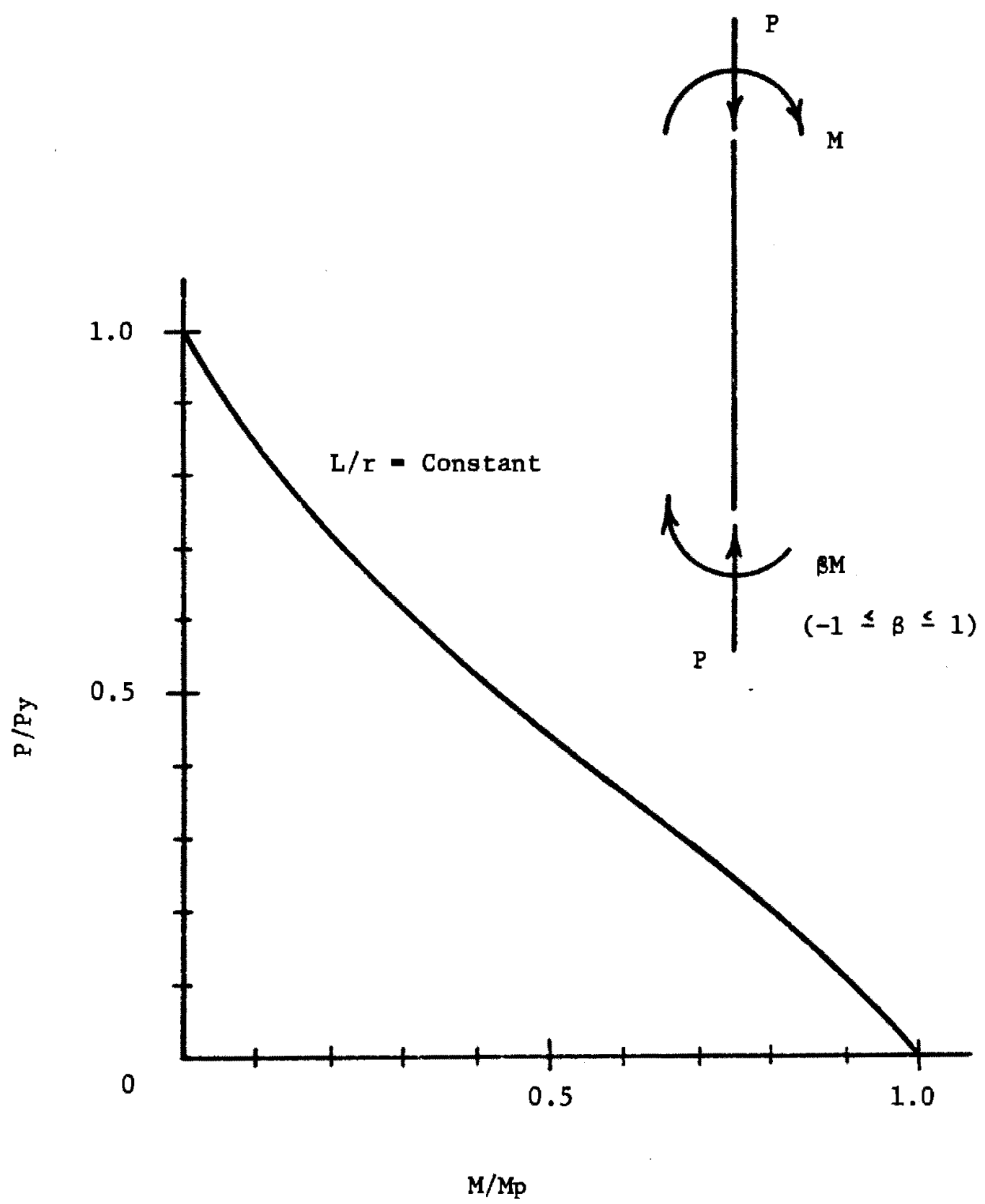

Figure 2 Qualitative interaction diagram 
The economical design of tubular members is of special interest to engineers involved in the design of offshore facilities. C1.cular tubes are commonly used in offshore construction because of their ability to resist bending equally well in any direction. They also exhibit a greater flexural reserve strength beyond first yleld thail the wide-flange shape, and are not subject to lateral-torsional buckling. Engineers will be limited to avallable design equations developed for wide-flange sections until acceptable criteria specifically for circular tubes is established. Information dealing with the overall column stability of circular tubes will provide a basis for the development of a design specification for such members.

The analytical investigation was supplemented by a testing program which consisted of loading four model tubes to fallure by an eccentric axial load. The results of these tests and published test results of other investigators were used to check the validity of the computer model used in this study.

The following discussion includes a brlef review of research related to tubular members, a documentation of both the computer model and the testing program, and a comparison of the analytical and experimental results. 
CHAPTER II

REVIEW OF LITERATURE

A great deal of work has been done on the analysis of wideflange members loaded as beam-columns $(8,11)$, however there seems to be a scarcity of published information concerning the response of round steel tubes subjected to the combined effects of bending and axial 1oad. Work by Ellis (5) consisting of both an analytical and experimental investigation has been reported. Another analytical invest1gation by Snyder and Lee (18) is available, however, the application of the method proposed is limited to specialized beam-column configurations.

Results of experimental studies include the report of tests on square tubes by Dwyer and Galambos (4). The major thrust of the report was to compare the relative strengths of the square tube and wideflange cross sections. Tests of circular tubes in pure bending have been carried out by Sherman $(16,17)$ with the major objective being the determination of a limiting diameter to thickness ratio to prevent local buckling. In view of the somewhat limited nature of the reported investigations concerning circular tubes, a computer model which has applicability to a wide variety of support and loading conditions would be useful.

The beam-column analysis technique used in this investigation (Matlock's Recursive Technique) has been modified by previous invest- 
1gators to perform advanced beam-colum analysis. For example, Mueller (15) modified the technique to handle beam-colums on nonlinear foundations. Also, the technique was used by Matlock and Taylor (14) in a computer program to analyze beam-columns under moveable loads. However, so far as can be determined, the technique has not been applied to the ultimate strength analysis of beam-colums. 


\section{CHAPTER III}

COMPUTER MODEL

The initial portion of this paper documents the development of the computer model used to determine the ultimate load capacitles of tubular beam-columns. Also included are design applications in the form of Interaction diagrams, and a comparison of the analytical results with published test results of other Investigators.

\section{PROBLEM DEFINITION}

The collapse of a beam-column may be classified as elther elastic Instability (no ylelding at any cross section) or plastic instability (partial or complete yielding at some or all cross sections). While the determination of the elastic buckling load is normally accomplished by a closed form solution technique (1.e., Euler's Equation), the determination of the plastic buckling load involves non-1inear relationships and is most readily handled by an open form approach. The major difficulty arises from the fact that once plastic action starts, Hooke's Law is no longer valid. The computer model developed In this investigation may be used to predict the ultimate strength of tubular beam-columns which fall by elther elastic or plastic instability.

Other factors considered in this study include residual atresses due to the manufacturing processes of the tube and the effect of the 
actual stress-strain relationship of the material. Local buckling was not investigated, however, reports of other Investigators i..e referenced to be used as a separate check. The problems of Initial crookedness of the member and ovalization of the cross section were beyond the scope of this profect.

\section{OVERVIEW}

As mentioned previously, the computer model consists of two mafor components; generation of moment-thrust-curvature (M-P- $\emptyset)$ relationships and determination of fallure loads. The moment-thrustcurvature relationships are a property of the member cross section and define, for a given strain condition, the stress distribution and magnitude necessary for equilibrium. The $M-P-\emptyset$ curves are the basic data from which overall column stability can be determined in that they define the behavior of the member in both the elastic and inelastic range. The $M-P-\emptyset$ relationships are a direct input into the fallure load program (Figure 1). This allows M-P- data developed by other Investigators to be used in calculating failure loads, Detalls of each phase of the computer model are now presented.

\section{MOMENT-THRUST-CURVATURE RELATIONSHIPS}

\section{General}

The determination of the $M-P-\emptyset$ relationship is accomplished by an open-form solution technique. As noted by previous investigators (6), closed form solutions for determining $M-P-\emptyset$ relationships are often tedious and time consuming since several spectal derivations 
must be made. Also, because of the complexity of the derlvations Involved, closed form solutions use an Ideallzed bilinear stres.strain diagram and have limited ability to incorporate resifual stress patterns into the analysis. An open-form solution technique to determine $\mathrm{M}-\mathrm{P}-\emptyset$ relationships for circular tubes by dividing the crois section into horizontal sectors has been previously developed (6). However, it is belleved that the method presented herein is more accurate and complete for element idealization, allows the InvestIgation of more general residual stress patterns, and contributes to the overall efficlency of the computer model.

The open-form technique developed in this investigation divides the cross section of the circular tube into layers of elements distributed around the circumference as shown in Figure 3a. The number of layers and elements per layer are limited only by the size of the specified arrays in the computer program. This technique permits the inclusion of any configuration of material stress-strain relationship and residual stress distribution patterns directly into the solution. To maintain maximum flexibility for the user, one of two forms of input for the inclusion of residual stresses may be used:

1. An assuned stress pattern consisting of a linear variation between three peak values (FIgure $3 b$ ).

2. Any distribution of stresses in matrix form.

Although the assignment of any residual stress value to each element is possible, it is required that the final distribution be statically admissible by satisfying basic conditions of static equilibrium. (See Appendix III for adjustment of an assumed stress pattern.) 


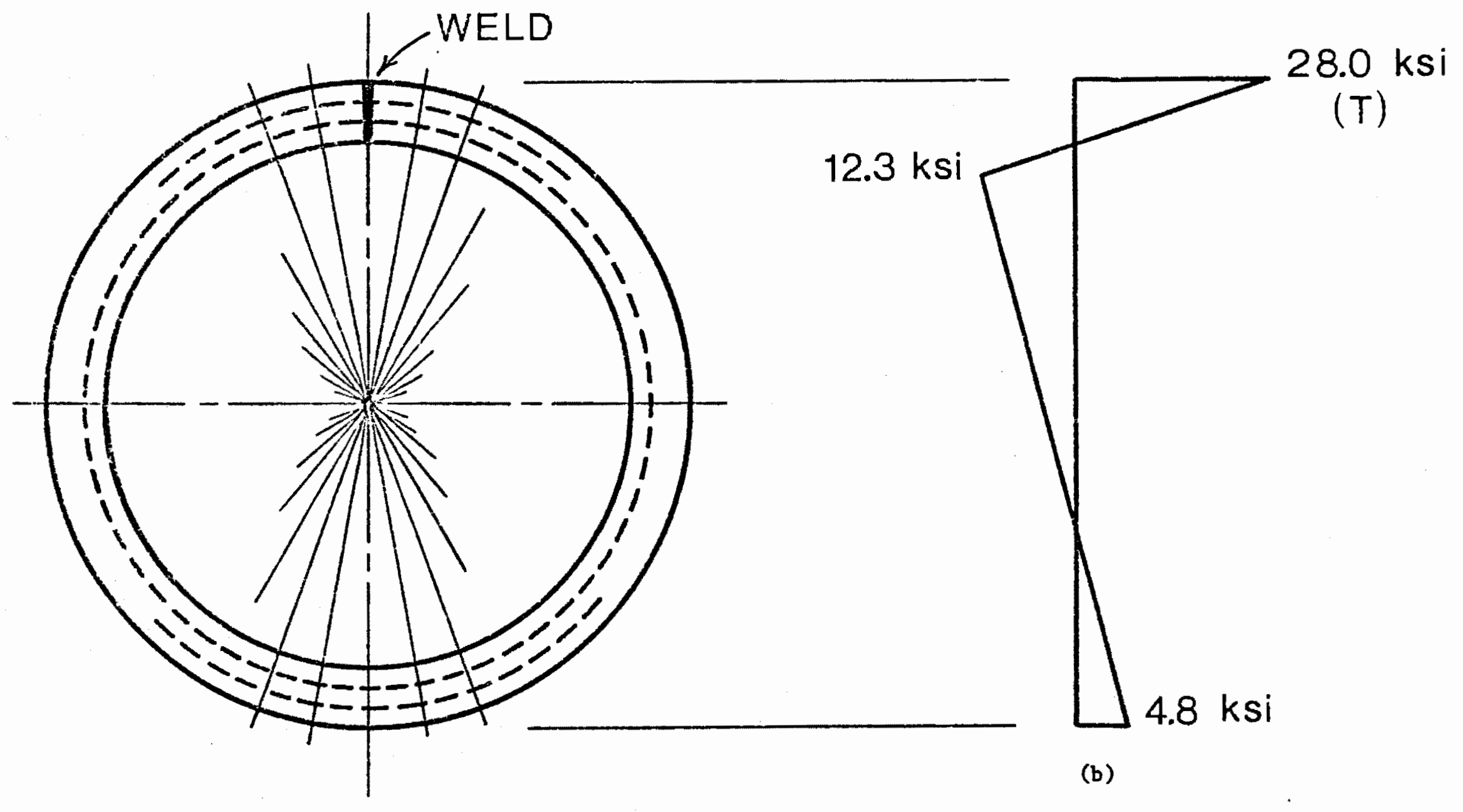

(a)

Flgure 3 Element configuation and assumed residual stress distribution 
Analytical Procedure for Determining M-P- Data

The technique used to generate the $M-P-\emptyset$ data uses three ategorles of stress and strain; those due to residual stress, axial load, and bending. The loads are applied in the following order. First, the applicable residual stress and strain value is assigned to each element. A percentage of the stub-column yleld load, Py, is then applied to the cross section. This axially stressed cross section Is then given a value of curvature and the moment corresponding to a state of equilibrium is calculated. The result is a value of moment, thrust and curvature (M-P- $\emptyset$ ) satisfying equilibrium. The process is repeated with different combinations of axial load and curvature to obtain an adequate number of points to describe the famlly of M-P- $\emptyset$ curves .

The calculation of the $M-P-\emptyset$ relationship uses two iteration loops as shown in the flow chart of Figure 4. The first determines the correct axlal strain value due to the applied percentage of $\mathrm{P}_{\mathrm{y}}$. This is necessary because it is possible for the sum of the axial strain, $P / A E$, and the residual strain to exceed the yield value on some elements. In such cases the elemental stress avallable to resist axial load is less than that predicted by elastic theory. Since the residual stress distribution 1 s an Intial condition, its value cannot be changed. Therefore, the additional force must be provided by other elements. It should be noted that the stress distribution and Its magnitude are calculated by allowing the strain on all elements to be increased by the same amount. The resulting stresses are obtained from the material stress-strain information. The second iter- 


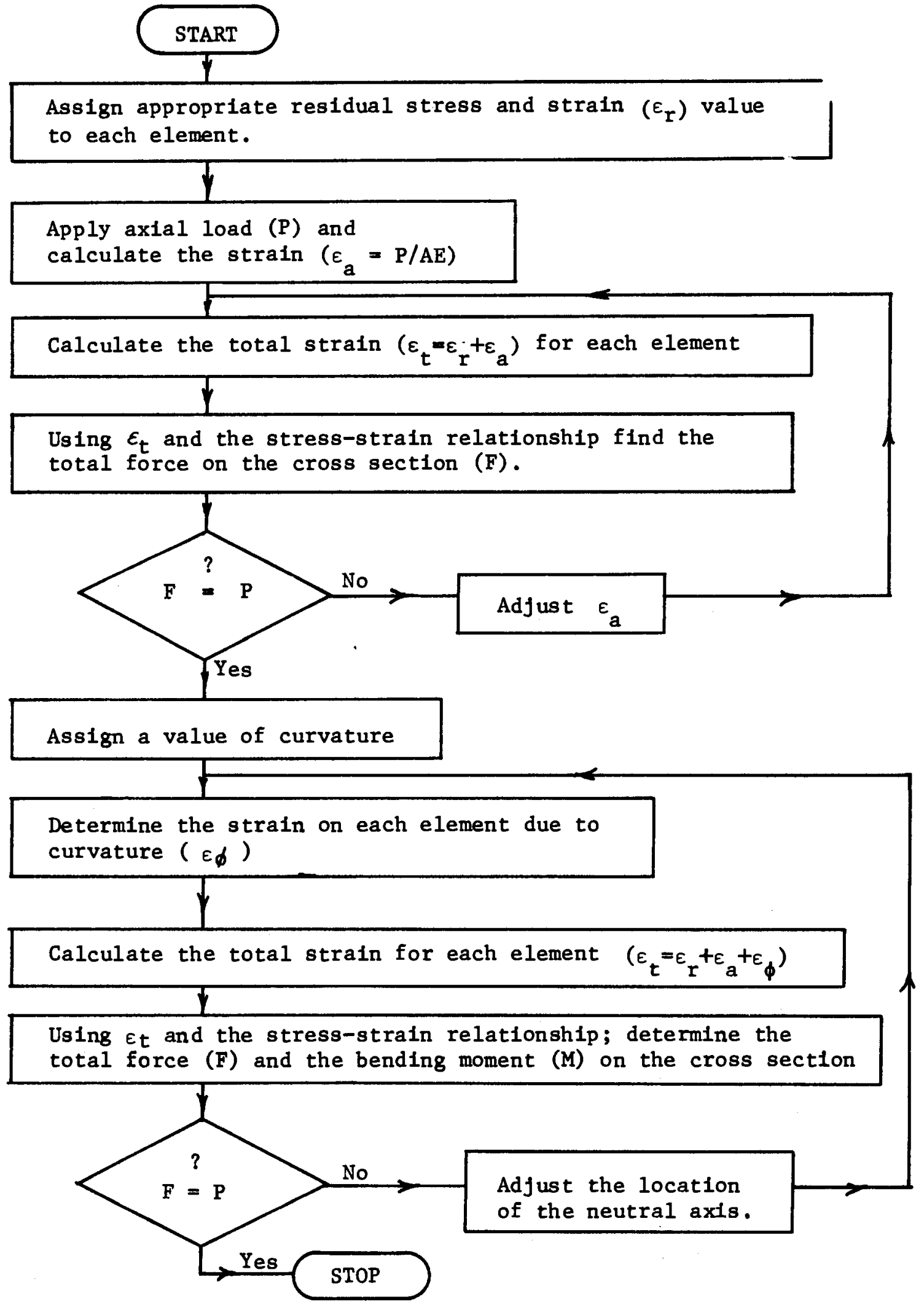

F1gure 4 Flow diagram for calculation of $M-P-\emptyset$ data 
ation determines the correct location of the neutral axls given a value of curvature. It is inftally assumed to be at the centrold or the cross section. As mentioned earlier, with an axial load applied to the colum section, a value of curvature 1s assumed; then the bending moment and thrust necessary to hold this state of strain are calculated. If the calculated thrust does not agree with the applled axtal load, the location of the neutral axis is shifted until agreement within a spectfled tolerance is obta1ned. The M-P- data calculated by this procedure are normally depicted as a family of curves such as those In Figure 5. These curves represent the correct combination of bending moment, axial load and curvature for a clrcular tube. As may be observed, the $\mathbb{M}-P-\emptyset$ data have been normalized by dividing each quantity by 1 ts value at flrst yleld. Normalization is helpful in presenting data of this type since the data represent c1rcular tubes in general rather than one spectflc clrcular tube. A famlly of curves for percentages of $P_{y}$ ranging from 0.0 to 1.0 make up the $M-P-Q$ data used by the beam-column analysis program.

The M-P- $\emptyset$ relationship shown in Figure 5 were calculated for a standard welght round structural tube with a 10 inch nominal outside diameter $(I D / O D=0.932$ ) without considering resldual stress effects. The material properties were approximated by a bilinear stress-strain relationship with a modulus of elasticity of $30 \times 10^{3} \mathrm{ks} 1$ and a yield stress of $35 \mathrm{ksl}$. These values are the minlmum spectfled in the American Soclety for Testing and Materlals standard A53 for Grade B plpes of types $E$ and $S$. Although the $M-P-\emptyset$ data presented in Figure 5 were calculated for a particular circular tube, they may be used to 


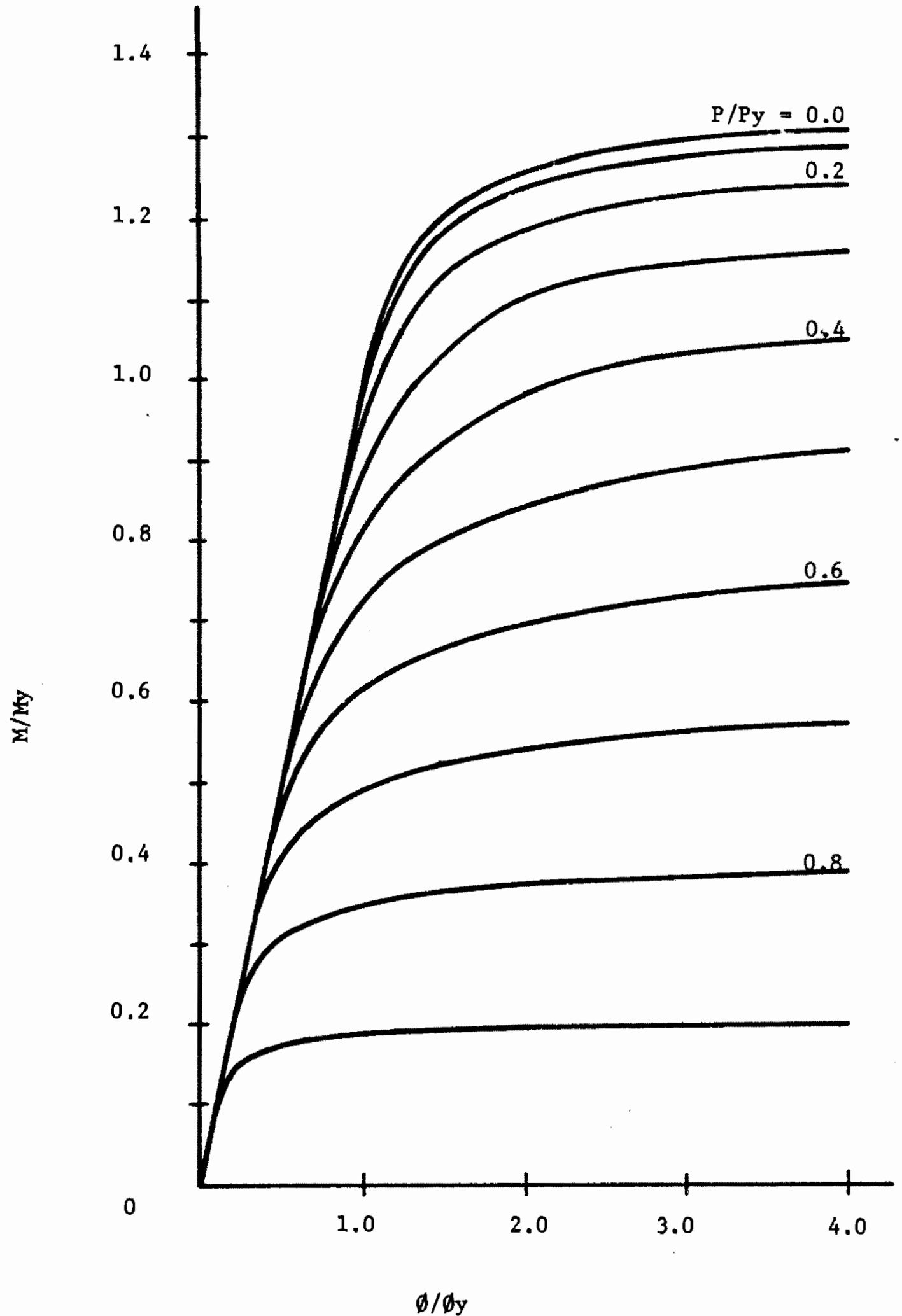

F1gure 5 Moment-thrugt-curvature relationsh1p 
represent the moment-thrust-curvature characteristics of all thin walled circular tubes with an average shape factor of 1.30 .

It is important to note that local buckling criteria and ovalling effects have not been incorporated in the moment-thrust-curvature calculations. A separate check for local buckling should be made for the specific tubular section under consideration. Suggested methods for determining the limiting diameter to thickness ratio $(D / t)$ have been previously outlined $(13,16,17)$.

Consideration of Residual Stresses and Nonbilinear Stress-Strain Relationships

As noted earlier the computer model may be used to determine the effect of residual stresses and nonbilinear stress-strain relationships on the predicted fallure load. The approach selected was to incorporate the particular residual stress pattern and/or stressstrain relationship into the moment-thrust-curvature data which was then used in the fallure load analysis. The effect on the M-P- $\emptyset$ curves is an indication of what change to expect in the ultimate load value, 1.e., M-P- $\emptyset$ curves which exhibit relatively higher bending moment capacities will result in relatively higher ultimate load values.

Consider first the effect of residual stresses. Since no test data on the actual residual stress distribution in a circular tube was avallable, the stress distribution shown in Figure $3 b$ was assumed. This stress distribution is the assumed result of the longitudinal welding of the tube. The cross section used in this comparison is the same as that used for the generation of the $M-P-\emptyset$ curves shown in Figure 5. In determining the moment-thrust-curvature relationship it 
was assumed that the axis of bending passed through the weld although any axis orientation could have been chosen. A comparison of ti.e $M-P-\emptyset$ curves with and without the effect of the assumed residual stress pattern is shown in Figure 6. Notice that for a constant value of axial load and curvature the calculated value of bending moment is significantly lower for the case which used the assumed residual stress pattern. The relative difference is especially large at combinations of low curvature and high axtal load.

As developed, the computer model permits elther an 1dealized bllinear stress-strain relationship or stress-strain values obtained from the results of coupon tests to be used in the development of the moment-thrust-curvature relationship. $M-P-\emptyset$ curves using the stressstrain data depicted in Figure 7 are presented in Figure 8. The cross section considered had an outslde diameter of 10.752 inches and a wall thickness of 0.194 Inches. Note, for low straln values the bilinear stress-strain relationship overestimates the actual strength. As the strain values increase the effects of strain hardening become noticeable as the curve representing the actual stress-strain data shows a greater bending moment capacity than the curve developed using the billnear stress-strain relationship.

The procedure for including the actual stress-strain data involves Interpolating a stress value for a given strain value from tabular data. The tangent modules approach was used with the interpolation performed by a second order divided difference. Unequally spaced points may be used thus permitting a better idealization in areas of special interest, such as the initial part of the stress- 


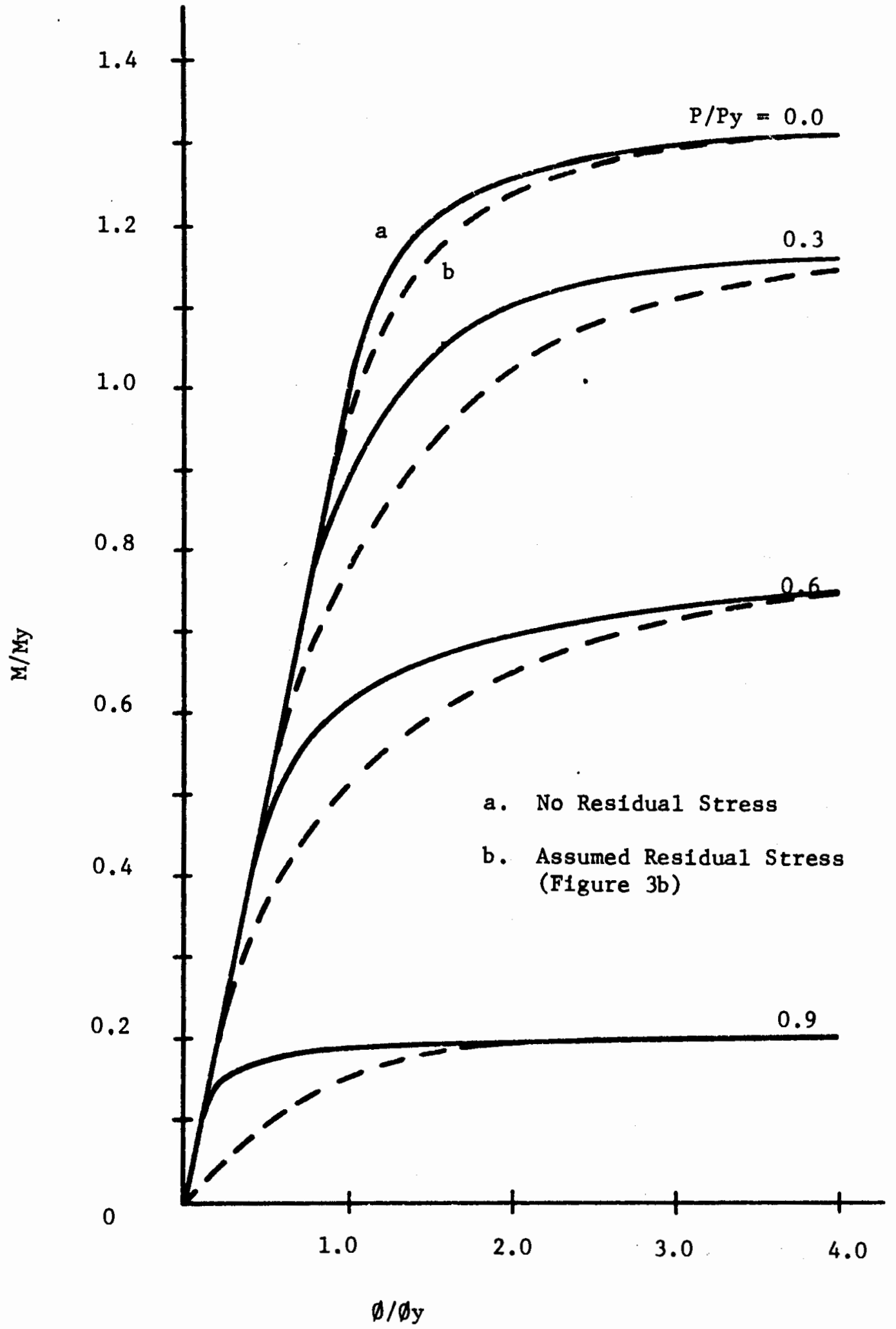

Figure 6 Moment-thrust-curvature relationship. 


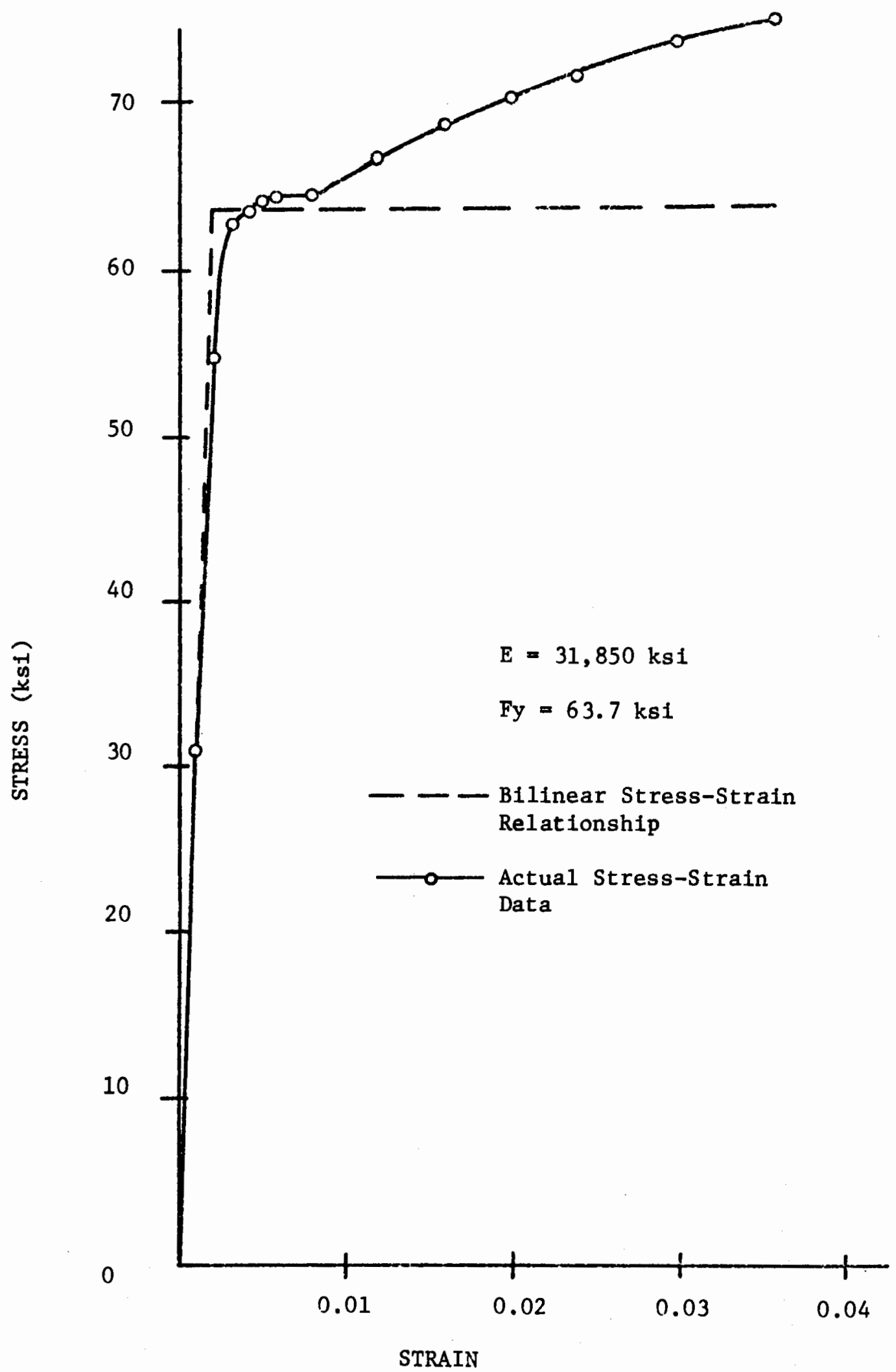

Figure 7 Stress-strain relationship 


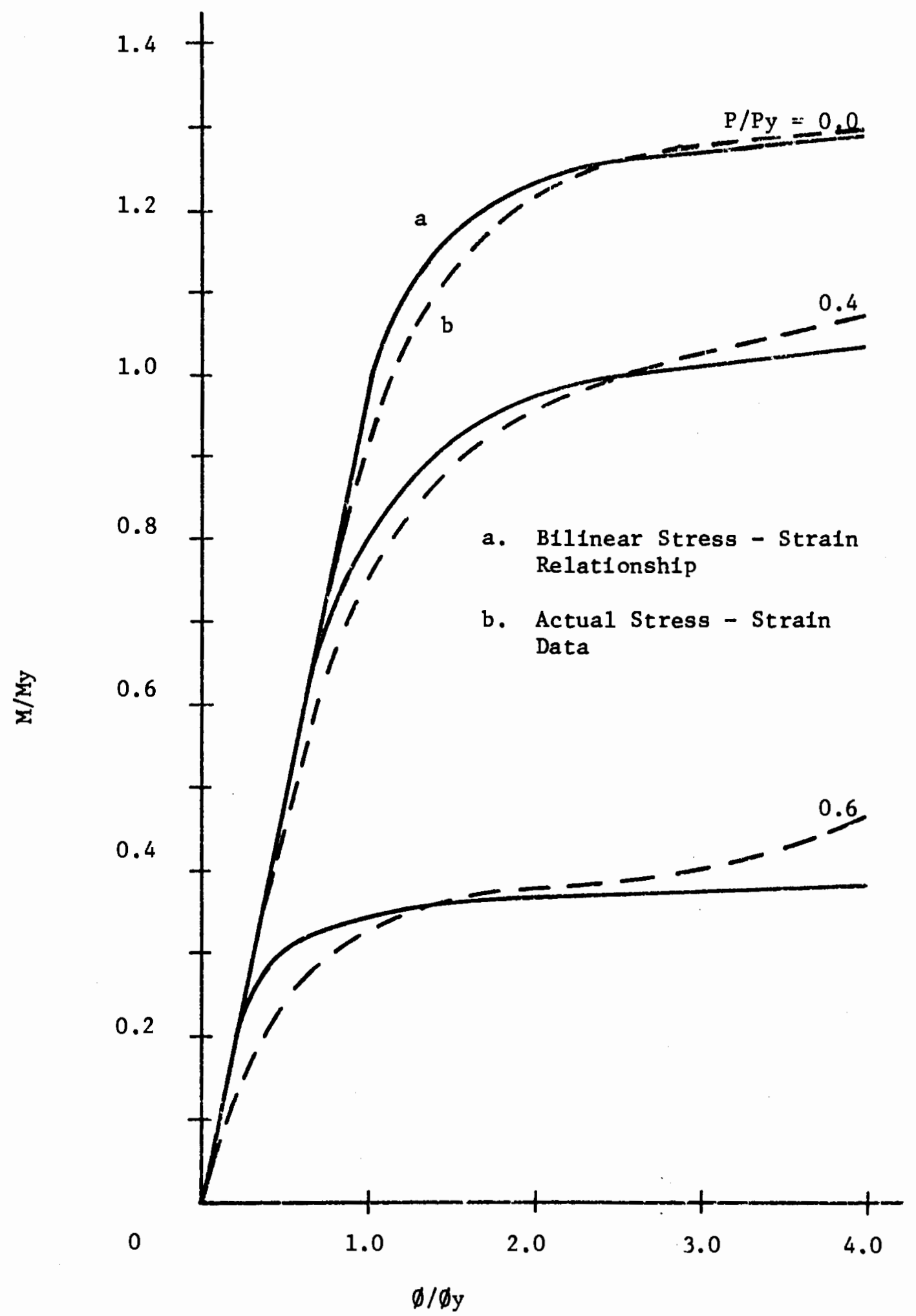

Figure 8 Moment-thrust-curvature relationsh1p. 
strain curve. Detalls of the interpolation procedure are given in Appendix IV.

\section{DETERMINATION OF FAILURE LOADS}

\section{General}

The determination of the ultimate load capacity of a beam-column Is accomplished by a numerical method which increments the load until fallure. For each value of load the beam-column is analyzed and a check for fallure is made. Next, the bending stiffness is adjusted as required. The member is then reanalyzed until the adjustment is negligible at which time the load is increased and the process continued. The following are required to implement this procedure:

a) method for analyzing beam-columns

b) detection of yielding and appropriate adfustments

c) mathematical definftion for buckling

d) iterative procedure for incrementing the load

A detalled explanation of each of these follows.

\section{Beam Colum Analysis}

The beam-column analysis employs Matlock's recursive solution technique $(9,14,15)$. The following discussion deals only with the fundamental characteristics of Matlock's technique. A complete derivation of the recursion equations is given in Appendix I.

Matlock's method is a general purpose elastic beam-column analysis technique. The method conveniently handles a wide variety of support and loading conditions, and accounts for the P-Delta effect. The bending stiffness can vary along the member length in any concelvable 
configuration. Since plastlc action essentially changes the bending stiffness, the latter characteristic of this method allows 1 t. 1 be employed in an 1terative analysis of beam-columns with stress conditions above the elastic range. However, the method is 1 imfted to a planar problem, 1.e. all loads and support reactlons pass throug:1 the vertical axls of the member.

The method of analysis may be characterlzed as a finite difference approach which divides the member Into a number of equal length segments, as shown in Figure 9. Each segment is assumed rigid with the bending stiffness (EI) concentrated at the foints which, hereafter, are referred to as stations. All distributed load and support values are Input to the computer program as concentrated values at the stations. The solution procedure is to first calculate the transverse deflection at each station and then perform a finite difference differentiation to calculate slope and curvature. As the curvature values are calculated the bending moment at each station is determined from the equation of the deflected elastic beam:

$$
\begin{aligned}
& M_{1}=(E I)_{1}\left(\frac{d^{2} y}{d x^{2}}\right)_{1} \\
& \text { where } 1 \text { = station number } \\
& M=\text { bending moment } \\
& E I=\text { bending stiffness } \\
& \frac{d^{2} y}{d x^{2}}=\emptyset=\text { curvature }
\end{aligned}
$$

The differentiation is then continued to calculate shear and net load. For beam-type members the calculated net load provides a positive check on the solution, that is, if the calculated net load is equal 
to the input load, then the solution is correct. However, if axlal load is present, the P-Delta contribution to the bending moment vill show up in the net load making it differ slightly from the input load (see Appendix I for a detalled explanation).

\section{Detection of Ylelding and Appropriate Adjustments}

The method of analysis fust described is an elastic solution, however for beam-columns of short and intermediate length there w111 be some ylelding before fallure. The procedure used to account for yleldIng is to adjust the bending stiffness (EI) at all stations where yielding has occurred. The approach used is the "Secant Stiffness" method. The adfustment results in a member with a varlable stiffness along 1 ts length, which Matlock's method is capable of handling. It should be noted that the adjustment is to the data describing the member belng analyzed and not to the basic analytical procedure.

The moment-thrust-curvature relationship represents the correct combination of bending moment, axial load, and curvature. Note that equation (1) represents the Initial straight-line portion of the $M-P-\emptyset$ curves with the slope equal to the bending stiffness. As the $M-P-\emptyset$ curve in Figure 10 indicates, the relationship between moment and curvature is not 11near after the cross section starts to yleld. At this point the bending moment calculated from equation (1) w111 not agree with the bending moment determined by the $M-P-\emptyset$ curve for given values of axial load and curvature. (The procedure for Interpolating the bending moment from the M-P- $\emptyset$ curves is given in Appendix IV.) To achleve agreement a "secant stiffness" value is substituted for the old stiffness so that the bending moment on the $M-P-\emptyset$ curve equals the 


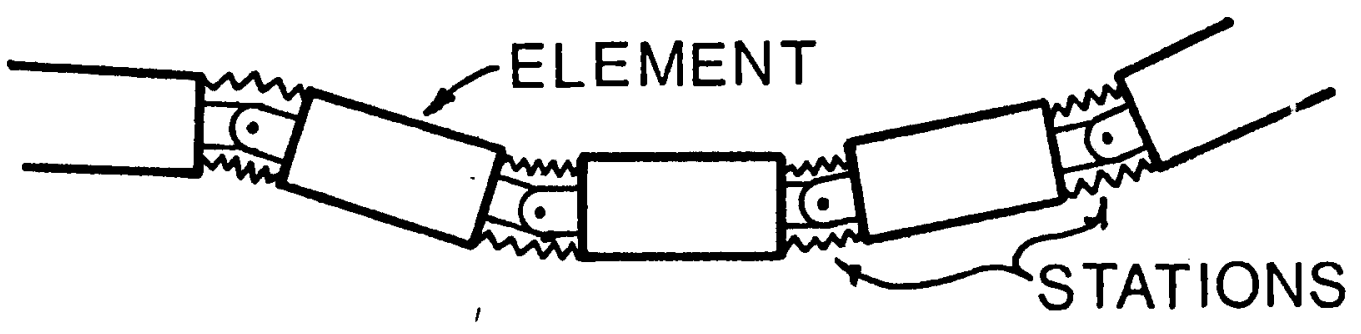

Figure 9 Physical beam-column model

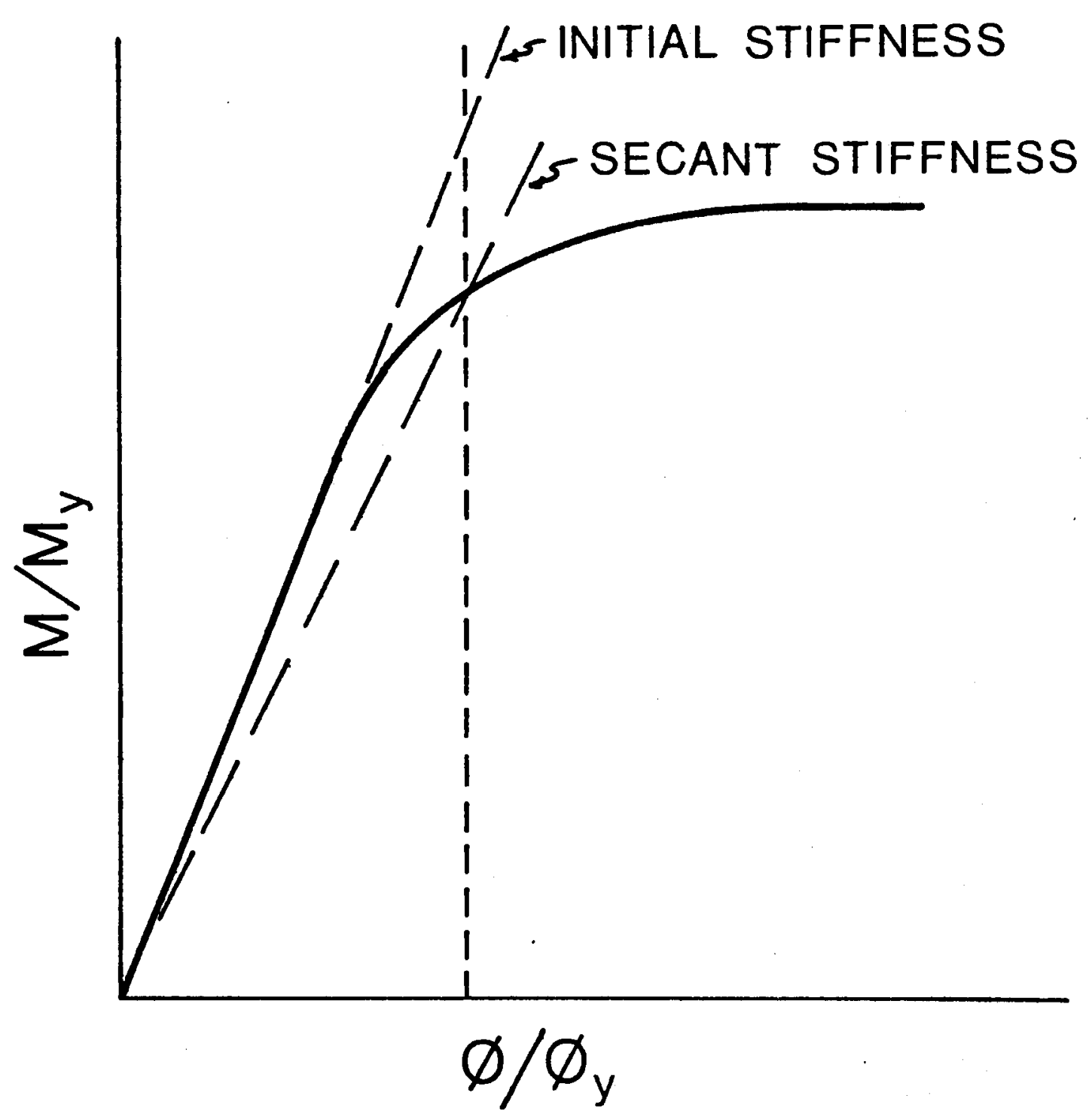

Figure 10 Stiffness adjustment 
product of the secant stiffness and the curvature. The procedure is repeated for each station which is not in agreement with the M-P-? data, and the beam-column then reanalyzed. The whole process is continued until all stations along the beam-column are in agreement with the moment-thrust-curvature relationship.

\section{Buckling Criteria}

A major concern of this study was the determination of a mathematical definition for buckling. The analysis of a member, using the recursive technique, for load values up to and beyond the buckling load will produce a point of discontinuity at the critical load value. While this sudden change in the sign of a deflection, as shown in Figure 11, could possibly have been used as a test for buckling it was necessary to have a more fundamental definition. To achieve this, the equations used in the beam-column analysis were examined.

The two basic recursion equations in Matlock's method are:

$$
a_{i} y_{i-2}+b_{1} y_{i-1}+c_{i} y_{i}+d_{i} y_{i+1}+e_{i} y_{i+2}=f_{i}
$$

(Eq. 1.15, Appendix I)

and

$y_{i}=A_{i}+B_{i} y_{i+1}+C_{i} y_{i+2}$

where

$$
\begin{aligned}
& A_{i}=D_{i}\left(\left(a_{1} B_{i-2}+b_{i}\right) A_{i-1}+a_{i} A_{i-2}-f_{i}\right) \\
& B_{i}=D_{i}\left(\left(a_{1} B_{i-2}+b_{i}\right) c_{i-1}+d_{i}\right) \\
& C_{i}=D_{i}\left(e_{i}\right) \\
& D_{i}=-1.0 /\left(c_{1}+\left(a_{i} B_{i-2}+b_{i}\right) B_{i-1}+a_{i} C_{i-2}\right)
\end{aligned}
$$




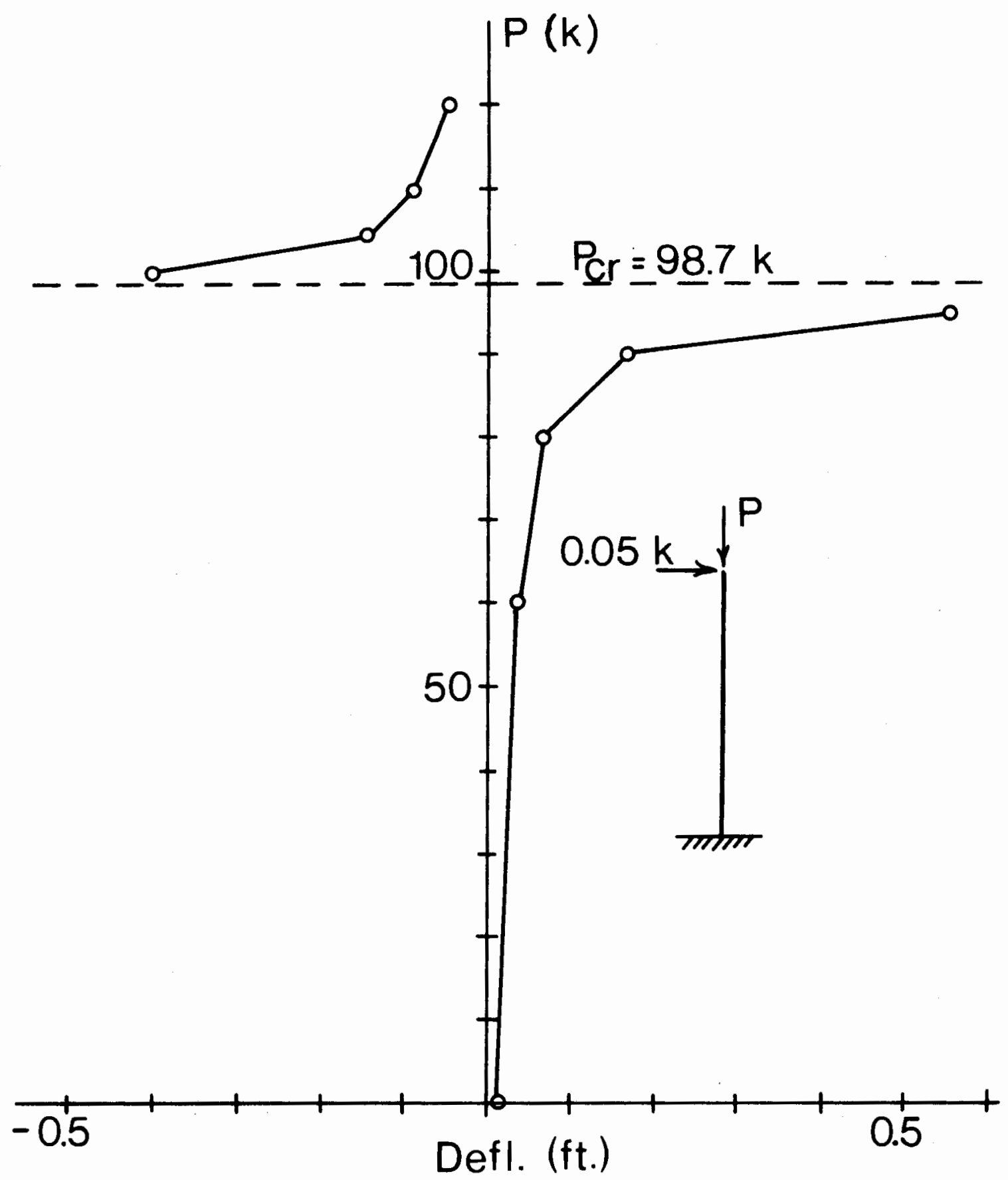

FIgure 11 Load vs. lateral deflection. 
If equation (2) is repeated for each station ' 1 ' along the member and the result written in matrix form, the coefficlents $a_{1}-e_{1}$ make up a stiffness matrix with a bandwidth of five. Furthermore, if the elements below the diagonal of this stiffness matrix are driven to zero by a Gaussian Elimination procedure, the resulting equations ire described by equation (3). Solving equation (3) for each station amounts to back substituting for calculating deflectons. Therefore, since Matlock's method is equivalent to a Gaussian Elimination with back substitution the checks for stability used in classical matrix methods may be applied.

In classical matrix analysis stability requires that the stiffness matrix be positive definite (12). Mathematically this condition exists when all terms on the diagonal of the stiffness matrix are positive after elimination (12). Therefore, if a negative or zero term appears as a diagonal element of the stiffness matrix after the elimination process, the structural system is unstable or buckling has occurred. Note that $D_{1}$ is the negative reclprocal of the diagonal element for each row of the stiffness matrix after elimination. Therefore, as a diagonal term approaches zero $D_{1}$ approaches Infinity and $1 f$ a diagonal term is negative the corresponding $D_{1}$ value w11l be positive. Figure 12 shows the behavior of $D_{1}$ as the buckling load is approached.

\section{Iterat1ve Procedure for Incrementing the Load}

A vartable step load Incrementing procedure was used to determine the ultimate load value. In order to save computer time, a large load increment was chosen to start the process. It was decreased by one-half, and the member solved again if one of the following conditions 


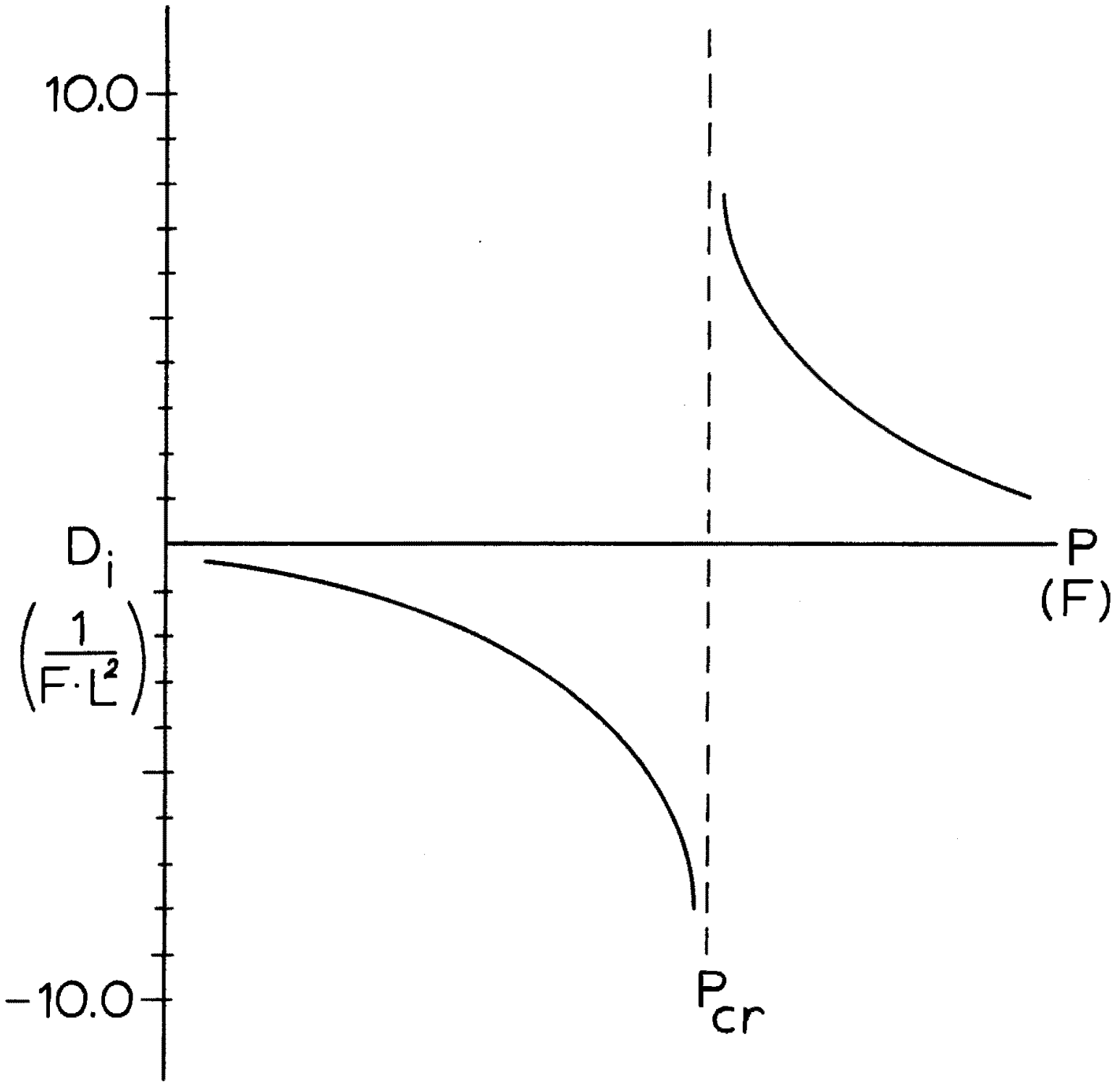

FIgure 12 Stability criterla 
occurred:

a) Instabillty was reached

b) the number of 1terations to achleve agreement with the M-P- $\emptyset$ data exceeded a 11mt set in the program.

The process of decreasing the load increment was continued until it became suffictently small. At this point fallure was considered to have occurred. It should be noted that any load Including axtal load, applied moment, or transverse load may be 1ncremented to fallure. A flow chart summarizing the procedure is shown in Figure 13. Appendix (IV) contains a detalled flow chart of the beam-column analysis.

\section{DESIGN APPLICATIONS}

The computer model used in this investigation is very flexible and thus allows the systematic study of the change in the ultimate strength of tubular beam-columns caused by varylng different parameters. The program can account for the effect of a nonblinear materlal stressstrain curve and longltudinal residual stresses in the generation of the M-P- $\emptyset$ data and consequently can calculate the resulting change In fallure load. In addition to the effect of these material imperfections, the changes in fallure load capacity caused by varying support and/or loading conditions may be studied. The program can analyze beam-columns with any combination of axial and transverse loads and discrete moments applied along the member. Supports may conslst of rollers, fixed ends or transverse and rotational springs. Intermedlate supports and varying stiffness along the member may also be studled. 


\section{START}

Analyze the beam-column. Save calculated values for curvature and bending moment $\left(\mathrm{M}_{\mathrm{CAI}}\right)$ for each station.

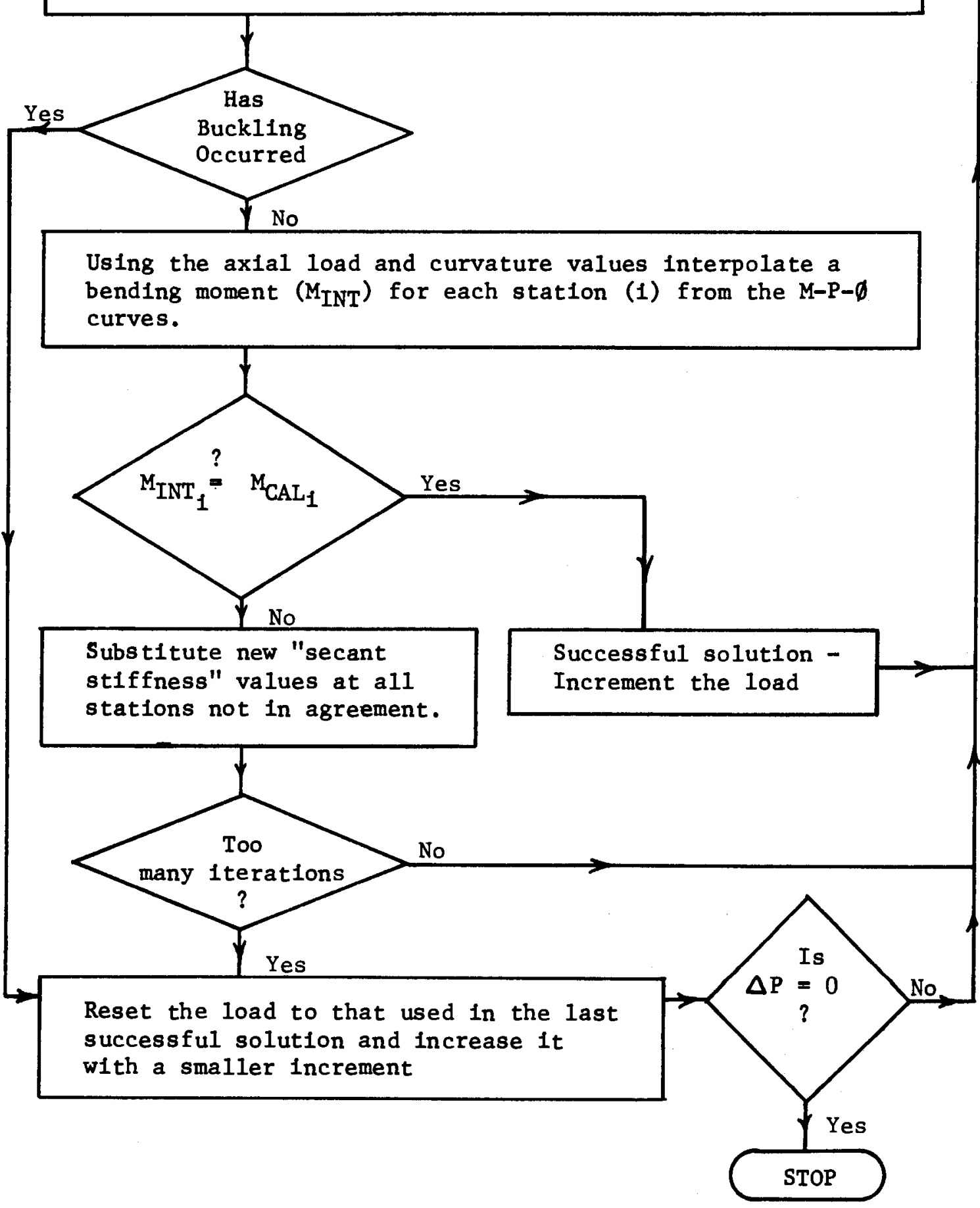

Figure 13 Flow diagram for determination of fallure load. 
The presentation of the ultimate load capacity of beam-columns Is normally accomplished by interaction diagrams which providf the maximum combination of axial load and bending moment that can be supported for specified slenderness ratios $(L / r)$. Although the program is capable of developing interaction diagrams for a wide range of slenderness ratios, end conditions and loading configurations, the scope of the project dictated that only a few be developed. The interaction curves selected were for loading patterns most common in design applications and consisted of axial load and the following end-moment configurations :

a. Equal end moments causing single curvature (Figure 14)

b. Moment at one end only (Figure 15)

c. Equal end moments causing double curvature (F1gure 16)

The loading sequence was to apply the end moment(s) first and then Increment the axial load until fallure. Slenderness ratios of $\mathrm{L} / \mathrm{r}=$ 40 and $L / r=120$ were selected to deplct the behavior of short and long beam-columns. The M-P- $\emptyset$ data used in developing these interaction curves are those presented in Figure 5.

The effect of residual stresses on the ultimate load capacity of a beam-column was also determined. Using the M-P- $\emptyset$ data shown in Figure 6, corresponding interaction diagrams were generated for a circular tube with equal end moments causing single curvature. The resulting interaction diagrams are shown in F1gure 14 and Indicate that residual stresses cause a reduction of the ultimate strength of the circular tubes. This effect appears to be more prominent for the higher values of $\mathrm{P} / \mathrm{P}_{\mathrm{y}}$. 


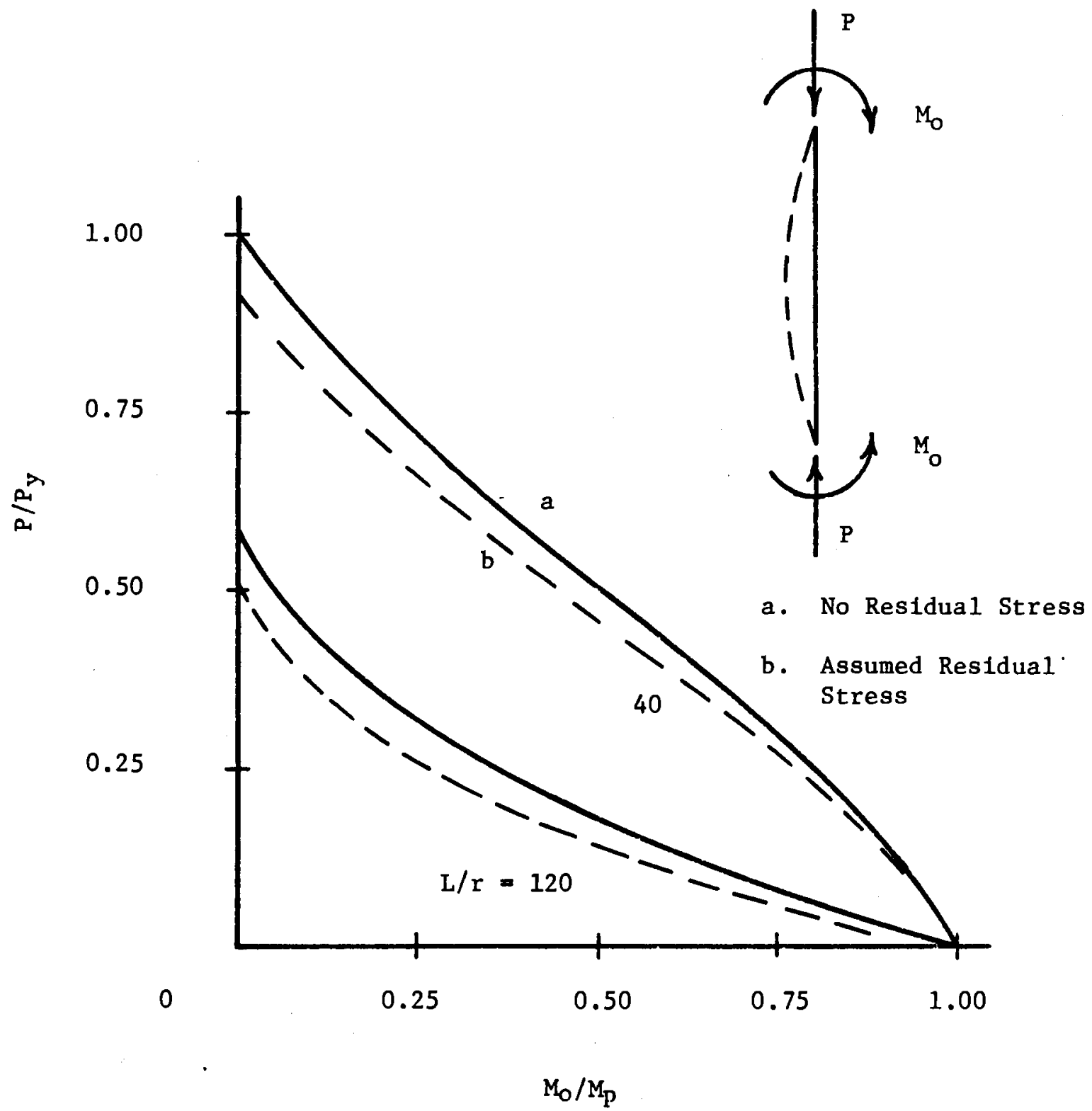

Figure 14 Interaction diagram, Fy $=35 \mathrm{ksI}$

Equal end moments - Single curvature 


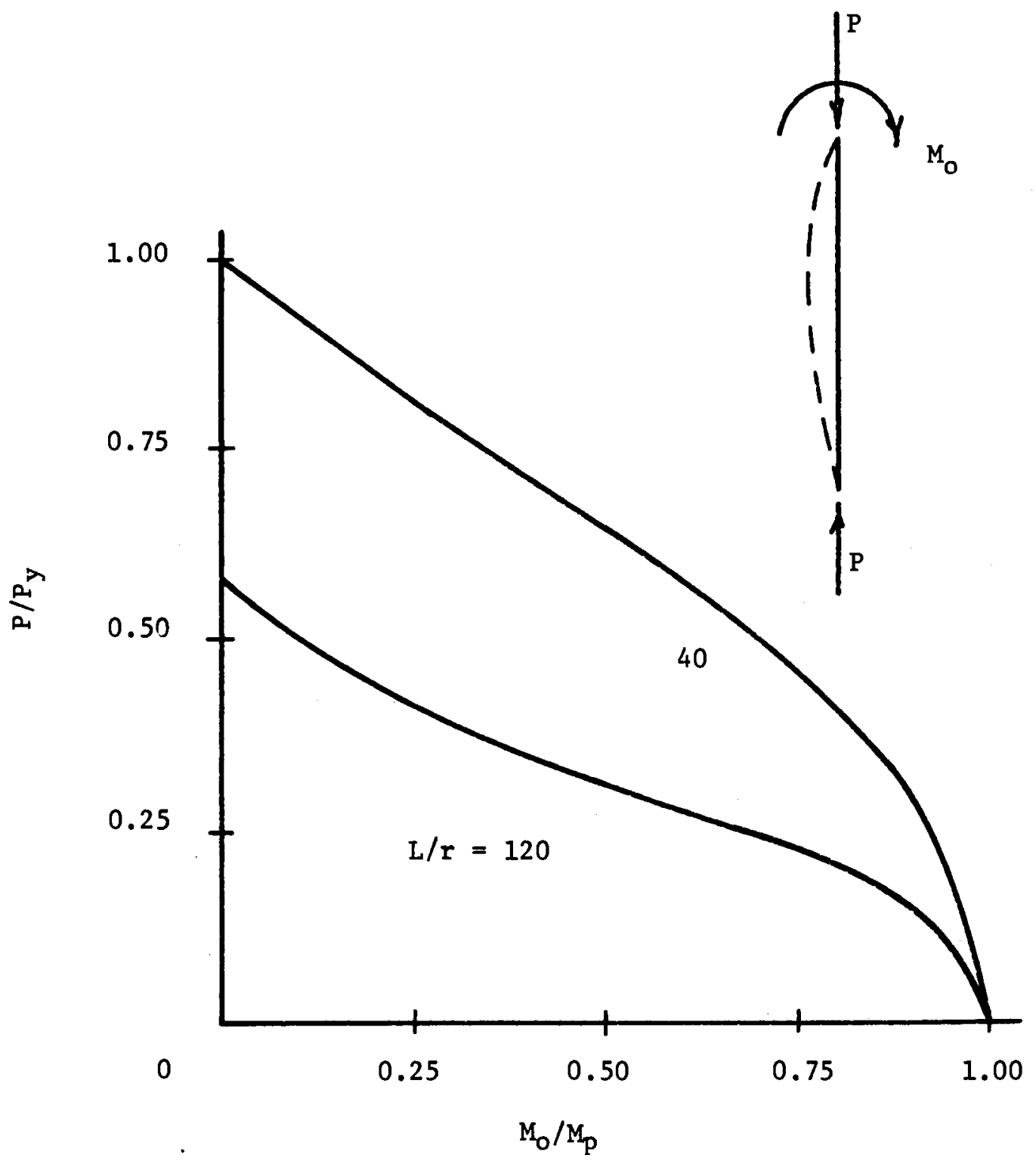

F1gure 15 Interaction diagram, Fy = $35 \mathrm{ks1}$ Single end moment 


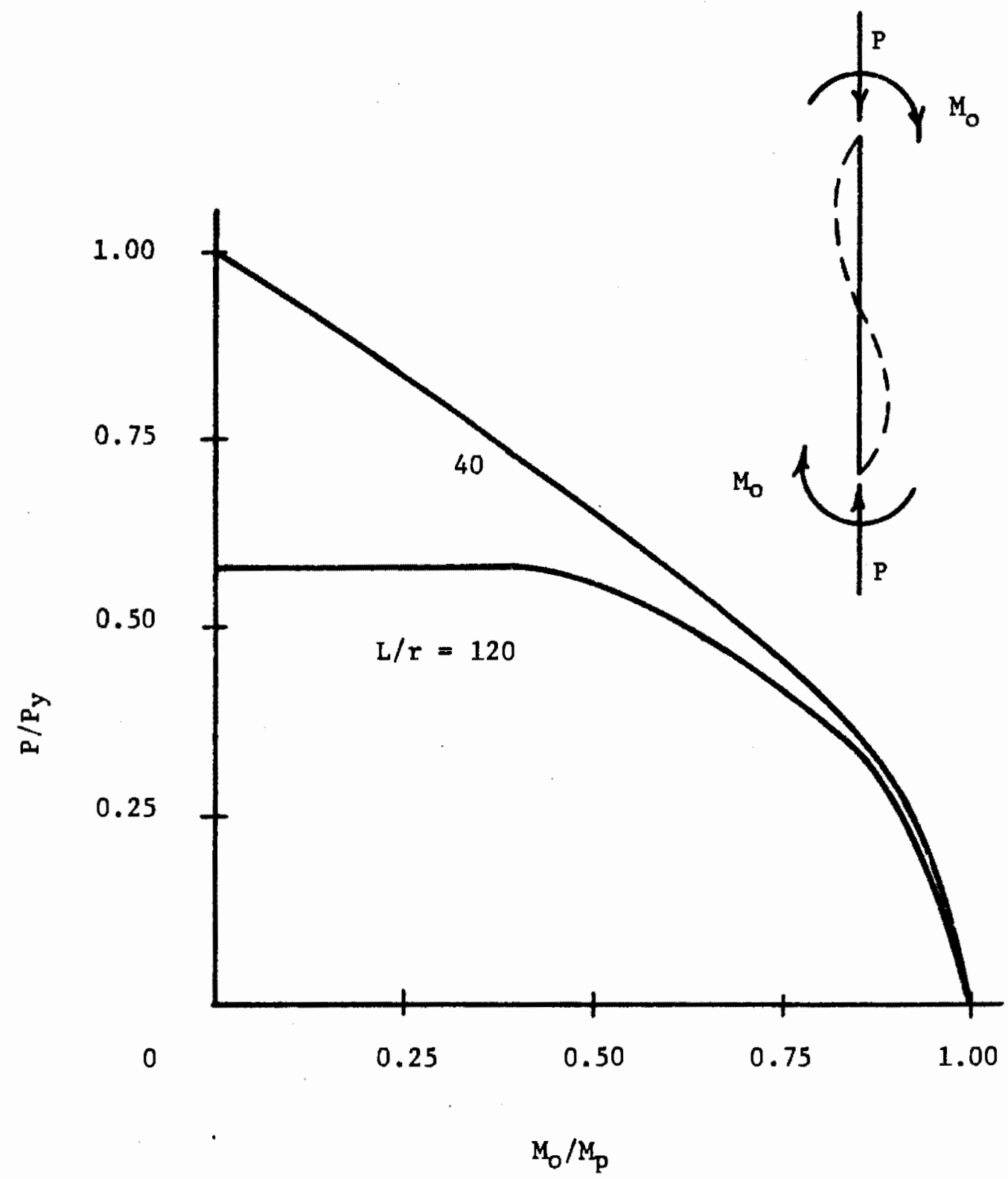

F1gure 16 Interaction dlagram, Fy - $35 \mathrm{ksl}$

Equal end moments - double curvature 


\section{COMPARISON WITH PUBLISHED TEST RESULTS}

The M-P- $\emptyset$ data represent the correct combination of bending moment, axial load and curvature which a given section of tube will sustaln when subjected to a loading condition consisting of bending moment and thrust. As mentioned previously the first phase in calculating fallure loads is the generation of M-P- data. An orderly check of the computer model should thus begin with a comparison of the M-P- data calculated and that obtained experimentally. Sherman (16) presents moment-curvature data developed from tests of tubes subjected to bending only 1.e., $P / P_{y}=0$. Figure 17 shows a comparison between Sherman's results and those predicted by the computer model presented In this paper. The test values lie below the analytical curve Indicating a lower load carrying capability which is expected since no attempt was made to account for residual stresses, ovalling or member Imperfections during the generation of the calculated values. However, the comparison reveals that the computer model is capable of representing actual behavior with reasonable accuracy. To obtaln an indication as to the rellability of the computer model used in the fallure load calculations, a comparison was made with laboratory results by other investigators. Plotted with the interaction curves of Figure 18 are the results of beam-column tests by Ellis (5) which agree closely with the values predicted by the computer model assuming zero residual stress. A cursory review might suggest that these test results should lie closer to curve b of Figure 18 plotted from values calculated using an assumed residual stress distribution. However, it should be noted 


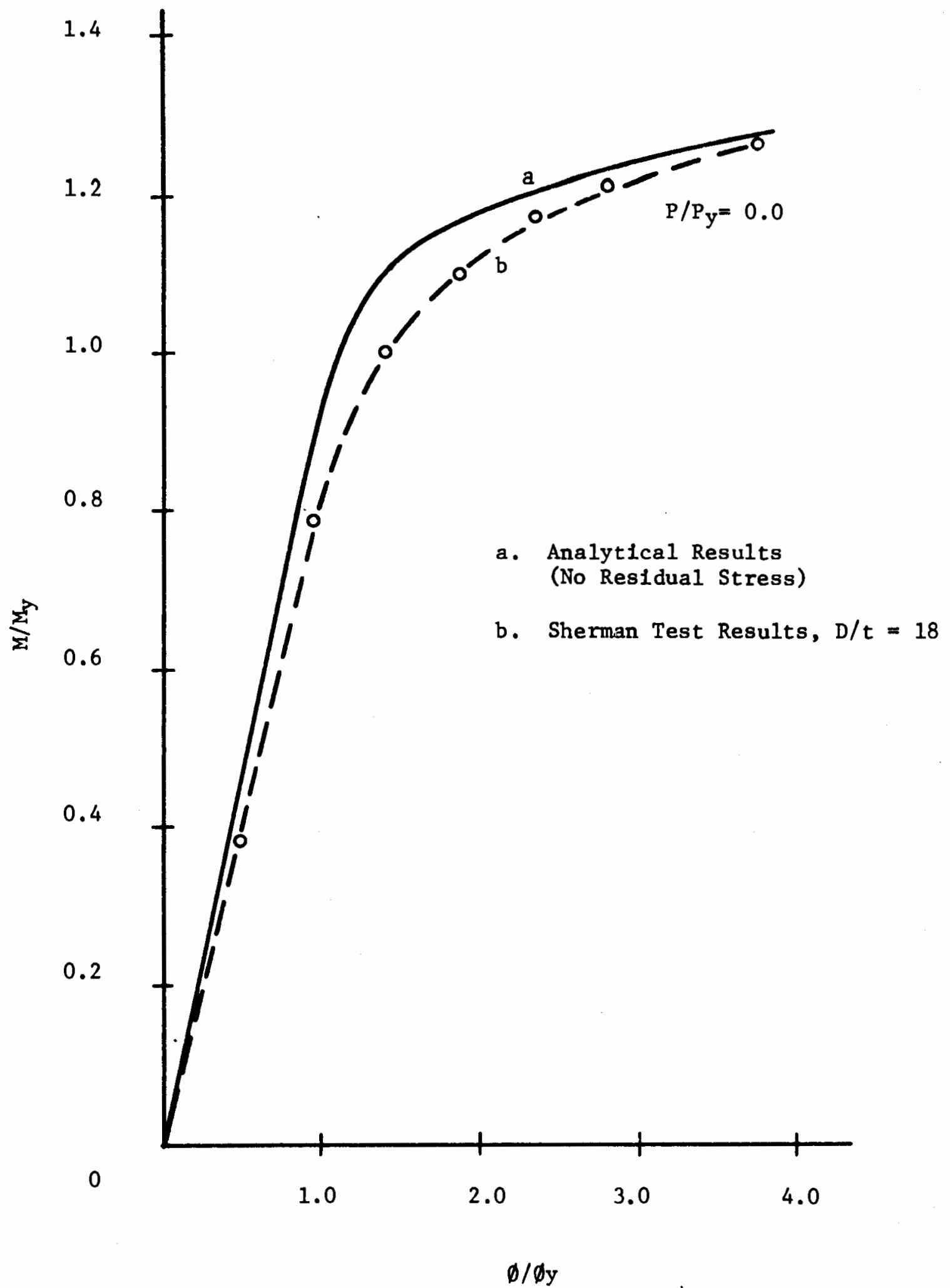

Figure 17 Moment-curvature relationship 


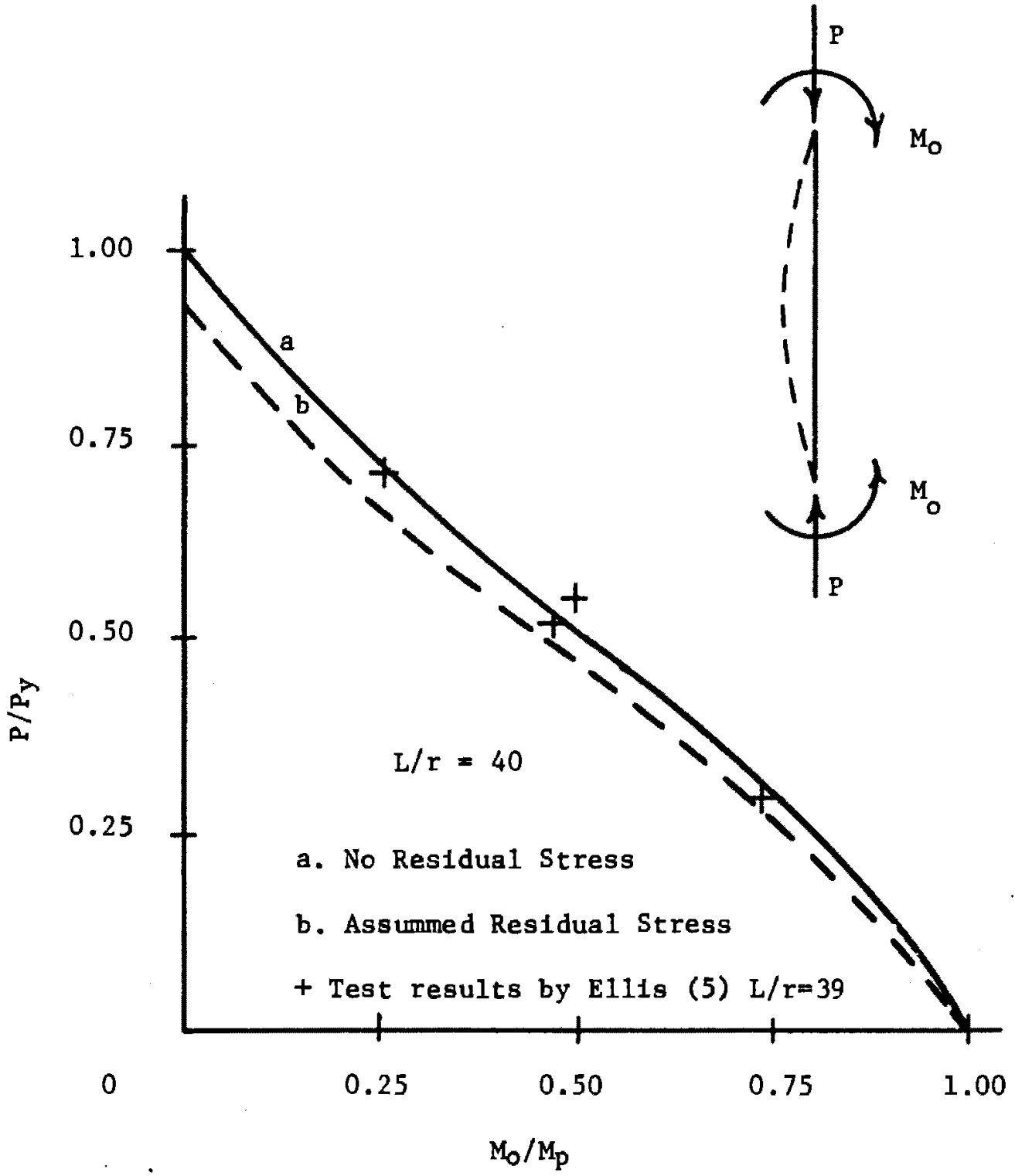

F1gure 18 Interaction curves, Fy $=35 \mathrm{ksi}$

Equal end moments - single curvature 
that neither the orfentation of the bending axis during the tests with respect to the weld nor the nature of the residual stresses in the specimens tested, were specified in reference (5). 
CHAPTER IV

EXPERIMENTAL PROGRAM

The remalnder of this paper documents the testing of model beamcolumns. Attention is given to the experimental setup and the models selected. Also, each test is consldered Individually with a comparIson made between the experimental results and the load-displacement history predicted by the computer model.

\section{OVERVIEW}

The experimental program conststed of loading four model beamcolumns to fallure by appling an eccentric axial load. A schematic of the loading patterns 1s shown In Figure 19. The values of Beta chosen were -1.0 (single curvature), 0.0 , and 1.0 (double curvature). For Beta equal to -1.0 one long column and one column of intermediate length were tested. One colum of Intermediate length was tested for each of the other values of Beta.

\section{EXPERIMENTAL SETUP}

The experimental setup is shown in Figure 20. A load frame was supported horizontally on rollers with the axtal load applied by the actuator of the MS Electrohydraulic Test1ng Mach1ne. As shown in Figure 21 the base of the actuator was securely bolted to the load frame with the other end supported on rollers. This configuration 
40

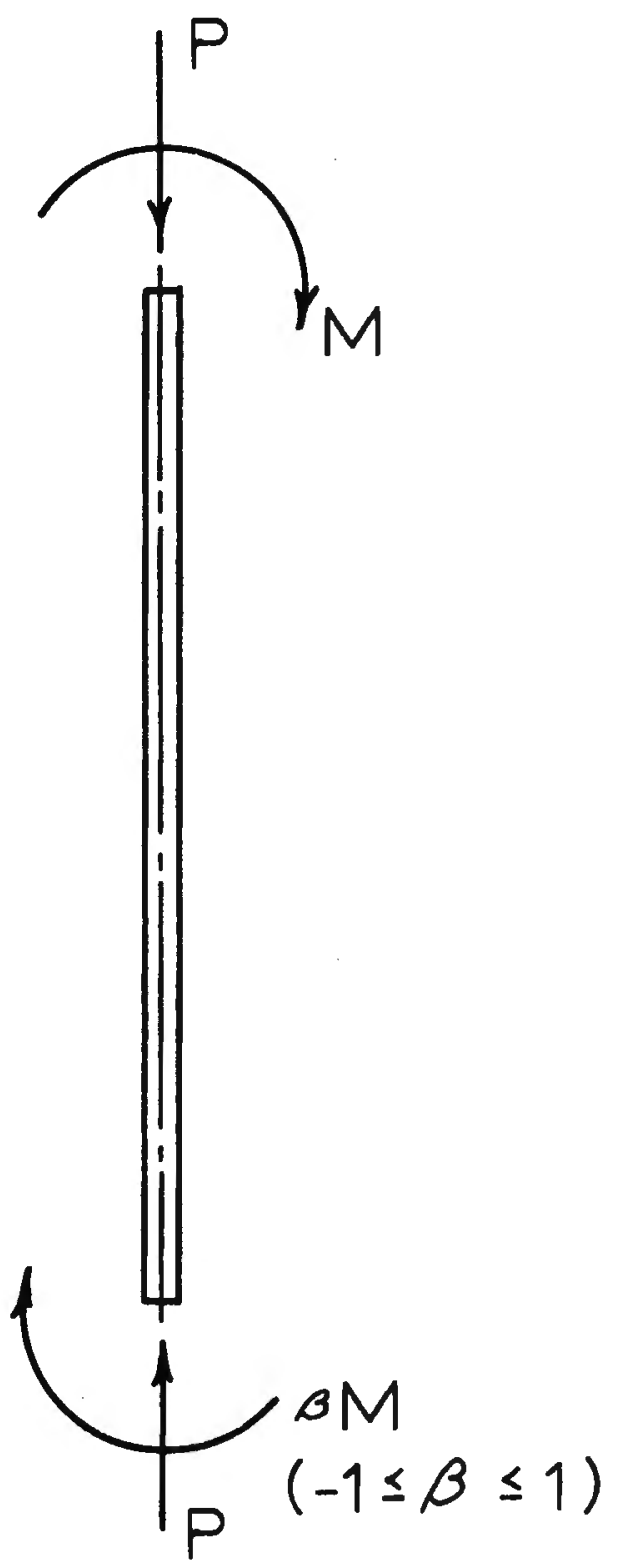

Figure 19 Loading configuration 


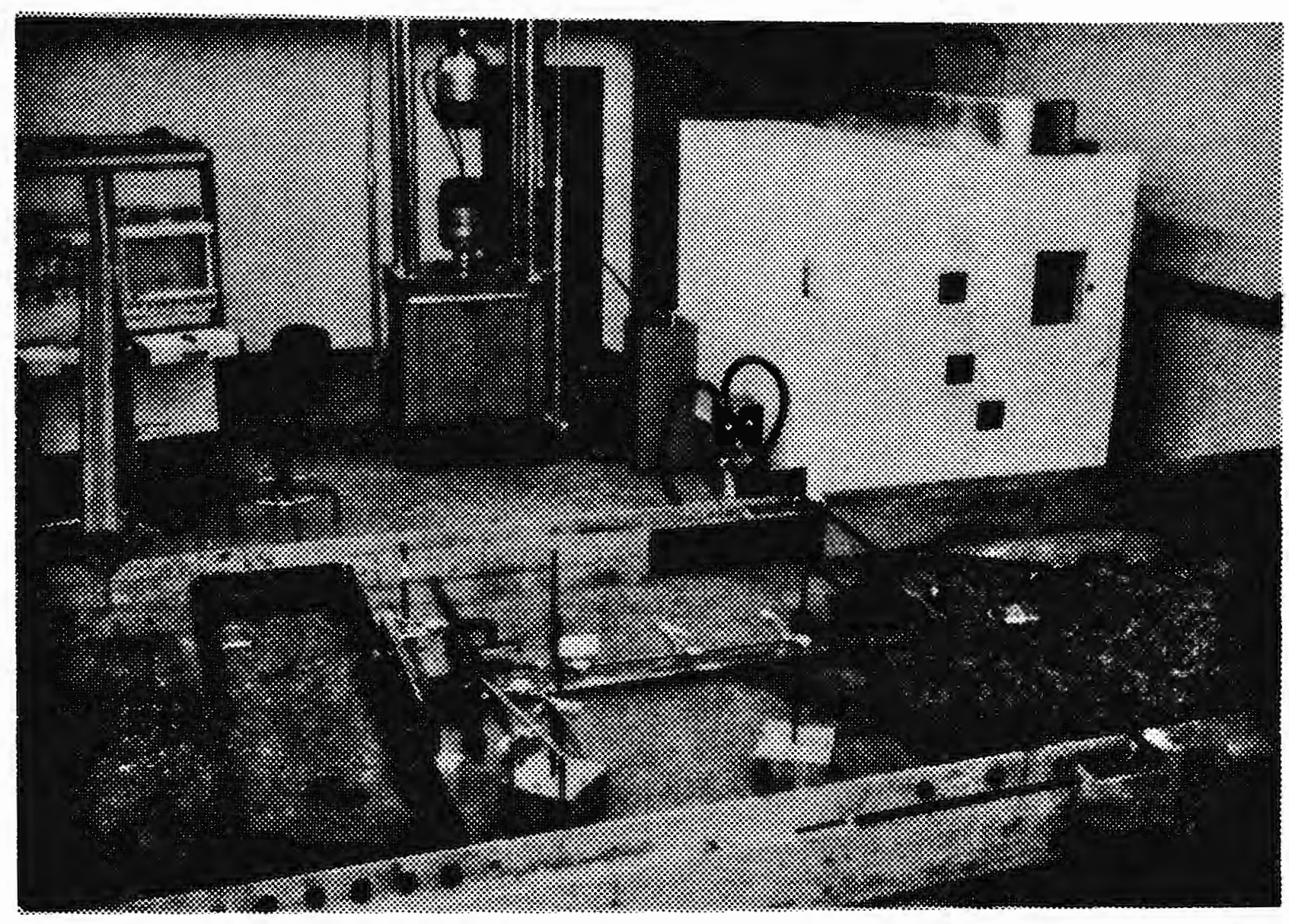

Figure 20 Experimental setup 


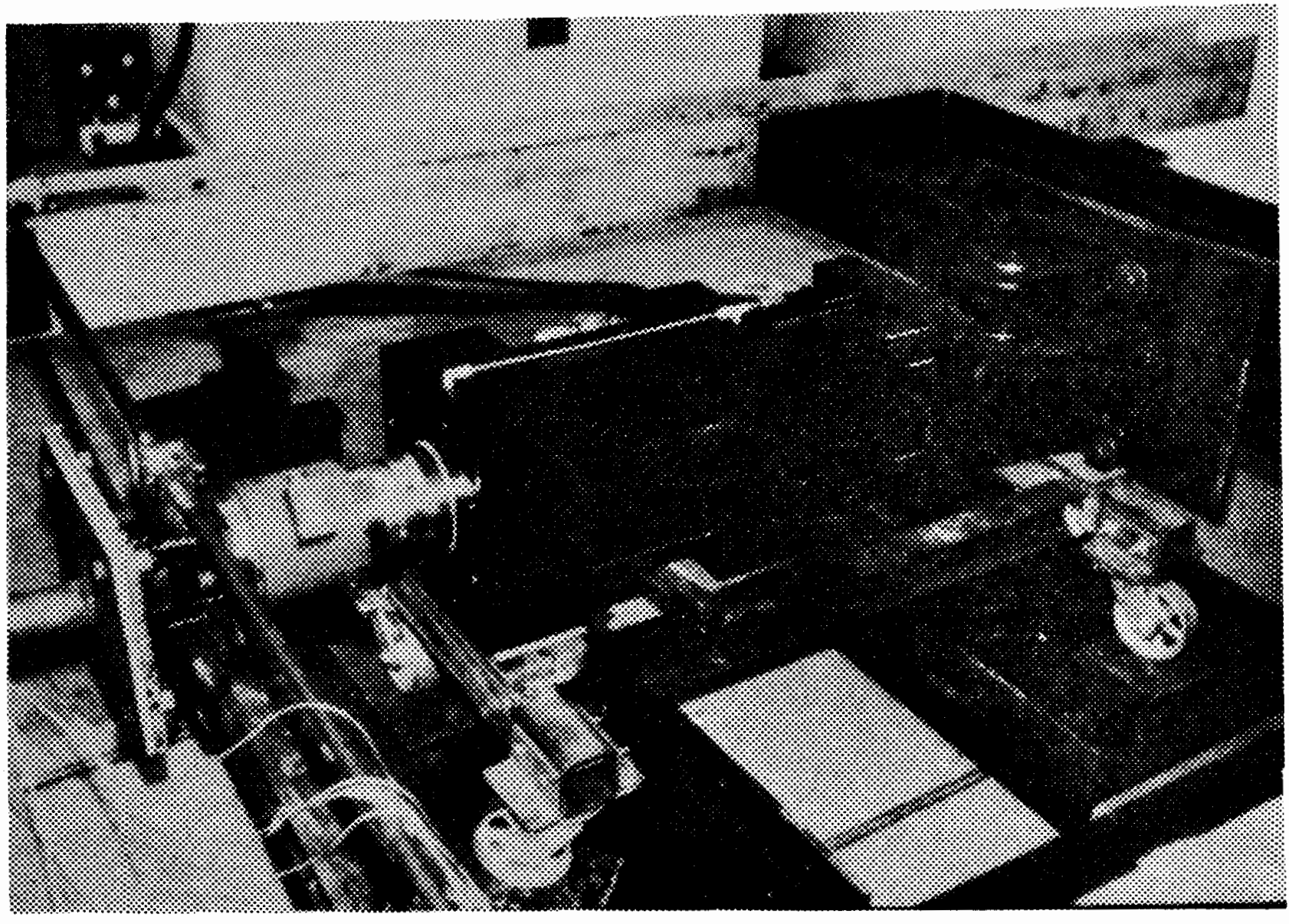

Figure 21 Actuator supports 
may be idealized as a three-hinge condition as shown in Figure 22 . Adfustment rods attached to the actuator (center hinge) were us d during the test as necessary to maintaln alignment of the three hinges.

The eccentricity of the axial load, $P$, was provided by welding end plates to the specimens with the desired offset. Special care was taken to assure that the end plates were perpendicular to the columns. The end plates provided the connection between the specimens and the load frame and were held in place with high strength bolts (ASTM A325).

Since the specimens were to be loaded to fallure safety considerations dictated that deflections rather than load be controlled during the tests. The specific deflection chosen was the stroke of the actuator which was set during the tests at $0.0005 \mathrm{in./sec..}$ The actuator stroke was held constant at predetermined intervals to fac11itate reading the desired measurements. The test was terminated when an increase in stroke resulted in no increase in load.

\section{DESCRIPTION OF MODELS}

The models were constructed of AISI C 1018 cold drawn steel tubing which was selected because of the close dimensional tolerances maintained during its manufacture. To prevent the occurrence of local buckling during the tests values of $\mathrm{D} / \mathrm{t}$ were chosen as out1ined by Marshall (13). Two sizes of tubing were tested. The nominal dimenslons were 2 inch outside diameter, $1 / 4$ Inch wall thickness. Both out-of-roundness and initial crookedness were checked for each beamcolumn and found to be negligible quantities when compared to the dimensions of the models. 


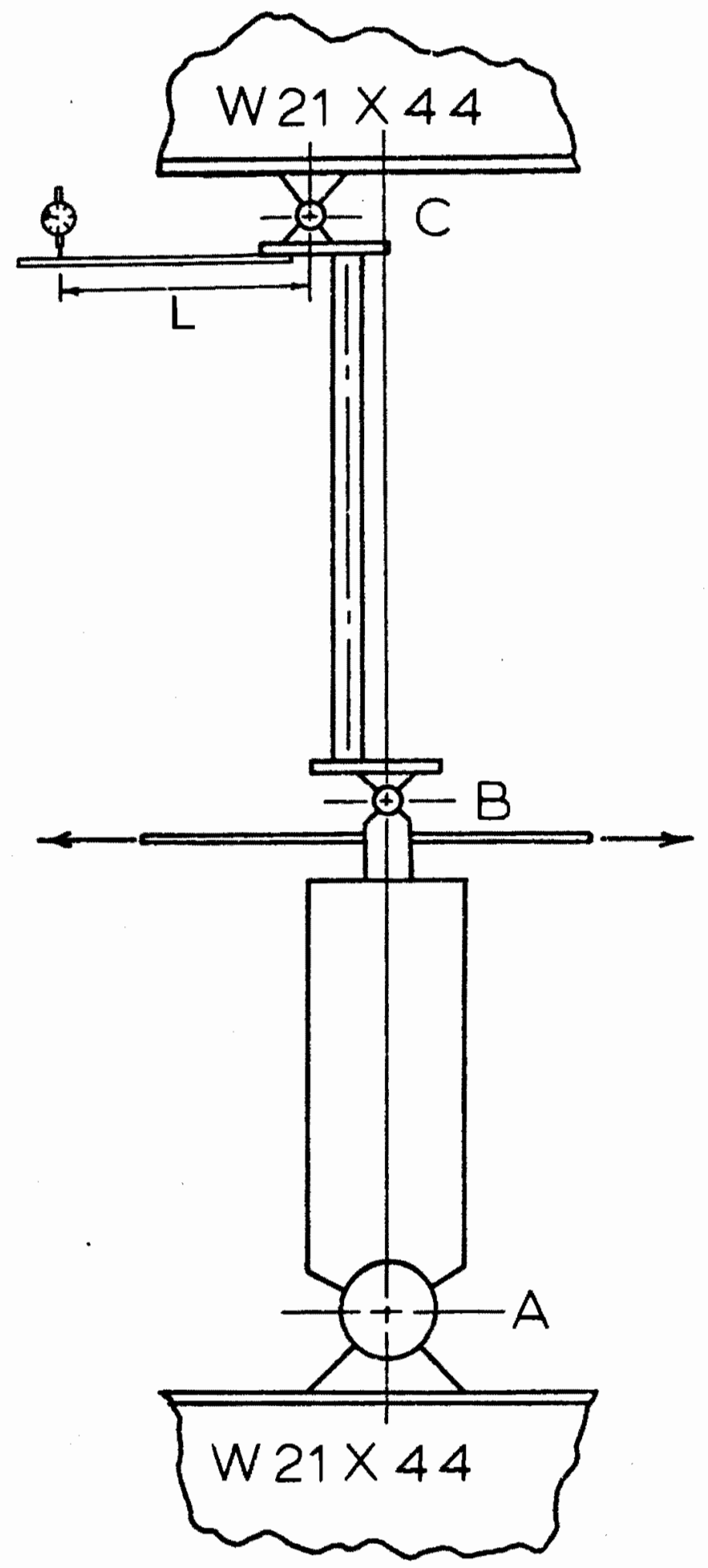

F1gure 22 Schematic of experimental setup. 
INSTRUMENTATION

The Instrumentation was simflar for each of the models tes ed, the only difference being the locations along the member length at which measurements were taken. The measured quant1ties included load and end rotation; transverse deflections and curvature. The load value was read directly from the MTS control panel. Dial gages were used to obtain transverse deflections; end rotations were measured by two dial gages located on arms perpendicular to the beam-column at the hinge, Figure 22. Rotation is determined by dividing the dial gage reading by the arm length, L. Strain gages located on opposite sides of the tube were used to measure curvature, curvature belng equal to the difference in the strain values divided by the outside diameter of the tube.

\section{STEEL PROPERTIES AND COUPON TESTS}

To provide consistency, all test specimens of a given diameter were cut from a single piece of tubing. This eliminated the necessity of testing a set of coupons for each specimen. ASTM Standard coupons were cut In the longltudinal direction from a section of tubing. Two coupons for each size of tube were tested with results as shown in Table 1. The yleld stress Indicated was determined on the basis of a $0.2 \%$ offset. The coupons were tested on the MTS Testing Machine using load control with a load rate of $75 \mathrm{lb} / \mathrm{sec}$. which corresponds to a stress rate of $777 \mathrm{ps} 1 / \mathrm{sec}$. for the coupon from the 2 inch tube and $585 \mathrm{ps} 1 / \mathrm{sec}$. for the coupon from the 3 inch tube. All coupons tested exhibited the gradual ylelding stress-strain curve typlcal of coldworked material. The average stress-strain relationship for each size 
Table 1 Results of coupon tests.

\begin{tabular}{|c|c|c|c|c|}
\hline & $\begin{array}{l}\text { Yteld } \\
\text { Stress }\end{array}$ & $\begin{array}{l}\text { Ult Imate } \\
\text { Stress }\end{array}$ & $\mathbf{E}$ & $\begin{array}{c}\% \\
\text { Elongation }\end{array}$ \\
\hline 2" o.D. & & & & \\
\hline$\# 1$ & $75.7 \mathrm{ksI}$ & $85.2 \mathrm{ks} 1$ & $32,400 \mathrm{ksi}$ & 10.5 \\
\hline \#2 & $73.9 \mathrm{ksi}$ & $85.3 \mathrm{ksi}$ & $28,800 \mathrm{ksi}$ & 11.0 \\
\hline Average & $74.8 \mathrm{ksi}$ & $85.3 \mathrm{ksi}$ & $30,600 \mathrm{ksi}$ & 10.8 \\
\hline 3" O.D. & & & & \\
\hline \#1 1 & $83.8 \mathrm{ksi}$ & $89.7 \mathrm{ksi}$ & $34,300 \mathrm{kgl}$ & 11.0 \\
\hline \#2 & $85.2 \mathrm{ksi}$ & $91.8 \mathrm{ksi}$ & $27,900 \mathrm{ksi}$ & 8.0 \\
\hline Average & $84.5 \mathrm{ksi}$ & $90.8 \mathrm{ksi}$ & $31,100 \mathrm{ksi}$ & 9.5 \\
\hline
\end{tabular}


of tube are shown in Figures 23 and 24.

$$
\text { MOMENT - THRUST - CURVATURE DATA }
$$

The moment-thrust-curvature relationship was determined for each size of tube with the stress-strain values as shown in Figures 23 and 24 included in the calculations. No attempt was made to incorporate a residual stress distribution since seamless tubes are generally believed to have low residual stresses. A slight difference was observed between the $M-P-\emptyset$ relationships for the two tube sizes. This was caused by the relative difference in $F_{u} / F_{y}$ as indicated in the stress-strain relationships. Also note that stress values may exceed the yield value thus some bending moment capacity is realized for $P / P_{y}$ equal to 1.0 . The M-P- $\emptyset$ relationships shown in Figures 25 and 26 were used by the computer model to determine the load-displacement history for each test.

\section{COMPARISON OF EXPERIMENTAL AND ANALYTICAL RESULTS}

\section{Test 1 T2}

The model used in test $1 \mathrm{~T} 2$ was constructed of a 2.0 inch outside diameter tube. The length of the tube was 58.0 inches resulting In a slenderness ratio of 90.3. The loading consisted of axial load and equal end moments causing single curvature, Figures 27 and 28 . The eccentricity of the axial load was 0.75 inches.

The load was applied by slowly increasing the stroke of the actuator. No adjustment to the lateral reaction rods was required during the test. 


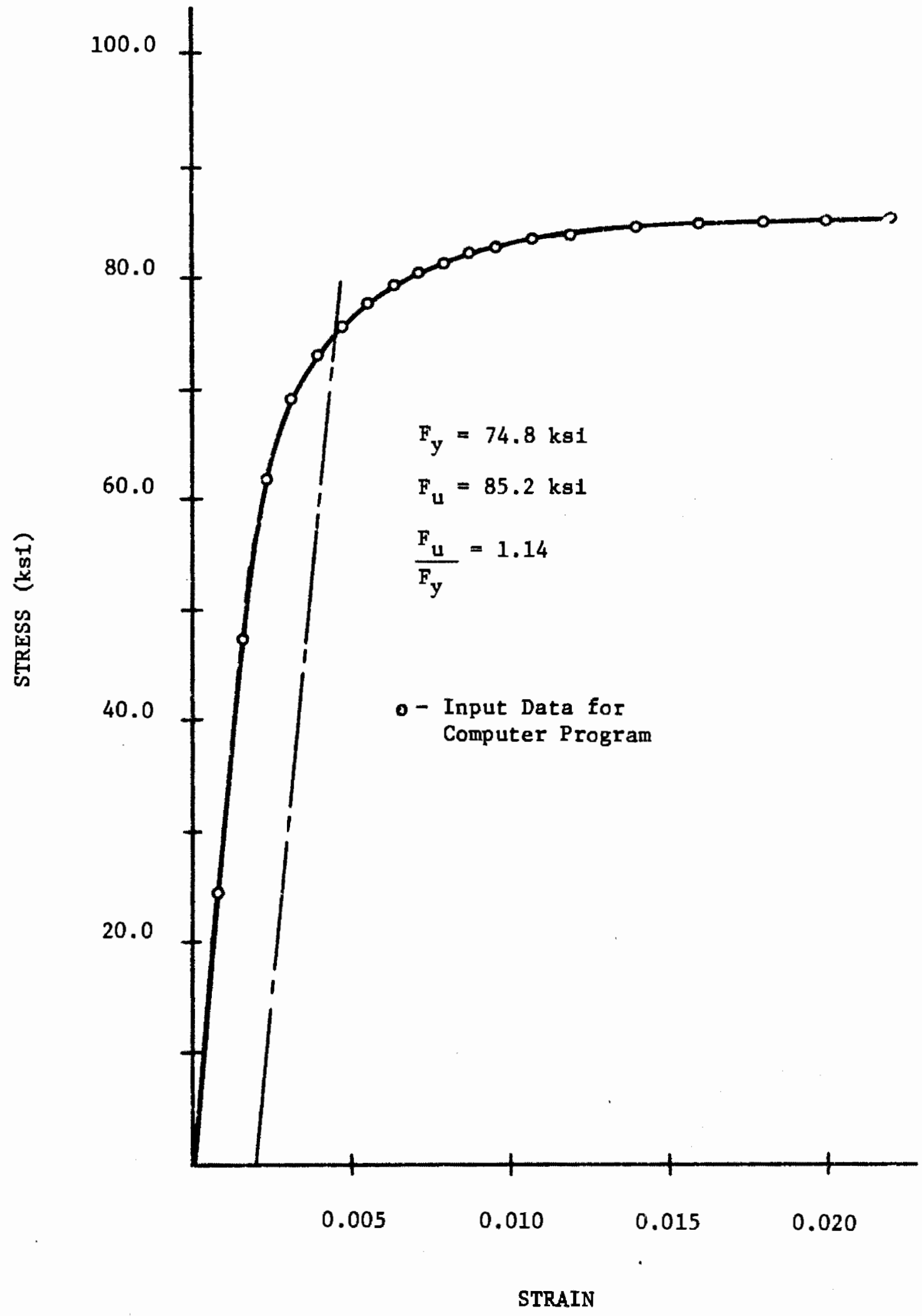

F1gure 23 Stress-straln relationshlp for 2.00 in $0 . D$. tube 


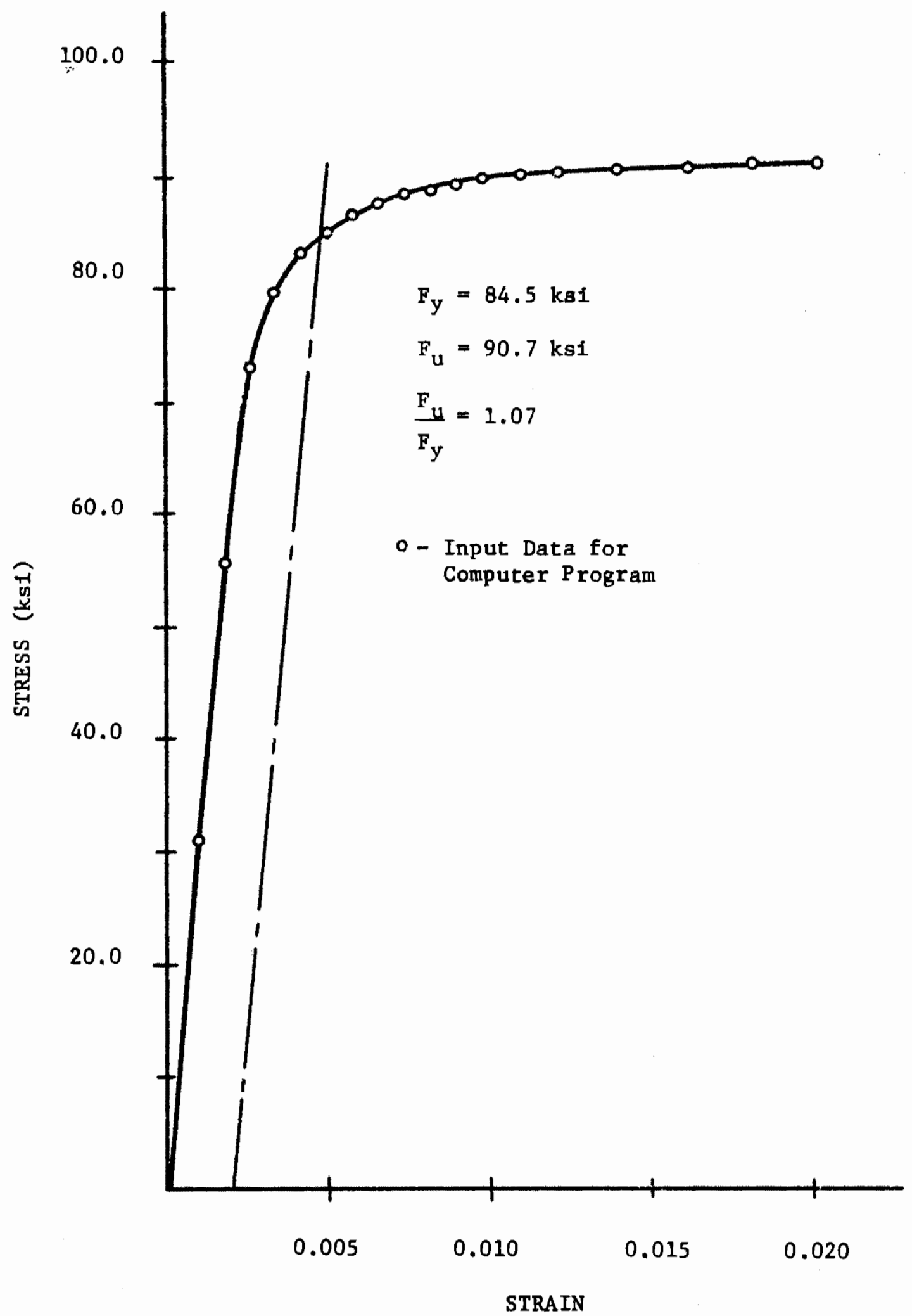

F1gure 24 Stress-strain relationshtp for 3.00 in $0 . D$. tube. 


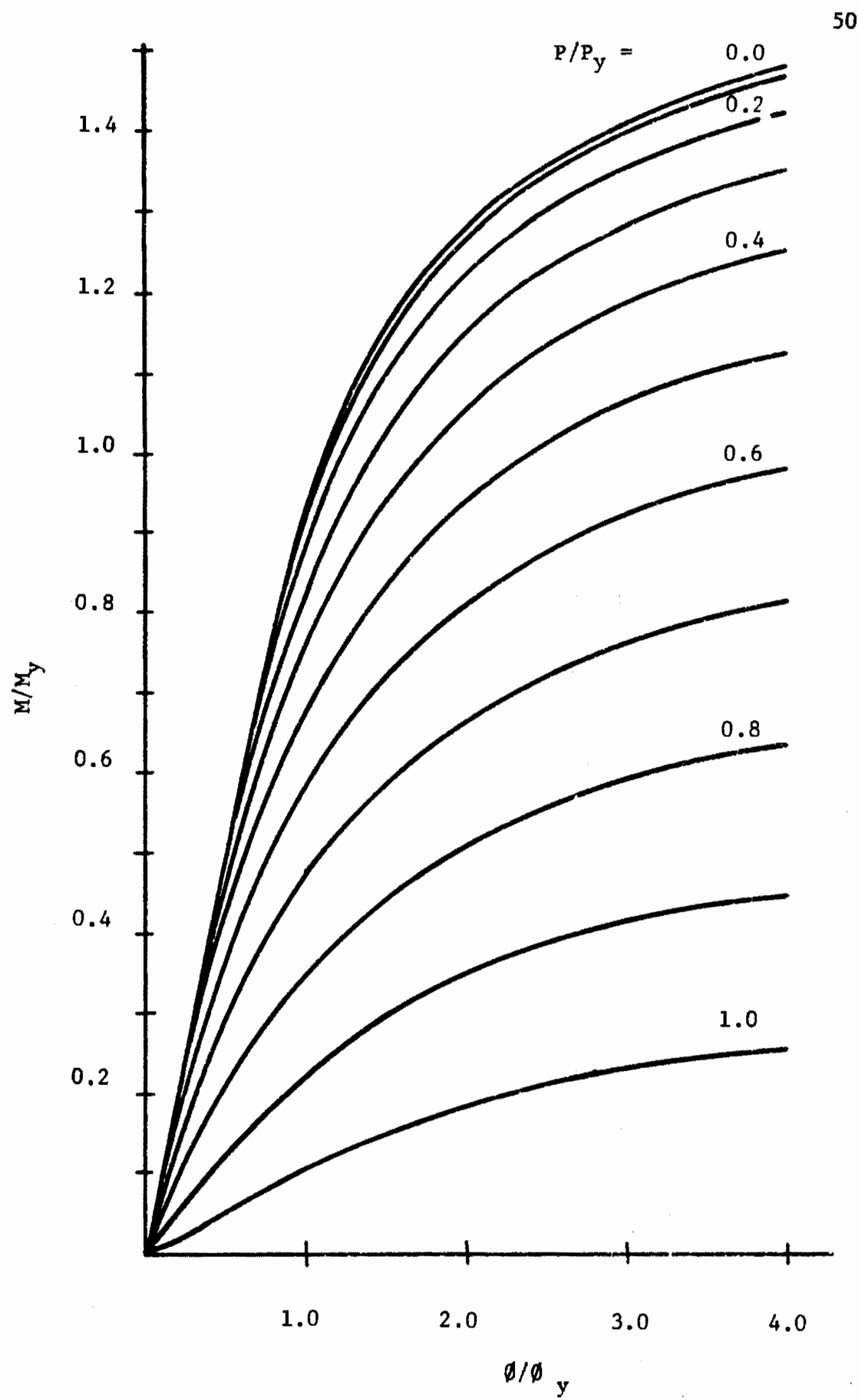

F1gure 25 Moment-thrugt-curvature relationship; 2.00 in $0 . D$. tube 


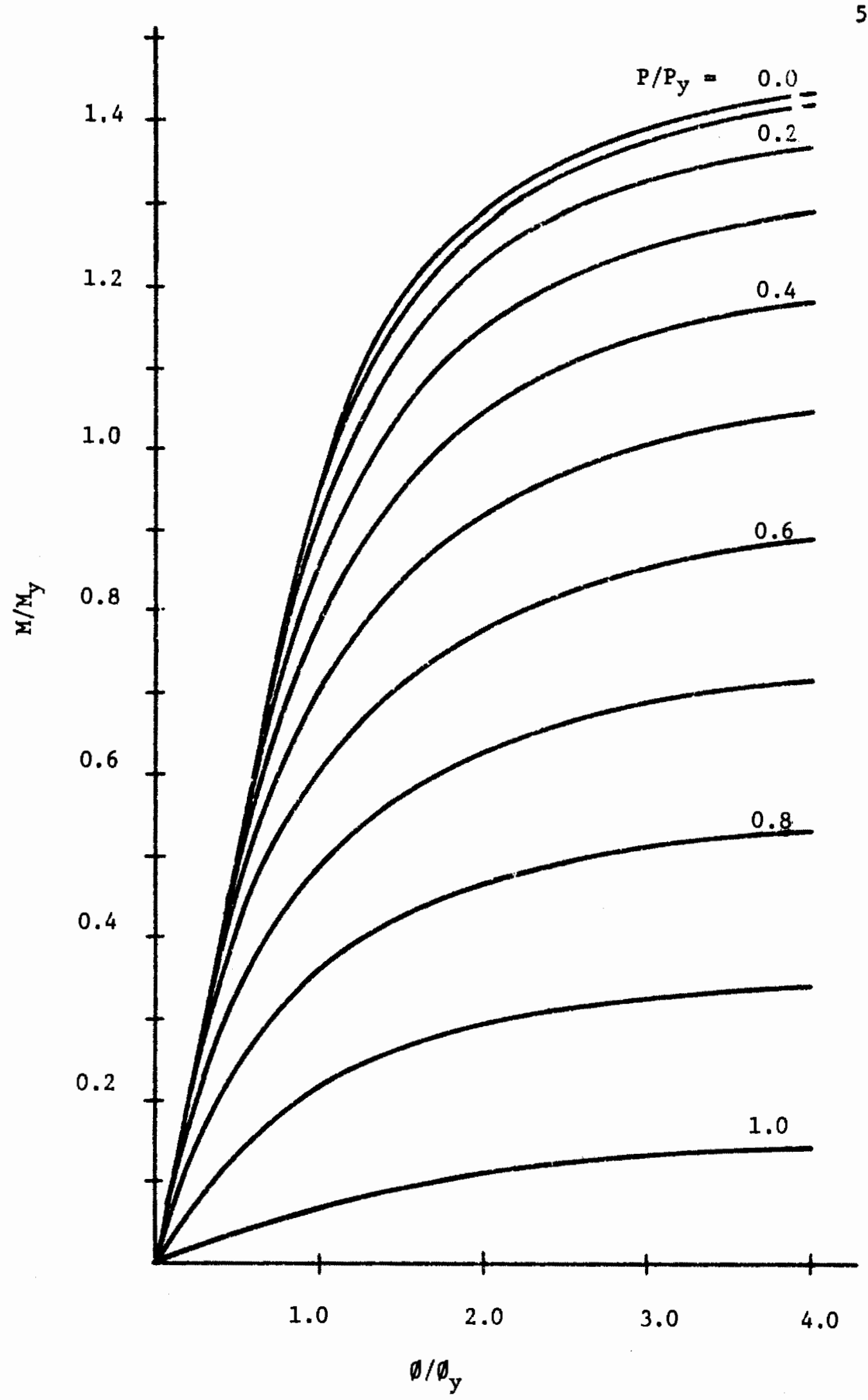

F1gure 26 Moment-thrust-curvature relat1onsh1p; 3.00 in $0 . D$. tube. 


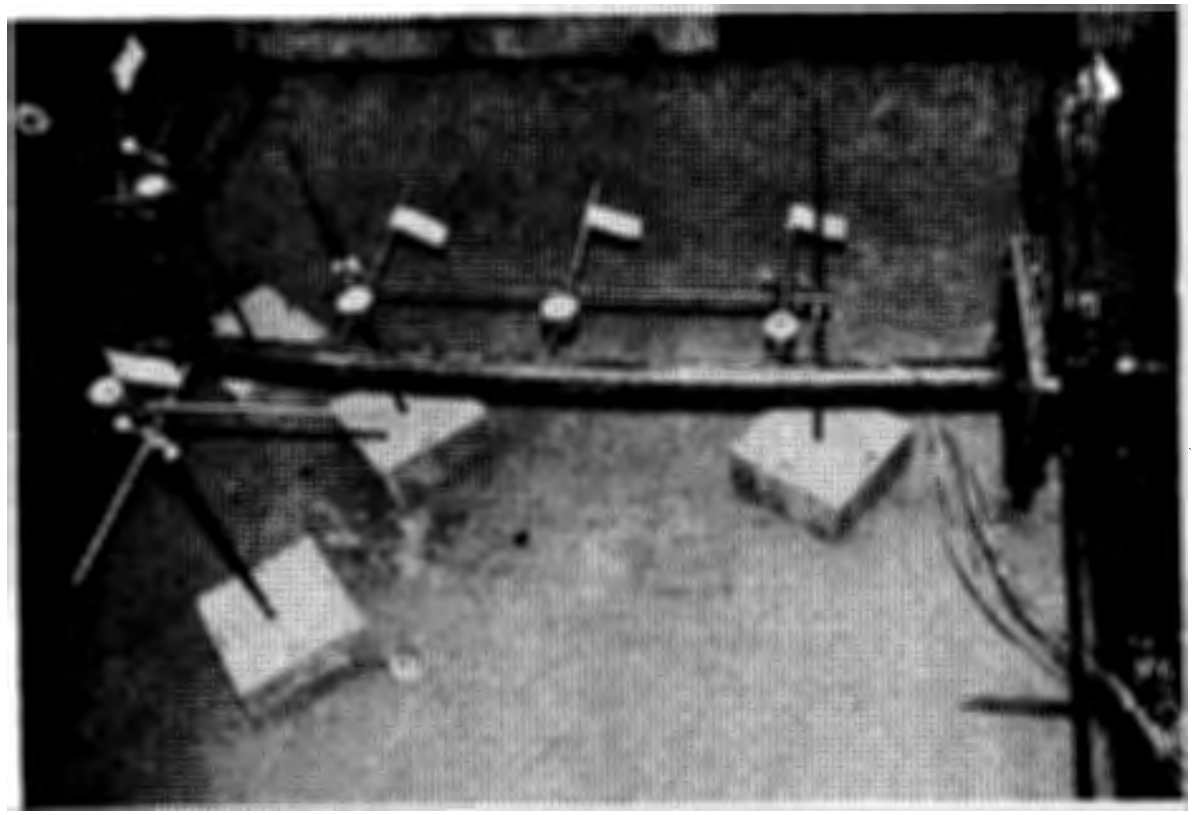

Figure 27 Test 1T2

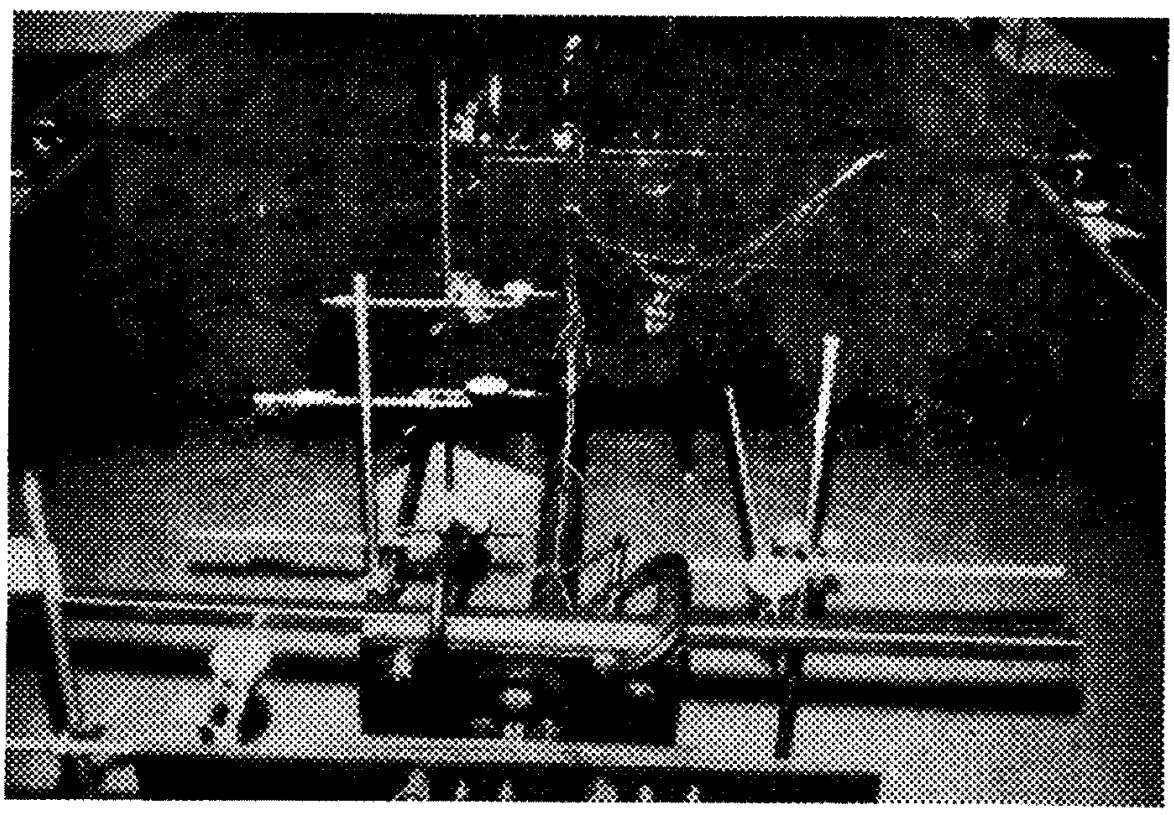

F1gure 28 Test 1 T2 
A comparison ts made between the test results and the loaddisplacement history predicted by the computer model in Figures $? 9$ thru 31. The deflection plotted In F1gure 29 and the curvature plotted in Figure 31 were measured at the center of the beam-colum. The end rotation was measured at the end of the beam-colum opposite the actuator. The results of all three measured values show a simllar trend and agree well with the values predicted by the computer model.

\section{Test 1 T 3}

In test $1 T 3$ a 3.0 inch outside diameter tube was loaded to fallure by a comblnation of axtal load and equal end moments causing single curvature. The length of the tube was 60.0 inches and the resulting slenderness rat10 was 61.4 . This is an indication that the colum w111 undergo considerable ylelding before fallure. The eccentricity of the axial load was 1.50 inches.

The load was applied by programming a slow Increase in the stroke of the actuator. As was the case w1th test 1 T2 no adjustment of the lateral reaction rods was required during the test.

F1gures 32 through 34 depict a comparison of the test results and the corresponding values determined by the computer model. The deflection and curvature values shown in Figures 32 and 34 were measured at the midpoint of the beam-column. The end rotation was measured at the end opposite the actuator. The results of all three measured values show good agreement with the analytical values.

\section{Test $2 \mathrm{~T} 3$}

The model tested in Test $2 \mathrm{~T} 3$ was constructed from a 3.0 inch 


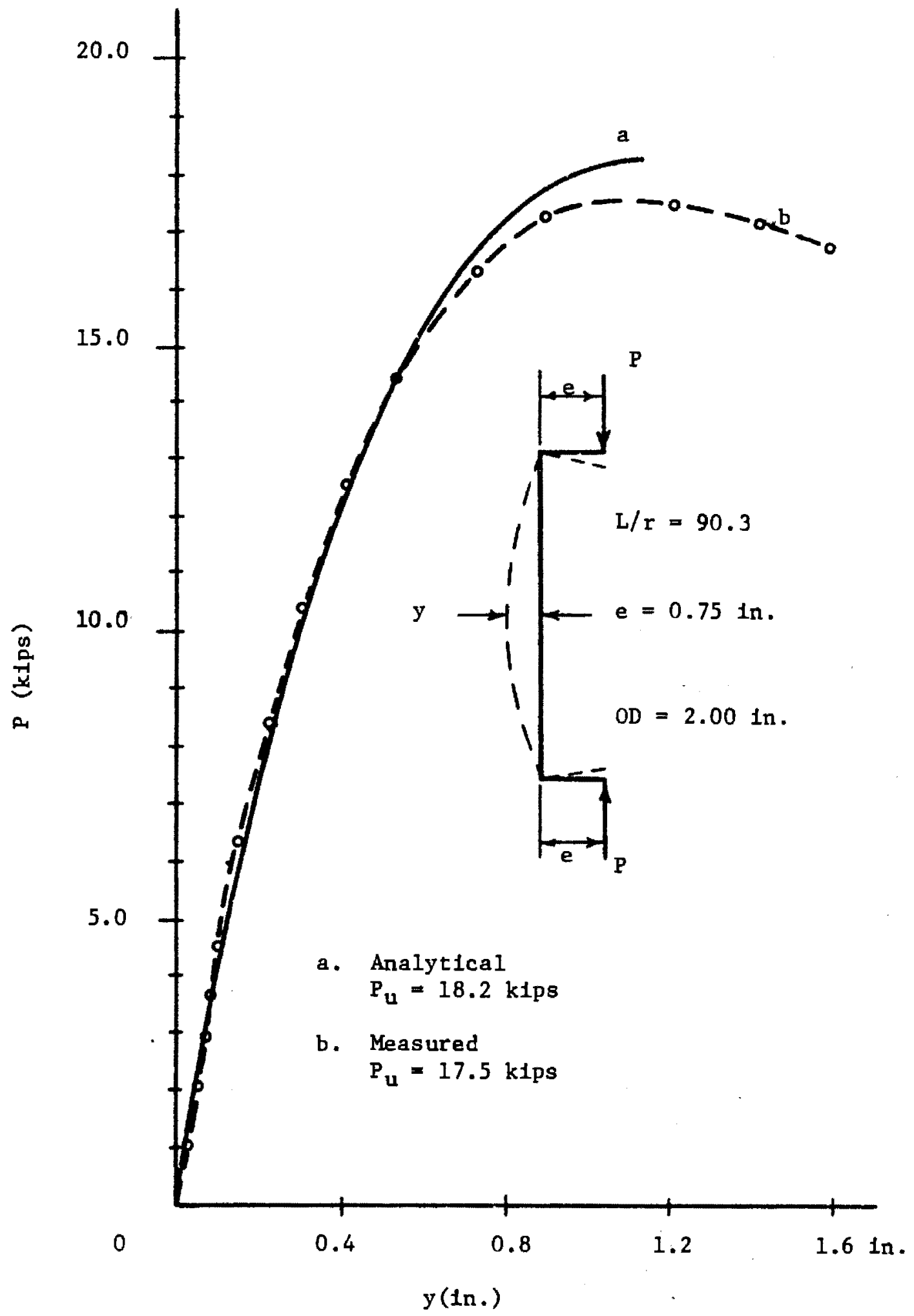

F1gure 29 Load vs. max1mum deflection - Tegt 1 2 


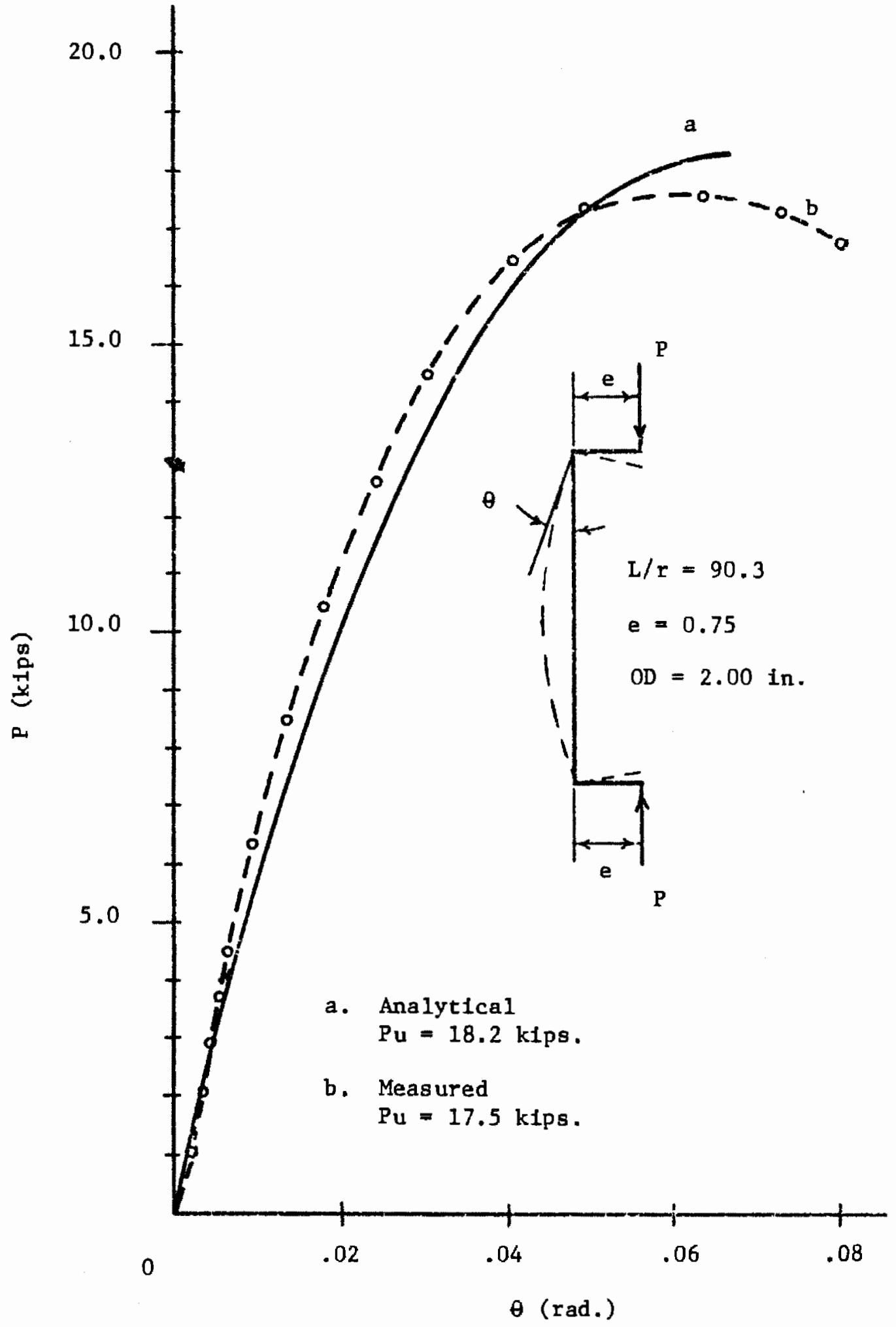

Figure 30 - Load vs. end rotation - Test 1 T2 


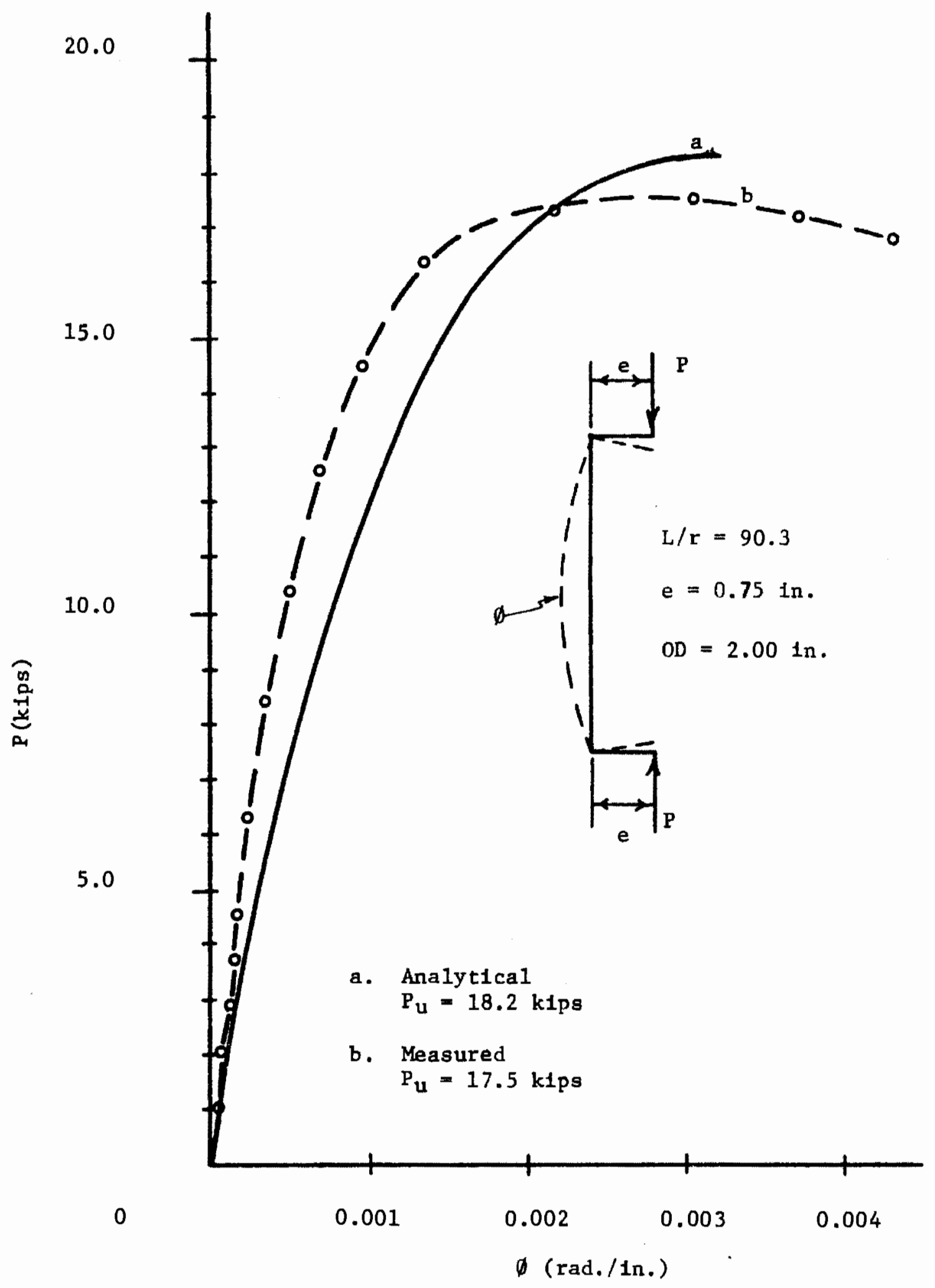

F1gure 31 Load vs. curvature - Test $1 \mathrm{~T} 2$ 


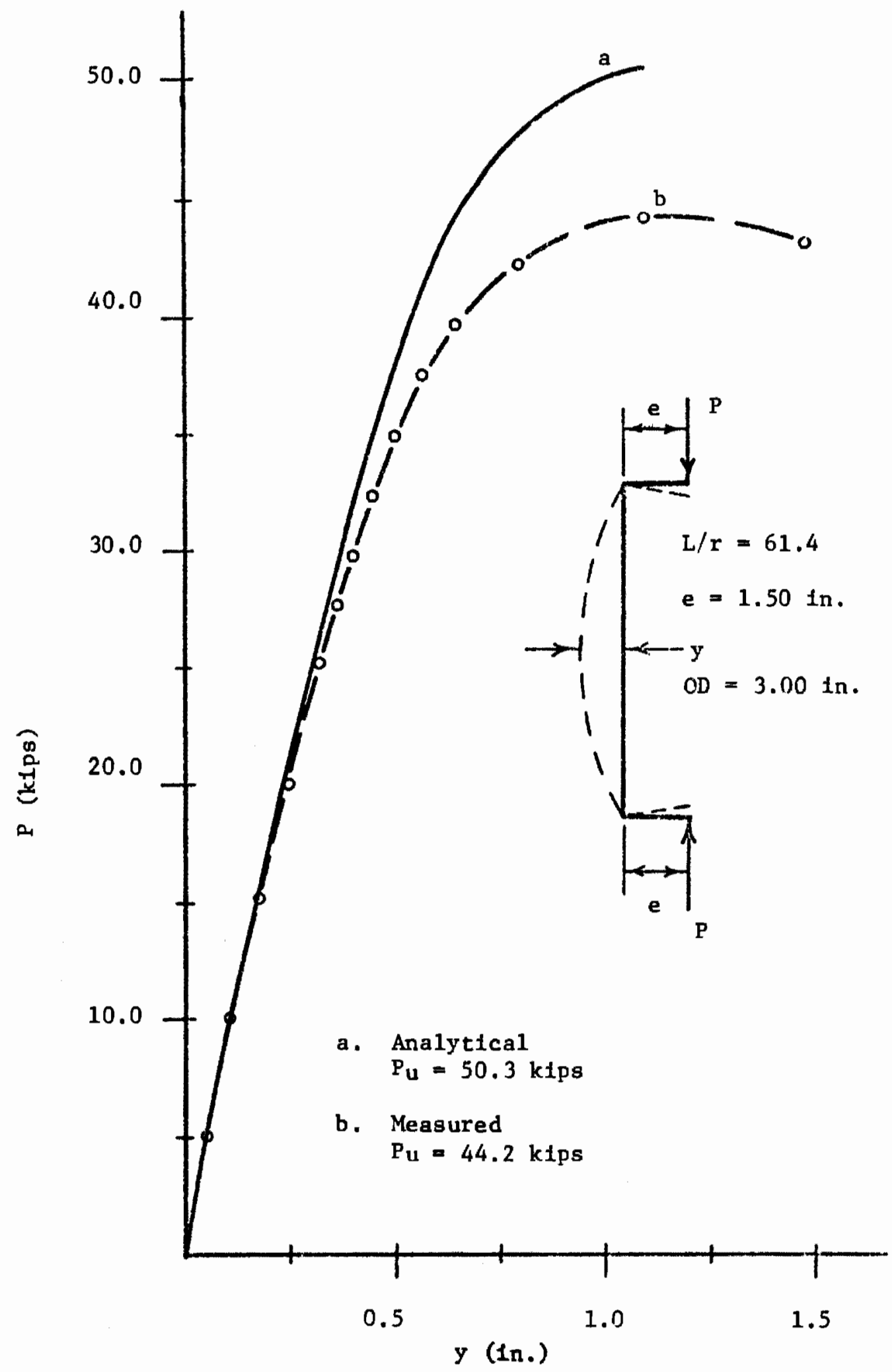

F1gure 32 Load vo. maximum deflection - Test 1T3 


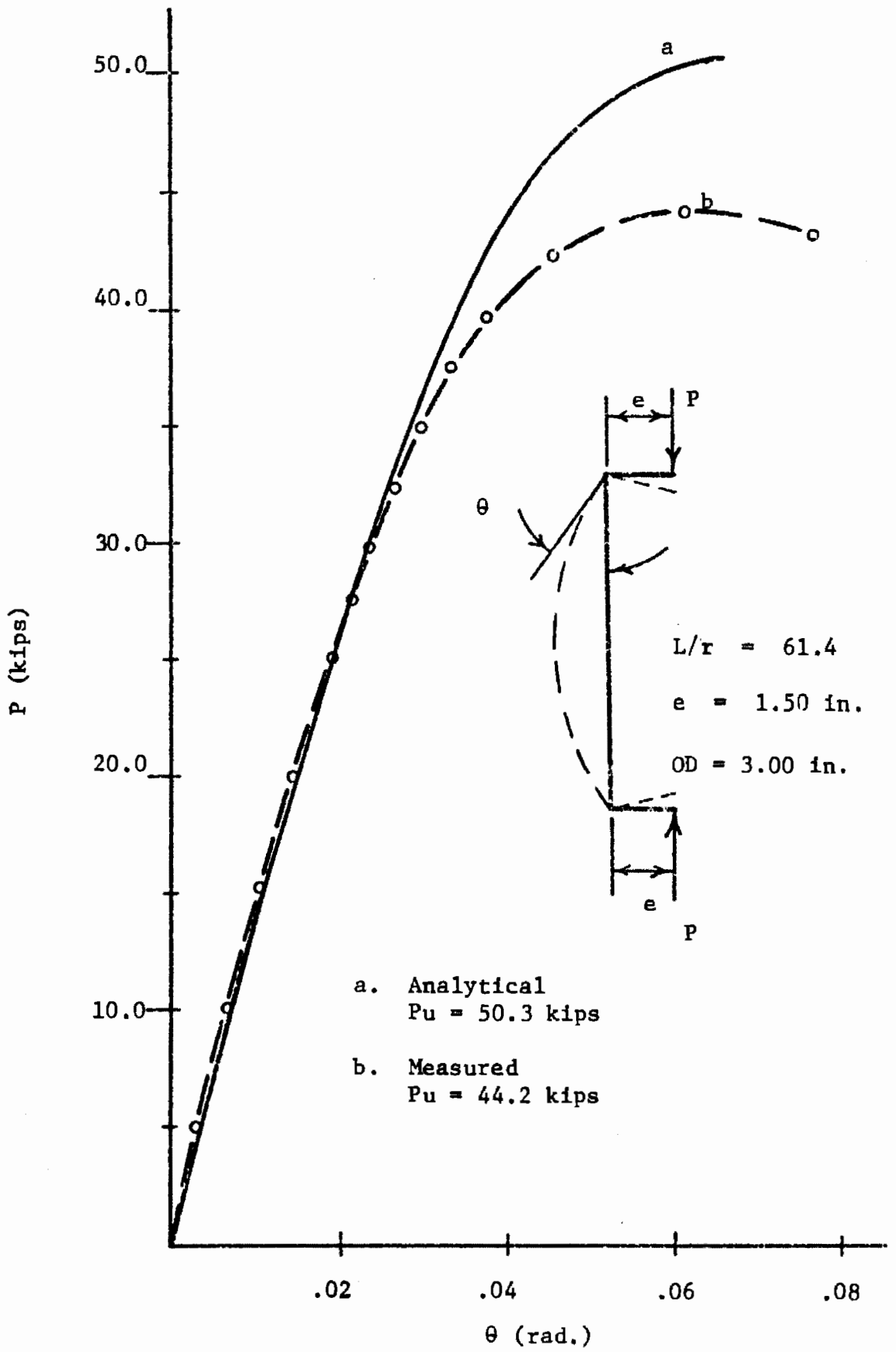

Figure 33 Load v8, end rotation - Tegt 173 


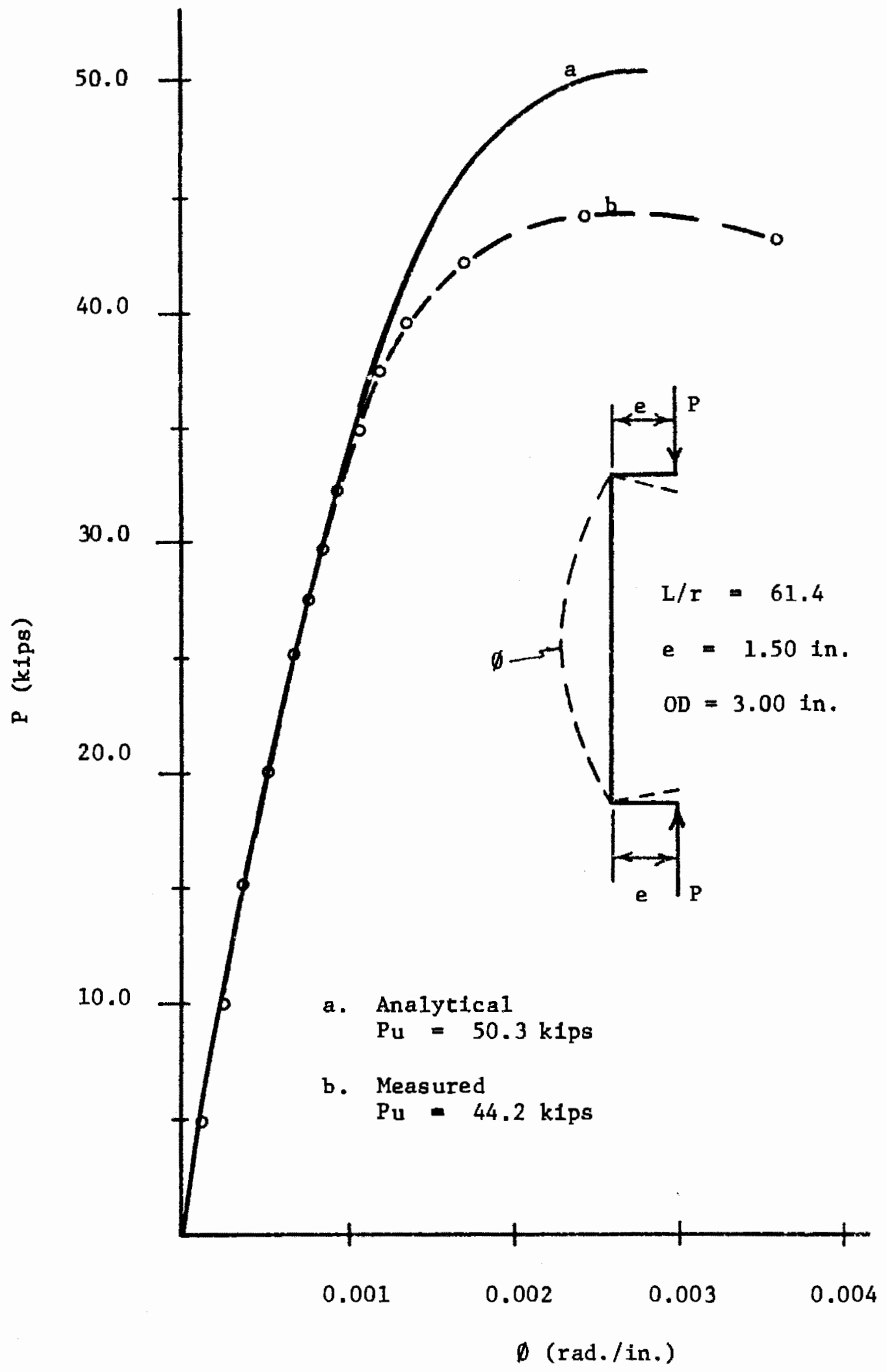

F1gure 34 Load vs. curvature - Test 1T3 
outside diameter tube with a $1 / 4$ inch wall thickness. The tube was 60.0 Inches long corresponding to a slenderness ratio of 61.4 . The loading conflguration consisted of axlal load with bending moment at one end. The eccentriclty of the axial load with bending moment at one end. The eccentriclty of the axial load was 1.50 inches.

The load was applied by Increasing the actuator stroke. No adjustment of the lateral reaction rods was required during the test.

A comparison is made between the test results and the load-displacement history predicted by the computer model in Figures 35 through 37. The deflection plotted in Figure 35 is the maximum lateral deflection predicted by the computer model. The curvature was measured at the point of maximum lateral deflection and the end rotation measured at the end opposite the actuator. The results of all measured values agree well with the analytical values.

\section{Tegt $3 \mathrm{~T} 3$}

The model used In Test $3 T 3$ was constructed from a 3.0 Inch outside diameter, $1 / 4$ inch wall thickness tube. The tube was 60.0 inches long which corresponds to a slenderness ratio of 61.4 . The loading was a comblnation of axial load and equal end moments causing double curvature. The eccentricity of the axial load was 1.50 inches. The test setup is shown in Figure 38.

The load was applied by slowly increasing the stroke of the actuator. After each load increment a slight adjugtment of the lateral reaction rods was made. However, as the fallure load was approached, the deflected shape drifted into single curvature. 


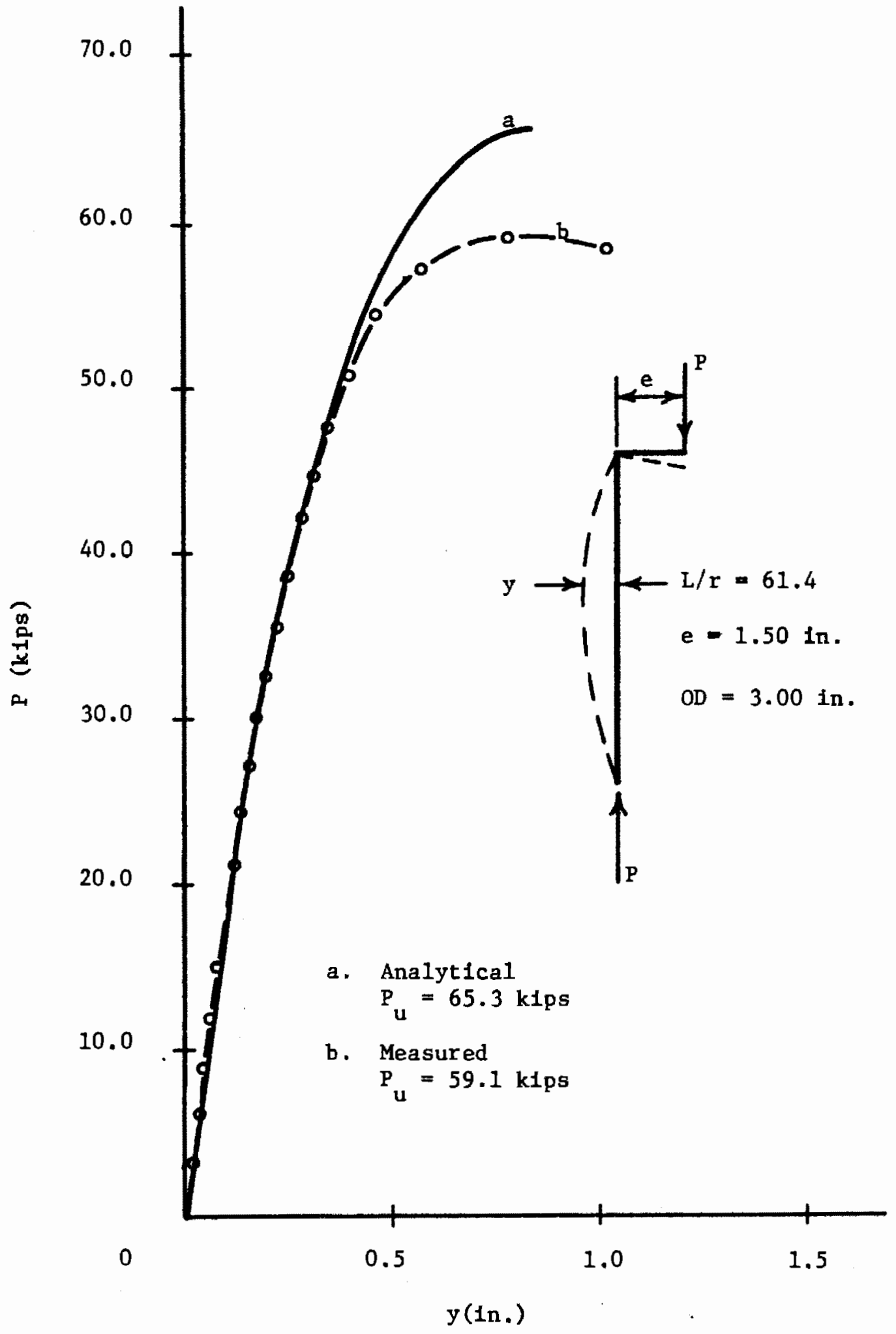

F1gure 35 Load vs. maximum deflection - Test 2T3 


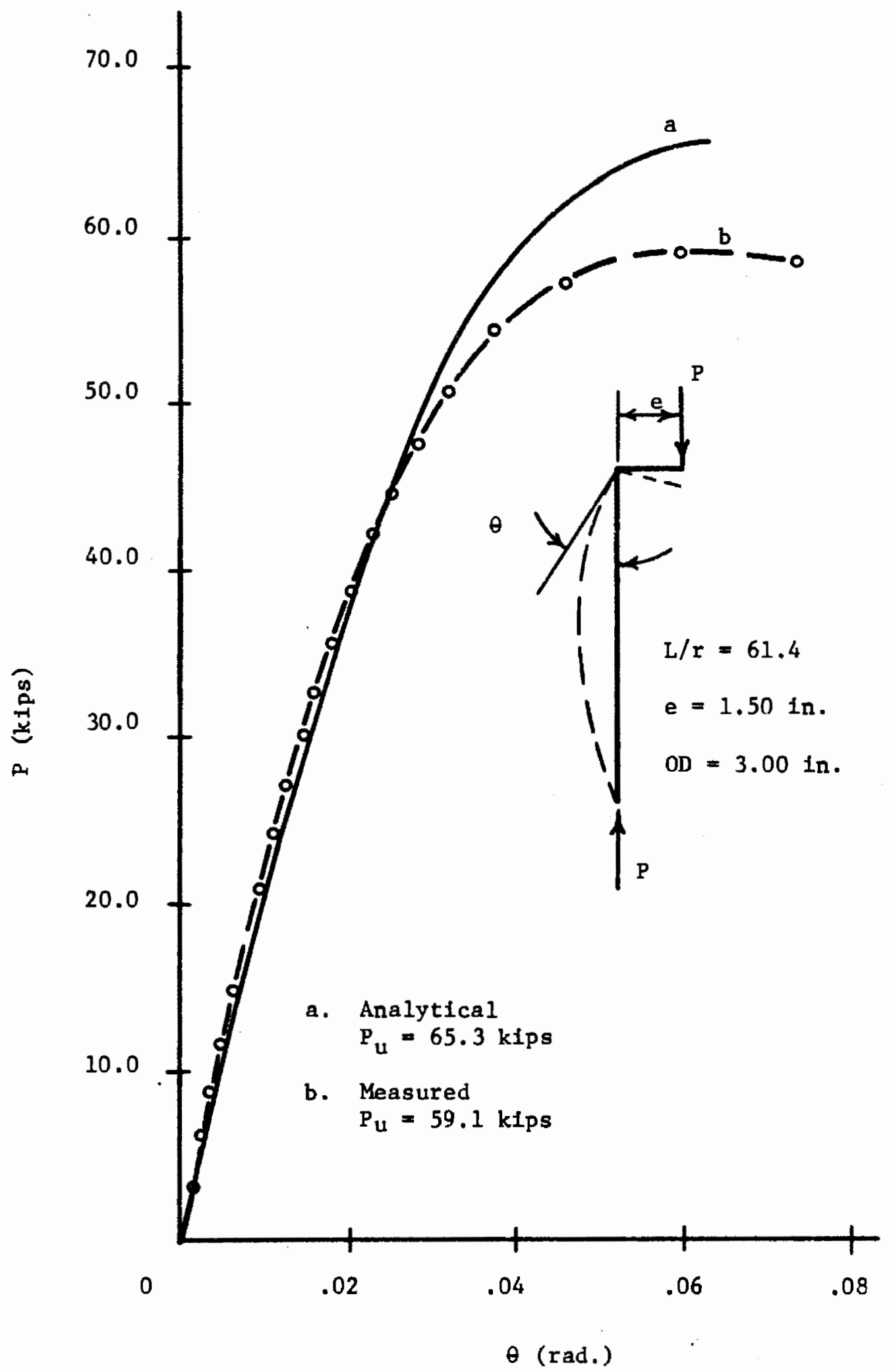

F1gure 36 Load vs, end rotation - Test 2 T3 


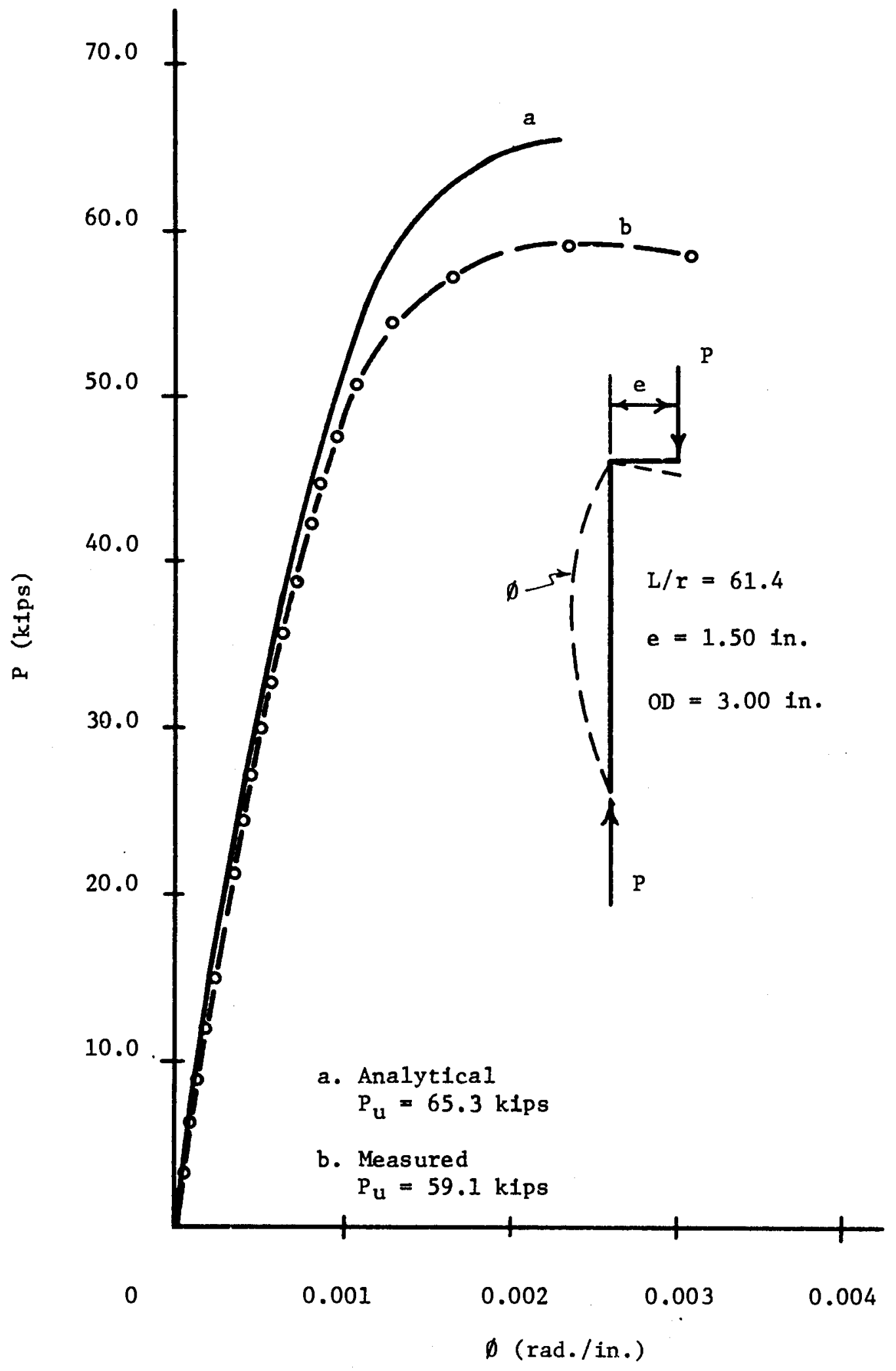

F1gure 37 Load vs. curvature - Test 2 T3 


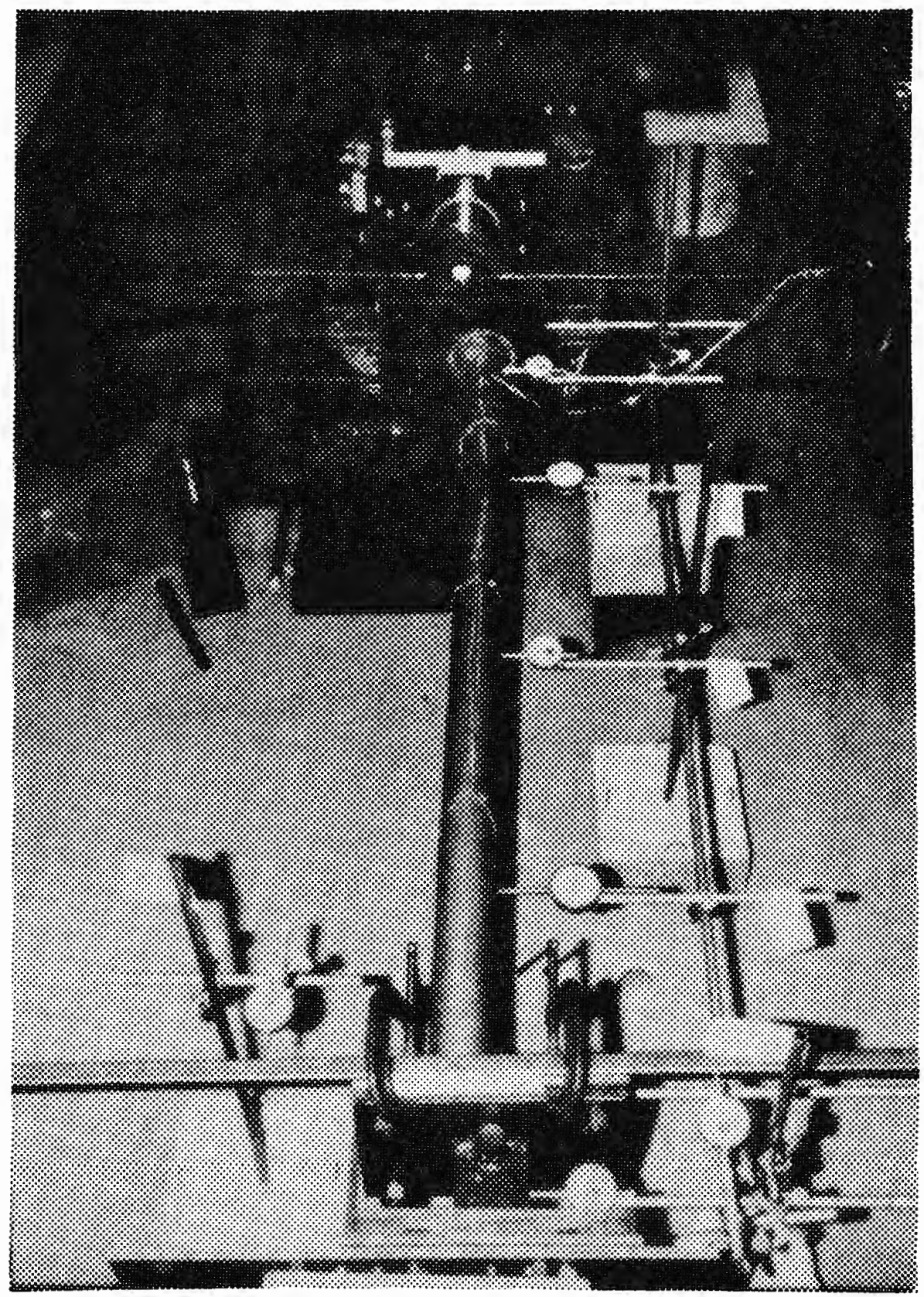

F1gure 38 - Test $3 \mathrm{~T} 3$ 
F1gures 39 through 41 present a comparison of the test results and the load-displacement history predicted by the computer moc:1. The curvature was measured at the point of maximum lateral deflection and the end rotation at the end opposite the actuator. The agreement Is good between the analytical and measured results up to fust befure fallure, however, as the beam-colum drifted into single curvature, It rapidly lost its ablifty to support additional load.

The following table is a summary of the experimental results.

Table 2 Comparison of Predicted and Measured Ult1mate Load Values

\begin{tabular}{|c|c|c|c|c|c|}
\hline $\begin{array}{c}\text { Test } \\
\text { Number }\end{array}$ & $\mathrm{L} / \mathrm{r}$ & $\begin{array}{c}\text { Wall } \\
\text { ThIckness, In. }\end{array}$ & $\begin{array}{l}\text { Ult1mate Load } \\
\text { Calculated }\end{array}$ & $\begin{array}{l}\text { Values, k1ps } \\
\text { Measured }\end{array}$ & $\frac{P_{\text {meas. }}}{\mathbf{P}_{\text {cal. }}}$ \\
\hline IT2 & 90.3 & 0.193 & 18.2 & 17.5 & 0.96 \\
\hline $1 \mathrm{~T} 3$ & 61.4 & 0.257 & 50.3 & 44.2 & 0.88 \\
\hline $2 \mathrm{~T} 3$ & 61.4 & 0.257 & 65.3 & 59.1 & 0.91 \\
\hline 3T3 & 61.4 & 0.257 & 85.8 & 74.0 & 0.86 \\
\hline
\end{tabular}




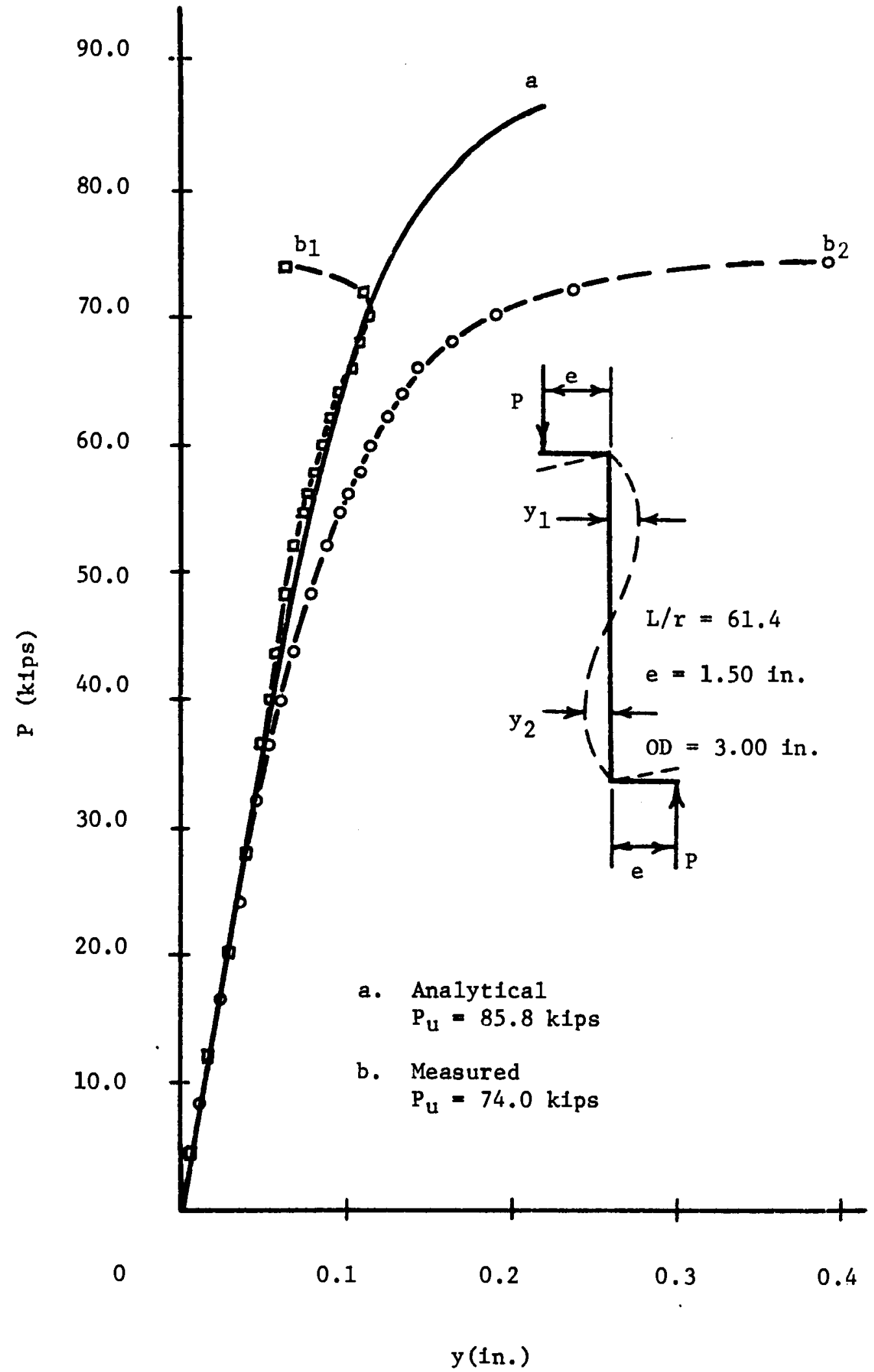

Figure 39 Load vs. maximum deflection - Test 3 T3 


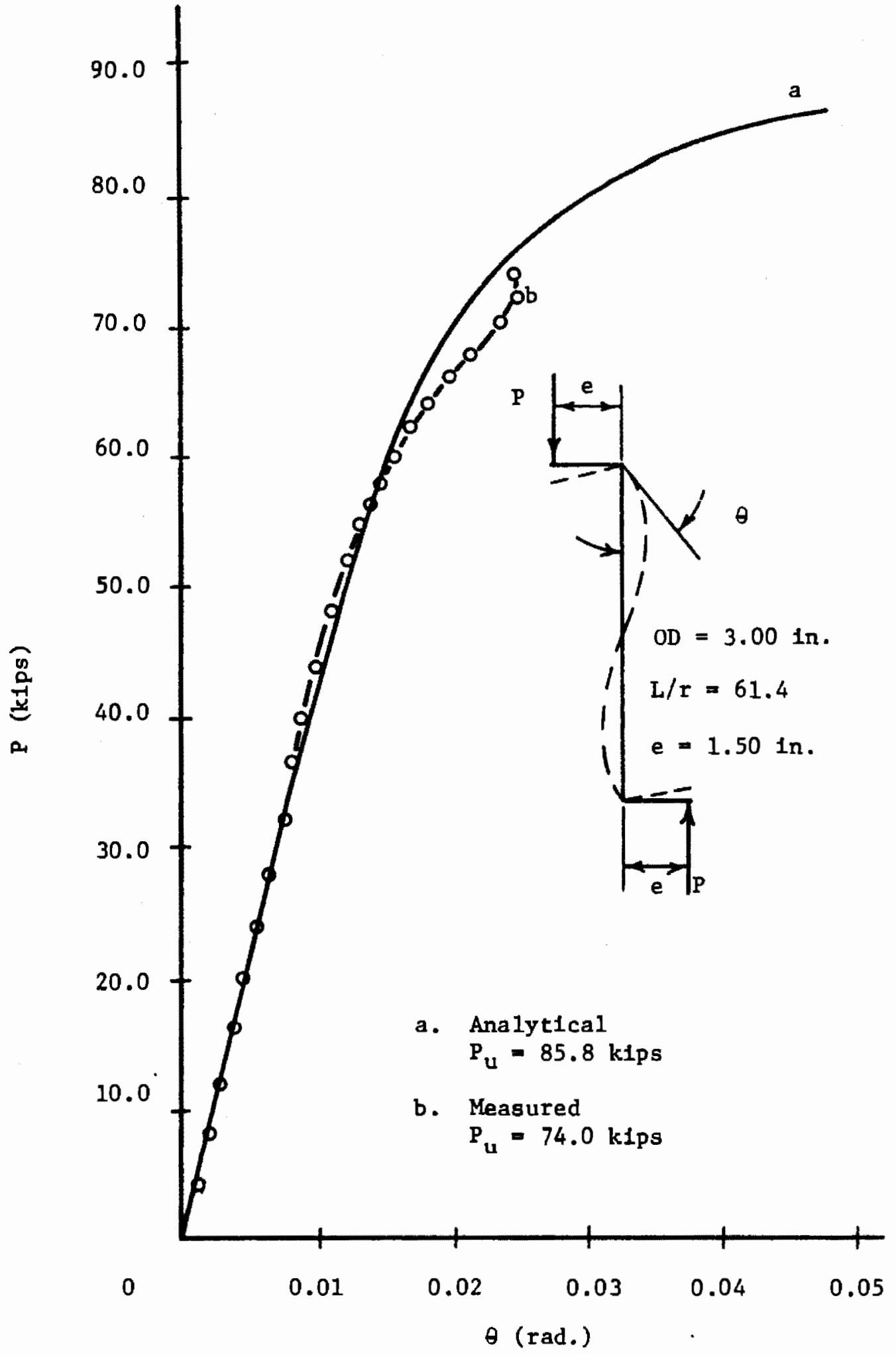

F1gure 40 Load vs, end rotation - Test 3T3 


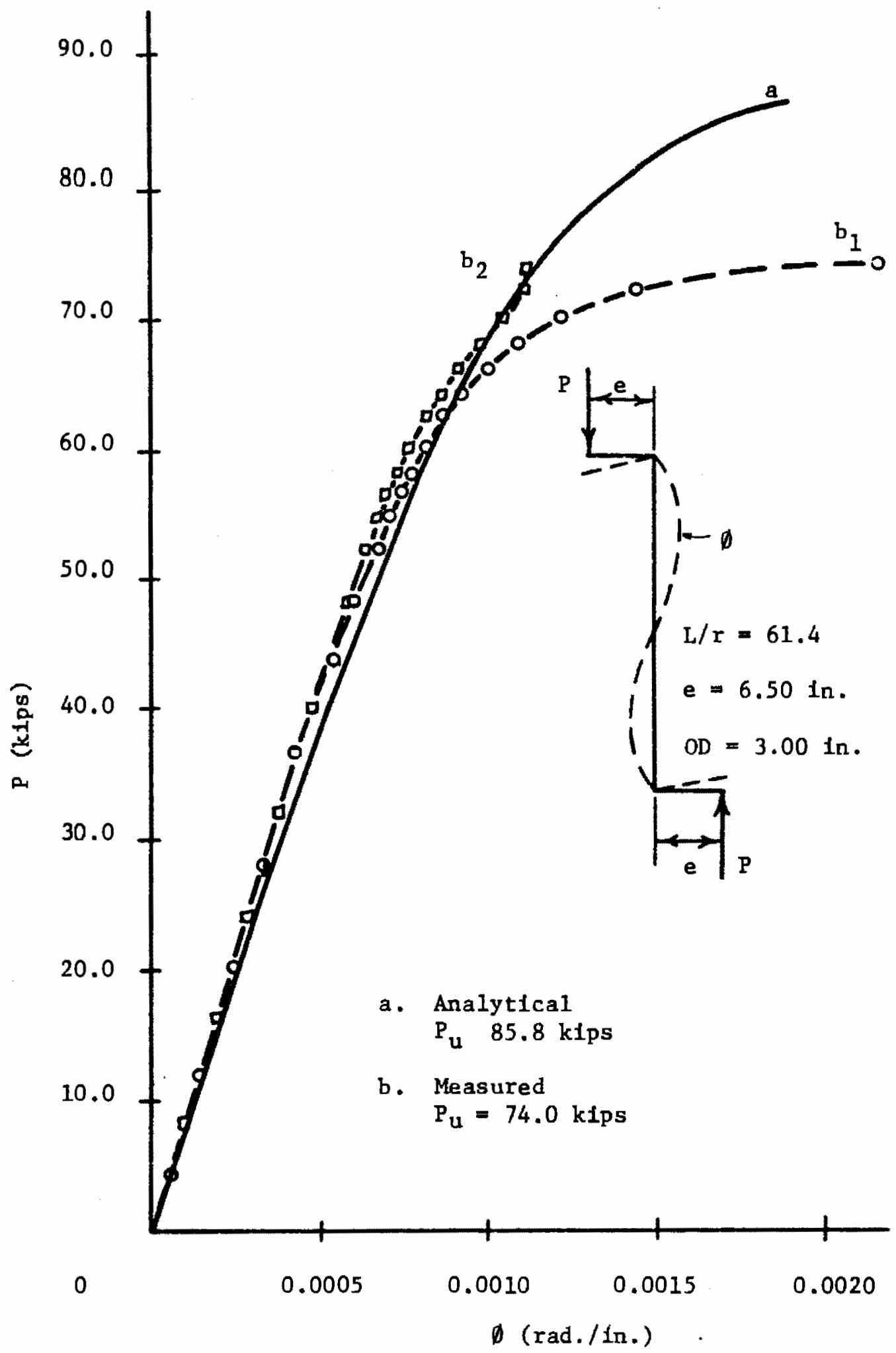

Figure 41 Load vs. curvature - Test 3T3 


\section{CHAPTER V}

\section{CONCLUSIONS AND RECOMMENDATIONS}

The primary purpose of this paper was to provide a basis for the development of design interaction curves for beam-columns made of circular tubes and to check the validity of the computer model by test results. Baged on the materlal presented herein the following conclustons appear valid.

1. The computer model described in this paper predicts both the load-displacement history and the ultimate strength of c1rcular tubes subjected to the combined effects of axial force and flexure within the requirements of engineering accuracy.

2. It is possible to incorporate non-bilinear stress-strain relationships and $s$ tatically admissible residual stress patterns Into the model.

3. Interaction diagrams sultable for design use may be developed for various loading patterns.

4. As also noted by E111s (3), beam-columns tested in this program which were inftially deflected in double curvature tended to drift into single curvature at or near fallure load.

However, it 1s apparent that there exists a need for further research to provide additional experimental data on the residual stress 
distribution of circular tubes as well as data pertaining to the ultimate strength of tubular beam-columns. 


\section{REFERENCES}

1. "Specification for the Design, Fabrication and Erection of Structural Steel for Bulldings", American Institute of Steel Construction, 7th Edition, 1969.

2. Beedle, L. S., "Plast1c Design of Steel Frames", John Wiley and Sons, Inc., 1958.

3. Beedle, L. S., and others, "Structural Steel Design", The Ronald Press Company, 1964.

4. Dwyer and Galambos, "Plast1c Behavior of Tubular Beam-Columns, "Journal of the Structural Division, ASCE, Volume 91, ST4, August, 1965.

5. Ell1s, J. S., "Plastic Behaviour of Compression Members", Transactions of the Englneering Institute of Canada, Volume 2, p. 49-60, May 1958.

6. Flale, D. W., and Erzurumlu, H., "Moment-Thrust-Curvature of Tubular Members by Iteration", Fourth Offshore Technology Conference, Paper No, 1668, Volume II, P. 479-486, May 1972.

7. Fowler, D. W., Erzurumlu, H., and Toprac, A. A., "Ult1mate Strength of Tubular Columns Under Combined Bending and Axial Load", Paper presented at the ASCE National Structural Engineering Meeting, San Francisco, California, April 1973.

8. Galambos, T. V., and Ketter, R. L., "Columns under Combined Bending and Thrust, "Journal of the Eng. Mech. Division, ASCE, Volume 85, EM2, P. 1-30, Apr11 1959.

9. Haliburton, T. A., "Soll Structure Interaction", Technical Publication No. 14, School of Civil Engineering, Oklahoma State Un1versity, February 1971.

10. Hildebrand, F. B., "Introduction to Numerical Analysis", McGrawH111, 1956.

11. Ketter, R. L., Kaminsky, E. L., and Beedle, L. S., "Plastic Deformation of Wide Flange Beam-Columns", Transactions, ASCE, Volume 120, P. 1028-1061, 1955.

12. Livesley, R. K., "Matrix Methods of Structural Analyada", "Pergamon Press Ltd., 1964.

13. Marshall, P. W., "Stab1l1ty Problens In Offshore Structures", presentation at the Annual Technical Meeting of the Column Research Counc1l, St. Louls, March 25, 1970. 
14. Matlock, H., and Taylor, T. P., "A Computer Program to Analyze Beam-Columns Under Movable Loads", Research Report No. 56-4, Center for Highway Research, The Untversity of Texas at Austin, June 1968.

15. Mueller, W. H., "A Numerlcal Solutton for Beam-Columns on NonLInear Foundations", Masters Thes1s, UnIvers1ty of Missourl at Rolla, 1966.

16. Sherman, D. R., "Structural Behavior of Tubular Sectlons", Third Speclalty Conference on Cold-Formed Steel Structures, St. Louls, Missour1, November 1975.

17. Sherman, D. R., "Plastic Strength of C1rcular Steel Tubes", ASCE National Structural Engineering Meeting, preprint 2514, New Orleans, Loufsiana, April 1975.

18. Snyder, J., and Lee, S., "Buckling of Elastlc-Plastlc Tubular Columns", Journal of the Structural Division, ASCE, Volume 94, ST1, January 1968. 
APPENDIX I

\section{MATLOCK'S RECURSIVE SOLUTION \\ FOR ELASTIC BEAM-COLUMNS}

The assumptions in this method of beam-column analysis are as follows :
a. Plane sections before bending remain plane after bending
b. Hooke's Law is valid
c. Deflections are small
d. Loads are applied in the plane of the vertical axis of the member (i.e., no torsion)

The following discussion is broken into five major areas:
a. Derivation of the recursive solution
b. Specifying desired deflections
c. Specifying desired slopes
d. Finite difference determination of slope, curvature, bending moment, shear and net load
e. A check of the net load for axially loaded members

DERIVATION OF THE RECURSIVE SOLUTION

A beam-column subjected to a general loading and support configuration is shown in Figure 42. Consider an infinitesimal increment of this member to be loaded and restrained as shown In Figure 43 . All quantities in Figure 43 are positive as shown and are defined as follows: 


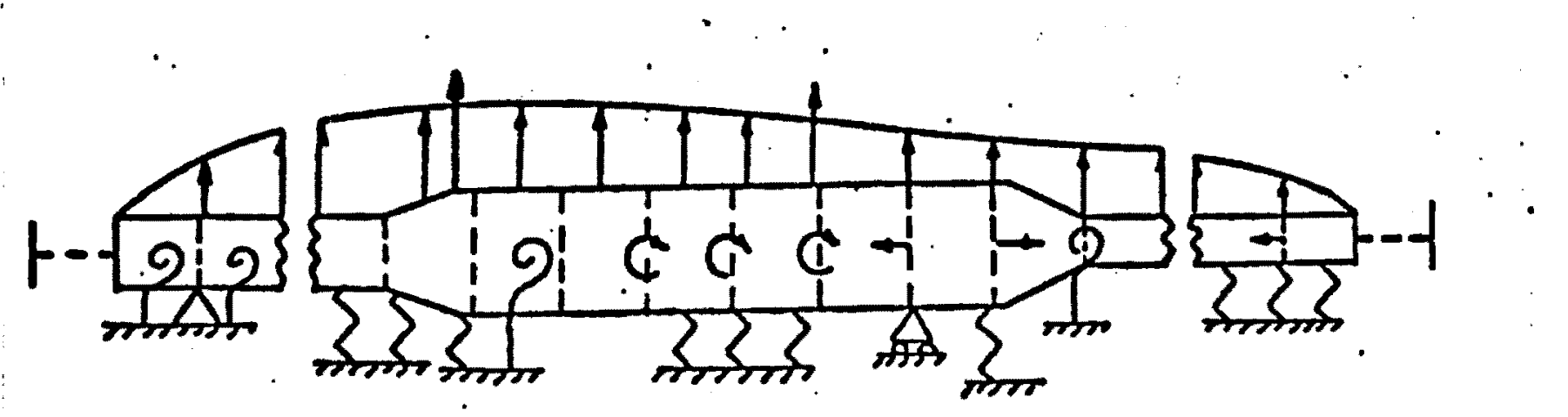

$-1: 0 \quad 1 \quad 1-4 \quad 1 \div 3 \quad 1-2 \quad 1-1 \quad 1 \quad 1+1 \quad 1+2 \quad 1+3 \quad 1+4 \quad m \quad m-1=0+1$

F1gure 42 Beam of variable stiffness subjected to general

loading condition. 


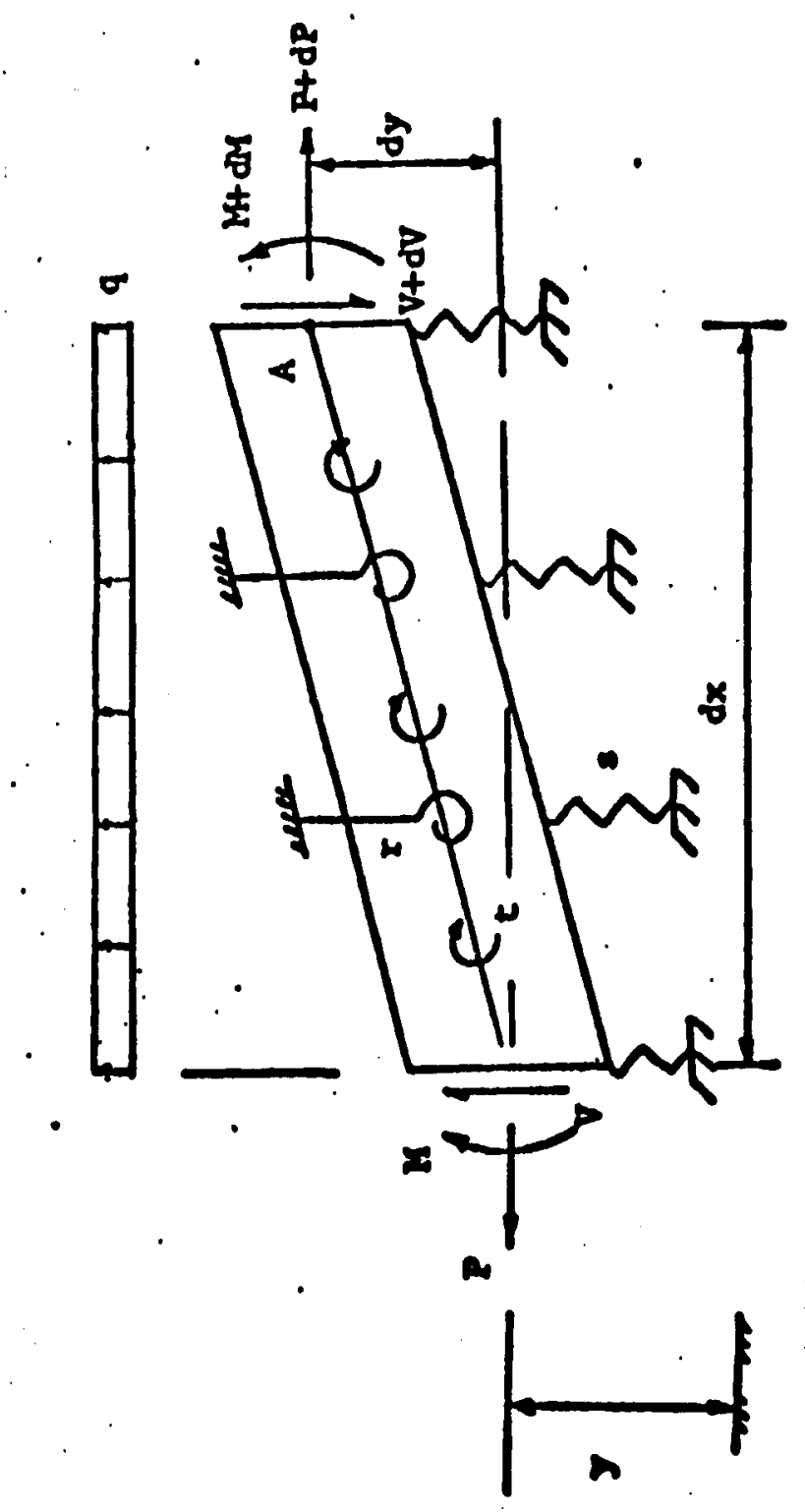

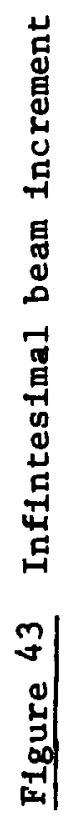


Symbol

$\mathbf{P}$

M

V

$q$

$\mathrm{t}$

$\mathbf{r}$

$\mathbf{s}$
Description

axtal load on cross-section

bending moment on cross-section

total shear on cross-section

transverse load

externally applied moment

stiffness of spiral springs

(rotational restraint)

stiffness of coll springs

(translational restraint)
Dimension

$(\mathbf{F} \cdot \mathrm{L})$

$(\mathrm{F} / \mathrm{L})$

$\frac{F \cdot L}{L}$

$\frac{F \cdot L}{\text { Angle } \cdot L}$

$\frac{F}{L \cdot L}$

It should be noted that $q, r, t$ and $s$ are considered to be uniformly distributed over each element, and the cross section of each element is considered constant. As will be shown later when a finite increment Is considered, these values are taken as the average of the distribution which actually exists on the element. Since the element is in equilibrium, the net moment about point A in Figure must be zero, 1.e.,

$$
-d M+P d y+V d x+q \frac{(d x)^{2}}{2}-s y \frac{(d x)^{2}}{2}+r d x \frac{d y}{d x}+t d x=0
$$

Neglecting higher order differentials and dividing this equation by dx results in

$$
\frac{d M}{d x}=V+t+(r+P) \frac{d y}{d x}
$$

Taking the derivative of $\mathrm{Eq} .(1.2)$ once with respect to $x$ gives

$$
\frac{d^{2} M}{d x^{2}}=\frac{d V}{d x}+\frac{d}{d x}\left[t+(r+P) \frac{d y}{d x}\right]
$$

When the equilibrium of the element in the vertical direction is considered the equation of equilibrium of vertical forces on the element Is 


$$
V+q d x-s y d x-V-d V=0
$$

from which it is seen that $\frac{d V}{d x}=q-s y$

Therefore,

$$
\frac{d^{2} M}{d x^{2}}=q-s y+\frac{d}{d x}\left[t+(r+P) \frac{d y}{d x}\right]
$$

Expressing the left side of Eq. (1.5) in finite difference form gives the following:

$$
\frac{d^{2} M}{d x^{2}}=\frac{M_{1-1}-2 M_{1}+M_{1+1}}{h^{2}}
$$

where $h$ is the length of the finite increment and the subscript i is the number designation of a particular finite increment. (Note that the beam shown in Figure 42 is divided into m finite increments). In this derfvation all increments are considered to have the same length $h$. Also, the number of a particular increment, 1 , will hereafter be referred to as the station or station number of the increment.

From elementary strength of materials comes the well known differential equation of the deflected elastic beam

$$
M=F \frac{d^{2} y}{d x^{2}}
$$

where $F$ is the flexural stiffness (EI) of the beam and $\frac{d^{2} y}{d x^{2}}$ is the beam curvature.

Assuming $F$ is constant through the length of increment 1 , the finite difference expression for Eq. (1.7) is

$$
M_{i}=F_{i}\left[\frac{Y_{1-1}-2 y_{1}+y_{1+1}}{h^{2}}\right]
$$

Substituting Eq. (1.8) Into Eq. (1.6) and collecting terms results in: 


$$
\begin{aligned}
\frac{d^{2} M}{d x^{2}}= & \frac{1}{h^{4}}\left[F_{1-1} y_{1+1}-2\left(F_{1-1}+F_{1}\right) y_{1-1}+\left(F_{1-1}+4 F_{1}+F_{1+1}\right) y_{1}\right. \\
& \left.-2\left(F_{1}+F_{1+1}\right) y_{1+1}+F_{1+1} y_{1+2}\right]
\end{aligned}
$$

The above equation represents the left side of Eq. (1.5) In finite difference form.

Now consider the right side of Eq. (1.5) which is rewritten for conventence.

$$
\frac{d M^{2}}{d x^{2}}=q-s y+\frac{d}{d x}\left[t+(r+P) \frac{d y}{d x}\right]
$$

First, considering the differential inside the brackets:

$$
(r+P) \frac{d y}{d x}=(r+P)\left(\frac{-y_{1-1}+y_{1+1}}{2 h}\right)
$$

Now writing the whole right side of Eq. (1.5) In finite difference form:

$$
\begin{gathered}
\frac{d M^{2}}{d x^{2}}=q_{1}-s_{1} y_{1}+\frac{1}{2 h}\left[\left(t_{1+1}-r_{1+1} \frac{y_{1}}{2 h}+\frac{r_{1+1} y_{1+2}}{2 h}-\frac{P_{1+1} y_{1}}{2 h}+\frac{P_{1+1} y_{1+2}}{2 h}\right)-\right. \\
\left(t_{1-1}-\frac{r_{1-1} y_{1-2}}{2 h}+\frac{r_{1-1} y_{1}}{2 h}-\frac{P_{1-1} y_{1-2}}{2 h}+\frac{P_{1-1} y_{1}}{2 h}\right]
\end{gathered}
$$

Removing a factor of $1 / h^{4}$ and collecting terms gives the result:

$$
\begin{aligned}
\frac{d M^{2}}{d x^{2}}- & \frac{1}{h^{4}}\left[h^{4} q_{1}+\frac{h^{3} t_{1+1}}{2}-\frac{h^{3} t_{1-1}}{2}+\left(\frac{h^{2} r_{1-1}}{4}+\frac{h^{2} P_{1-1}}{4}\right) y_{1-2}+\right. \\
& \left(-h^{4} s_{1}-\frac{h^{2} r_{1+1}}{4}-\frac{h^{2} P_{1+1}}{4}-\frac{h^{2} r_{1-1}}{4}-\frac{h^{2} P_{1-1}}{4}\right) y_{1}+ \\
& \left.\left(\frac{h^{2} r_{1+1}}{4}+\frac{h^{2} P_{1+1}}{4}\right) y_{1+2}\right]
\end{aligned}
$$

Eq. (1.12) represents the right side of Eq. (1.5) In finite difference form.

Before writing the entire Eq. (1.5) in finite difference form the following substitutions will be made: 


$$
\begin{aligned}
& \mathrm{PH}_{1}=h / 4\left(\mathrm{R}_{1}+h \mathrm{P}_{1}\right) \\
& \mathrm{R}_{1}=h r_{1} \\
& \mathrm{~s}_{1}=h^{4} \mathrm{~s}_{1} \\
& \mathrm{Q}_{1}=h^{4} \mathrm{q}_{1} \\
& \mathrm{~T}_{1}=h^{3} / 2 \mathrm{t}_{1}
\end{aligned}
$$

The entire Eq. (1.5) may now be rewritten with all terms having a deflection coefficient on the left:

$$
\begin{gathered}
\left(F_{1-1}-P H_{1-1}\right) y_{1-2}-2\left(F_{1-1}+F_{1}\right) y_{1-1}+\left(F_{i-1}+4 F_{1}+F_{1+1}+S_{i}+P H_{1-1}\right) \\
y_{1}-2\left(F_{1}+F_{1+1}\right) y_{1+1}+\left(F_{1+1}-P H_{1+1}\right) y_{1+2}=Q_{1}+T_{1+1}-T_{1-1}
\end{gathered}
$$

The above equation is commonly written in the form

$$
a_{1} y_{1-2}+b_{1} y_{1-1}+c_{1} y_{1}+d_{1} y_{1+1}+e_{1} y_{1+2}=f_{i}
$$

where

$$
\begin{aligned}
& a_{i}=F_{1-1}-P H_{1-1} \\
& b_{1}=-2\left(F_{1-1}+F_{1}\right) \\
& c_{1}=F_{1-1}+4 F_{1}+F_{1+1}+S_{1}+P_{1+1}+P H_{1-1} \\
& d_{1}=-2\left(F_{1}+F_{i+1}\right) \\
& e=F_{1+1}-P H_{1+1} \\
& f_{1}=Q_{1}+T_{1+1}-T_{1-1}
\end{aligned}
$$

The coefficients $a_{1}-e_{1}$ make up a stiffness matrix with a bandwidth of five and the coefficients $f_{1}$ make up the load matrix. Note that the axial load term appears in coefficients $a, c$ and $e$. It is inter- 
esting to observe that the problem of instability may be detect d by an examination of the stiffness matrix and axial load is the only applied load that can cause elastic instability in an otherwise stable structure.

Assume that the deflection at a given station can be expressed as a linear function of the deflections at the two following stations, 1.e.,

$$
\mathrm{y}_{1-2}=\mathrm{A}_{1-2}+\mathrm{B}_{1-2} \mathrm{y}_{1-1}+\mathrm{C}_{1-2} \mathrm{y}_{1}
$$

and

$$
y_{1-1}=A_{1-1}+B_{1-1} y_{1}+C_{1-1} y_{i+1}
$$

where $A, B$ and $C$ are constants to be determined.

Substituting Eqs. 1.17 and 1.18 1nto Eq. 1.15 yields

$$
y_{1}=A_{i}+B_{1} y_{1+1}+C_{1} y_{1+2}
$$

where

$$
\begin{aligned}
& A_{1}=D_{1}\left(E_{1} A_{1-1}+a_{1} A_{1-2}-E_{1}\right) \\
& B_{1}=D_{1}\left(E_{1} C_{1-1}+d_{1}\right) \\
& C_{1}=D_{1}\left(e_{1}\right)
\end{aligned}
$$

in which

$$
\begin{aligned}
& D_{1}=1 /\left(C_{1}+E_{1} B_{1-1}+a_{1} C_{1-2}\right) \\
& E_{1}=a_{1} B_{1-2}+b_{1}
\end{aligned}
$$

It $1 \mathrm{~s}$ therefore seen that the assumption of Eqs. 1.17 and 1.18 is valid.

If Eqs. 1.16 are substituted 1nto Eqs. 1.20 the following equations result:

$$
A_{1}=D_{1}\left(E_{1} A_{1-1}+G_{1} A_{1-2}-Q_{1}-T_{1+1}+T_{1-1}\right)
$$




$$
\begin{aligned}
& B_{1}=D_{1}\left(E_{1} C_{i-1}-2 F_{1+1}-2 F_{1}\right) \\
& C_{1}=D_{1}\left(F_{i+1}-P H_{i+1}\right)
\end{aligned}
$$

where

$$
\begin{aligned}
& G_{1}=F_{1-1}-P H_{1-1} \\
& E_{1}=G_{1} B_{1-2}-2\left(F_{1-1}+F_{1}\right) \\
& D_{1}=-1 /\left(F_{1-1}+4 F_{1}+F_{1+1}+S_{1}+P H_{1+1}+E_{1} B_{1-1}+G_{1} C_{1-2}\right)
\end{aligned}
$$

Hence it is seen from Eqs. 1.21 that $A_{1}, B_{1}$, and $C_{1}$ are determined as functions of these same three constants at the two preceeding stations In addition to known loads and restraints. Also, the only unknowns needed to calculate the coefficients $A_{1}, B_{1}$ and $C_{1}$ at all beam stations are the values of these coefficients at stations -1 and -2 . From boundary conditions (Figure 42) it is seen that stations -1 and -2 do not exist on the beam Itself. However, if one considers the beam to extend beyond the end (station zero) but to have no stiffness and no loads or restraints, the coefficients can be calculated by beginning at station -1 and proceeding down the beam to station $\mathrm{m} 1$. Station -1 was chosen as a starting point because it has the quality that nothing before it affects the beam. This can be seen by considering Eq. 1.2 Likewise, nothing beyond station $m 1$ affects the beam; thus it is the last station at which $A, B$ and $C$ are calculated.

Once all of the coefficients, $A_{1}, B_{1}$ and $C_{1}$ are determined, deflections can be calculated by simply substituting into Eq. 1.19, starting at station $\mathrm{m} 1$ and continuing along the beam to station -1 . 
SPECIFYING DESIRED DEFLECTIONS

Usually in beam analysis the deflection $1 \mathrm{~s}$ known at one or more points along the beam. For example, one knows that the deflection at each end of a simple beam is zero, or perhaps one knows the settlement of one or more supports of a continuous beam. Known deflections such as these must be introduced into the recursive solution.

The Introduction of this known Information into the recursive solution is relatively easy. If it is desired to specify the deflection at some point on the beam, say at station 1 , one needs only to set $A_{i}$ equal to the desired deflection and $B_{1}^{\prime}$ and $C_{i}^{\prime}$ equal to zero.* The reason for setting the coefficients equal to these values becomes obvious upon considering Eq. 1.19. Note that the coeffictents must be set at the special values before one proceeds to calculate the coeffictents for the following stations because the coefficients at the following stations depend on those preceeding. Hence it is not correct to merely substitute the desired set of coefficients at the particular station after all coefficients for the beam have been calculated.

\section{SPECIFYING DESIRED SLOPES}

Sometimes it is desired to spectfy a particular slope at one or more points along a beam; such a case is the fixed-end beam. As was done in specifying deflections, slopes can also be spectfied by proper adjustment of the coeffictents A, B and C. However the operations of setting a slope are somewhat more Involved as will be seen.

*Primes are used to designate specially determined coefficients. 
A slope is set at a given station, say station $i$, by prov: iing at that station the necessary external moment to resist the efforis of other beam loads to change the slope. The necessary external moment, which will in general be unknown, is applied to the beam by means of a force $Z$ acting at stations $1-1$ and $i+1$ as shown in Figure

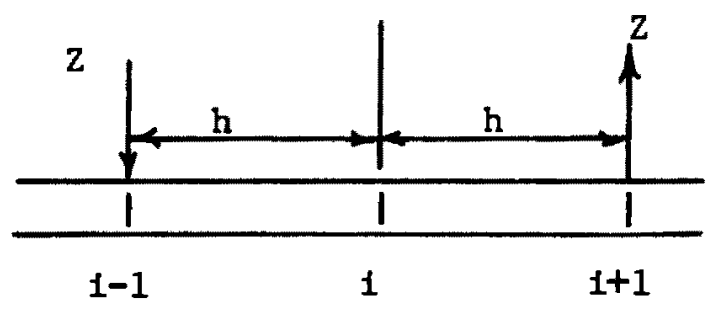

Figure 44 Couple acting to set the slope at station 1

Clearly then, the problem is to establish the adjusted coefficients $A, B$ and $C$ which include the effect of the $2 \mathrm{hZ}$ couple. To do this consider the finite difference expression for the slope, $\theta$, at station 1, 1.e.,

$$
\frac{d y}{d x} / 1=\theta_{i}=\frac{-y_{1-1}+y_{1+1}}{2 h}
$$

Thus the necessary coefficients at station $1-1$ are

$$
\begin{aligned}
& A_{i-1}^{\prime}=2 h \theta_{1} \\
& B_{i-1}^{\prime}=0 \\
& C_{1-1}^{\prime}=1
\end{aligned}
$$

Now let 1 t be desired to find the magnitude of the force $z$. Assume that $A, B$ and $C$ have been calculated for stations 1 and $1+1$ in the ordinary manner after the coefficlents have been properly adjusted 
at station 1-1. Notice in Eqs. 1.16 that the only equation whic has a transverse load term is

$$
f_{1}=Q_{1}+T_{1+1}-T_{1-1}
$$

Also, the term $f_{1}$ appears In Eqs. 1.20 only in the equation

$$
A_{1}=D_{1}\left(E_{1} A_{1-1}+a_{1} A_{1-2}-E_{1}\right)
$$

In light of these two equations it is seen that a load $z$ may be introduced at station 1-1 by combining 1 ts effect with the ordinarily calculated $A_{1-1}$. Thus,

$$
y_{1-1}=\left[A_{1-1}+D_{1-1}\left(h^{3} z\right)\right]+B_{1-1} y_{1}+C_{1-1} y_{1+1}
$$

Substituting Eq. 1.23 for $\mathrm{y}_{1-1}$ into Eq. 1.24 and solving for $z$ gives

$$
z=\frac{-1}{D_{1-1} h^{3}}\left[\left(A_{1-1}+2 h \theta_{1}\right)+B_{1-1} y_{1}+\left(C_{1-1}-1\right) y_{1+1}\right]
$$

In the same manner the Eq. 1.24 was obtained, the load $Z$ can be applied at station 1-1 (as Indicated in Figure) to get the equation

$$
y_{1+1}=\left[A_{1+1}-D_{1+1}\left(h^{3} z\right)\right]+B_{1+1} y_{1+2}+C_{1+1} y_{1+3}
$$

Substituting Eq. 1.19 for $\mathrm{y}_{1}$ Into $\mathrm{Eq} \cdot 1.25$ and substituting that result into $\mathrm{Eq} \cdot 1.26 \mathrm{gives}$

$$
y_{1+1}=A_{i+1}^{\prime}+B_{i+1}^{\prime} y_{i+2}+C_{i+1}^{\prime} y_{1+3}
$$

where

$$
A_{1+1}^{\prime}=\frac{A_{1+1}+\frac{D_{1+1}}{D_{1-1}}\left(A_{1-1}+2 h \theta_{1}+B_{1-1} A_{1}\right)}{1-\frac{D_{1+1}}{D_{1-1}}\left(B_{1-1} B_{1}+C_{1-1}-1\right)}
$$




$$
\begin{aligned}
& B_{1+1}^{\prime}=\frac{\frac{D_{1+1}}{D_{1-1}}\left(B_{1-1} C_{1}\right)+B_{1+1}}{1-\frac{D_{1+1}}{D_{1-1}}\left(B_{1-1} B_{1}+C_{1-1}-1\right)} \\
& C_{1+1}^{\prime}=\frac{C_{1+1}}{1-\frac{D_{1+1}}{D_{1-1}}\left(B_{1-1} B_{1}+C_{1-1}-1\right)}
\end{aligned}
$$

$A_{1+1}^{\prime}, B_{i+1}^{\prime}$ and $C_{i+1}^{\prime}$ should now be substituted for the originally calculated $\mathrm{A}_{1+1}, \mathrm{~B}_{1+1}$ and $\mathrm{C}_{1+1}$ and the coefficient calculations continued in a normal manner on down the beam.

It should be specifically pointed out that a deflection cannot be specified at a station adjacent to a station at which the slope has been spectfled. Also, there must be at least two stations between stations at which it is desired to specify the slope.

FINITE DIFFERENCE DETERMINATION OF SLOPE, CURVATURE, MOMENT, SHEAR AND LOAD Once the deflected shape of the loaded beam has been determined it is easy to determine the slope, curvature, moment, shear and transverse load at any desired station by using fintte difference techniques. Solving for these quantities requires only the substitution of the previously computed beam deflections into finite difference expressions of well known differentlal equations. These differential equations, which relate beam properties and loads, and their finite difference counterparts are listed below.

Slope: $\quad \theta=\frac{d y}{d x} \quad \theta_{1}=\frac{-y_{1-1}+y_{1+1}}{2 h}$ 
Curvature: $\phi=\frac{d^{2} y}{d x^{2}}$

$\phi_{1}=\frac{y_{1-1}-2 y_{1}+y_{1+1}}{h^{2}}$

Moment: $\quad M=F \frac{d^{2} y}{d x^{2}}$

$M_{1}=F_{1}\left[\frac{y_{1-1}-2 y_{i}+y_{1+1}}{h^{2}}\right]$

Shear: $\quad V^{\prime}=\frac{d M}{d x}$

$v_{i}^{\prime}=\frac{-M_{i-1}+M_{1+1}}{2 h}$

Load : $\quad w^{\prime}=\frac{d^{2} M}{d x^{2}}$

$w_{i}^{\prime}=\frac{M_{1-1}-2 M_{1}+M_{1+1}}{h^{2}}$

It has been found more convenient to work with the concentrated load

$$
\mathrm{w}_{1}^{\prime}=h \mathrm{w}_{i}^{\prime}
$$

rather than the uniform load, $w_{1}^{\prime}$. Therefore only $W_{1}^{\prime}$ will be considered hereaf ter.

\section{NET LOAD CHECK}

The procedure used by the recursive technique is to first calculate the deflection at each station. With the deflection at each station known a finite difference differentiation is performed to determine the slope and curvature at each station. The bending moment at a given station is obtained by the product of the curvature and flexural stiffness at that station. The differentiation is then continued to determine skear and net load. This procedure creates a unique situation in which the net load calculated from the deflections may be compared with the load input. If the two load values agree then the solution must be correct. 
In pure flexure the comparison is direct, however when axial load Is present a P-Delta contribution to the bending moment is incli ted In the net load calculated. The relationship used to calculate bending moment from curvature does not consider axial load, therefore the net load does not agree with the transverse load input. To demonstrate this partial results of a problem are shown in Figures 45 and 46. Figure 47 shows how the net load may be determined if the effect of axial load is ontted. Therefore, the net load is a combination of the axial load contribution to bending moment and the transverse load Input. 
BMCOL CHECK......PE=-240

TABLE 1 - CONTROL DATA

NUM INCREMENTS M $=40$
INCREMENT LGTH H=0.500E 00
NUM CARDS TABLE $2=0$
NUM CARDS TABLE $3=0$
NUM CARDS. TABLE $4=2$

TABLE 2. DATA ADDED THRU SPECIFIED INTERUAL

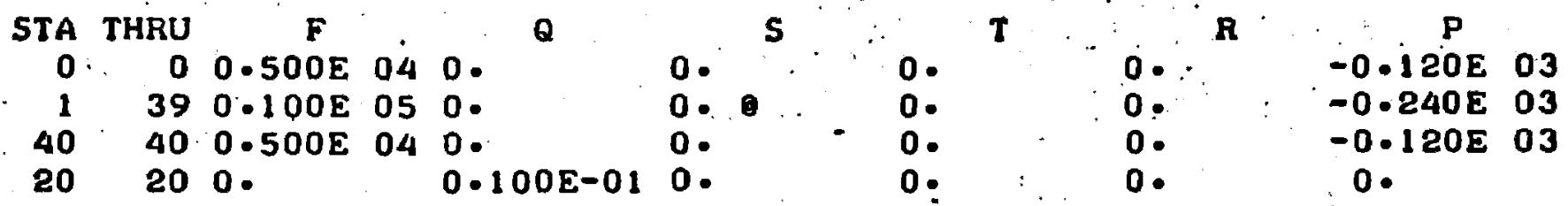

TABLE 3 - SPECIFIED DEFLECTIONS

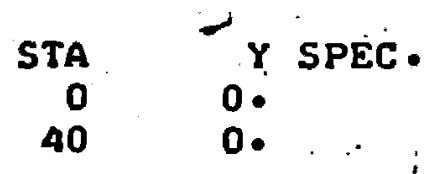

TABLE 4. SPECIFIED SLOPE VALUES.

STA DY/DX SPEC. .

F1gure 45 Example problem - net load check 
TABLE 5. RESULTS

\begin{tabular}{|c|c|c|c|c|c|}
\hline $\begin{array}{r}\text { TA } \\
-1 \\
0 \\
1 \\
2 \\
3 \\
4 \\
5 \\
6 \\
7 \\
8 \\
9 \\
10\end{array}$ & $\begin{array}{l}x . \\
0 \cdot 5 \\
0 \cdot \\
0 \cdot 5 \\
1 \cdot 0 \\
1 \cdot 5 \\
2 \cdot 0 \\
2 \cdot 5 \\
3 \cdot 0 \\
3 \cdot 5 \\
4 \cdot 0 \\
4 \cdot 5 \\
-5 \cdot 0\end{array}$ & $\begin{array}{l}\text { DEFL, } \\
-0.4576867 E-03 \\
0 . \\
0.4563157 E-03 \\
0.9098332 E-03 \\
0 \cdot 1357773 E-02 \\
0 \cdot 1797389 E-02 \\
0 \cdot 2225985 E-02 \\
0 \cdot 2640931 E-02 \\
0.3039679 E-02 \\
0.3419777 E-02 \\
0.3778886 E-02 \\
0.4114792 E-02\end{array}$ & 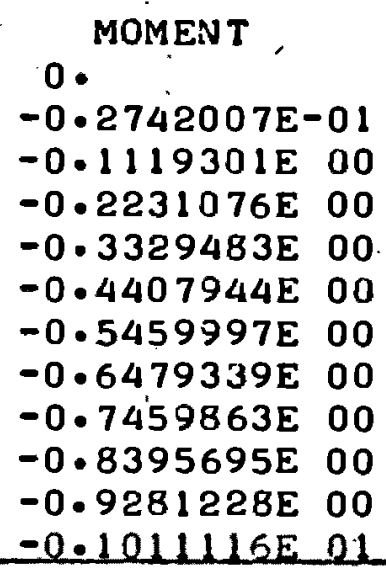 & $\begin{array}{c}\text { SHEAR } \\
-0.2742007 \mathrm{E}-01 \\
-0.2249845 \mathrm{E}-02 \\
0.2267247 \mathrm{E}-01 \\
-0.4668473 \mathrm{E}-02 \\
-0.4673470 \mathrm{E}-02 \\
-0.4680423 \mathrm{E}-02 \\
-0.4689291 \mathrm{E}-02 \\
-0.4700020 \mathrm{E}-02 \\
-0.4712547 \mathrm{E}-02 \\
-0.4726795 \mathrm{E}-02 \\
-0.4742681 \mathrm{E}-02 \\
-0.4760108 \mathrm{E}-02\end{array}$ & $\begin{array}{c}\text { LUAD } \\
-0.5484014 E-01 \\
-0.1141800 E \text { O0 } \\
-0.5333472 E-01 \\
0.2673281 E-02 \\
0.3989396 E-02 \\
0.5281611 E-02 \\
0.6542183 E-02 \\
0.7763561 E-02 \\
0.8938428 E-02 \\
0.1005974 E-01 \\
0.1112079 E-01 \\
0.1211522 E-01\end{array}$ \\
\hline $\begin{array}{l}11 \\
12 \\
13 \\
14 \\
15 \\
16 \\
17 \\
18 \\
19 \\
20 \\
21 \\
22\end{array}$ & $\begin{array}{l}5 \cdot 5 \\
6 \cdot 0 \\
6 \cdot 5 \\
7 \cdot 0 \\
7.05 \\
8 \cdot 0 \\
8 \cdot 5 \\
9.0 \\
9 \cdot 5 \\
0.0 \\
0.5 \\
1 \cdot 0 \\
1 \cdot 5 \\
2.0\end{array}$ & $\begin{array}{l}0.4425420 \mathrm{E}-02 \\
0.4708847 \mathrm{E}-02 \\
0.4963312 \mathrm{E}-02 \\
0.51872 .28 \mathrm{E}-02 \\
0.5379192 \mathrm{E}-02 \\
0.5537991 \mathrm{E}-02 \\
0.5662612 \mathrm{E}-02 \\
0.5752244 \mathrm{E}-02 \\
0.5806289 \mathrm{E}-02 \\
0.5824361 \mathrm{E}-02 \\
0.5806289 \mathrm{E}-02 \\
0.5752244 \mathrm{E}-02 \\
0.5662612 \mathrm{E}-02 \\
0.5537991 \mathrm{~F}-02\end{array}$ & 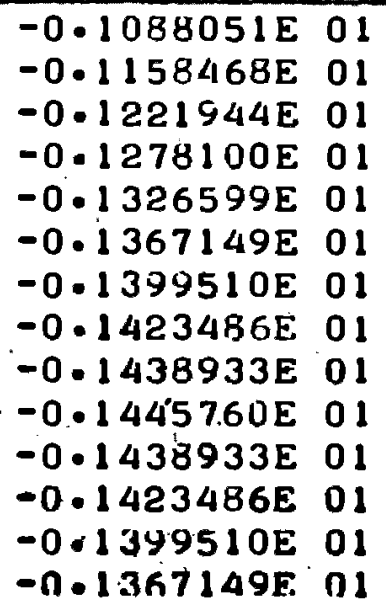 & $\begin{array}{r}-0.4778972 E-02 \\
-0.4799160 E-02 \\
-0.4820552 E-02 \\
-0.4843019 E-02 \\
-0.4866426 E-02 \\
-0.4890633 E-02 \\
-0.4915496 E-02 \\
-0.4940865 E-02 \\
-0.4966588 E-02 \\
0.3564721 E-15 \\
0.4966588 E-02 \\
0.4940865 E-02 \\
0.4915496 E-02 \\
0.4890633 E-02\end{array}$ & $\begin{array}{l}0.1303706 E-01 \\
0.1388079 E-01 \\
0.1464137 E-01 \\
0.1531423 E-01 \\
0.1589534 E-01 \\
0.1638122 E-01 \\
0.1676896 E-01 \\
0.1705624 E-01 \\
0.1724134 E-01 \\
0.2730816 E-01 \\
0.1724134 E-01 \\
0.1705624 E-01 \\
0.1676896 E-01 \\
0.1638122 E-01\end{array}$ \\
\hline
\end{tabular}

F1gure 46 Example problem - net load check 


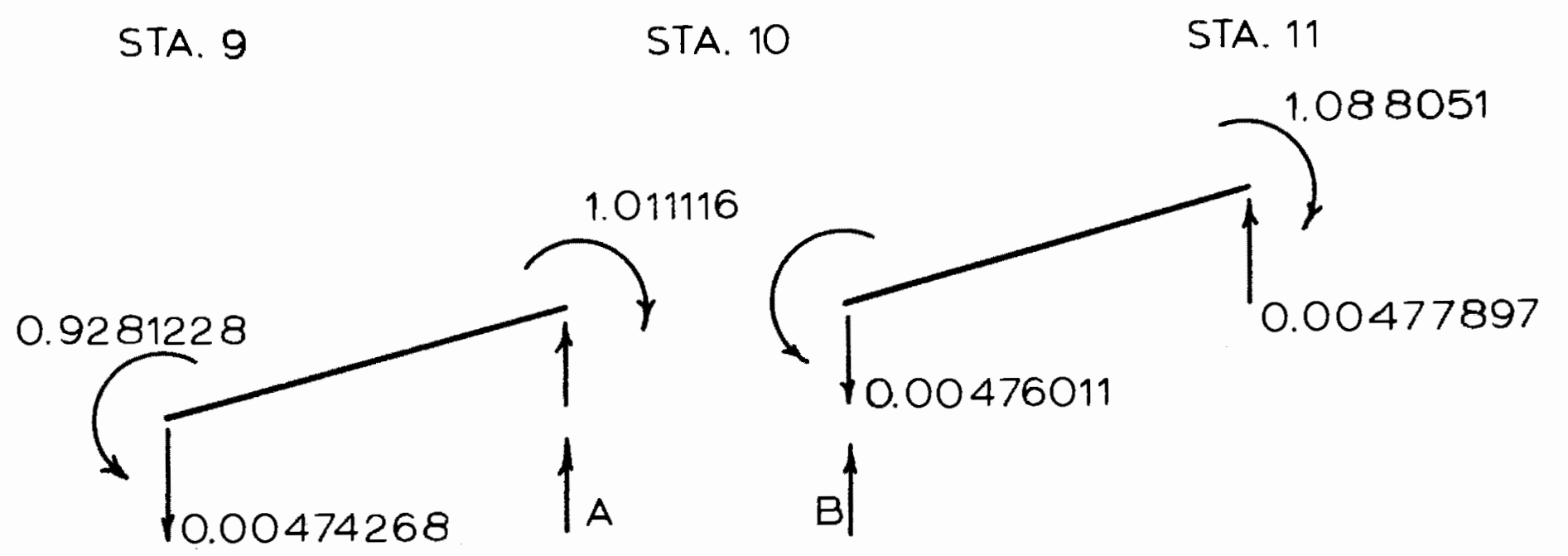

$$
\underline{A+B=0.0121164}
$$


APPENDIX II

INTERPOLATION ON THE MOMENT-THRUST-

CURVATURE DATA

It is necessary for the beam-column analysis program to have the ability to determine the bending moment from the moment-thrust-curvature data for any combination of axial load and curvature. The most stralghtforward way to accomplish this was to interpolate between tabulated values on the $M-P-\emptyset$ data. A divided difference 1nterpolation as described by Hildebrand (10) was selected because it easily allows the use of unevenly spaced points. Orders of interpolation from first order to fourth order were investigated to determine which was the most efficlent. The M-P- $\emptyset$ curve used in the Investigation was that for a solid rectangular cross section for which an exact solution is available (2). The results showed that the linear interpolation had large errors in the sharply curved portion of the M- $\emptyset$ curve (1.e., $\emptyset / \emptyset_{\mathrm{y}}$ between 1.0 and 2.0 ). Interpolations of third and fourth order had larger errors in the initial part of the $M-\emptyset$ curve (1.e., $\Phi / \phi_{y}$ legs than 1.0). This error was developed because the number of points required for the higher order of Interpolation dictated that points from the curved portion of the curve be used when Interpolating on the straight line portion. The second order interpolation gave satIsfactory results over all portions of the $M-\emptyset$ curve and was therefore selected. 
The Interpolation procedure uses two values (axlal load and curvature) to determine a third value (bending moment). A thr adimensional interpolation was requi red to have the ability to decermine bending moment for any comblnation of axial load and curvature, F1gure 48. The procedure used was to first select three curvature ratios and three axial load ratios to be used in the interpolation. Next, a bending moment value corresponding to the given curvature value was determined for each $P / P_{y}$ curve (points $a, b$ and $c$, Figure 48). Finally these bending moment values were used to interpolate between the $\mathrm{P} / \mathrm{P}_{\mathrm{y}}$ curves to determine the bending moment value corresponding to the given axtal load ratio (point d F1gure 48). The ab1lity to Interpolate anywhere on the $M-P-\emptyset$ Data, rather than follow one $P / P_{y}$ curve, was espectally useful in the analysis of the model beam-columns to be tested, since the loading procedure was to increment an eccentric axial load. 


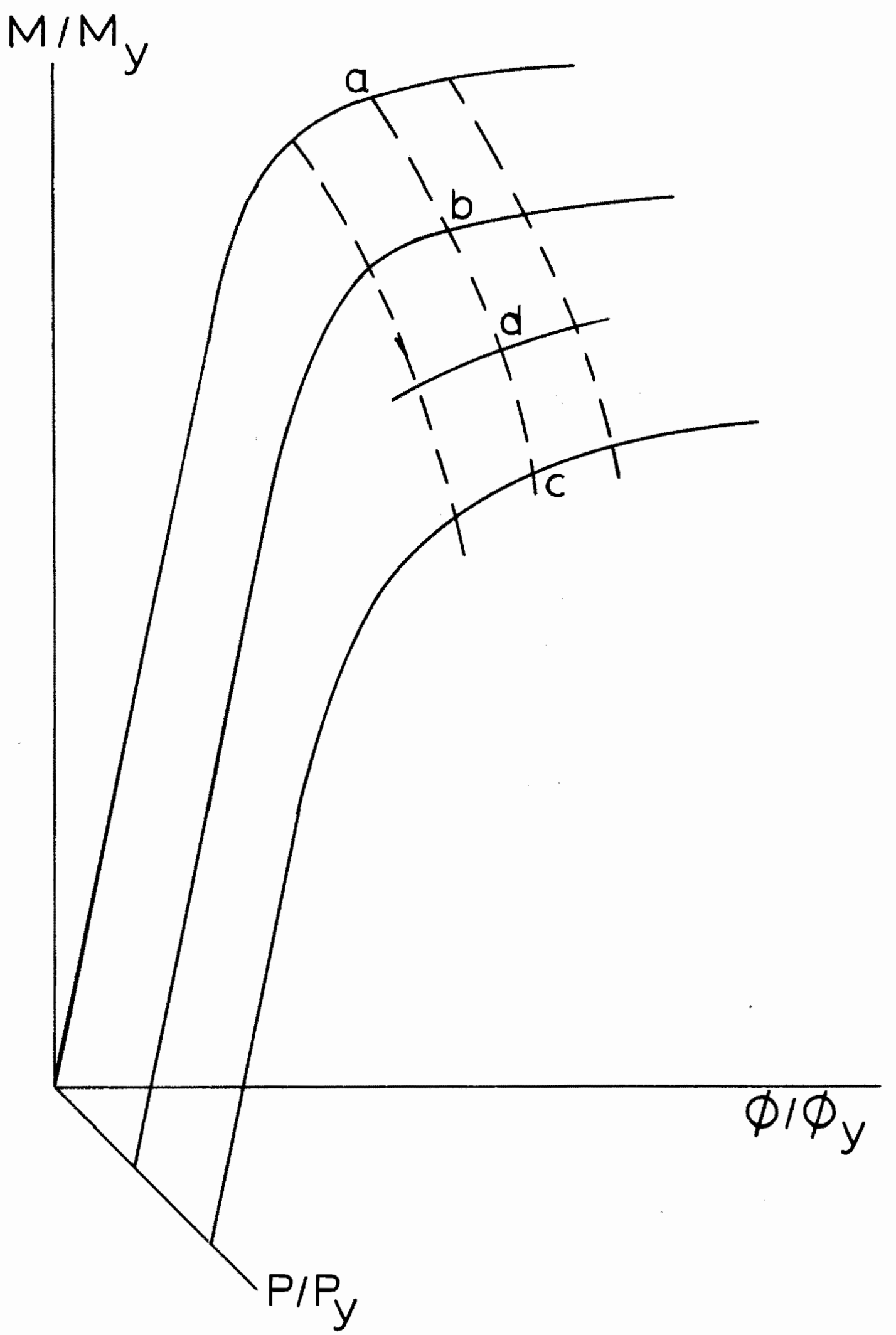

93

Figure 48 Interpolation on the M-P- $\emptyset$ data. 
APPENDIX III

CONSIDERATION OF RESIDUAL STRESS

In the manufacture of fabrlcated structural tubing a common procedure 18 to roll a flat plate 1nto a cylindrical can and then weld the longltudinal seam. The resldual stresses consldered here are caused by the welding of the seam. At this time there $1 \mathrm{~s}$ no experImental data avallable on the residual stress developed by longltudInal welding, however, some Ideas on a possible restdual stress distribution have been expressed (13). A Ilnear 1dealization of the residual stress distribution over the cross section is shown in Figure 50 .

Since there are no applied loads the residual stresses must satisfy equilibrium (1.e., both the net force and the net moment on the cross section must be zero.). This 1s not a trivial problem first due to the clrcular cross section Involved and second because the data must be In the form of a stress and strain value for each element. Therefore, a computer program was developed to adjust the assumed residual stress distribution shown In Figure 49 such that equilibrium would be satisfled.

The procedure used in the computer program is as follows. First the location of the maximum compressive stress ' $C$ ' 1 s adfusted to achleve zero net force. Then, if rotational equilibrium is not satis- 


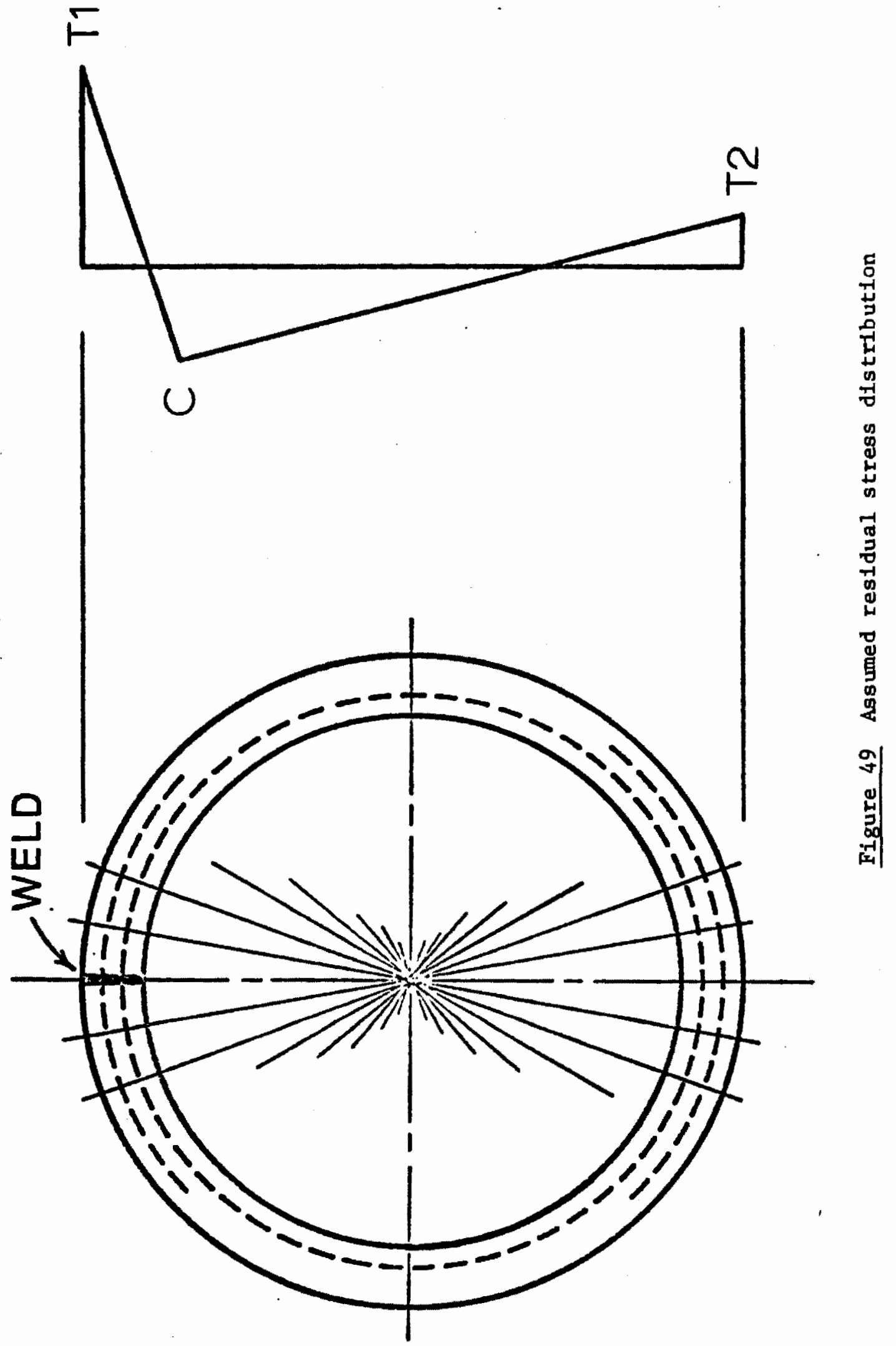


fled, the value of ' $\mathrm{T} 2$ ' is changed to achieve zero net moment. A new value of ' $\mathrm{T} 2$ ' requires a new location for ' $\mathrm{C}$ ', etc. The $\mathrm{P}$ ', cess is continued until both translational and rotational equilibrium are satisfied. 
APPENDIX IV

COMPUTER PROGRAM DOCUMENTATION 
BEAM-COLUMN ANALYSIS PROGRAM

DATA INPUT

Note: Numbers at left Indicate card colums.

Two blank cards w111 stop program.

A. Control Card (Omft for batch processing)

FORMAT (I5)

1-5 IWRT1:

+15 - Results for each station w11l be saved in file "15".

-15 = Results for each station will not be saved.

B. Title of Problem

FORMAT ( $80 \mathrm{H} \quad)$

1-80 Problem Title.

C. Control Data

FORMAT $(4 I 5$, E10.3)

1-5 Number of cards in table 2.

6-10 Number of cards in table 3.

11-15 Number of carda in table 4 .

16-20 Number of beam-column Increments.

21-30 Increment length.

D. Data Added Through Spectfled Intervals

FORMAT $(2 \mathrm{I} 5,6 \mathrm{E} 10,3, \mathrm{I5})$

$$
\text { 1-5 Station }
$$

6-10 Through

11-20 Flexural stiffness (EI) 
21-30 Transverse load

31-40 Transverse spring stiffness

41-50 Applied moment

51-60 Rotational spring stiffness

61-70 Axtal load

71-75 StIffness code

E. Speclfied Deflections

FORMAT $(2 I 5,6 E 10.3, I 5)$

1-5 Station

10 Enter 0

11-20 Spectfled deflection

F. Specified Slope Values

FORMAT $(2 I 5,6 E 10.3, I 5)$

1-5 Station

10 Enter 0

11-20 Specifled slope value

G. Control Card

FORMAT (E10.3)

1-10 +10.0 = Elastic solution.

-10.0 = Moment-Thrust-Curvature Data required.

H. Moment-Thrust-Curvature Data

(Ontt if the previous entry was +10.0 )

1. Control Card

FORMAT (I5)

1-5 Number of sets of M-P- Data 
2. Date and time of $M-P-Q$ Data calculation.

FORMAT (4I5)

\section{1-5 Month}

6-10 Day

11-15 Year

16-20 TIME

3. Values of First Yield

FORMAT (3E15.6)

1-15 Axdal load

16-30 Curvature

31-45 Bending Moment

4. Control Data

FORMAT (2I5)

1-5 Number of axtal load (P/Py) values.

6-10 Number of curvature $(\emptyset / 0 \mathrm{y})$ values.

5. $\mathrm{P} / \mathrm{Py}$ values .

FORMAT $(6 \mathrm{E} 10.3,1,6 \mathrm{E} 10.3)$

$$
\text { 1-10 P/Py (1) }
$$

11-20 P/Py (2)

21-30 etc.

$31-40$

41-50

$51-60$ 
6. $\phi / \phi$ and $M / M y$ values. (Do for each $\phi / \phi y$ value.)

FORMAT (7E10.4, 6E10.4)

$$
\begin{aligned}
& 1-10 \quad 0 / 0 y \\
& 11-20 \mathrm{M} / \mathrm{My} \text { for } \mathrm{P} / \mathrm{Py}(1) \\
& 21-30 \mathrm{M} / \mathrm{My} \text { for } \mathrm{P} / \mathrm{Py}(2) \\
& 31-40 \text { etc. } \\
& 41-50 \\
& 51-60 \\
& 61-70
\end{aligned}
$$

Return to 1 tem 2 and repeat for each set of moment-thrust-curvature data.

I. Load Incrementing Data

$$
\text { FORMAT (3E10.3) }
$$

1-10 Eccentriclty of axlal load

11-20 Rat1o of end moments

21-30 Load Increment.

J. Results to be Printed at Terminal (Outt for batch processing)

1. Control Card

FORMAT (I5)

1-5 Results for how many stations at terminal?

2. Stations for which results are desired.

FORMAT (10I5)

1-5 List station numbers. (more than one card may be used.)

6-10

11-15

etc. 


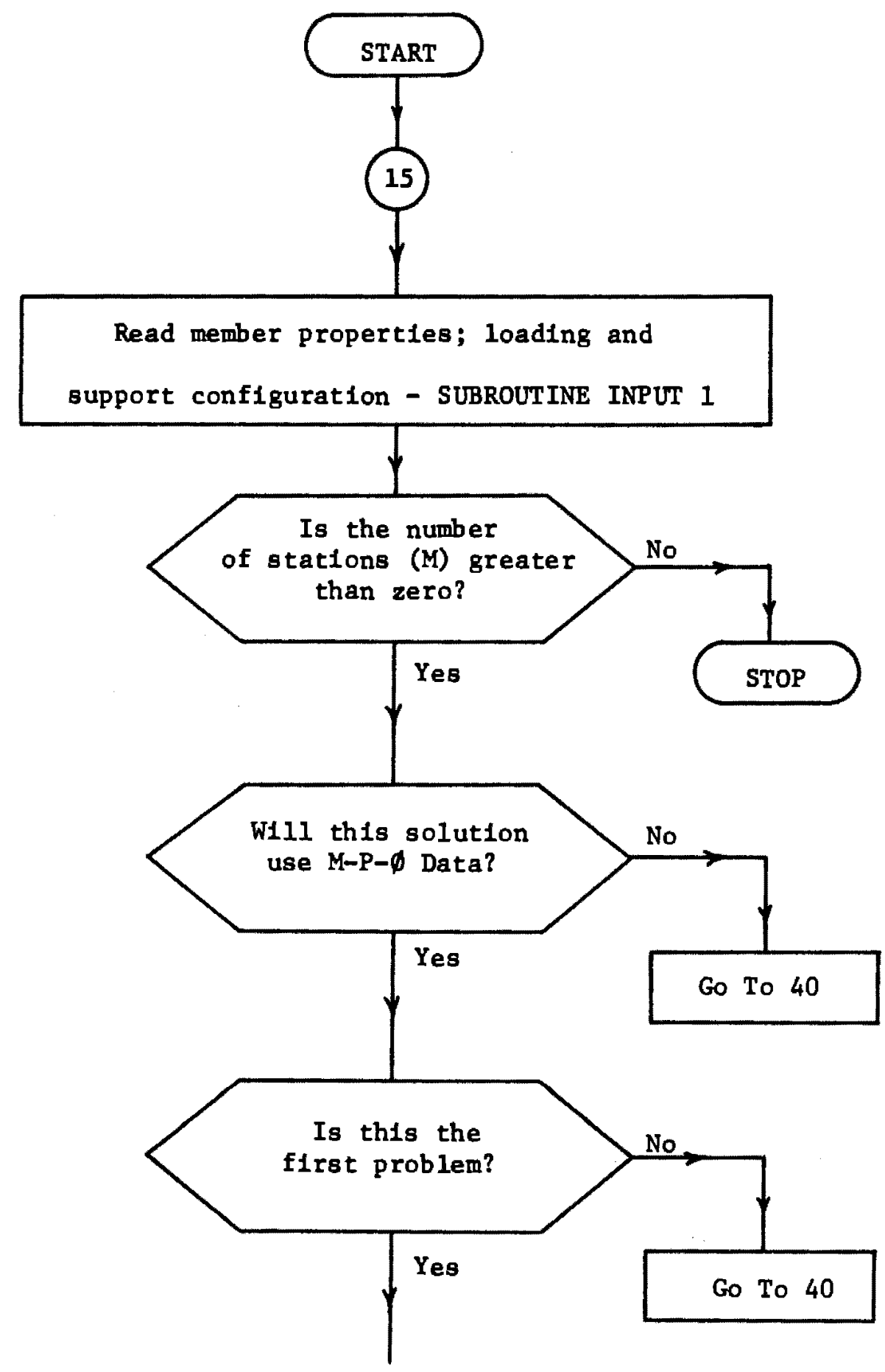




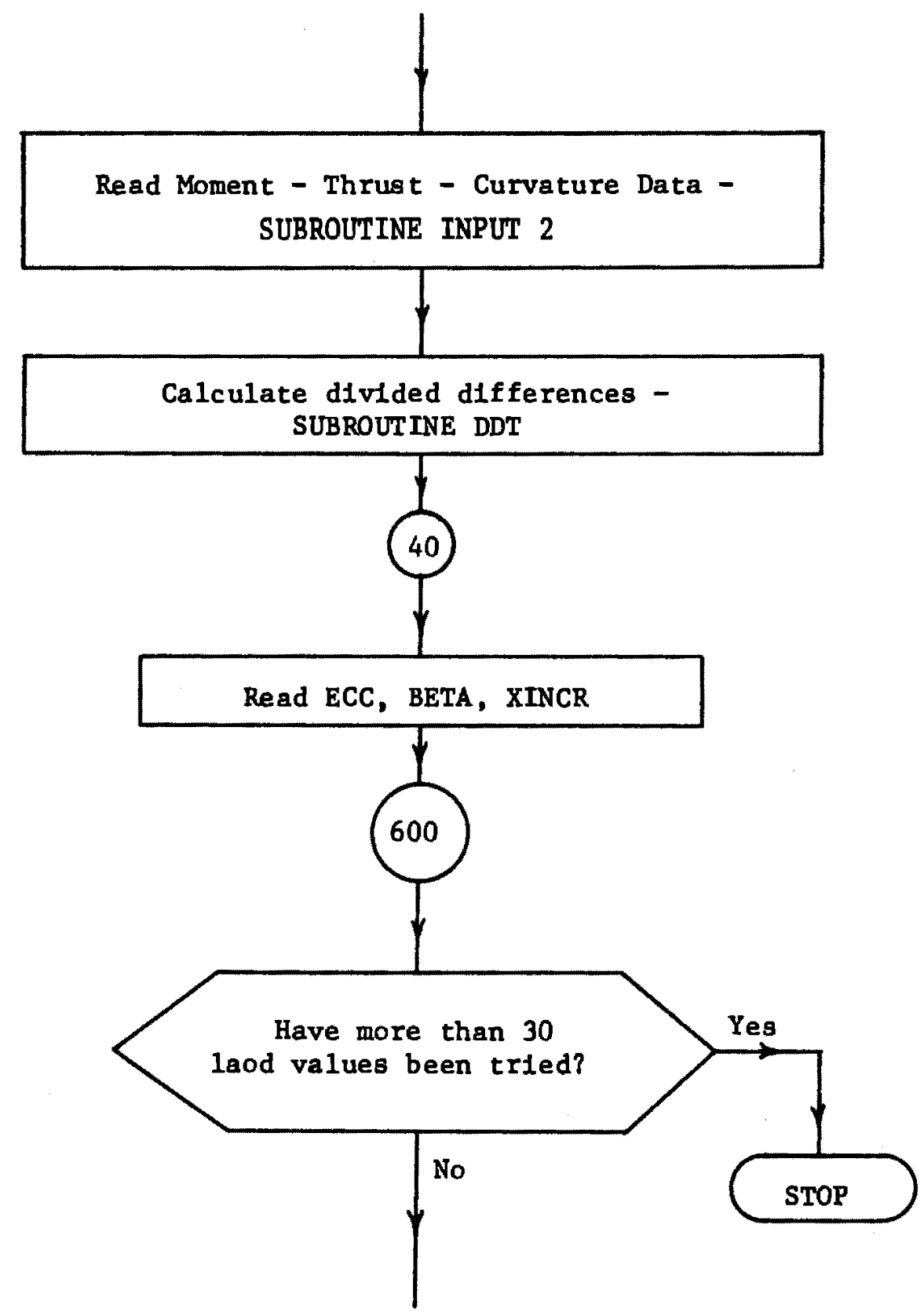




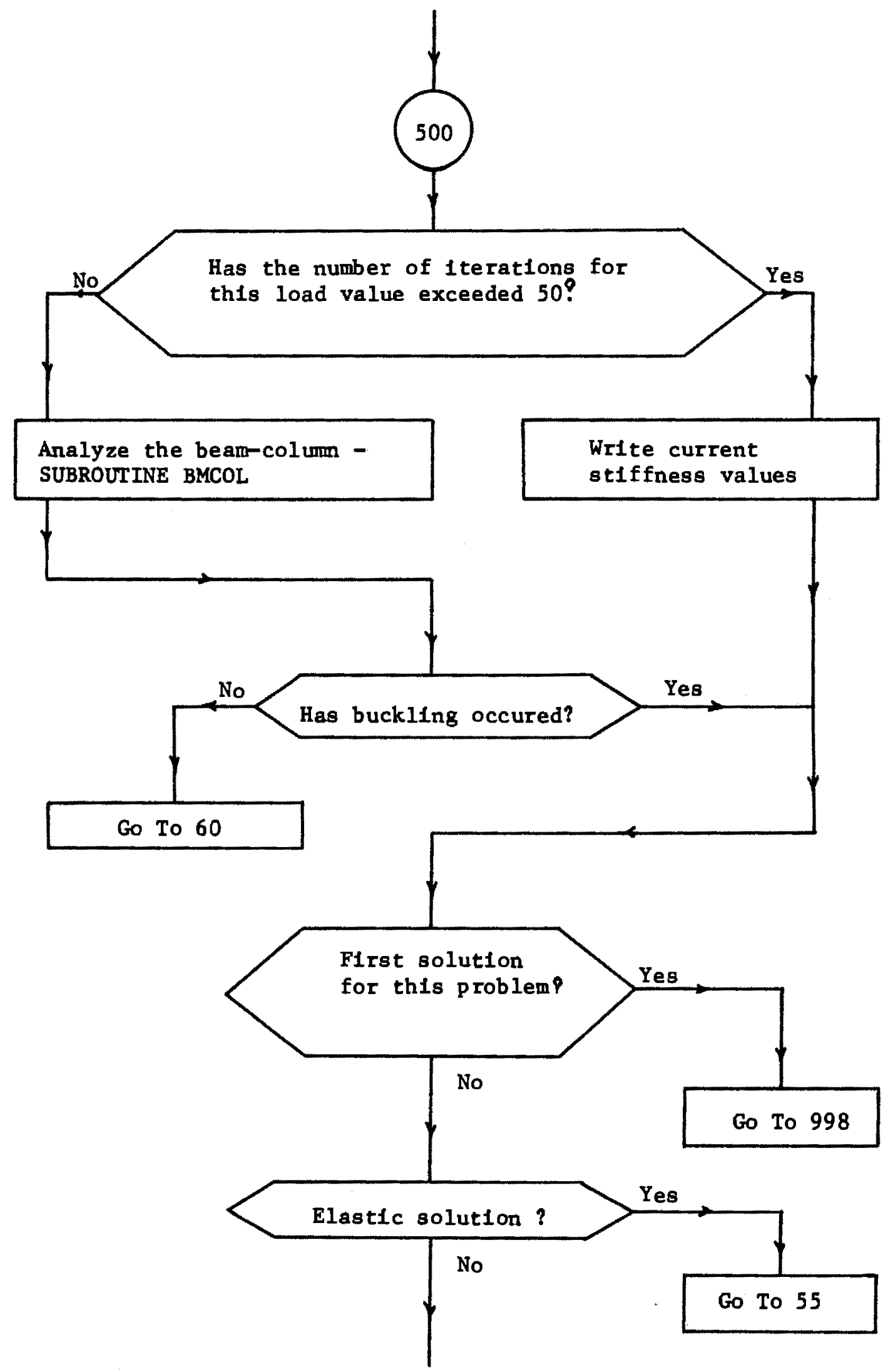



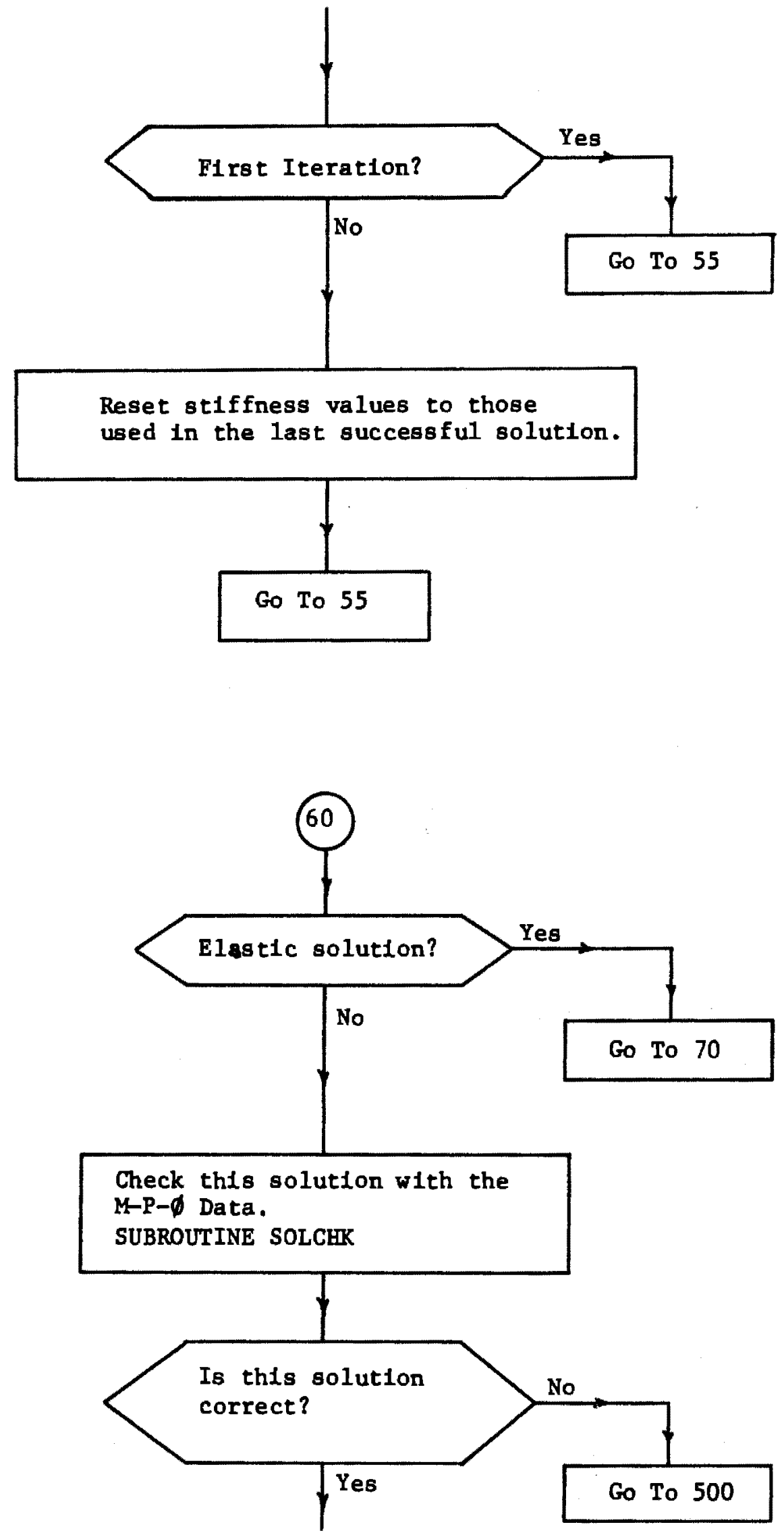


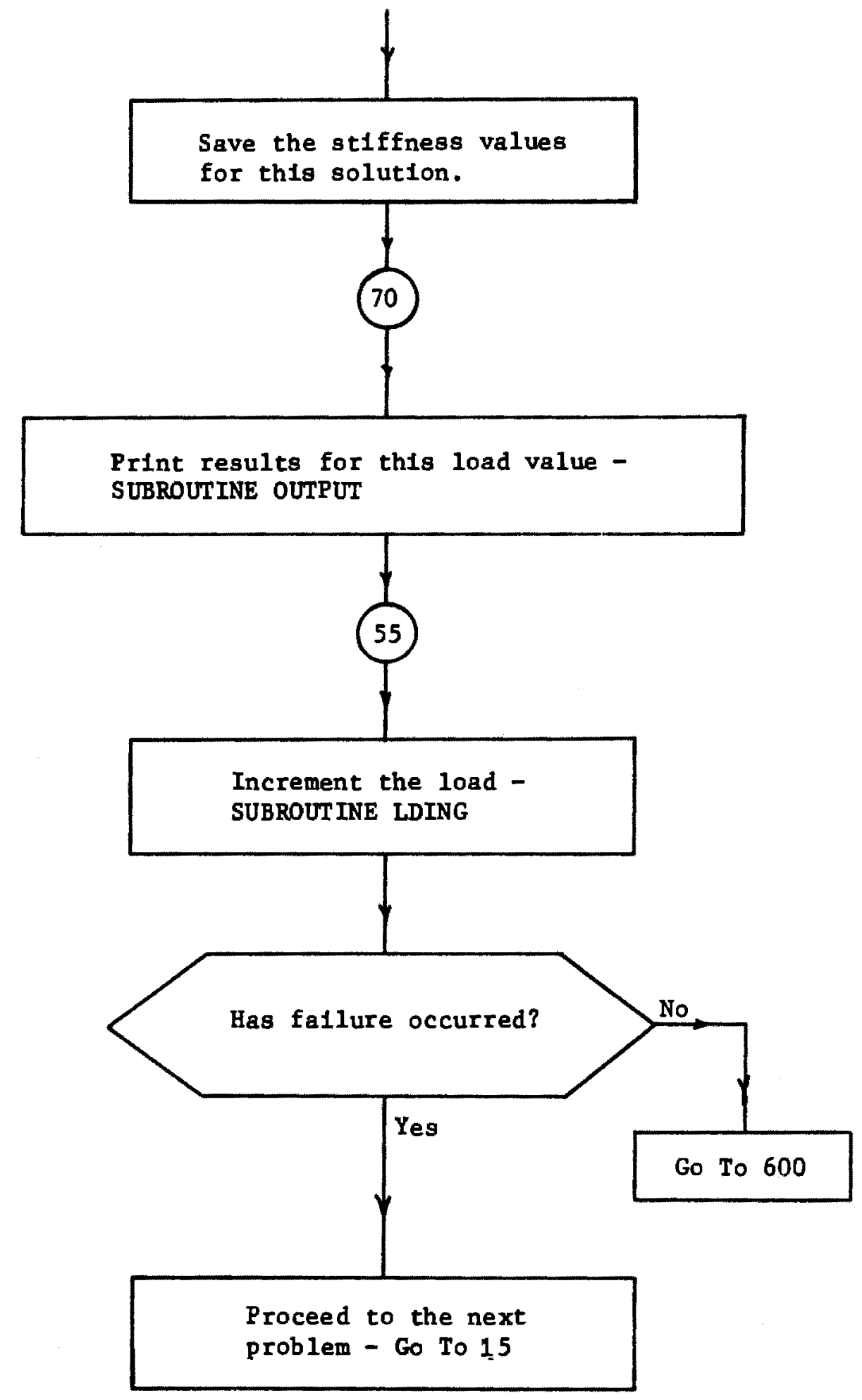




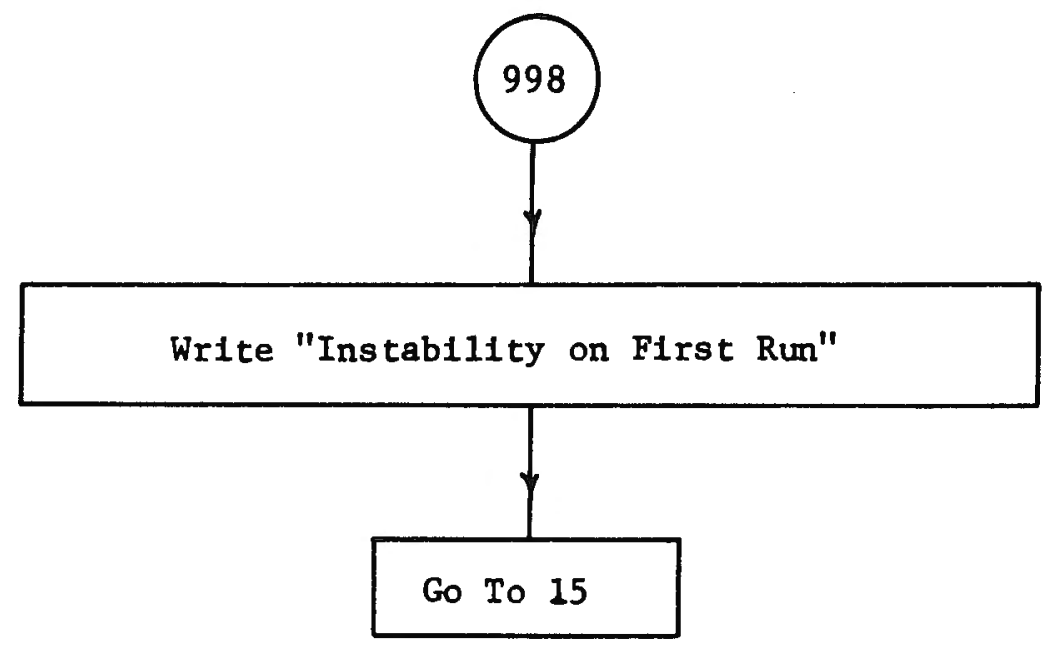


FLOW DIAGRAM - SUBROUTINE INPUT 1

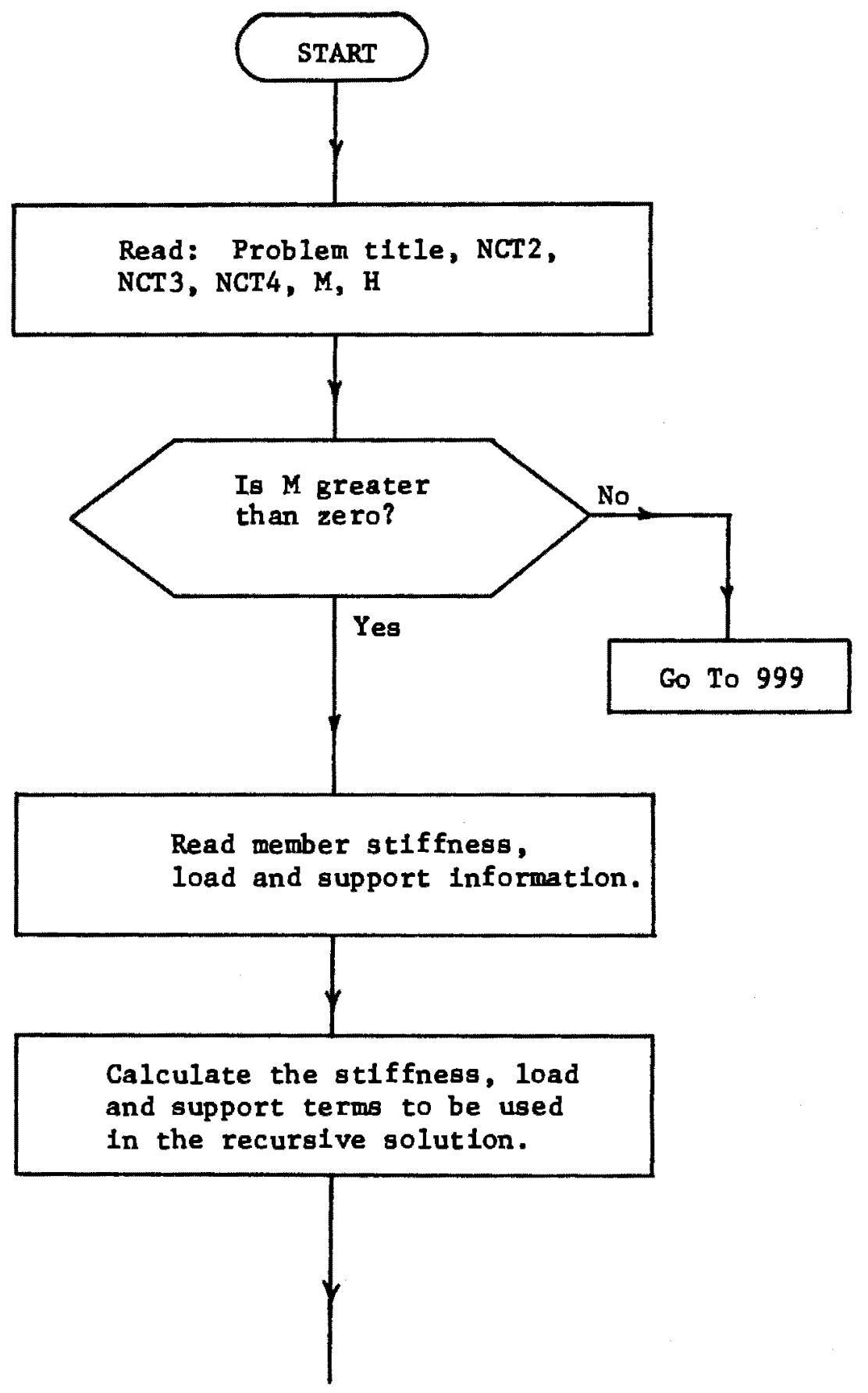




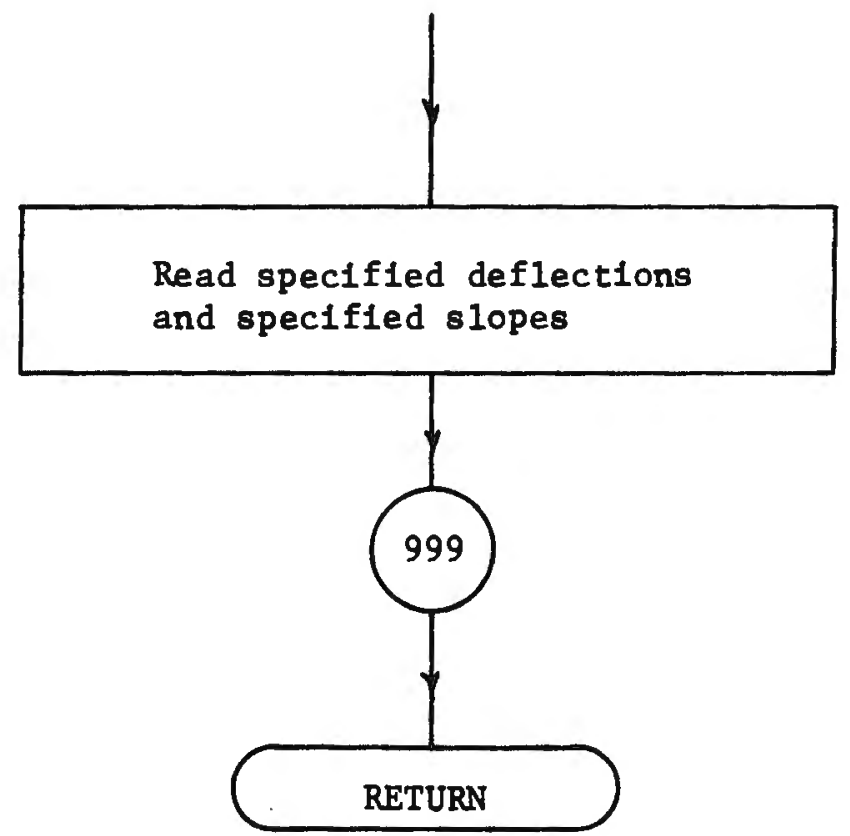


FLOW DIAGRAM - SUBROUTINE INPUT 2

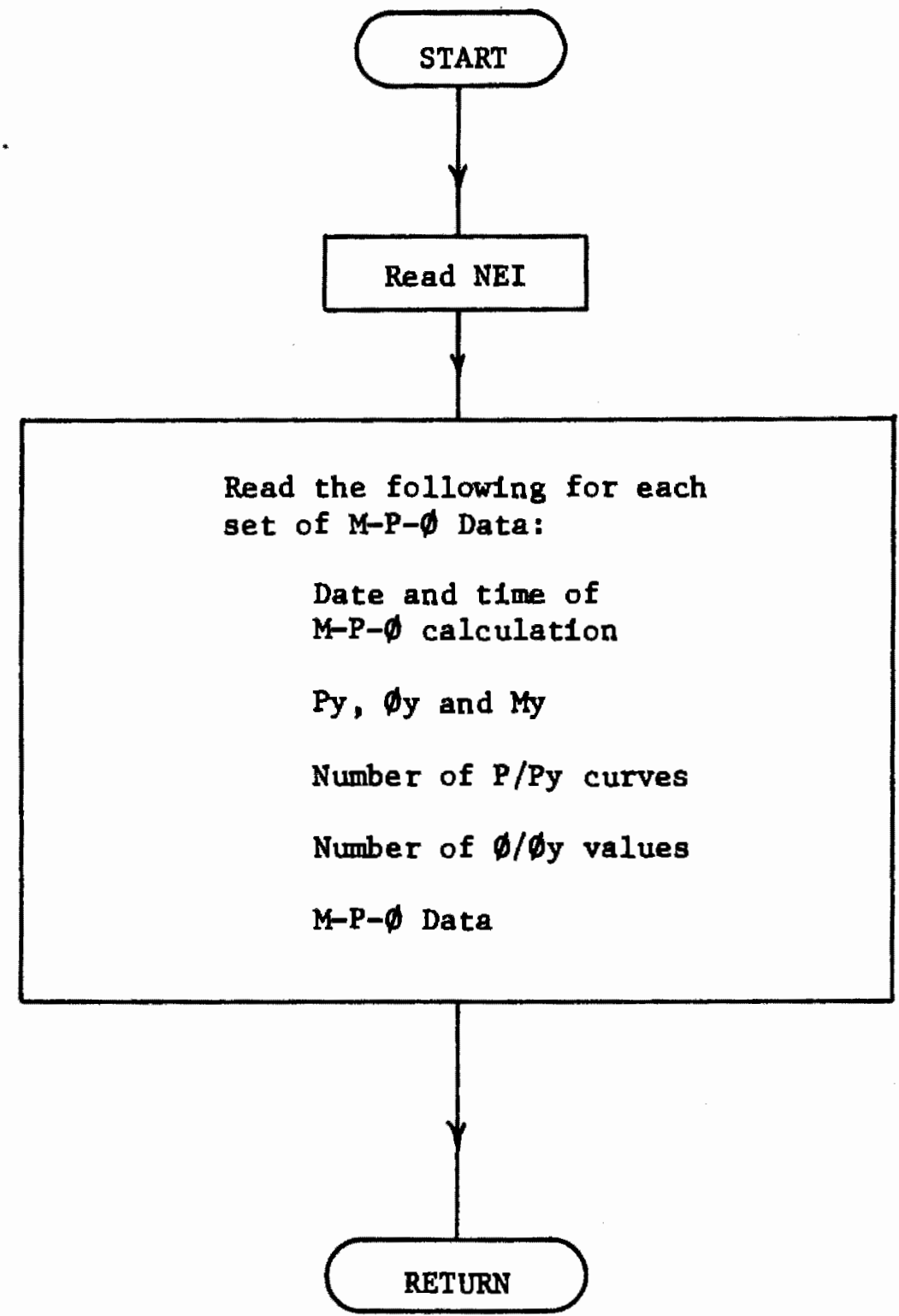


FLOW DIAGRAM - SUBROUTINE DDT

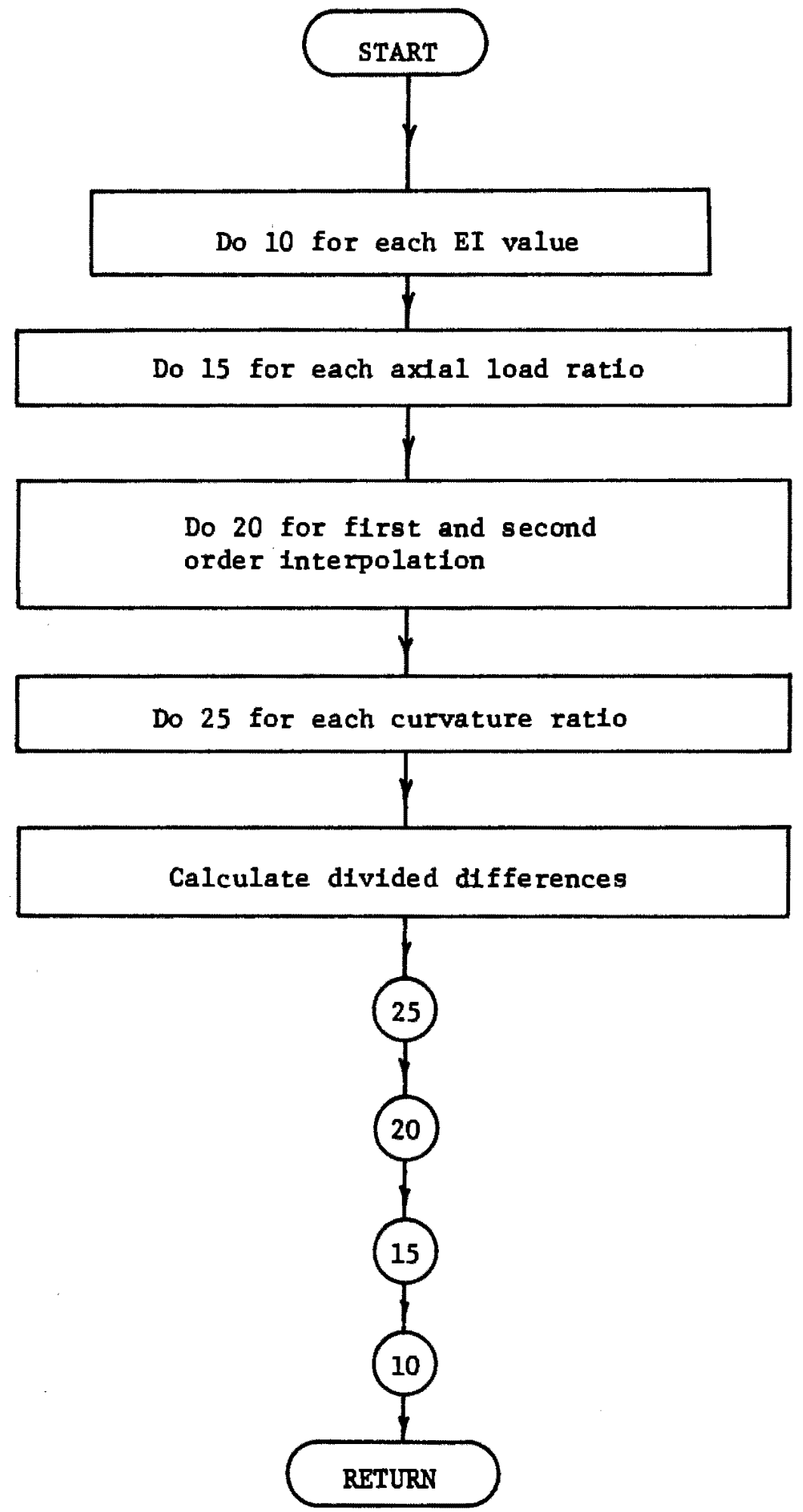


FLOW DIAGRAM - SUBROUTINE BMCOL

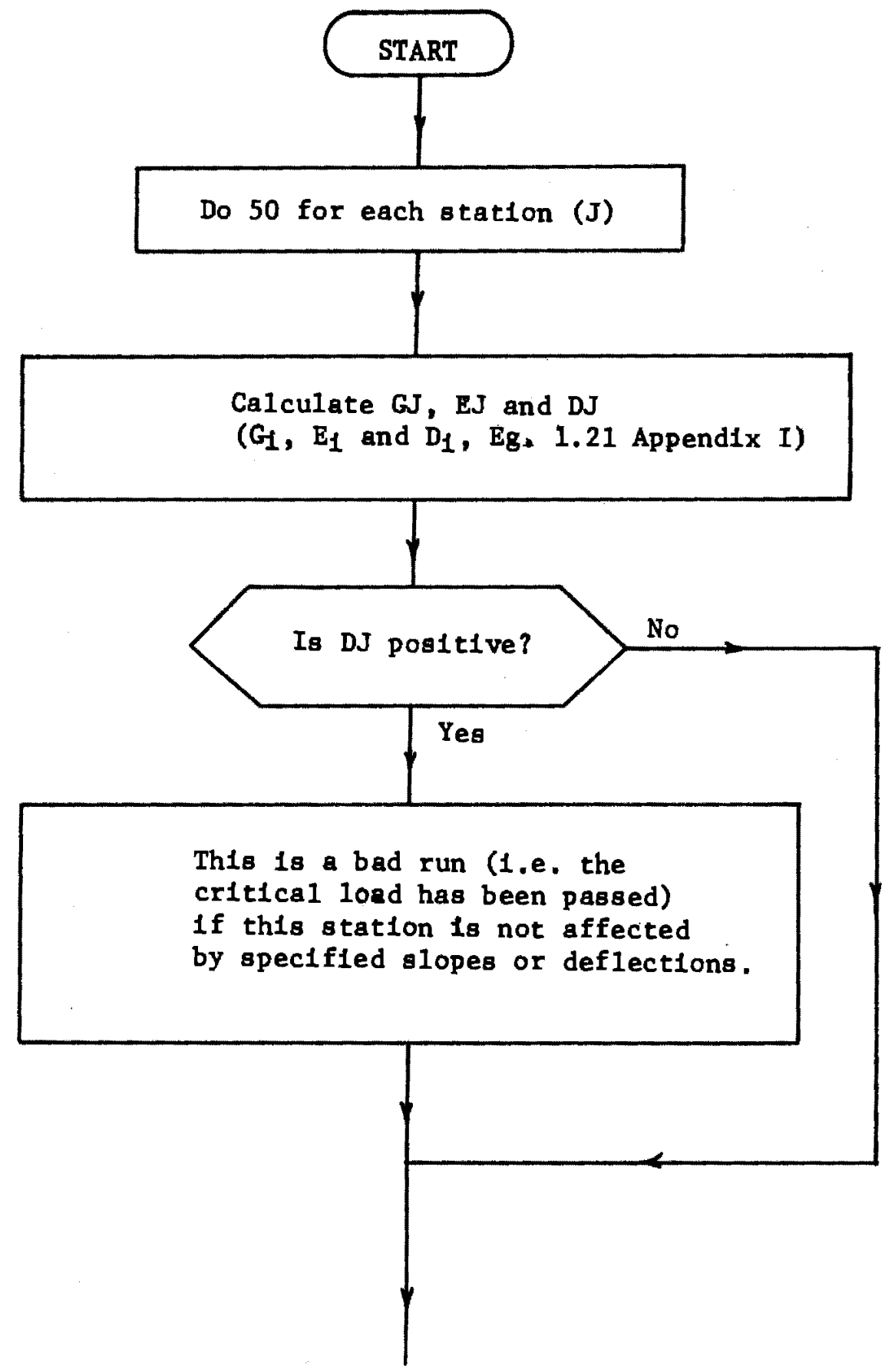




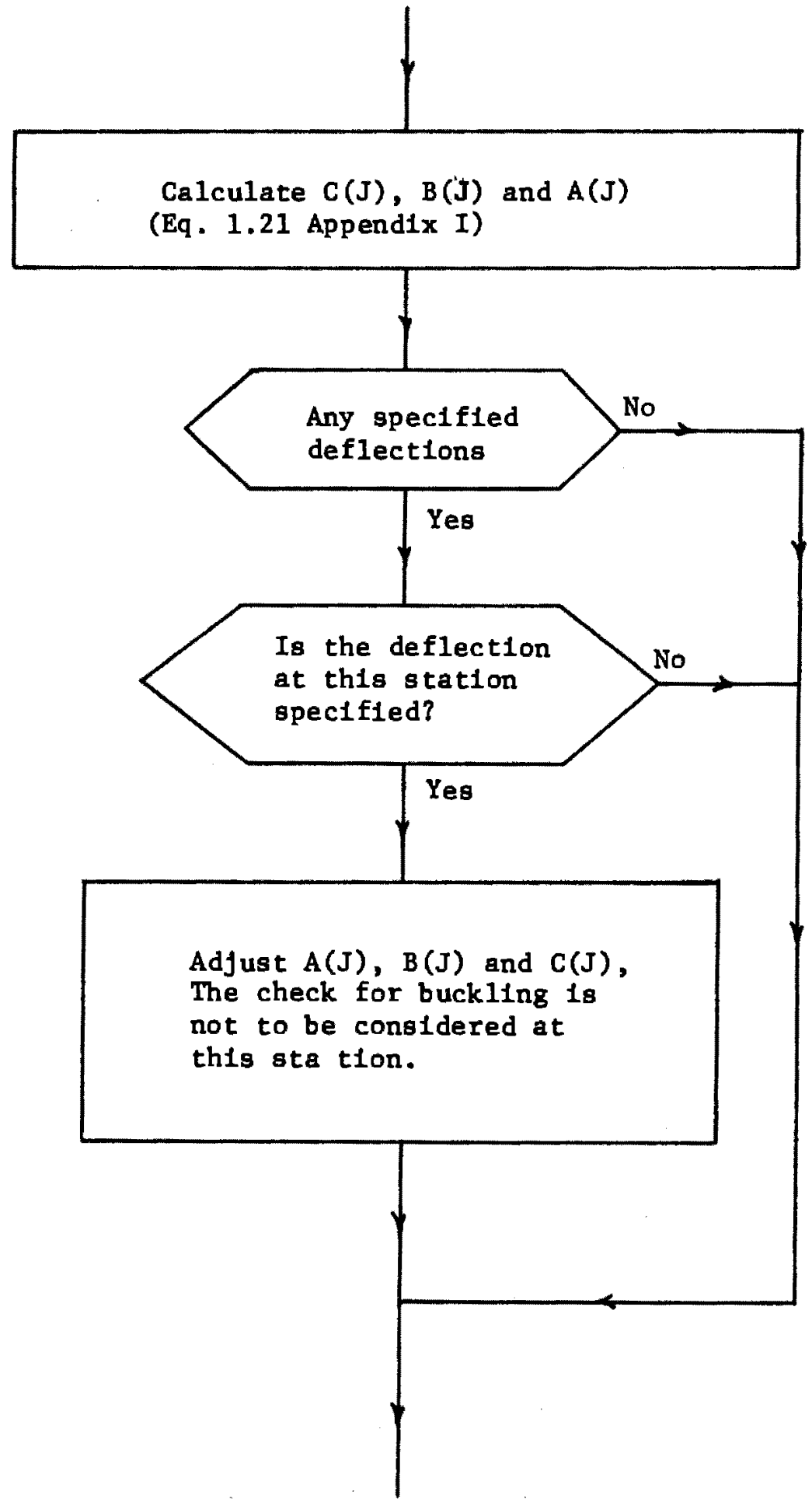




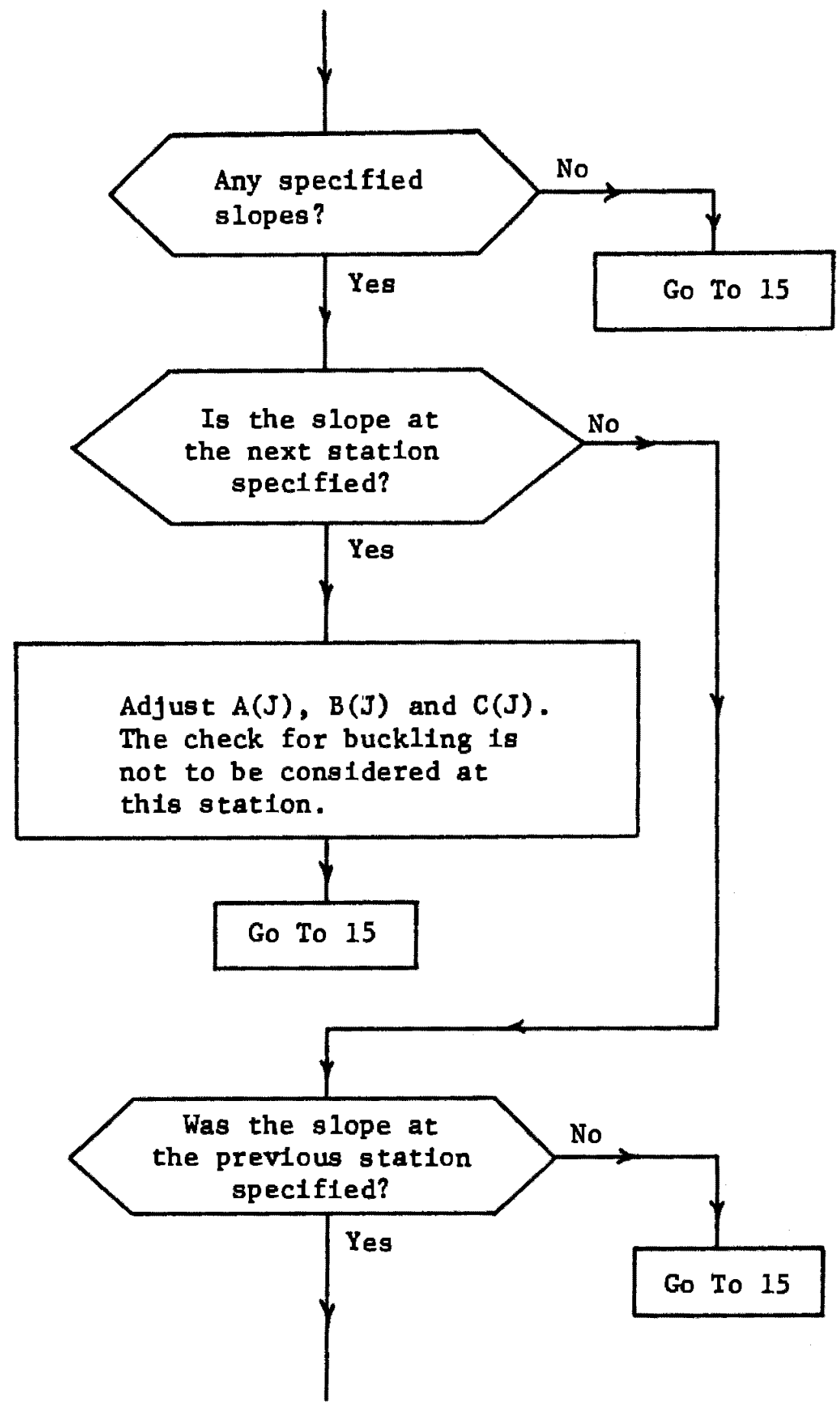




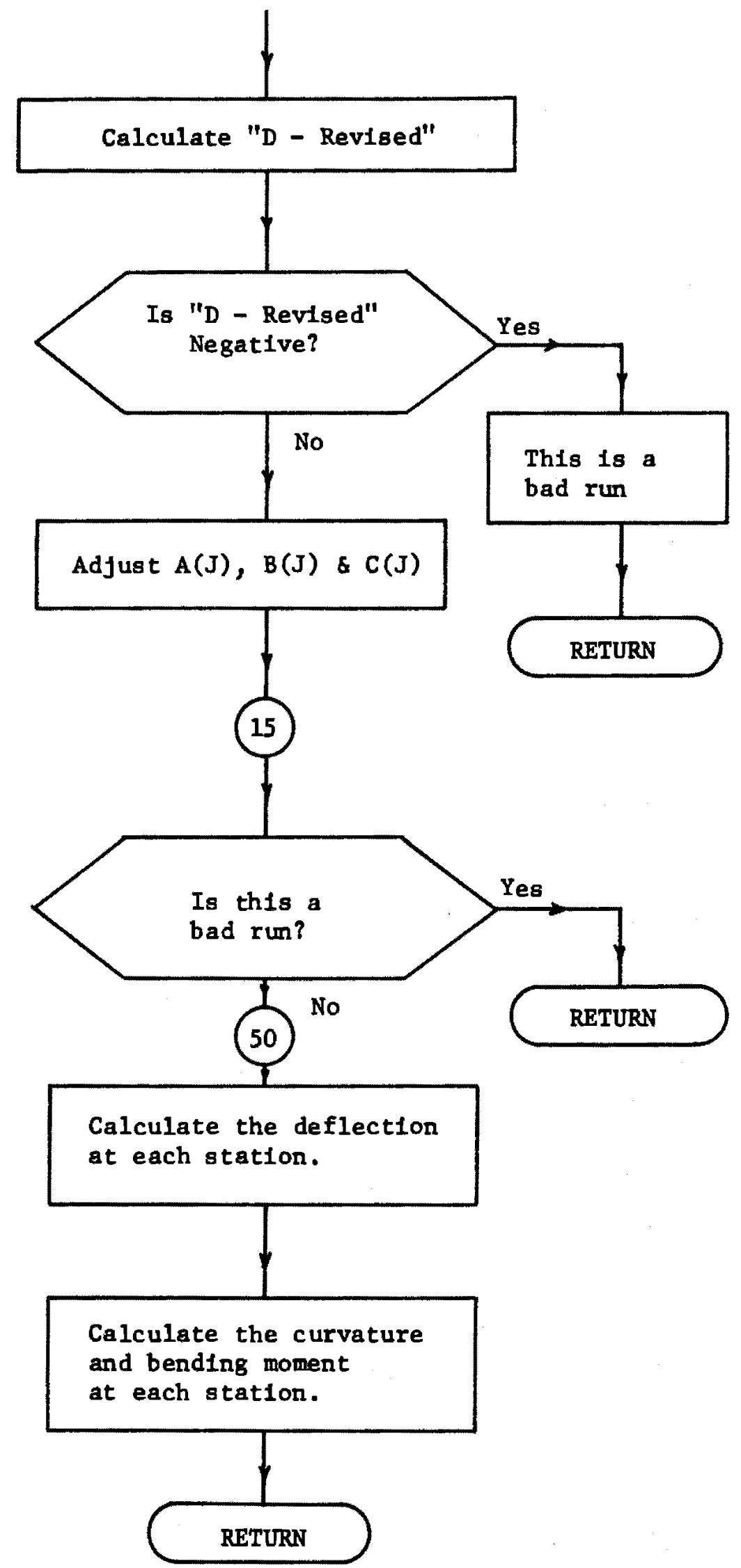


FLOW DIAGRAM - SUBROUTINE SOLCHK

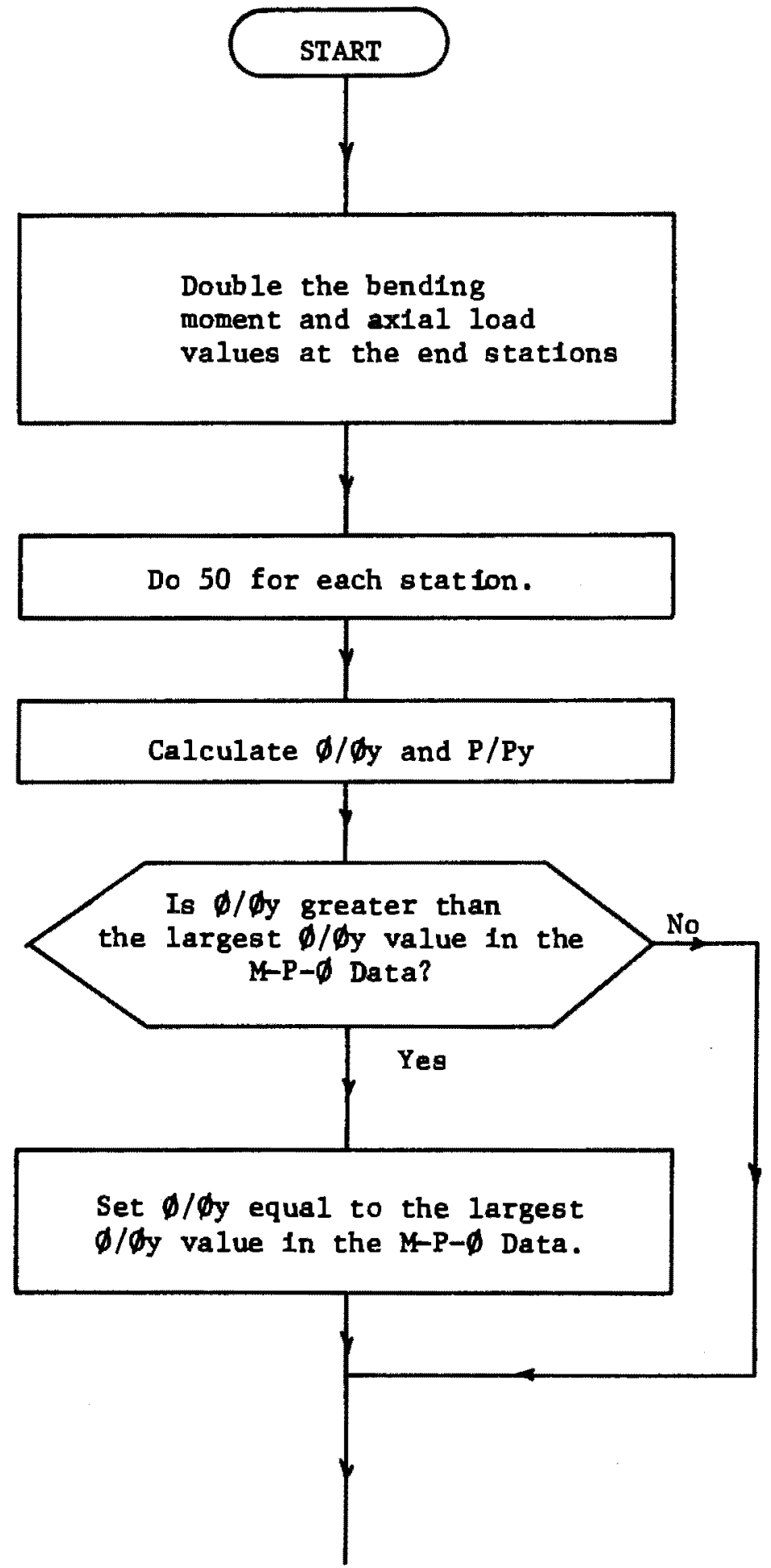




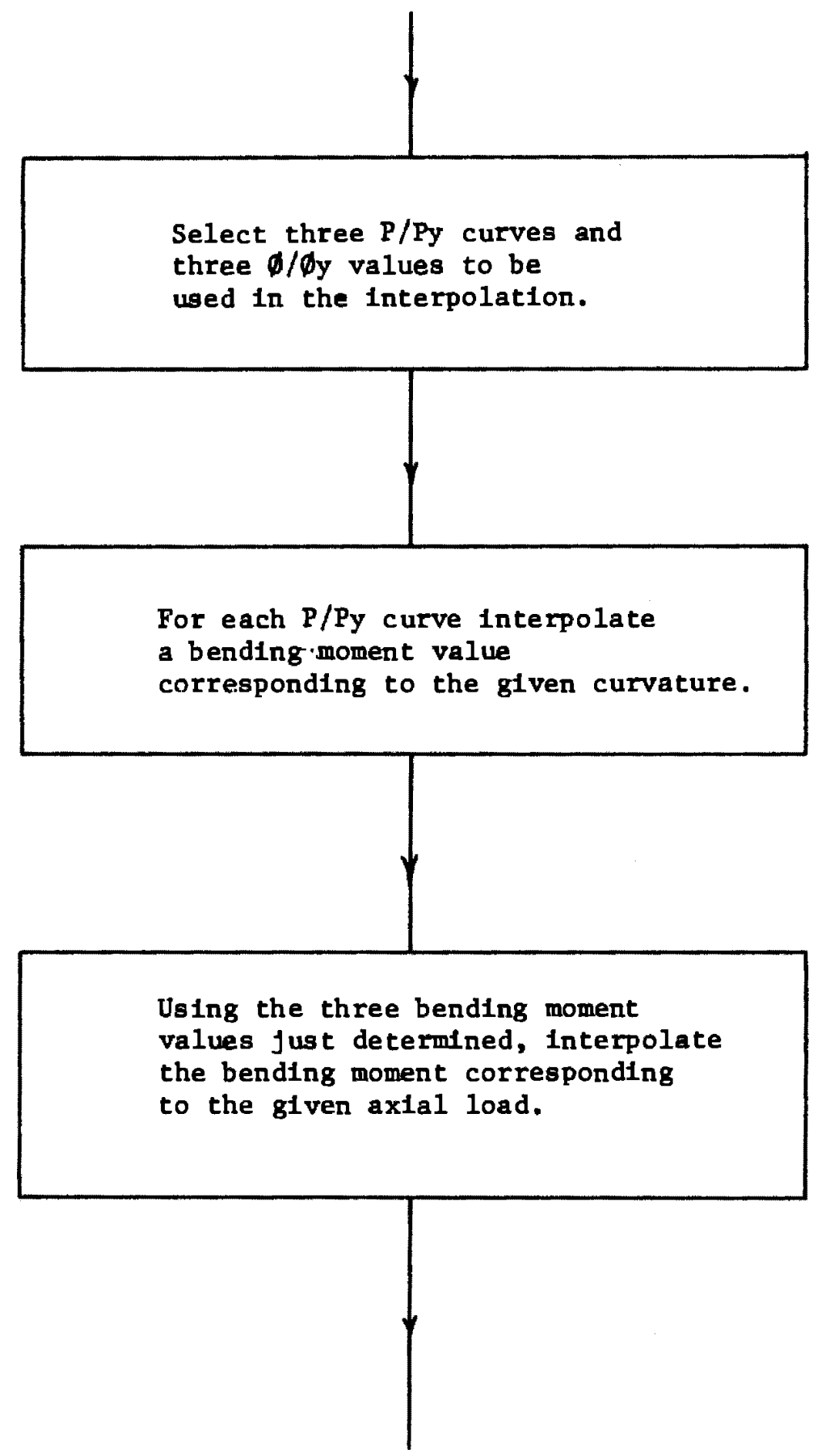




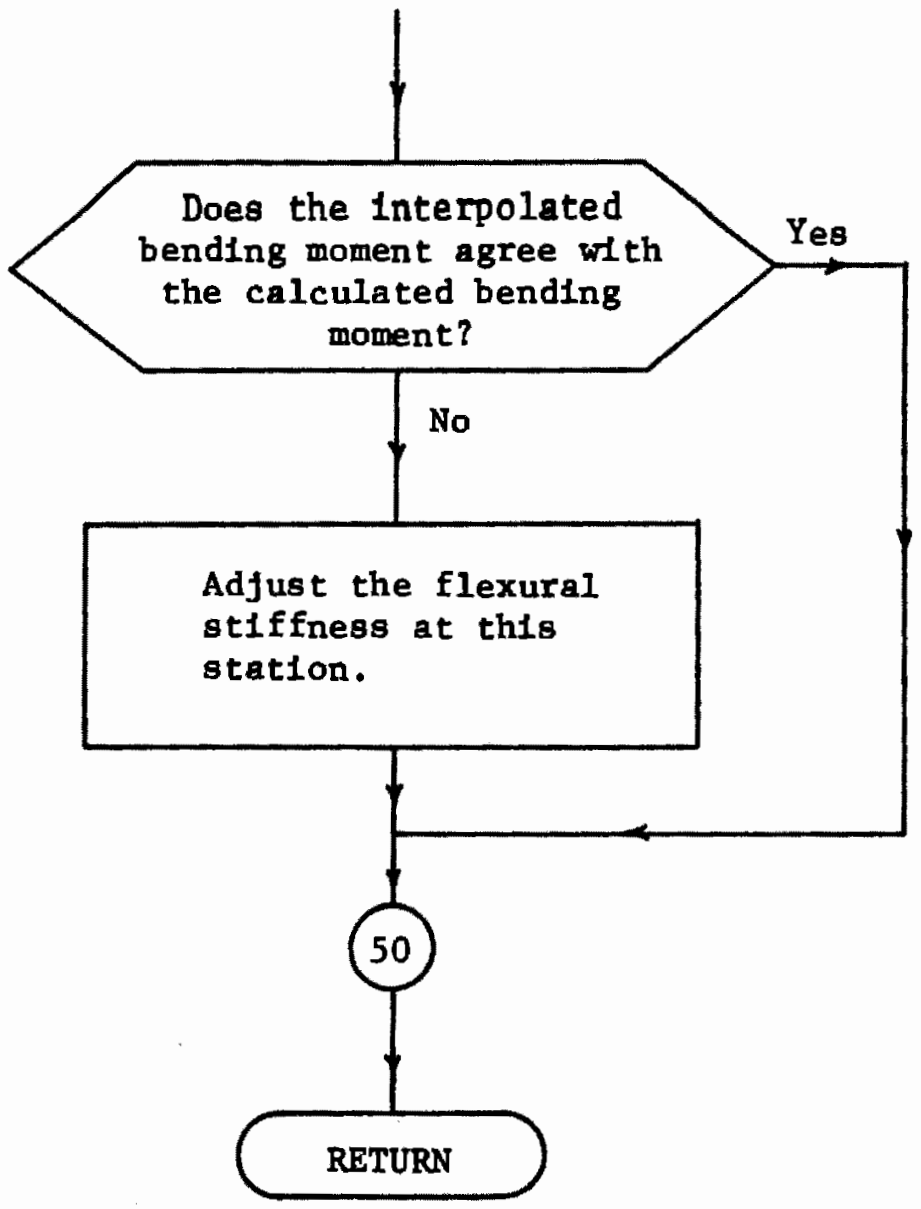


FLOW DIAGRAM - SUBROUTINE OUTPUT

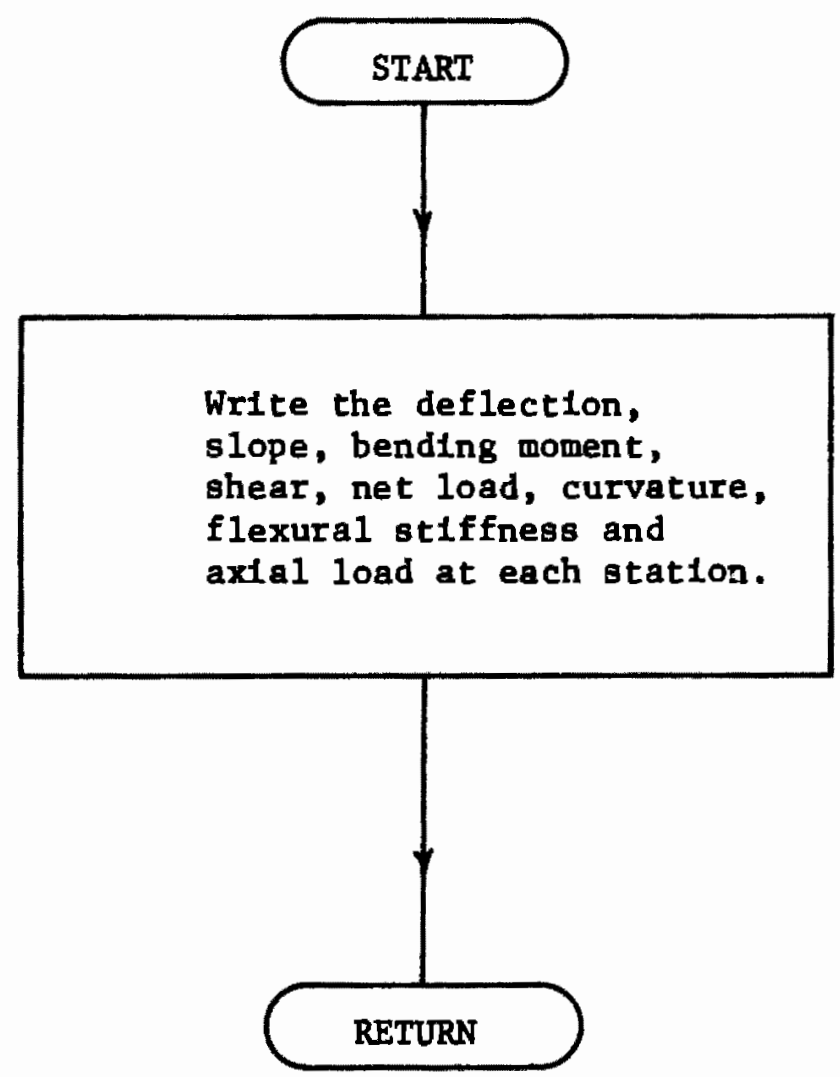


FLOW DIAGRAM - SUBROUTINE LDINC

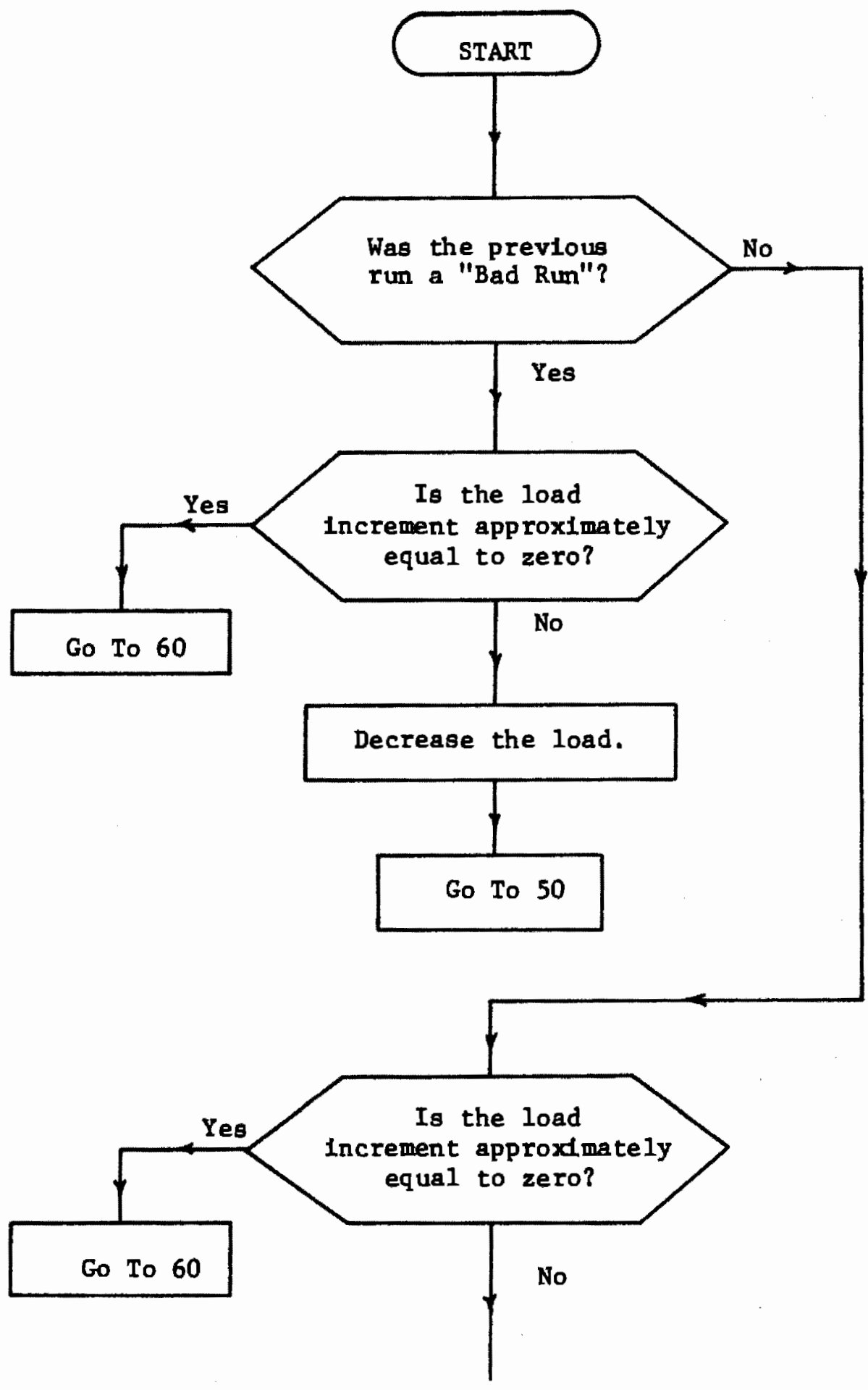



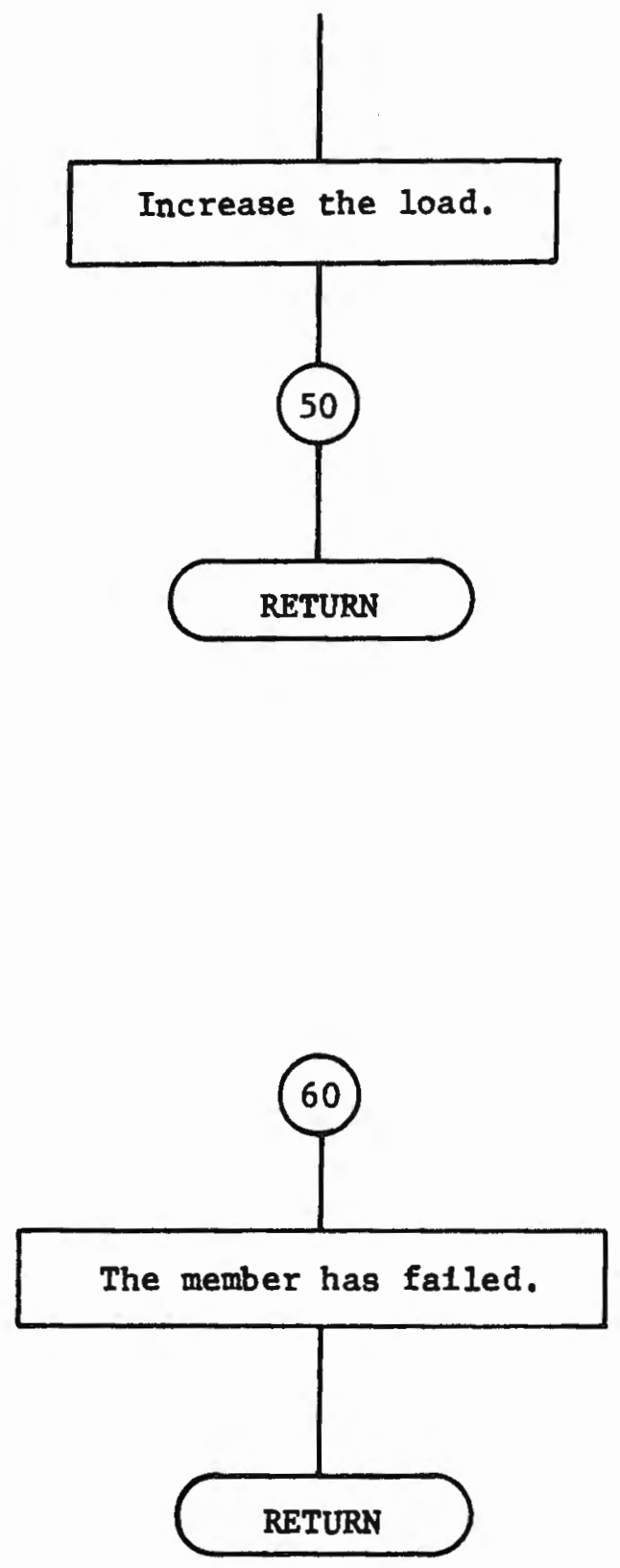


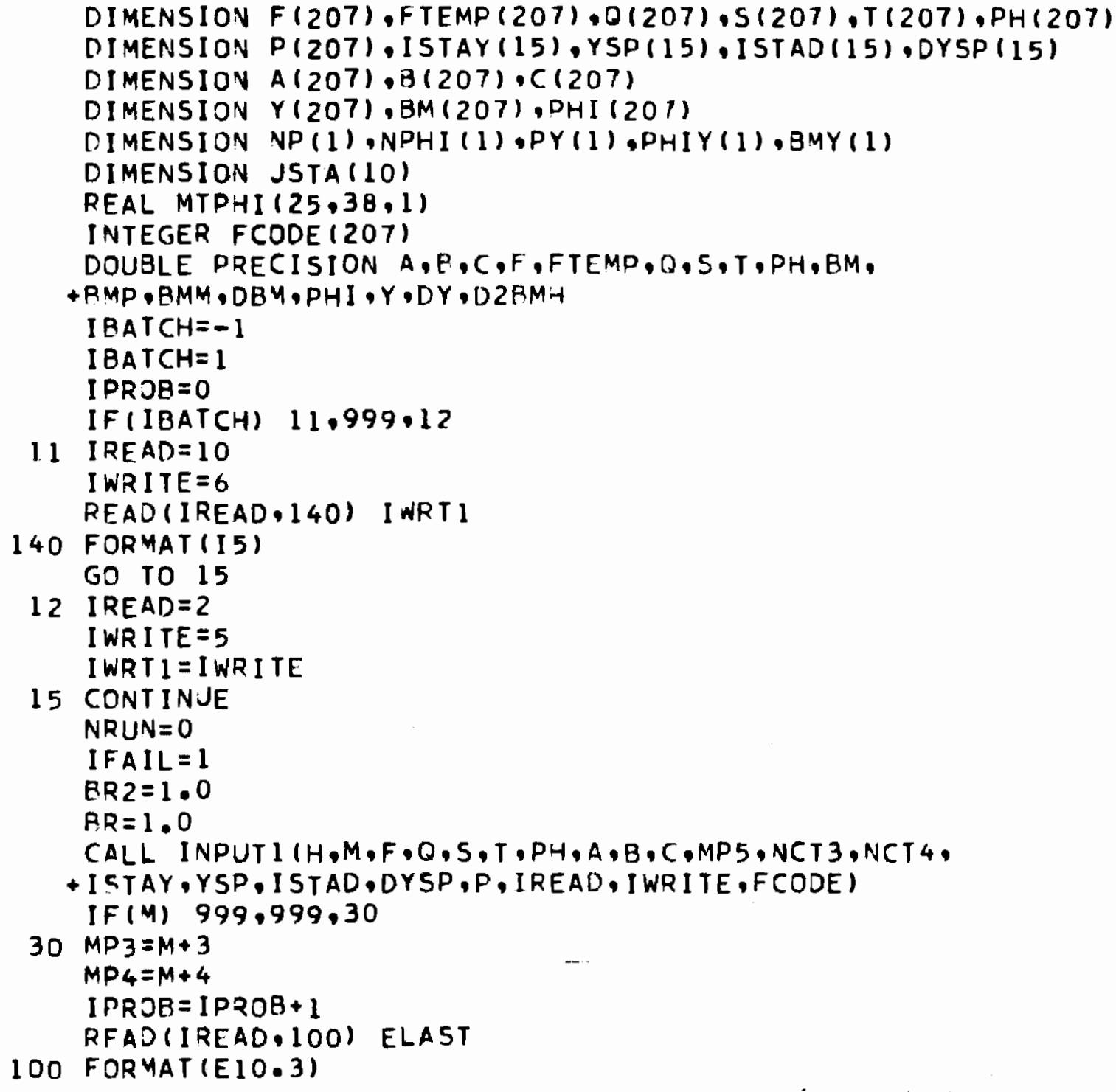




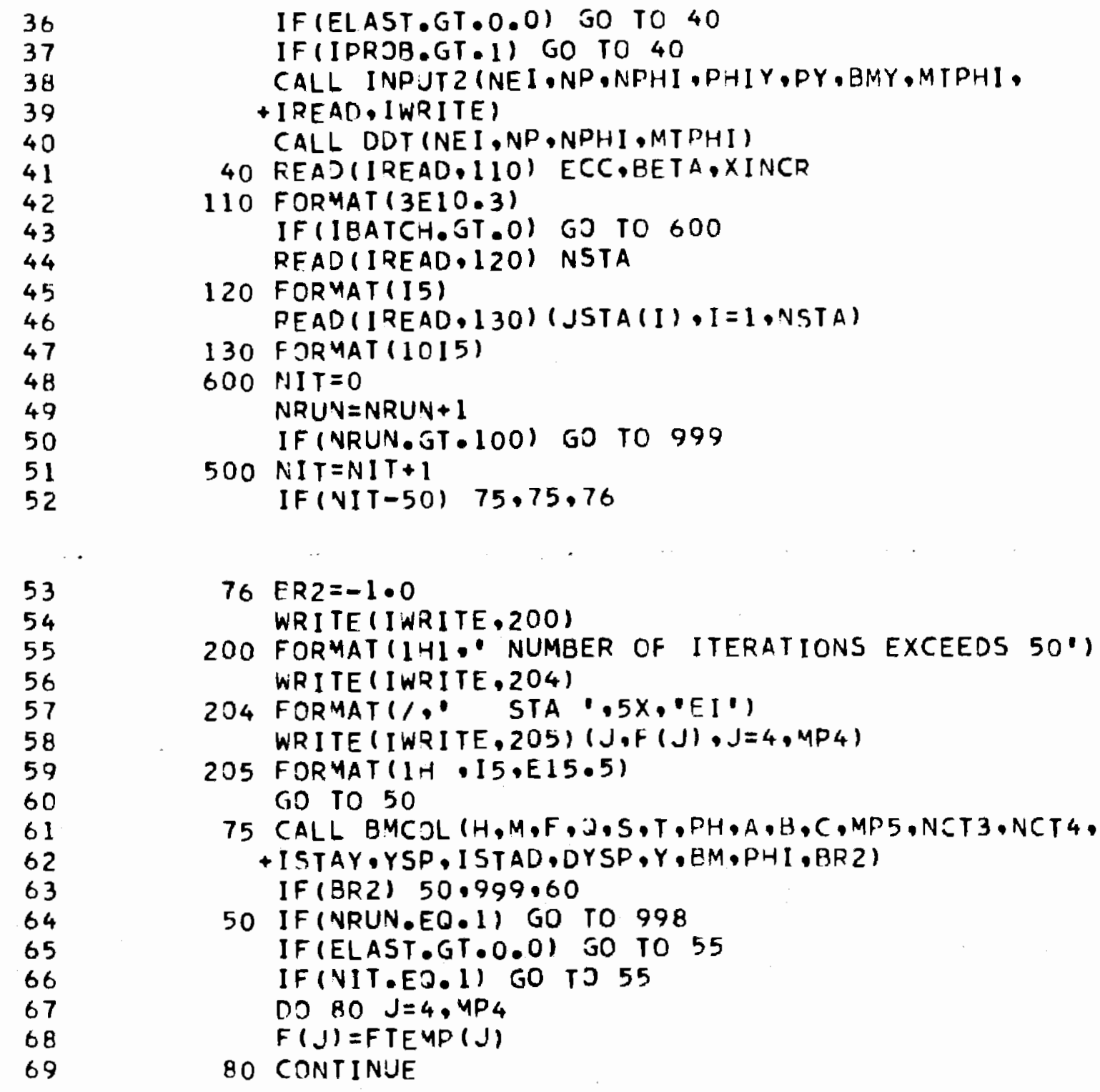




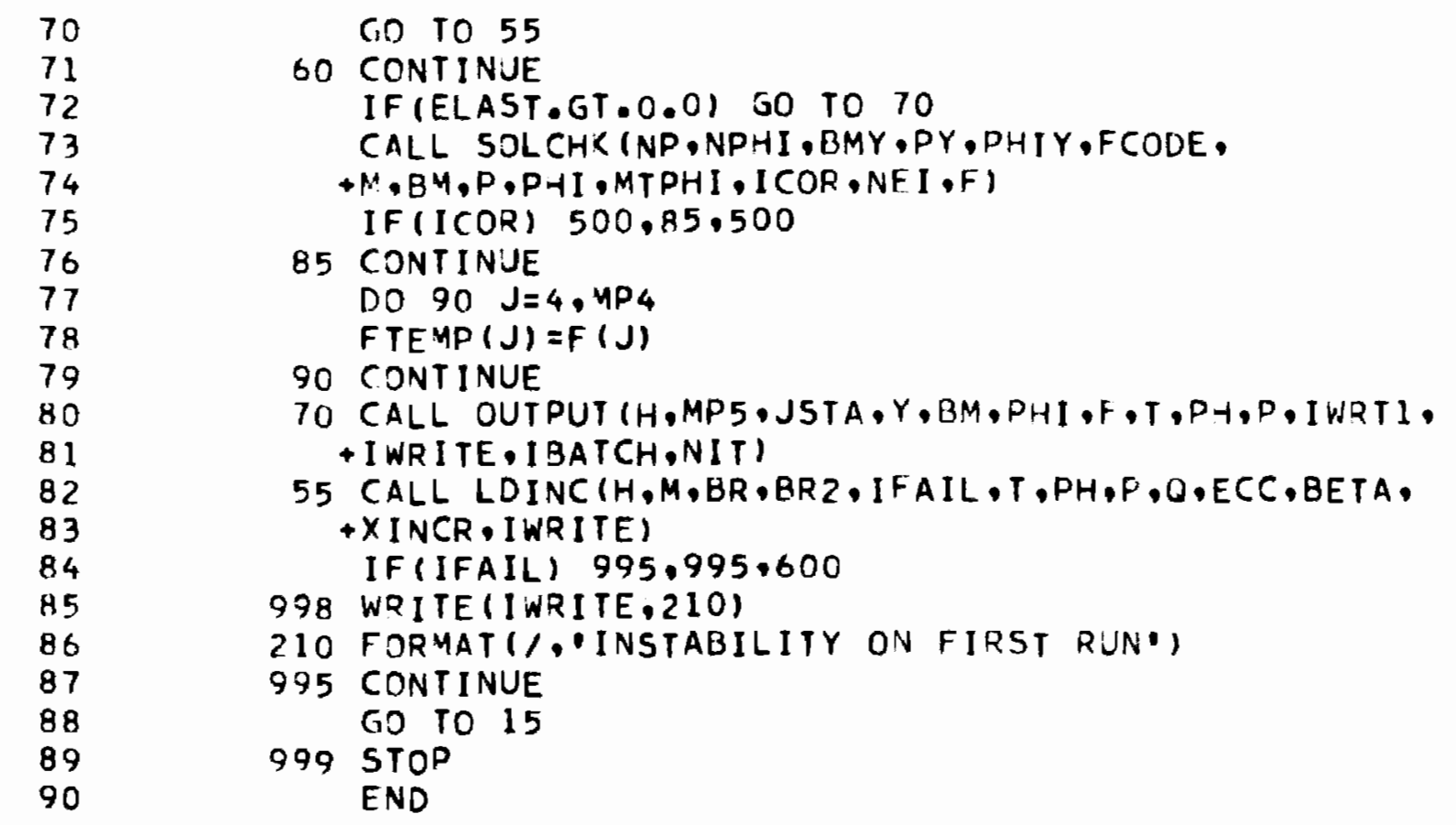


SUBROUTINE INPUT I $(H, M, F, O, S, T, P H, A, B, C, Y P 5, N C T 3, N C T 4$,

+ I STAY, YSP, I STAD, DYSP,P, IREAD, IWRITE, FCODE)

DIMENSION $F(207), 2(207), S(207), T(207), P-1(207)$, ISTAY(15)

DIMENSION YSP $(15)$, ISTAD $(15)$,DYSP $(15), A(207) \cdot B(207)$

DIMENSION P(207)

DIMENSION $C(207)$

INTEGER FCODE (207)

DOUBLE PRECISION A,E,C.F.J.S,T,PH

REAJ (IREAD, IOI)

WRITE (IWRITE, 104)

104 FOR YAT (IHI)

WR I TF ( IWRI TE, 101$)$

101 FORMAT I BOH

$+$

READ(IREAD, I) NCT2,NCT3.NCT4,M,H

IF (H) 999.999 .102

1 FORMAT $(4 I 5, E 10.3)$

2 FORMAT $(215,6 E 10.3,15)$

4 FORMAT $/ / / 3 O H$ TARLE 1 - CONTROL DATA //

$+\quad 3 O H$

$+3 \mathrm{OH}$

$+\quad 30 \mathrm{H}$

3OH

103 FORMATI $30 \mathrm{H}$

5 FORMATI// $49 \mathrm{H}$

$+63 H$ STA. THRU

+61 P

6 FORMAT $/ /$, 36H

$+\quad 22 \mathrm{H}$

7 FORMAT $15 X, 14$.

8 FOR MAT $(/ / 37 \mathrm{H}$

$+$

$24 \mathrm{H}$

NUM INCREMENTS $M=15.1$

I NCREMENT LGT' $H=E 10.3,1$

NUM CARDS TABLE $2=15,1$

NJM CARDS TABLE $3=15$,

NJM CARDS TABLE $4=15,11$

TABLF 2. DATA ADDED THRU SPECIFIED INTERVAL /

$F$

$Q \quad S$

$S T$

$R$

TABLE 3. SPFCIFIED DEFLECTIONS //

$4 \times, G E 10.31$

102 WRITE(INRITE,4) M.H,NCT2,NCT3

TABLE 4. SPECIFIED SLJPE VALUES //

WRITE (IWRITE,103) NCT4

$M P 5=M+5$ 


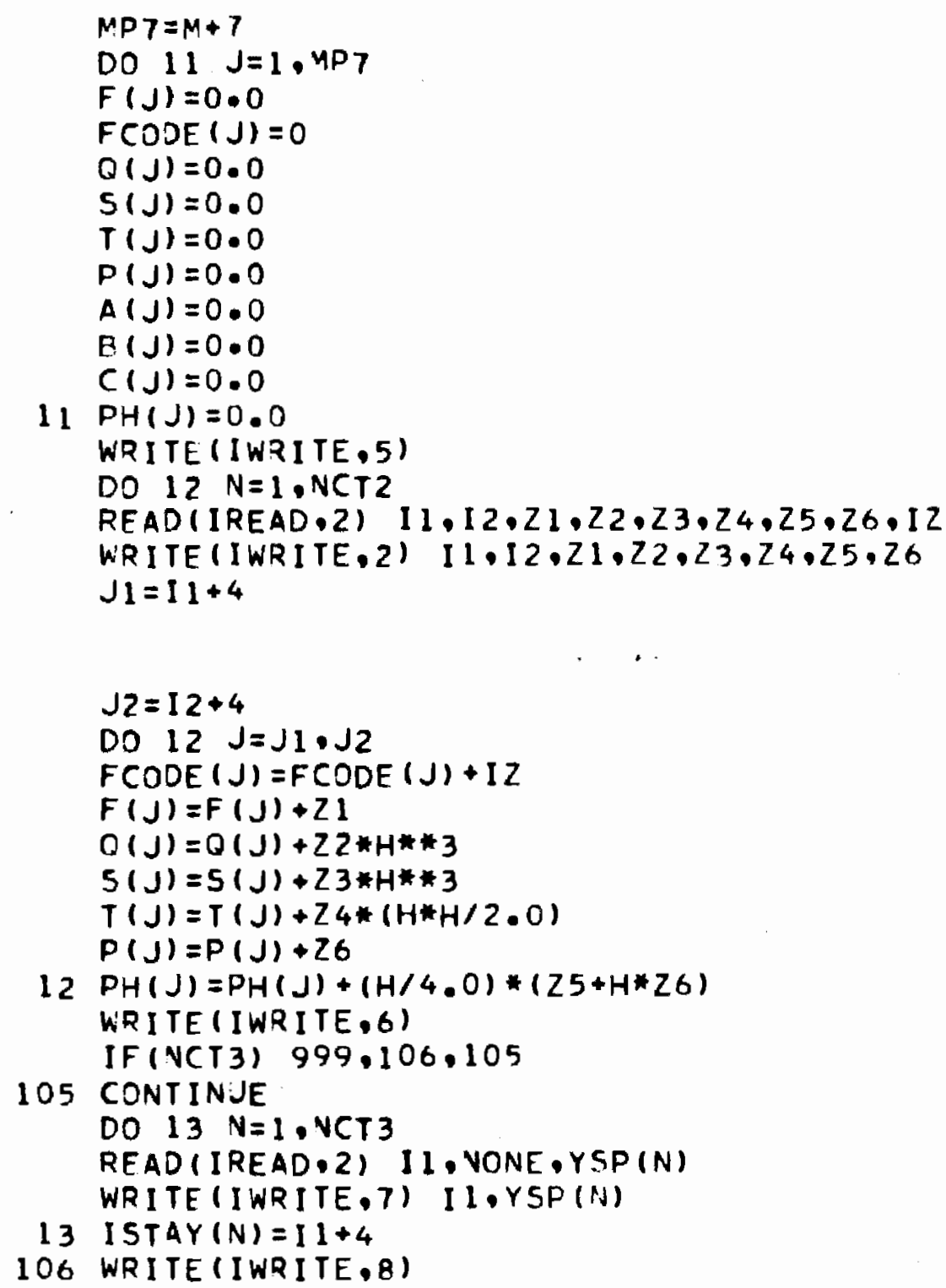




$\begin{array}{ll}70 & \text { IFINCT4) } 999,108,107 \\ 71 & 107 \text { CONTINUE } \\ 72 & \text { DO I4 N=1,NCT4 } \\ 73 & \text { READ IREAD,2) II, NONF, DYSP(N) } \\ 74 & \text { WRITE(IWRITE,7) I1,DYSP (N) } \\ 75 & 14 \text { ISTAD }(N)=I 1+4 \\ 76 & 108 \text { CONTINUE } \\ 77 & 999 \text { RETURN } \\ 78 & \text { END }\end{array}$


SUBROUTINE INPUT 2 (NEI,NP,NPHI,PHIY,PY,BYY,MTPHI ,

+ IREAD, IWR I TE)

DIMENSION NP(1), NPHI (1),PY (1),PHIY (1),BMY (1)

REAL MTPHI $(25,38,1)$

READ(IREAD, 100$)$ NEI

100 FORMAT (I5)

WR I TE (IWRITE,110) NE I

110 FORMAT $(1 \mathrm{HI}, 43$ HNUMBER OF STIFFNESS VALJES IN THIS PROBLEM=, I 2$)$ DO $10 K=1$, NEI

READ (IREAD, 120) ID1,ID2,ID3,ID4

120 FORMAT (415)

WR ITE (IWR ITE, 130) ID1,ID2,ID3,ID4

130 FORMAT $(1, \cdot$ DATE $=1,12,1,1,12,1,, 12,1, \cdot$ TIME $=1,15)$

READ (IREAD, 140) PY $(K), P H I Y(K), B M Y(K)$

140 FORMAT (3E15.6)

WRITE (IWRITE, 150) PY $(K), P H I Y(K), B M Y(K)$

150 FORMAT $(1.25 \mathrm{H}$ AXIAL LOAD (PY) $=, E 12.5 .1$,

$+\quad 25 \mathrm{H}$ CURVATURE (PHIY) $=.012 .5 .1$,

$+25 \mathrm{H}$ MOMENT (BMY) $=, E(2.5)$

READ (IREAD, 160) NP(K),NPHI(K)

160 FORMAT (215)

$N P K=N P(K)$

$N P K 3=N P K * 3$

NPHIK $=$ NPHI $(K)$

READ (IREAD, 180) (MTPHI $(I, I, K), I=1, N P K)$

180 FORMAT (6E10.3,/.6E10.3)

DO $15 \mathrm{I}=1$, NPHIK

READ (IREAD, 190) MTPHI $(I, 2, K),(M T P H I(I, J, K), J=3, N P K 3,3)$

190 FORMAT (7E10.4,/,6E10.4)

15 CONTINUE WR ITE (IWRITE, 200)

200 FOR MAT $(/ /, 28$ HMOMENT-THRUST-CURVATURE DATA) WR ITE (IWR I TE, 210)

210 FORMAT $/ / / 0^{\circ * * * *}$ M/MY FOR A GIVEN COMBINATION OF P/PY AND PHI/PHI $+Y * * * *, 1 /, 0$ PHI/ $P / P Y=1,5(6 X, \cdot P / P Y=0))$ 
WR ITE (IWR ITE, 220 ) (MTPHI $(1,1, K), I=1, N P K)$ 220 FORMAT $(7 H$ PHIY, $2 X, F 5.2,5(6 X, F 5.2), 1$, $+7 H \quad * * 2 X, F 5.2,5(6 X, F 5.2))$

DO $40 \quad I=1$, NPHIK

WRITE (IWR ITE, 230) MTPHI $(I, 2, K),(M T P H I(I, J, K), J=3, N P K 3,3)$

230 FORMATI/,FG.2,2X,F7.4,5(4X,F 7.4$), /, 7 H$

40 CONTINUE

10 CONTINUE

RET JRN

END 


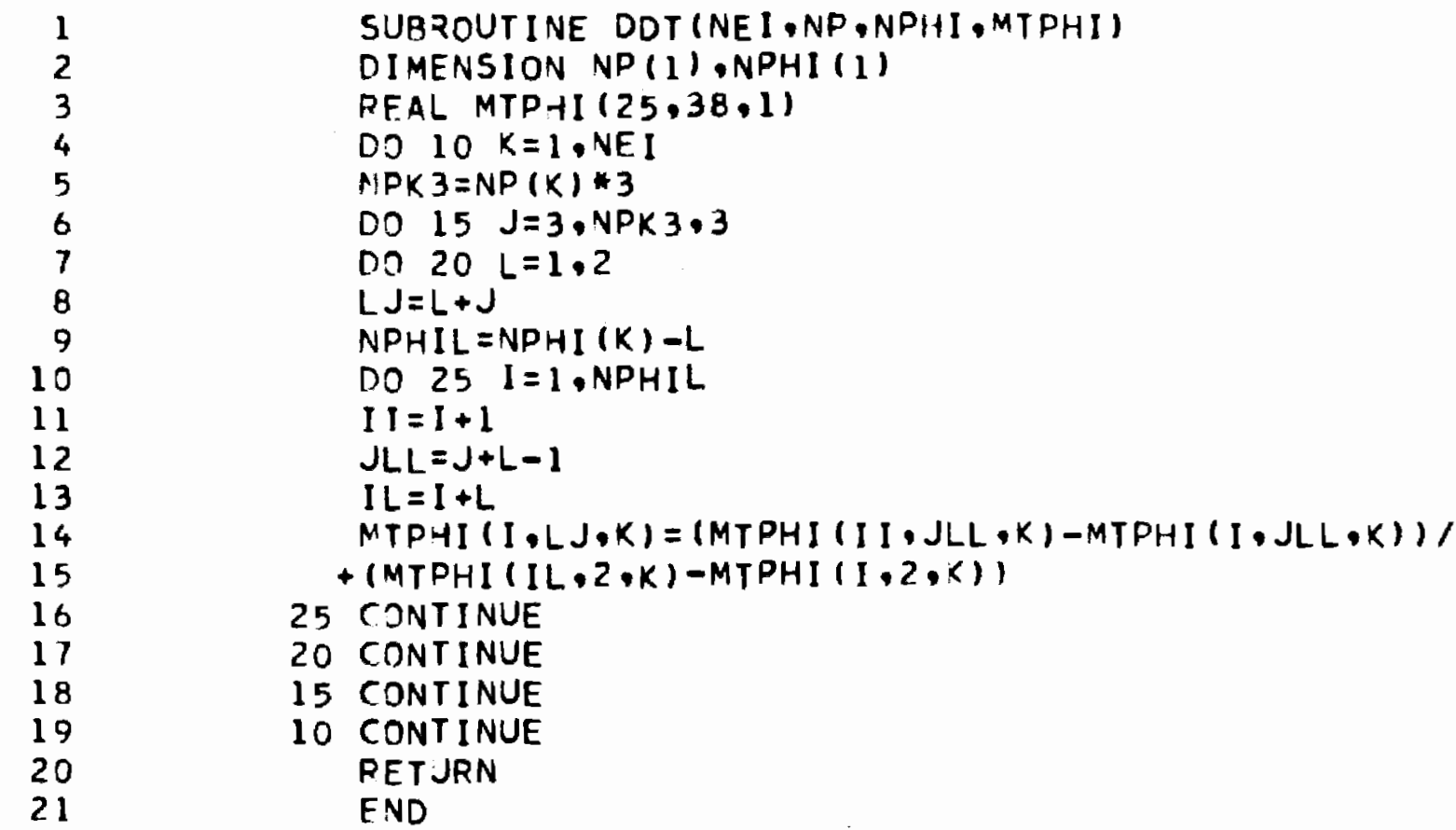


SUBROUTINE BMCOL $(H, M, F, Q, S, I, P H, A, B, C, M P 5, N C T 3, N C T 4$, + ISTAY,YSP, ISTAD,DYSP,Y,BM,PHI, BR2)

DIMENSION $F(207), 0(207), S(207), T(207), P H(207), A(207)$, $+R(207) \cdot C(207)$, ISTAY (15) , YSP (15), ISTAD (15), DYSP(15),

$+Y(207) \cdot B M(207) \cdot$ PHI (207)

DOUBLE PRECISION PHIJP,PM,BMP,BMM,PHI, GJ,EJ,DJ,A,B,C,

$+F, Q \cdot S, T, Y, P H, D R E V, Z D Y S P, A T E M P, B T E M P, C T E M P, D T E M P$

DOUBLE PRECISION BMJ

DO $50 \mathrm{~J}=3, \mathrm{MP5}$

$G J=F(J-1)-P H(J-1)$

$E J=\sigma J * B(J-2)-2 \cdot 0 *(F(J-1)+F(J))$

$D J=-1 \cdot 0 /(E J * B(J-1)+G J * C(J-2)+F(J-1)+4 \cdot 0 * F(J)$

$+F(J+1)+S(J)+P H(J-1)+P H(J+1))$

IF (DJ) $31,31,32$

32 RR2 $=-1 \cdot 0$

GO TO 35

$31 \quad B R 2=1.0$

$35 C(J)=D J *(F(J+1)-P+(J+1))$

$B(J)=D J *(E J * C(J-1)-2 \cdot 0 *(F(J)+F(J+1)))$

$A(J)=D J *(E J * A(J-1)+G J * A(J-2)-Q(J)+T(J-1)$

$+-T(J+1))$

IF (NCT3) $18 \cdot 18 \cdot 109$

109 CONTINUE

DO $16 \quad I=1, N C T 3$

$L=1$

IF(ISTAY (I)-J) $16,17,16$

16 CONTINUE

GO TO 18

$17 A(J)=Y S P(L)$

$B(J)=0.0$

$C(J)=0.0$

$B R 2=1.0$

18 CONTINJE

IF (NCI4) $15,15,110$

110 CONTINUE 
DO $19 \mathrm{I}=1, \mathrm{NCT} 4$

$$
L=I
$$

19 CONTINUE GO TO 21

$20 \triangle T E M P=A(J)$ RTEMP $=B(J)$ $C T E M P=C(\mathrm{~J})$ DTEMP $=D \mathrm{~J}$

21 CONTINUE

CO $22 I=1, N C T 4$

IF(ISTAD(I)-(J-1)) $22.23,22$

22 CONTINUE

GO TO 15

23 DREV $=1 \cdot 0 /(1 \cdot 0-(B T E M P * E(J-1)+C T E M P-1.0) * D J / D T E M P)$ IF (DREV) $41,42,42$

$41 B R 2=-1.0$

GO TO 999

42 P.R2 $=1.0$

$A(J)=D R E V *(A(J)+((H+H) * Z D Y S P+A T E M P+B T E M P *$

$+A(J-1)$ NDJ/DTEMP)

$B(J)=D R E V *(B(J)+(B T E M P * C(J-1)) * D J / D T E M P)$

$C(J)=D R E V * C(J)$

15 I $F(B R 2) \quad 999,999,50$

50 CONTINUE

DO $24 L=3$, YP5

$J=M+B-L$

$24 Y(J)=A(J)+B(J) * Y(J+1)+C(J) * Y(J+2)$ 


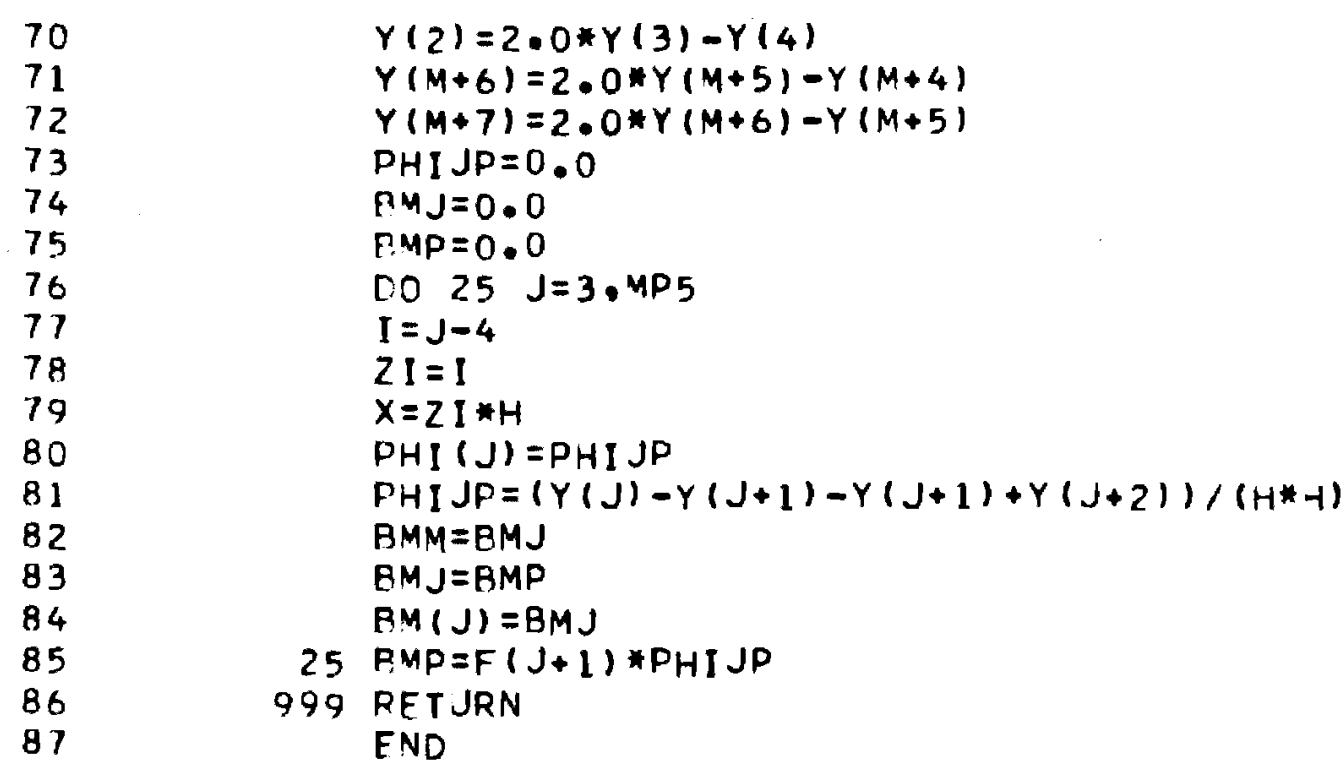

$Y(2)=2 \cdot 0 * Y(3)-Y(4)$

$Y(M+6)=2 \cdot 0 * Y(M+5)-Y(M+4)$

$Y(M+7)=2 \cdot 0 * Y(M+6)-Y(M+5)$

PHIJP $=0.0$

$\cap M J=0.0$

$P M P=0.0$

DO $25 \mathrm{~J}=3 . \mathrm{MP5}$

$I=J-4$

$Z I=I$

$X=Z I * H$

PHI $(J)=P H I J P$

$P H I J P=(Y(J)-Y(J+1)-Y(J+1)+Y(J+2)) /\left(H^{*}-1\right)$

$B M M=B M J$

$B M J=B M P$

$B M(J)=B M J$

$25 R M P=F(J+1) * P H I J P$

999 RETJRN

END 


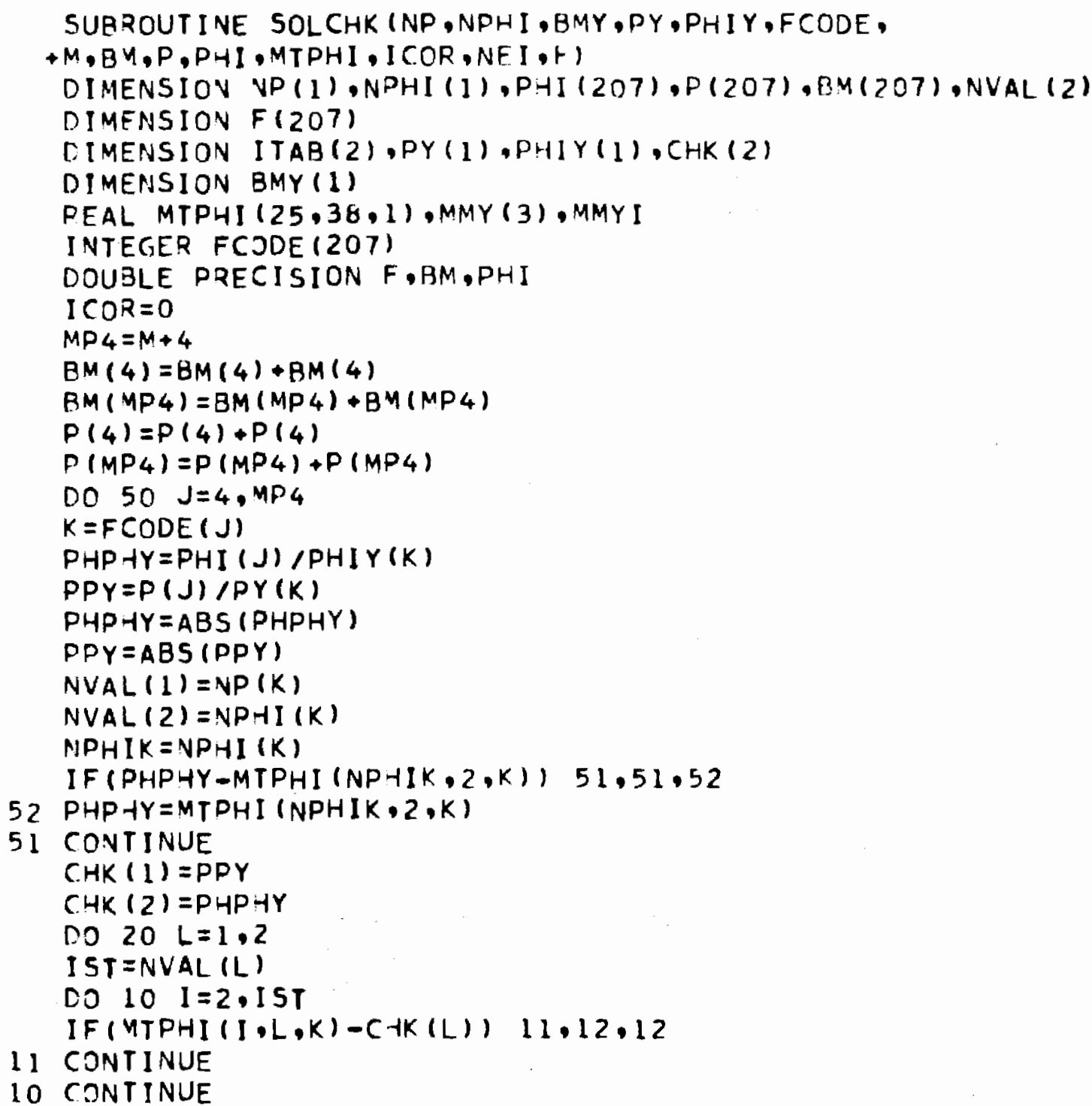




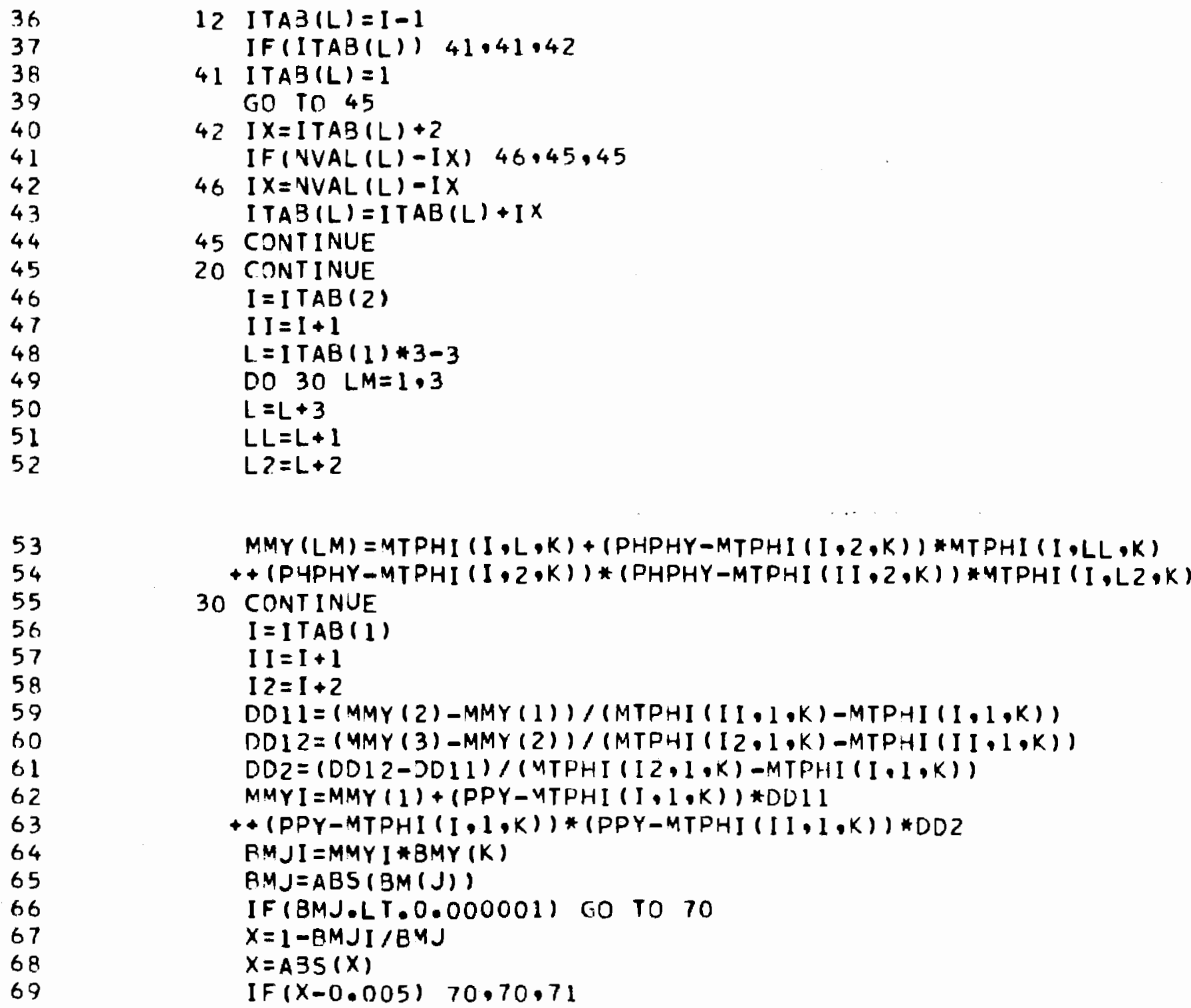

ITAB $(L)=I-1$ IF(ITAB(L)) $41,41,42$

$I X=I T A B(L)+2$

IF $($ NVAL $(L)-I X) \quad 46,45,45$

ITAB $T L)=I T A B(L)+I X$

45 CONTINUE

$L L=L+1$

MMY $(L M)=M T P H I(I, L, K)+(P H P H Y-M T P H I(I, 2, K)) * M T P H I(I, L L, K)$

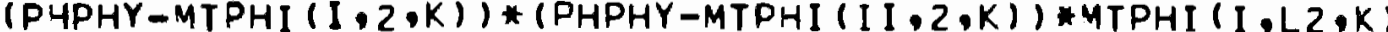

DDI $1=(M M Y(2)-M M Y(1)) /(M T P H I(I I, 1, K)-M T P H I(I, 1, K))$

$R M J I=M M Y I * B M Y(K$

IF (BMJ.LT.0.000001) GO TO 70

IF $(X-0.005) \quad 70,70,71$ 
70

71

72

73

74

75

76

77

78

$71 F(J)=F(J) * B M J I / B M J$ $1 C O R=I C O Q+1$

70 CONTINUE

50 CONTINUE

$R M(4)=B M(4) / 2.0$

$B M(M P 4)=B M(M P 4) / 2.0$

$P(4)=P(4) / 2.0$

$P(M P 4)=P(M P 4) / 2.0$

RET JRN

END 
SUBROUTINE OUTPUT $(H, M P 5, J 5 T A, Y, R M, P H I, F, T, P H, P, I W R T 1$, + IWR ITE, IBATCH,NIT I

DIMENSION J5TA(10),Y(207),F(207),T(207),PH(207),P(207)

DIMENSION BM(207), PHI (207)

DOUSLE PRECISION Y,BM,PHI,F,T,PH

IF (IBATCH) $11.999,12$

11 WRITE (IWRITE, 100) NIT

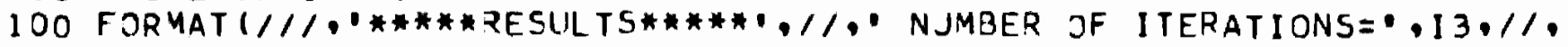

$+1 X_{0}, 5 T A \cdot, 3 X_{0} \cdot X^{\prime}, 6 X_{0} \cdot$ DEFL',

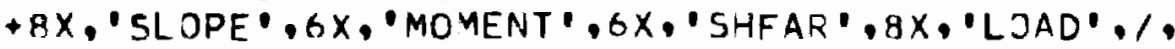

$+20 X,{ }^{\circ}$ CJRV', 6X, STIFFNES5',2X."AXIAL LJAD')

IF (IWRTI.LT.O) GO TO 30

12 WRITE (IWRT I,110) NIT

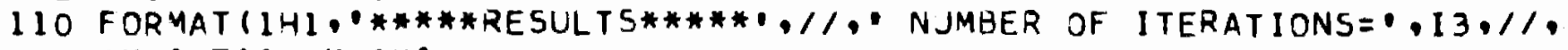
$+1 X_{0}, 5 T A \cdot, 3 X_{0}, 0 \times$,

$+6 x$, 'DEFL',8X,'SLOPE',6x, 'MOMENT',6X,'SHEAR',8X,'LOAD',9X,

$+\circ$ CURV'.6X,'STIFFNESS', $2 X^{\circ}$ 'AXIAL LUAD')

$30 \quad I I=1$

JSTA $4=J S T A(I I)+4$

SMDY $=0.0$

DO $25 \mathrm{~J}=3$, YP 5

$I=J-4$

$Z I=I$

$X=Z I * H$

$D Y=(-Y(J-1)+Y(J+1)) /(H+H)$

$S M D Y=5 M D Y+A B S(D Y)$

$C P M=(-B M(J-1)+B M(J+1)) /(H+H)$

$D R M=D B M-(T(J) * 2 \cdot) /(H * * 3)-P H(J) * 2 * *(Y(J+1)-Y(J-1)) /(H * * 3)$

$D 2 B M H=(B M(J-1)-B M(J)-B M(J)+B M(J+1)) / H$

IF (IWRTI.LT.O) GO TO 40

WRITE (IWRTI, 120) I, X,Y (J),DY,BM (J),DBM,D2BMH,PHI (J),F(J),P(J)

120 FOR MAT $([4, F 6,1,8 E 12,3)$

40 CDNTINUE

IF(IBATCH) $16.999 \cdot 25$

16 IF (J.EJ.JSTA4) GO TO 50 
GO TO 25

50 WRITE (IWRITE, 130$) 1, X, Y(J), D Y, B M(J), D B M, D 2 B M-, P H I(J), F(J), P(J)$

130 FORMAT $(1,14, F 6.1,5 E 12,3,1,16 \times, 3 E 12,3)$

$I I=I I+1$

J5TA $4=$ JSTA (II) +4

25 CONTINUE

IF (IBATCH.JT.O) GJ TO 60

IF (IWRTI.LT.O) 60 TO 60

WRI TE (I INRT 1,140) SMDY

140 FOR MAT (1, ' SUM OF SLOPE VALUES $=1$, E10.31

60 WRITE (IWRITE, 150) SMDY

150 FORMAT 11,0 SUM OF SLOPE VALUES $=1,010.31$

999 RFT JRN

END 
SUBROUTINE LDINCIH,M,BR,BR2, IFAIL,T,PH,P, J,FCC,BETA, $+X I N C R$, IWRITE)

DIMENSION T (207),PH(207),P(207), 2(207)

DOUBLE PRECISION PH,T,O

$M P 3=M+3$

$M P 4=M+4$

IF (BR2) $16,40,17$

16 WRITE (IWRITE, 100$) \quad P(5)$

100 FORMAT $(1$, 'BAD RUN …A AXIAL LOAD $=$,EIO.3)

$B R=0.5$

IF (ABS (XP)+ABS(XINCR).LT.0.000001) GO TJ 60

IF $(X P . L T .0 .000001)$ GO TO 25

$S T O P=A B S(X I N C R / X P)$

IF (STOP-0.005) 60.60 .25

$25 \times I N C R=A B S(\times I N C R) * B R$

GO TO 50

17 WR ITE (IWRITE, 110) P(5)

110 FORMAT $(/$, GOOD RUN ...... AXIAL LOAD $=\bullet, E 10.3)$

$B R=1.0$

$X P=A B S(P(5))$

IF (XP.LT.0.000001) GO TO 30

$S T O P=A B S(X I N C R / X P)$

IF (STOP-0.005) 60.60 .30

$30 \times I N C R=-1.0 * A B S(X I N C R) * B R$

50 CONTINUE

DO $20 \quad J=5, M P 3$

$\mathrm{PH}(J)=\mathrm{PH}(J)+(\mathrm{H} / 4 \cdot 0) *\left(H^{*} \times I N C R\right)$

$P(J)=P(J)+X I N C R$

20 CONTINUE

$P H(4)=P H(4)+(H / 4.0) *(H * X I N C R / 2.0)$

$P(4)=P(4)+X I N C R / 2.0$

$\mathrm{PH}(\mathrm{MP} 4)=\mathrm{PH}(4)$

$P(M P 4)=P(4)$

$Z 4=X I N C R * E C C$

$T(4)=T(4)+Z 4 *(H * H / 2.0)$ 
$T(M P 4)=T(4) * B E T A$

GO TO 40

60 IFAIL $=0$

WRITE (IWRITE, 120) P(5)

120 FORMAT $(/, \cdot$ ULTIMATE LOAD $=\bullet, \cdot E 10.3)$

40 RFT JRN

END 
MOMENT-THRUST-CURVATURE PROGRAM

DATA INPUT

Note: The last data card must assign the outside diameter a value of zero to stop the program.

Numbers at left indicate card colums.

A. Control Data; Cross Section and Material Properties. FORMAT (4I5, 4E15.5)

1-5 Actual stress-straln data used? $(+-$ Yes ; $-1=\mathrm{No})$

6-10 Residual stresses used? $(+1=$ Yes; $-1=\mathrm{No})$

11-15 Number of layers of elements. (Mnx. = 5)

16-20 Number of elements in $1 / 4$ circle of one layer. (The product of the last two numbers must not exceed 30. )

21-35 Outside diameter (in.)

36-50 Wa11 th1ckness (1n.)

51-65 Modulus of elast1city. (ks1)

66-80 Yleld stress. (ks1)

B. Date and T1me of Run

FORMAT (4I5)

$$
\text { 1-5 Month }
$$

6-10 Day

11-15 Year

16-20 T1me (001 - 2400) 
C. Control Data

FORMAT (2I5)
1-5 Number of $P / P Y$ values. (max. 12)
6-10 Number of PHI/PHIY values. $(\max .=25)$

D. Axial Load Values

FORMAT (6F10.5)

1-10 P/PY values (Always Positive)

$11-20$

21- 30

$31-40$

41-50

$51-60$

E. Curvature Values

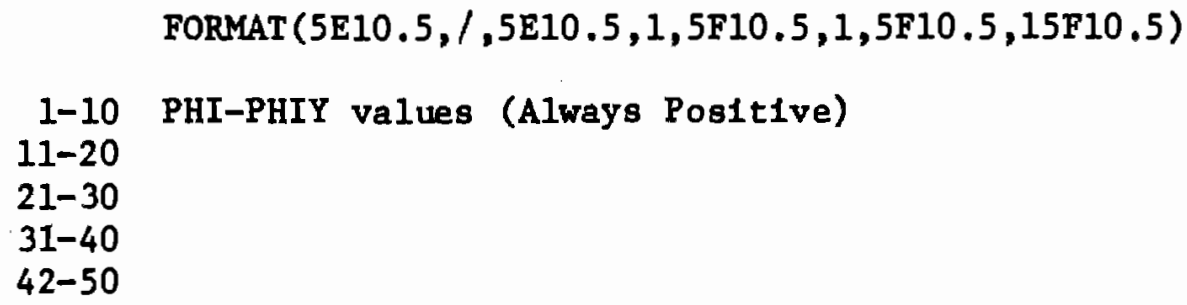

Note: The data for one problem is now complete if the actual stress-strain data and residual stresses are not used.

If both options are used, the stress-strain curve data is read in first.

F. Stress-Stra1n Curve Data

1. Control Card

FORMAT (I5)

1-5 Number of tabulated points on stress-strain curve.

2. For each tabulated point 


\section{FORMAT (2E15.5) \\ 1-15 Stress value \\ 16-30 Strain value}

G. Residual Stress Data

1. Time of Residual Stress Calculation

FORMAT (4I5)

1-5 Month

6-10 Day

11-15 Year

16-20 Time

2. For each element

FORMAT (2E15.5)

1-15 Stress value

16-30 Strain value 
FLOW DIAGRAM -

CALCULATION OF MOMENT-'THRUST-CURVATURE DATA

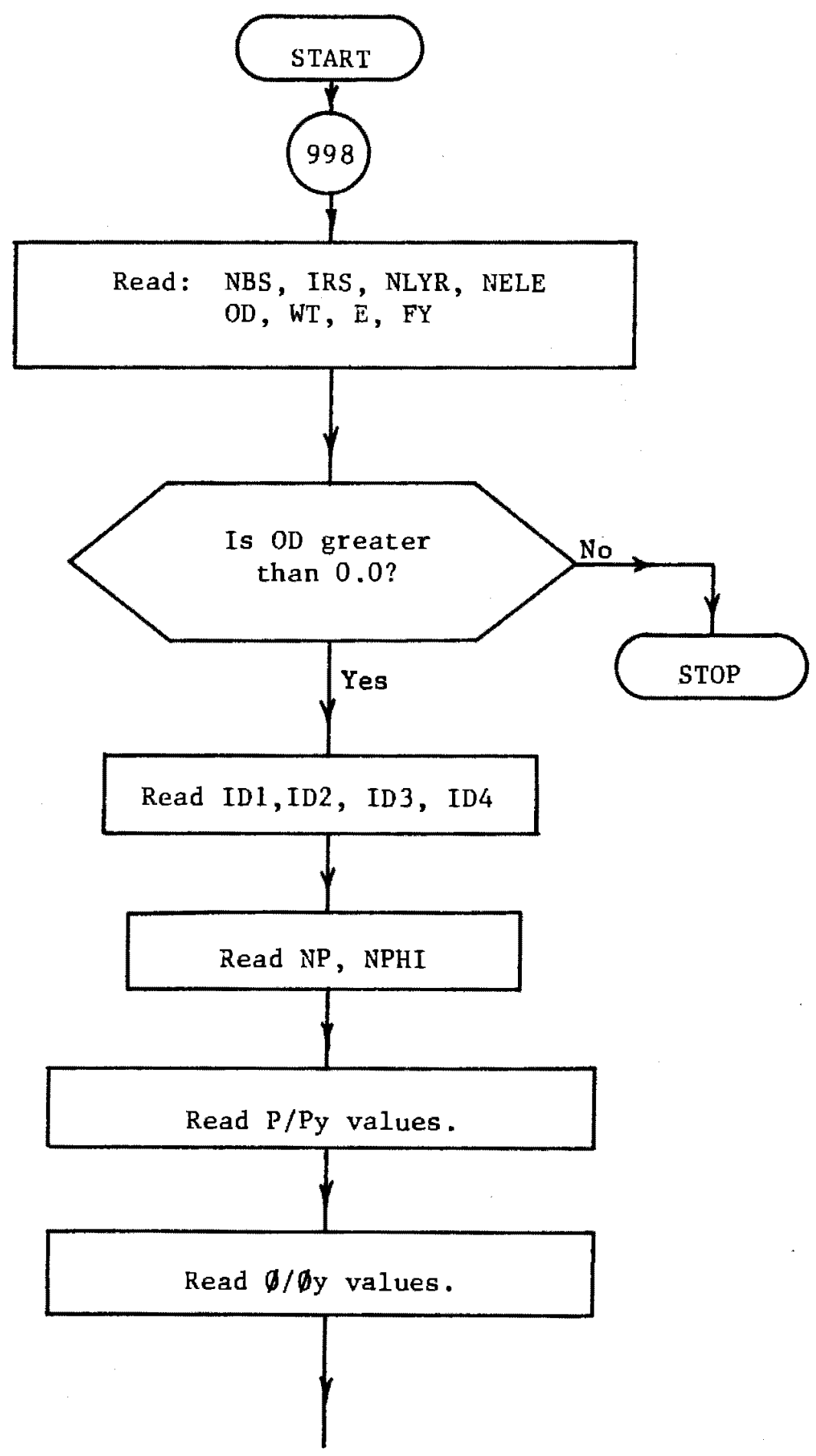




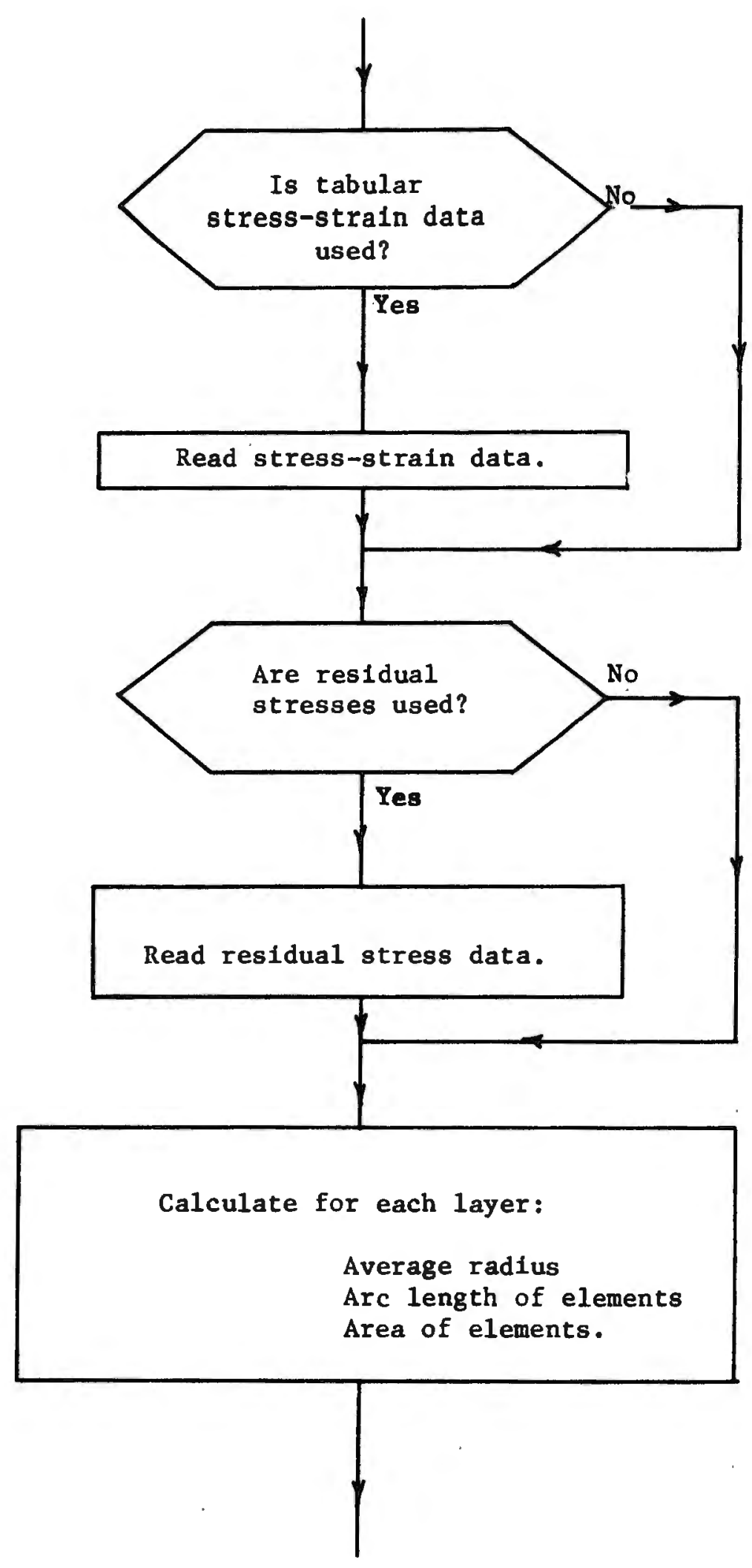




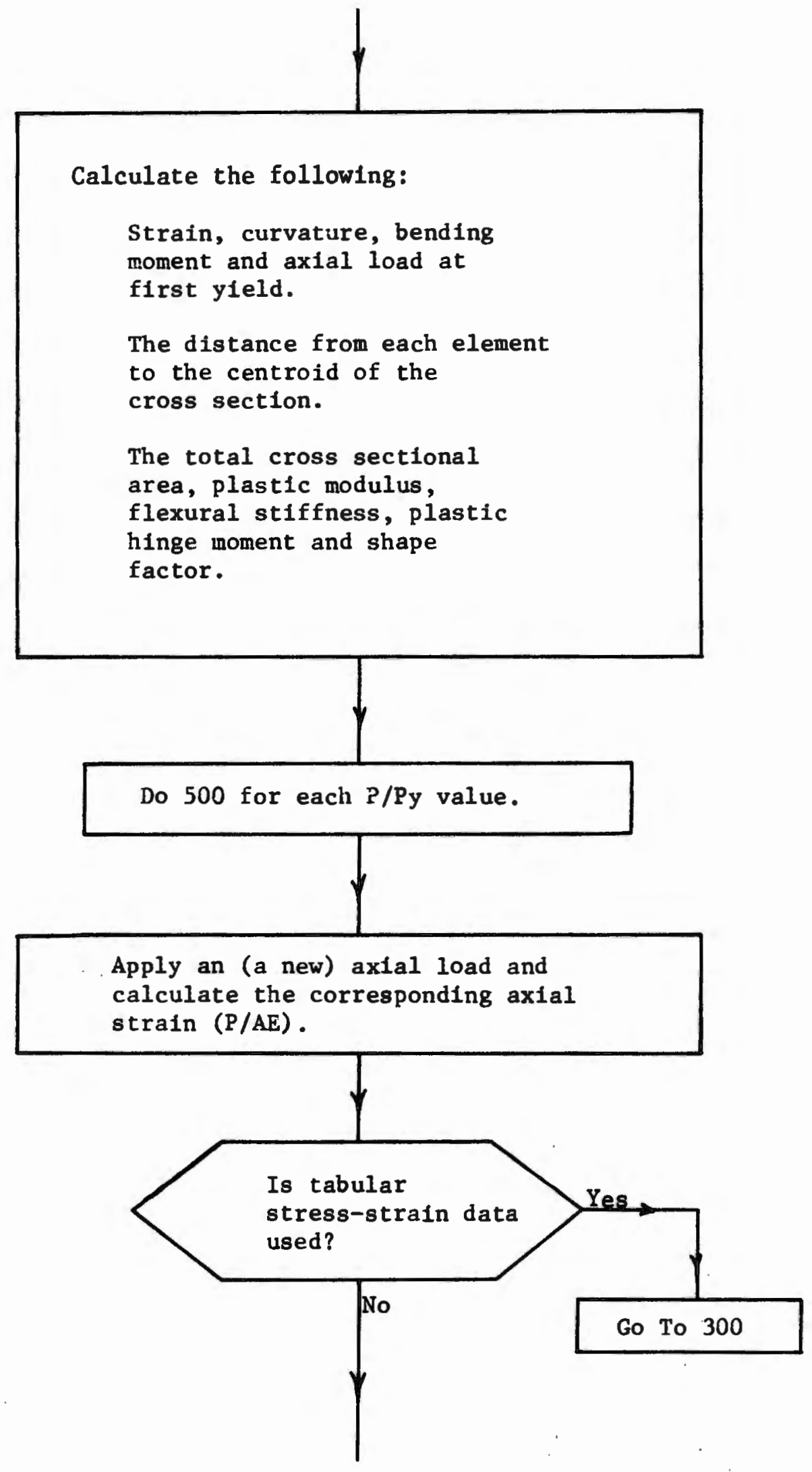



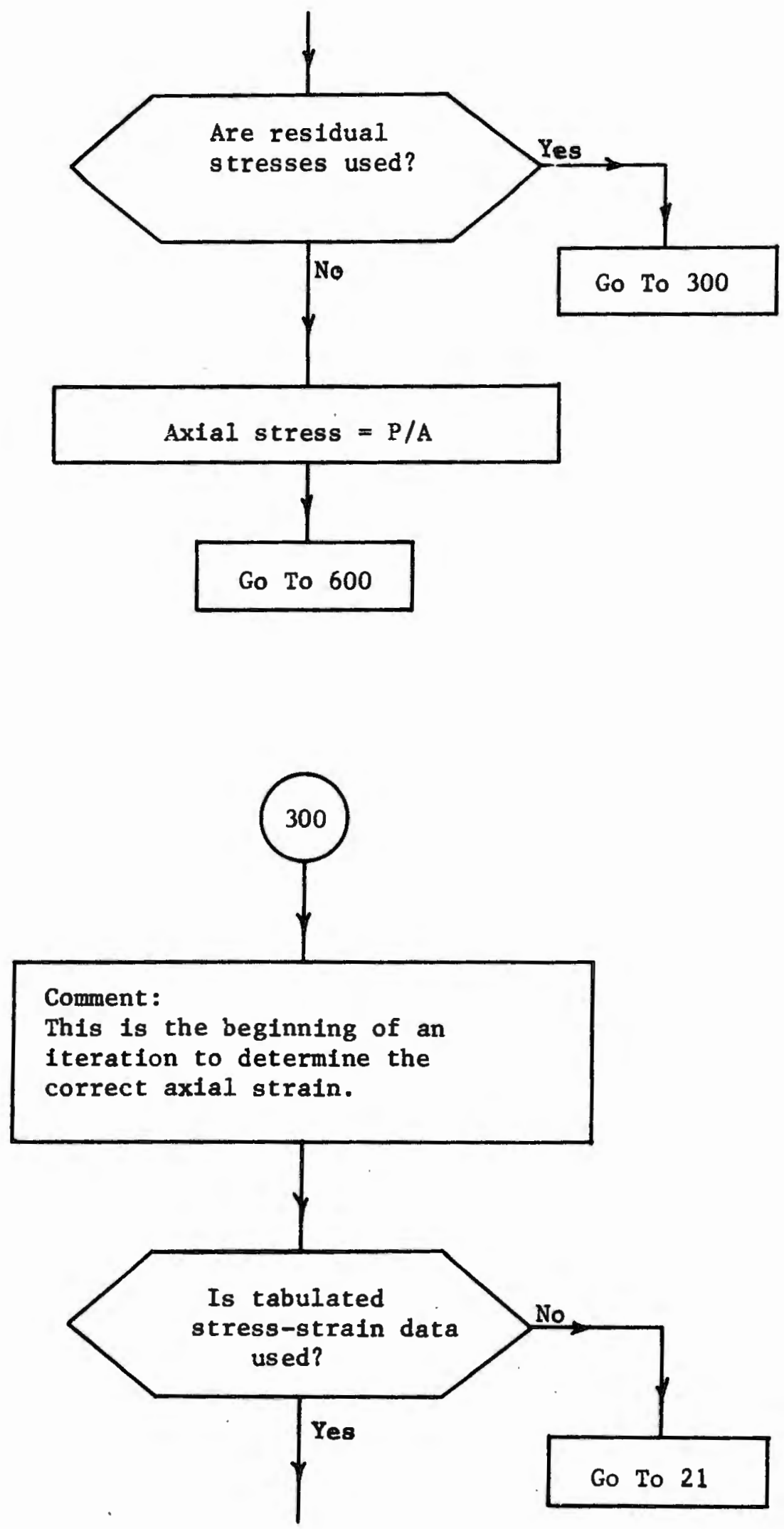

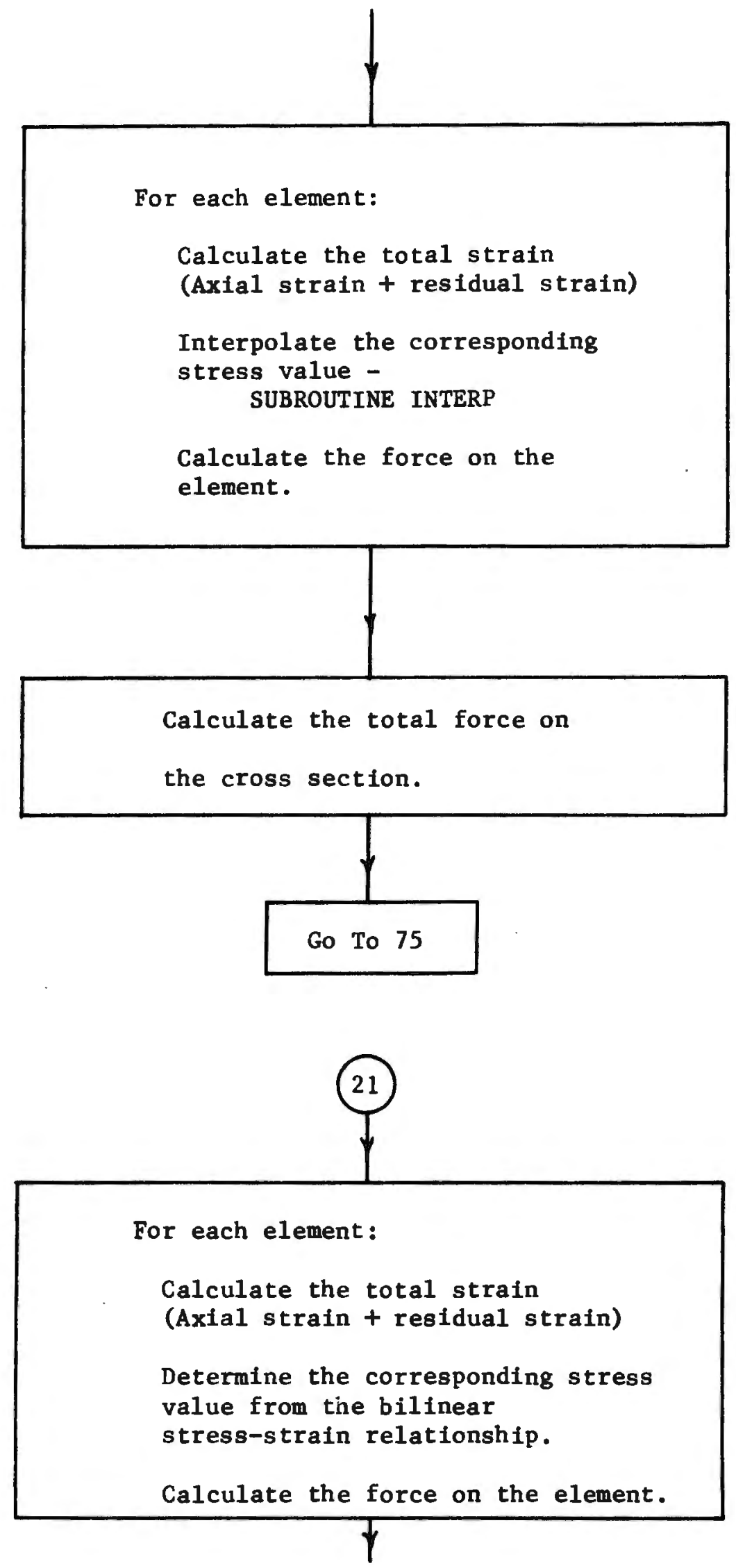


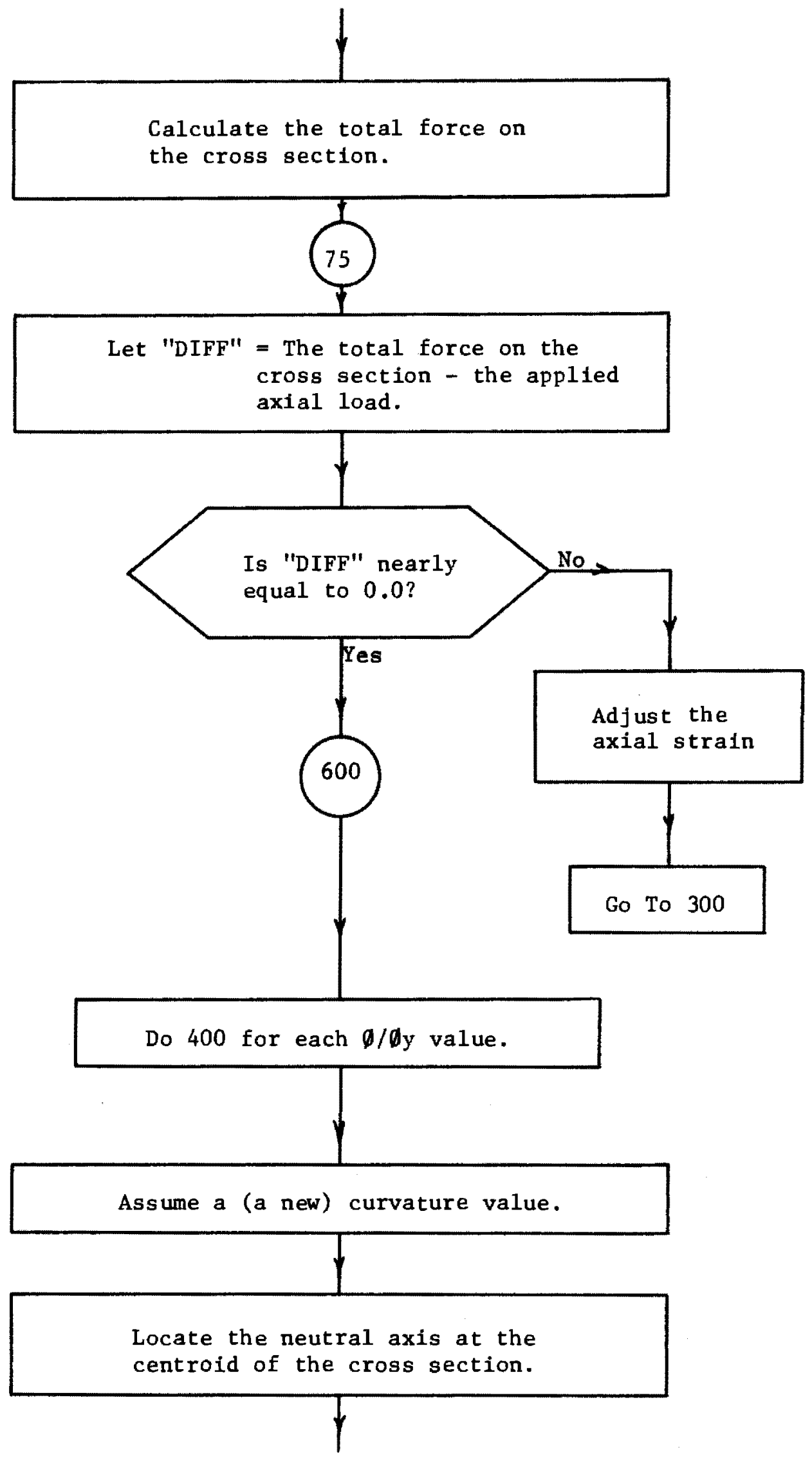




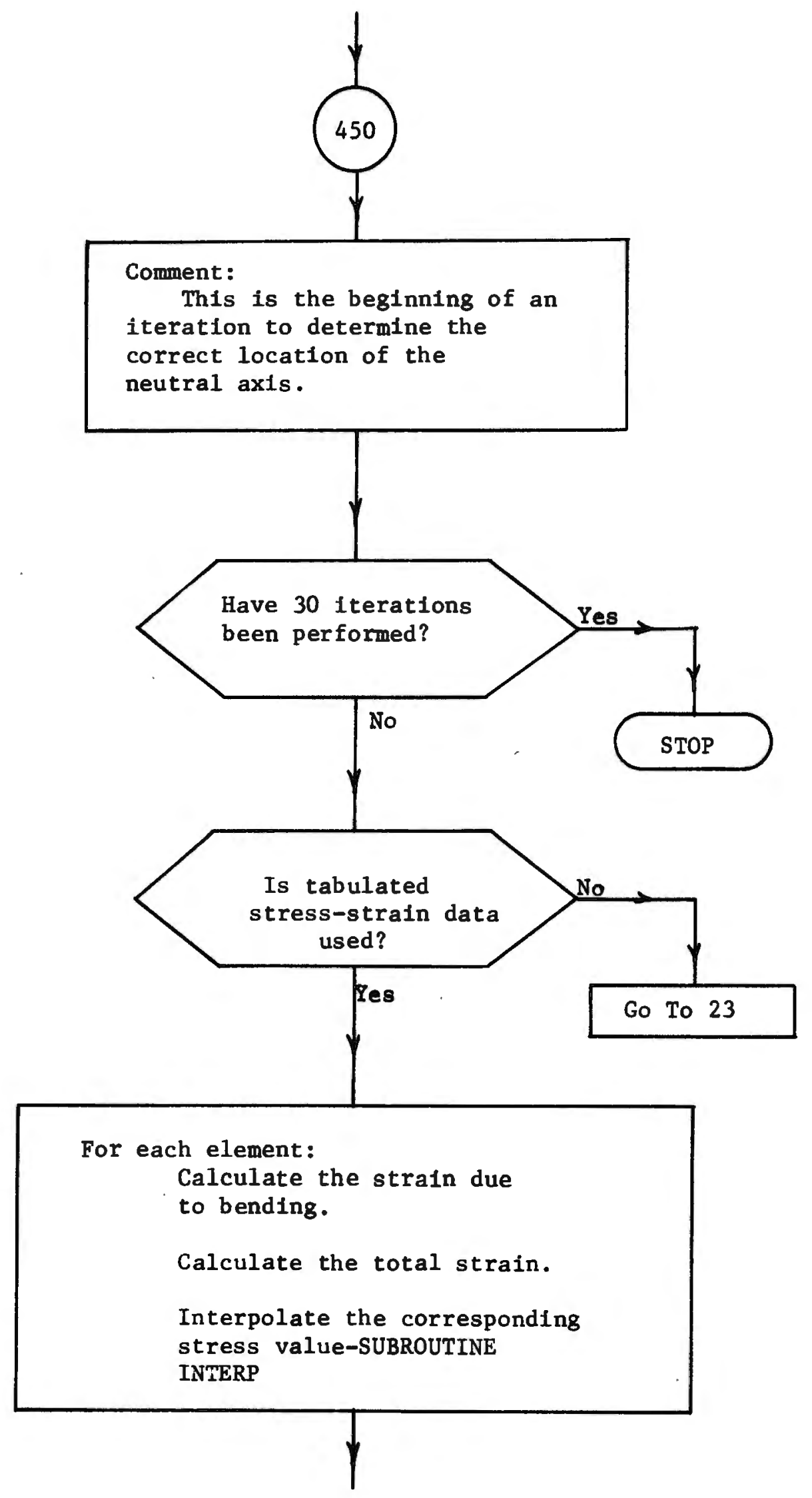



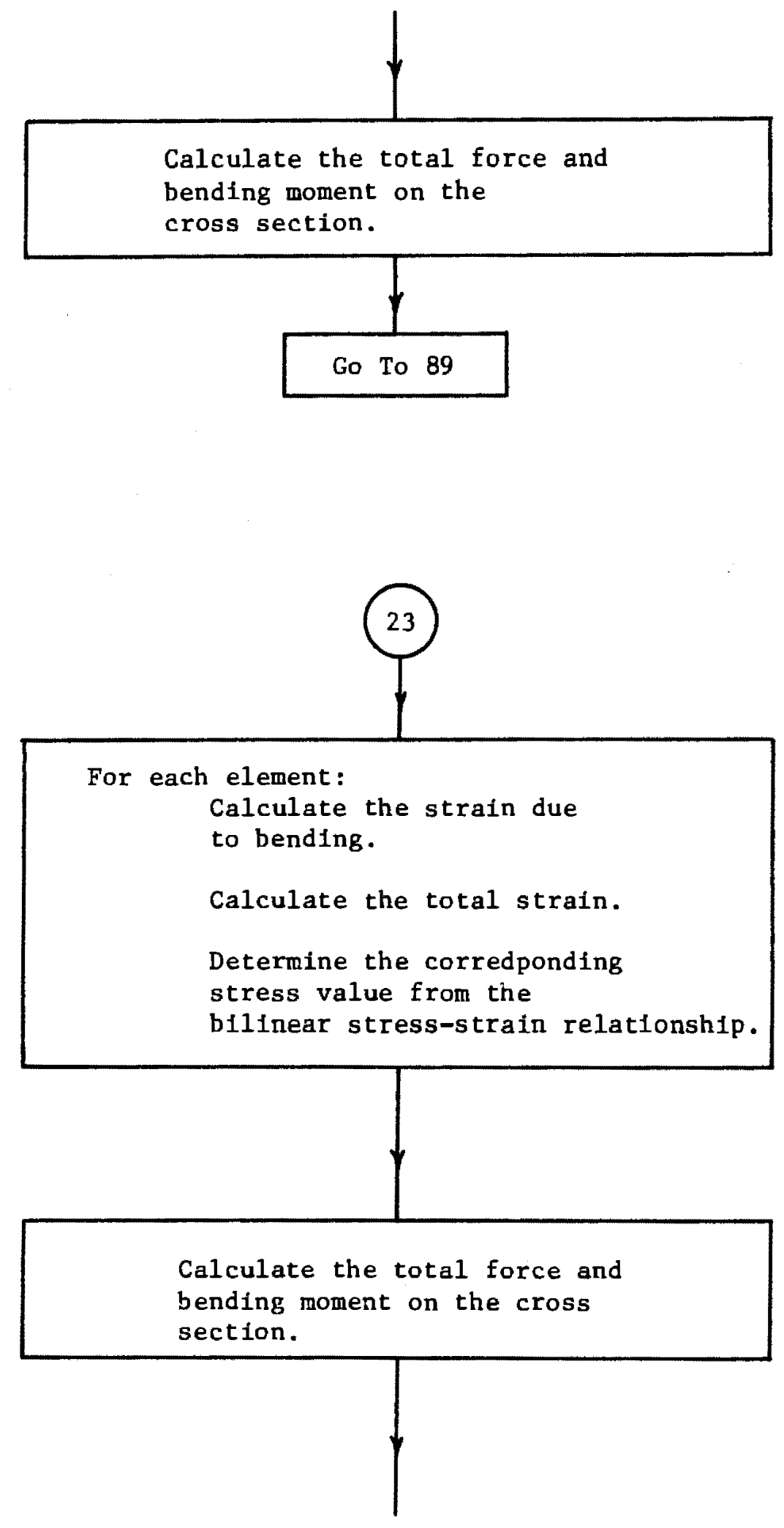


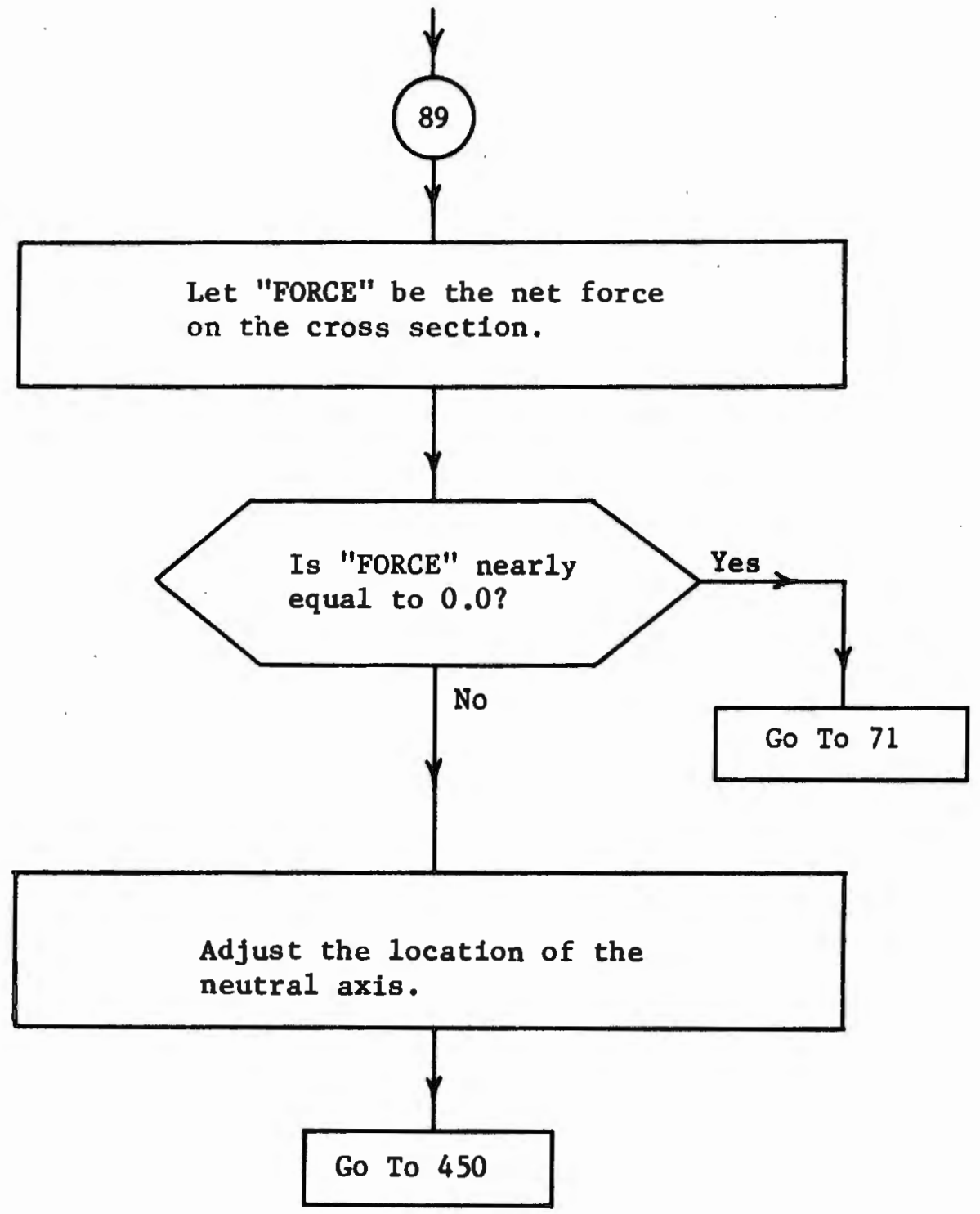




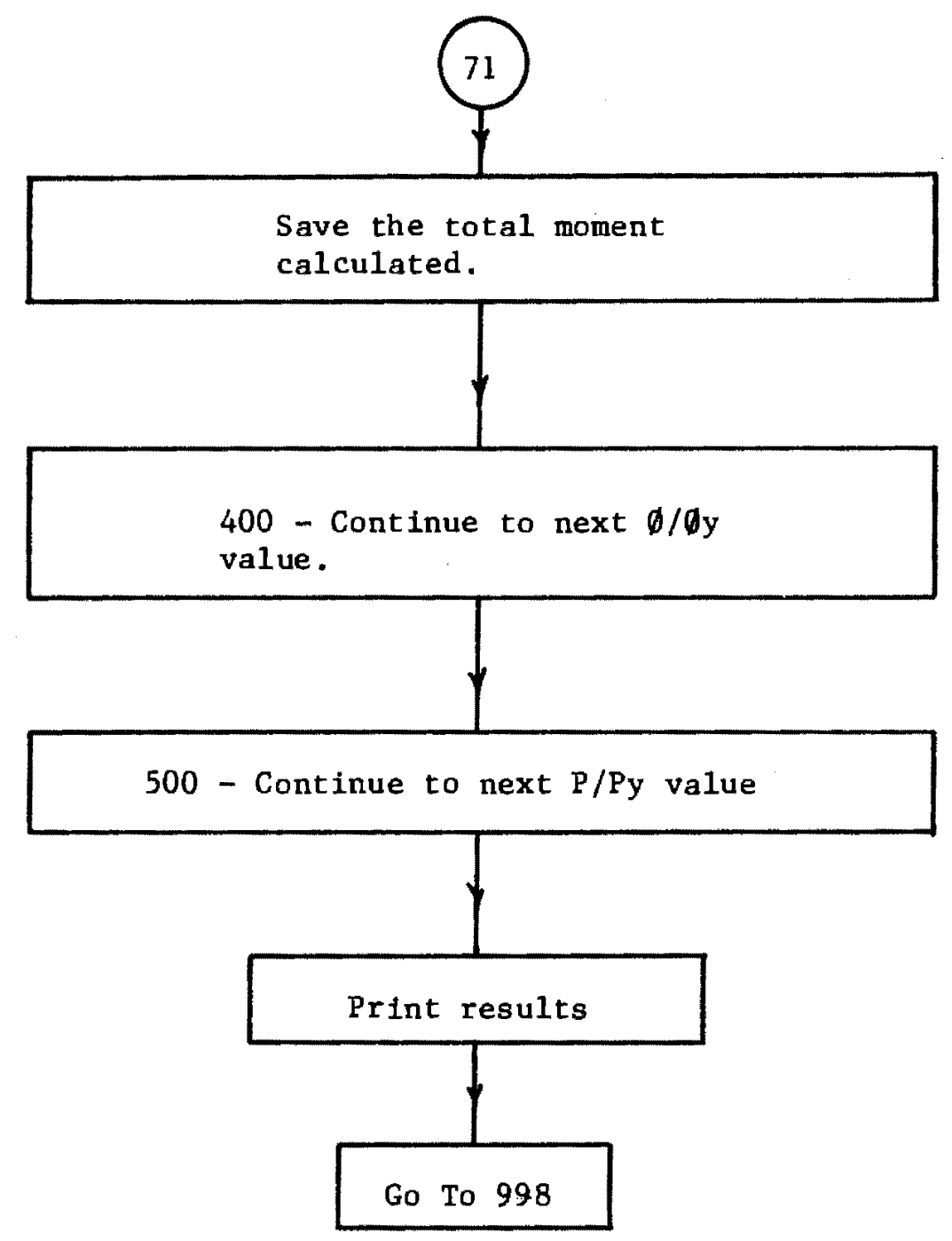




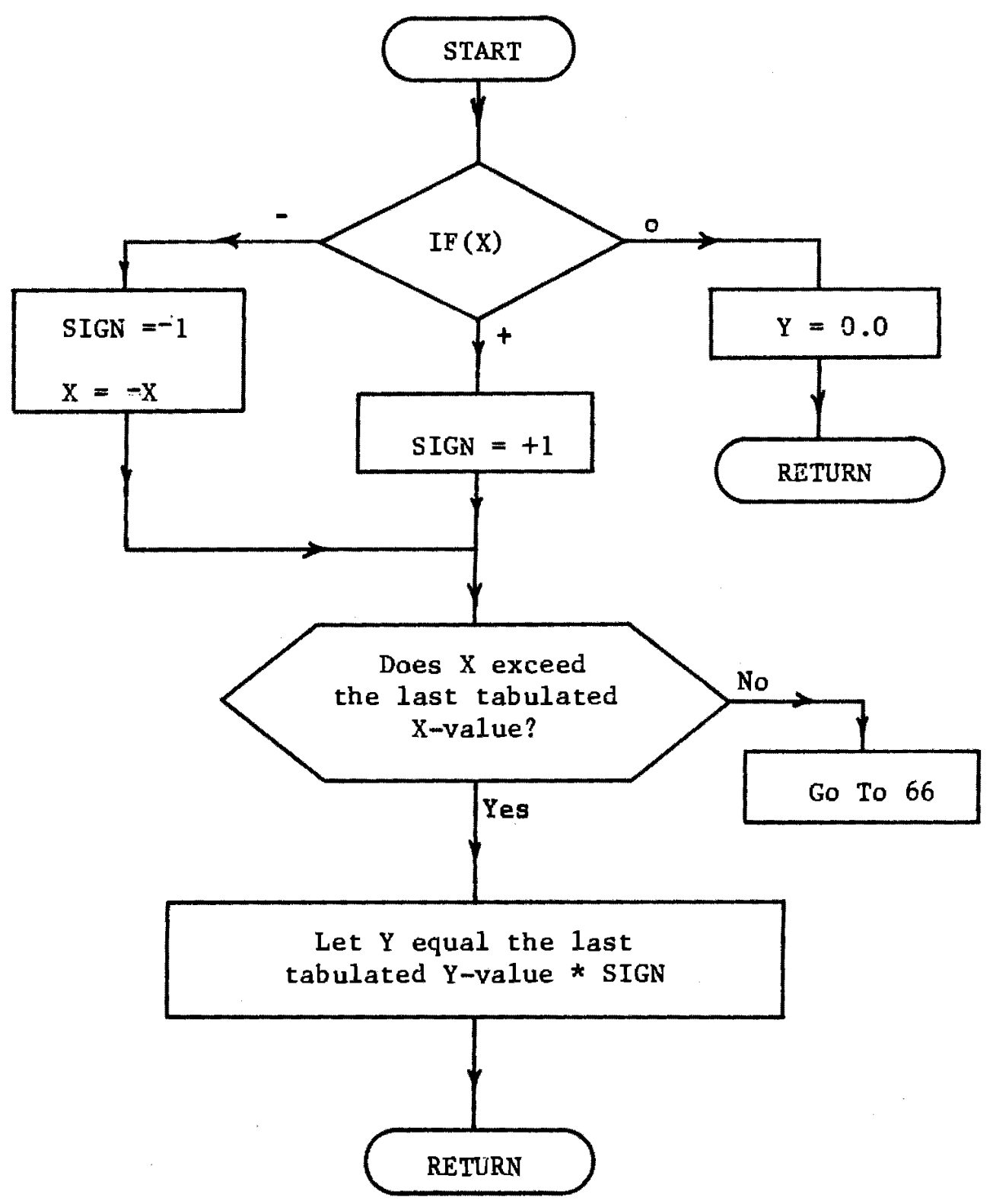




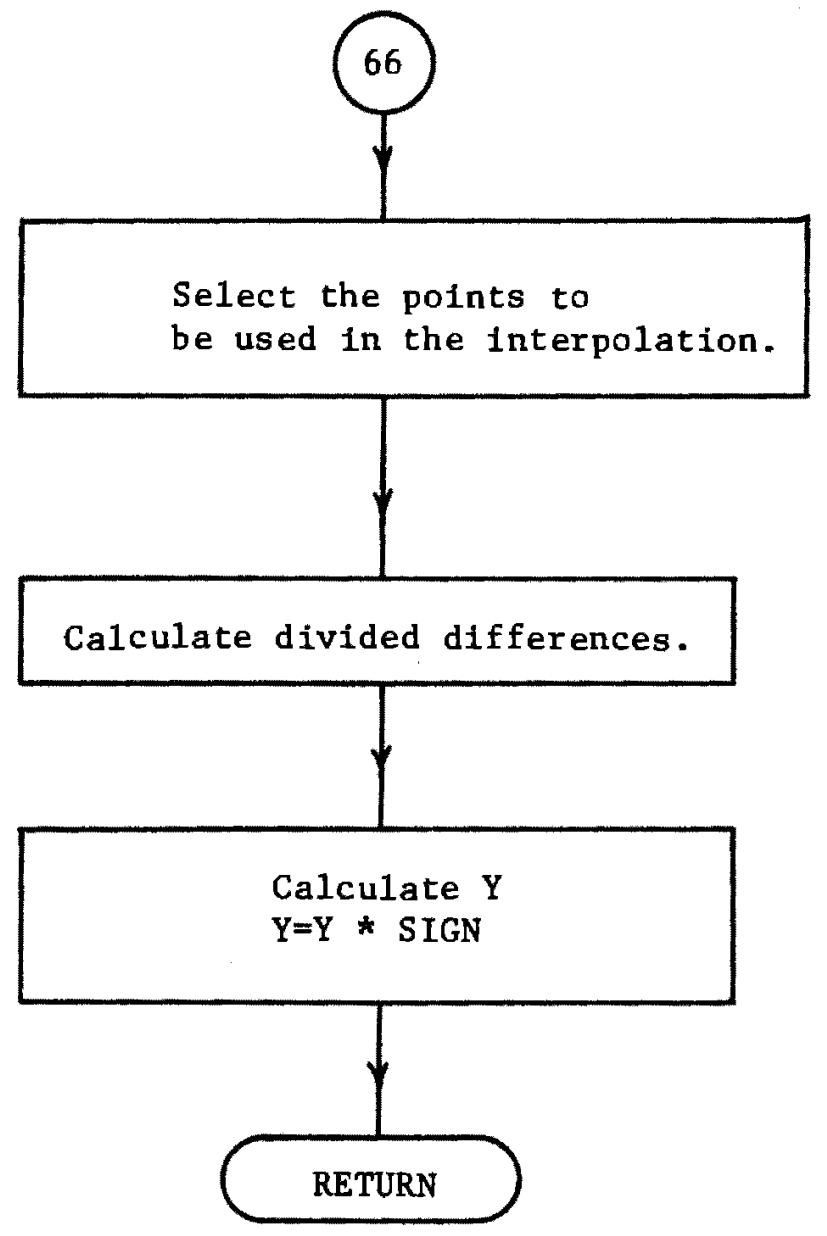




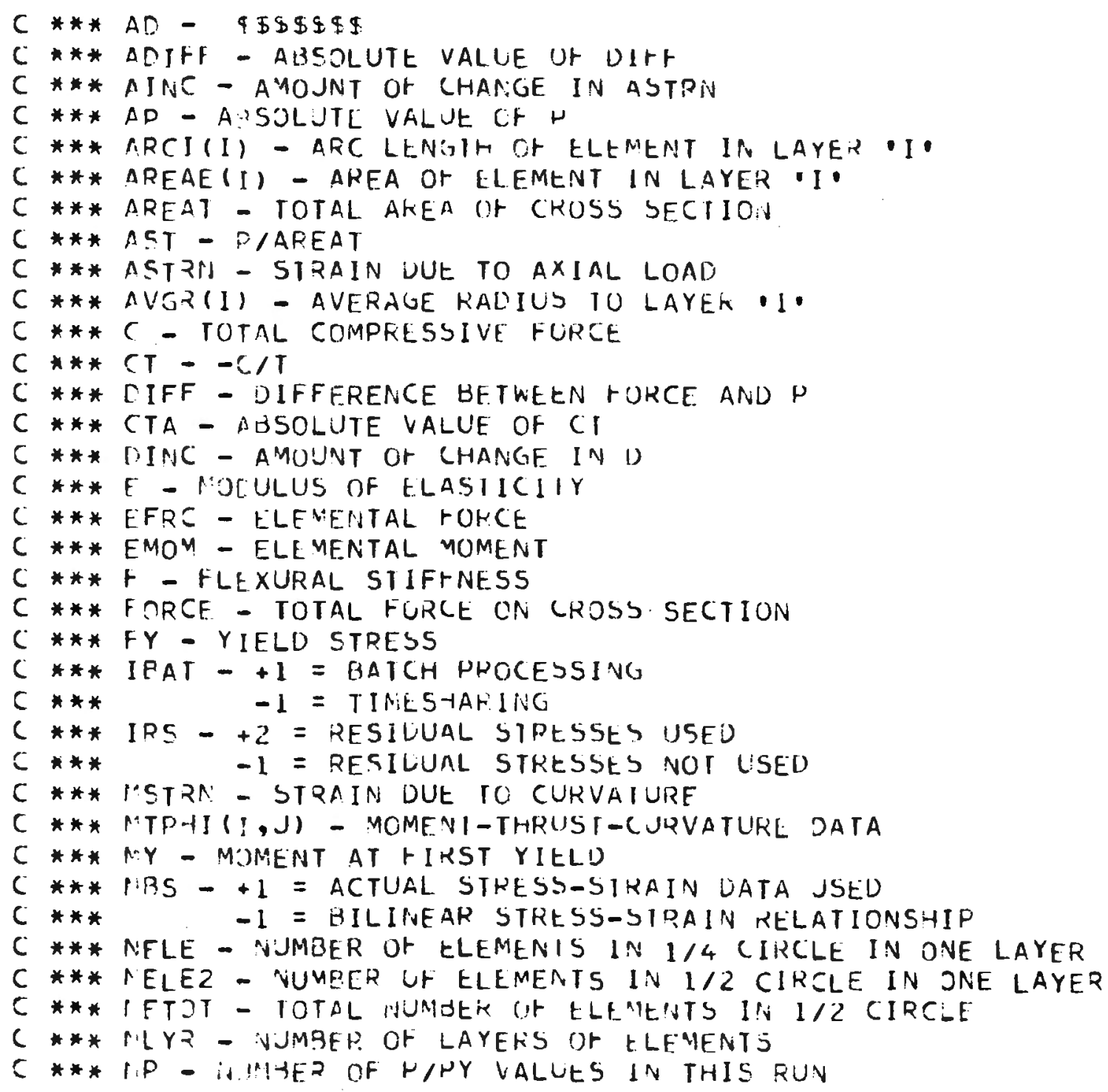




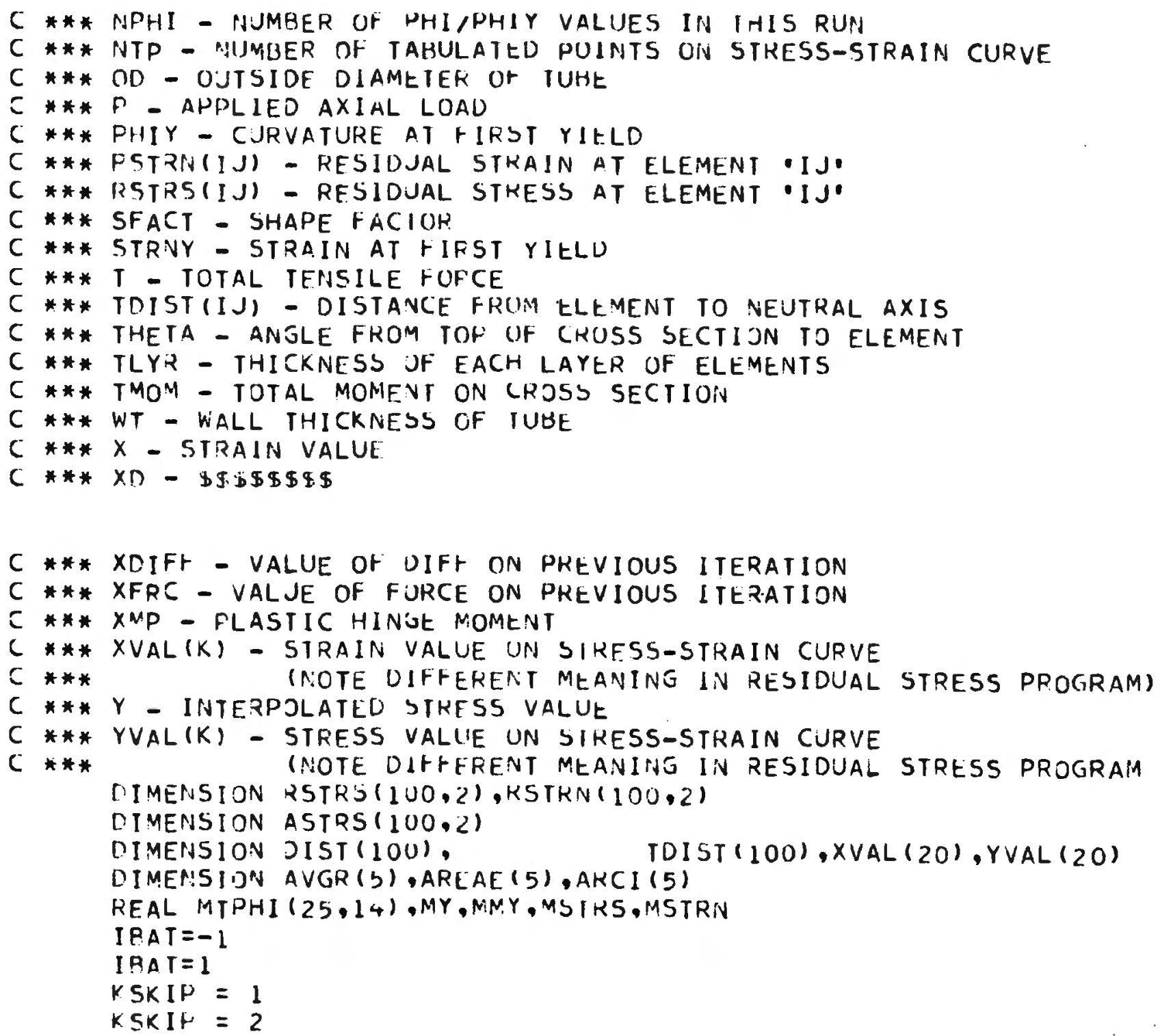




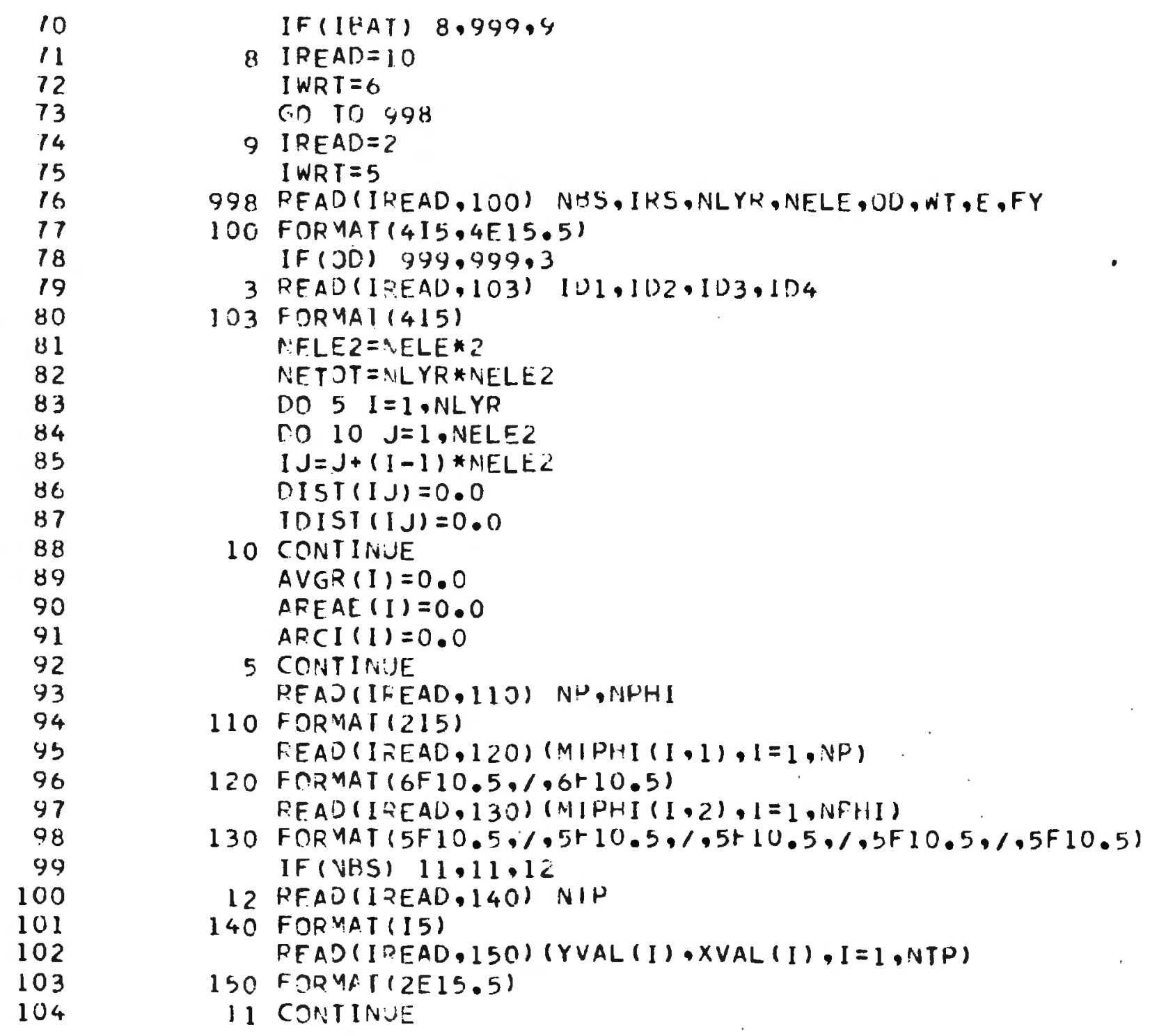




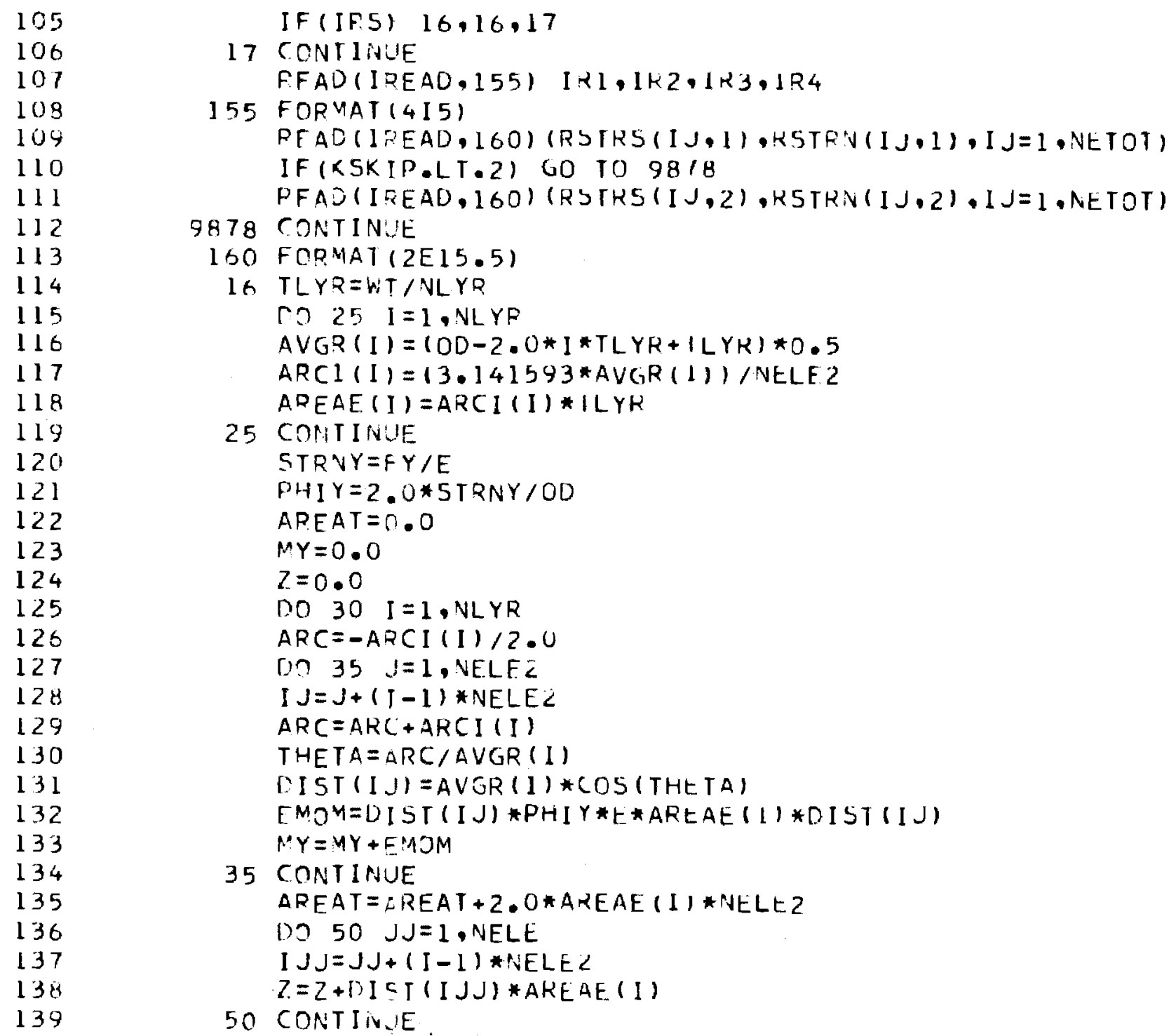


140

141

142

143

144

145

146

147

148

149

150

151

152

153

154

155

156

157
158
159
160
161
162
163
164
165
166
167
168
169
110
171
172
173
30 CONTINUE

$P Y=A R E A T * F Y$

$A: Y=M Y * Z .0$

$Z=Z * 4 \cdot 6$

$F=E *(M Y * 30) /(2.0 * Y Y)$

IF (NI'S) $18,18,19$

$18 X M P=F Y * Z$

GO TC 7

$19 X M P=Y V A L(N T P) * Z$

7 SFACT $=X M P / M Y$

WR ITE ( IWRT , 190)

190 FOR MAT $(1 H 1, / / / / / /, 41 H$ DEPT. UF ENGIIIEERING AND APPLIED SCIENCE,$/$, $+26 H$ POPTLAND STATE UNIVERSITY, $1 /$

$+45 H$ STRUCTJRAL TUDE MOMENT-IHRUST-CURVATURE DATA I

V:RITE (INRT, 195 I IUI,IU2, 103,104

195 FORMAT $(/, 6 H$ DATE $=, 12,1 \mathrm{H} /, 12,1 \mathrm{H} /, 12, /, 6 \mathrm{H}$ TIME $=, 15)$

WRITE(INRT,205) NELF,NLYR

205 FORMAT ( /,6H NELE $=, 13, /, 6 H$ NLYR=, I 2$)$

WRITE (TWRT,200) OU,WT,E, FY

WR ITE (INRT,210) PY,MY,PHIY, , SFACT

2OR FOR MATI/. $25 \mathrm{H}$ OUTSIDE UIAMEIER

$+$

$25 H$ WALL THICKNESS

$25 \mathrm{H}$ MUDULUS UT ELASTICITY

25H YIELU STRESS

$+$

210 FORMAT1. 24 HAXIAL LOAU (PY)

$+\quad 25 \mathrm{H}$ MOMiENT (MY)

+ 25H CURVATLRE (HHIY)

$+\quad 25 H$ FLEXURAL SIIHF NESS

$25 \mathrm{H}$ SHAHE FACIOR

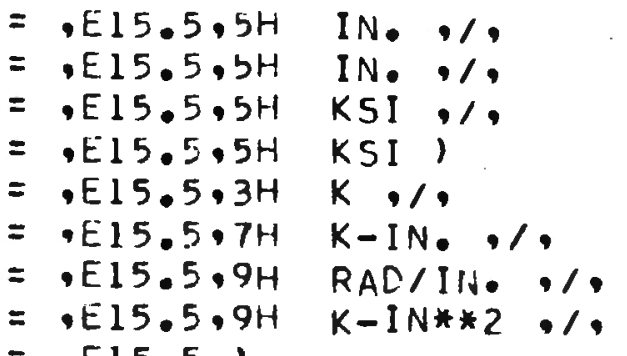

IF (NES) $38,38 \cdot 39$

39 VIRITE INRT,220)

220 FOR MAT $1 / 1,25 H$ STRESS-5TRAI CURVE DAIA, $1 /$,

$+4 x .23 H$ STRESS

$+5 \times, 23 H$ (KSI)

STRAIN, /,

$\left(1 N / I_{N}\right)$ ) 


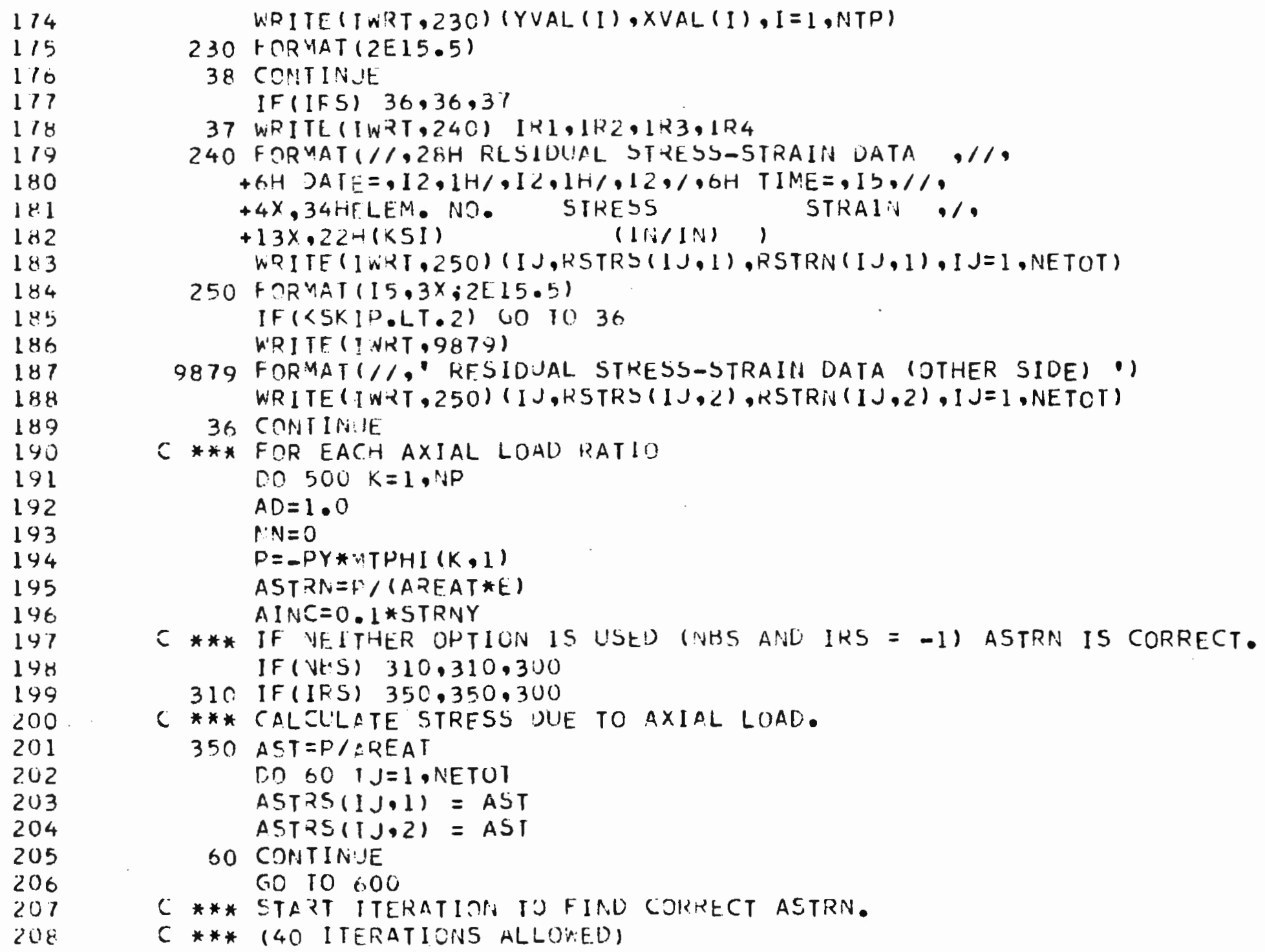


$300 \quad N M=N N+1$

IFINN.ST.40) GO TO 996

FORCL $=0.0$

C * FIND T IF STRESS OV EACH ELEMENT AND IHE TOTAL FORCE

C *** FOR THE CURRENT ASTRN VALUE

$C * * *$ IF NBS $=+1$ USE ACIUAL SIRESS-STRAIN DATA

$C * * *$ IF NHS $=-1$ USE BILINEAK SIRESS-STRAIN RELATIONSHIP IF (NES) $21,21 \cdot 22$

22. CONTINUE.

DC $70 \quad 1 \mathrm{~J}=1$, NETOT

$\mathrm{I}=(\mathrm{I} J+\mathrm{MELE} 2-1) / \mathrm{N}$ ELE 2

[0 70 KKK $=1$, KSKIP

$X=A S T R N+R S T K N(1 J, K K K)$

CALL INTRP (NTP, XVAL, YVAL, X,Y)

ASTRS $(I J \cdot K K K)=Y-R S T K S(I J \cdot K K K)$

FORCE = FORCE + AREAE (I)*ASIKS(IJ,KKK)

70 CONTIHUE

CO TO 76

21 CONTINUE

DO 75 I J $=1$, NETOT

$I=(I J+M E L E 2-1) /$ NELE 2

กO 74 KKK $=1, K S K I P$

$x=A S T R N+R S T K N(I J, K K K)$

IF (STRNY-ABS $(X)) \quad 31,31,32$

31 ASTRS I J,KKK) = SIGH $(F Y, X)-R S T R S(I J, K K K)$

GO TO 74

32 ASTRS IJ,KKK) $=X * E-R S T R S(I J, K K K)$

74 FORCE = FORCE + AKEAE (I)*ASIRS (IJ,KKK)

75 CONTINUE

76 CONTINJE

IF (KSKIP.LT.2) FORCE $=2 . U$. HORCE

DIFF $=F O R C E-P$

$A \cap I F F=\therefore 3 S(D I F F)$

$A \cap=A+S(P)$

(*** IS THE FJRCF Equal TC THE AHHLIED AXIAL LOAD $(600=$ YES, $52=$ NO) 


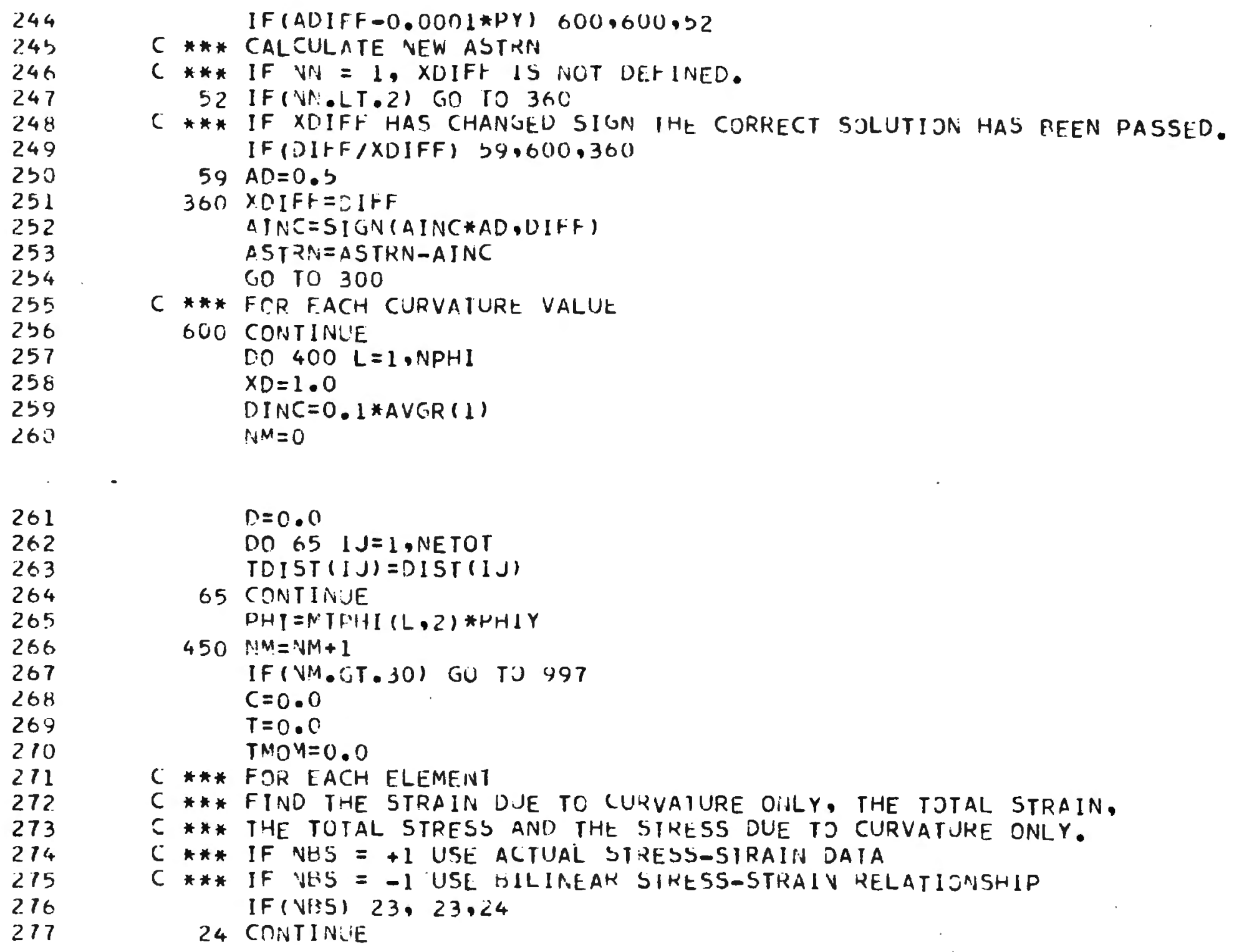




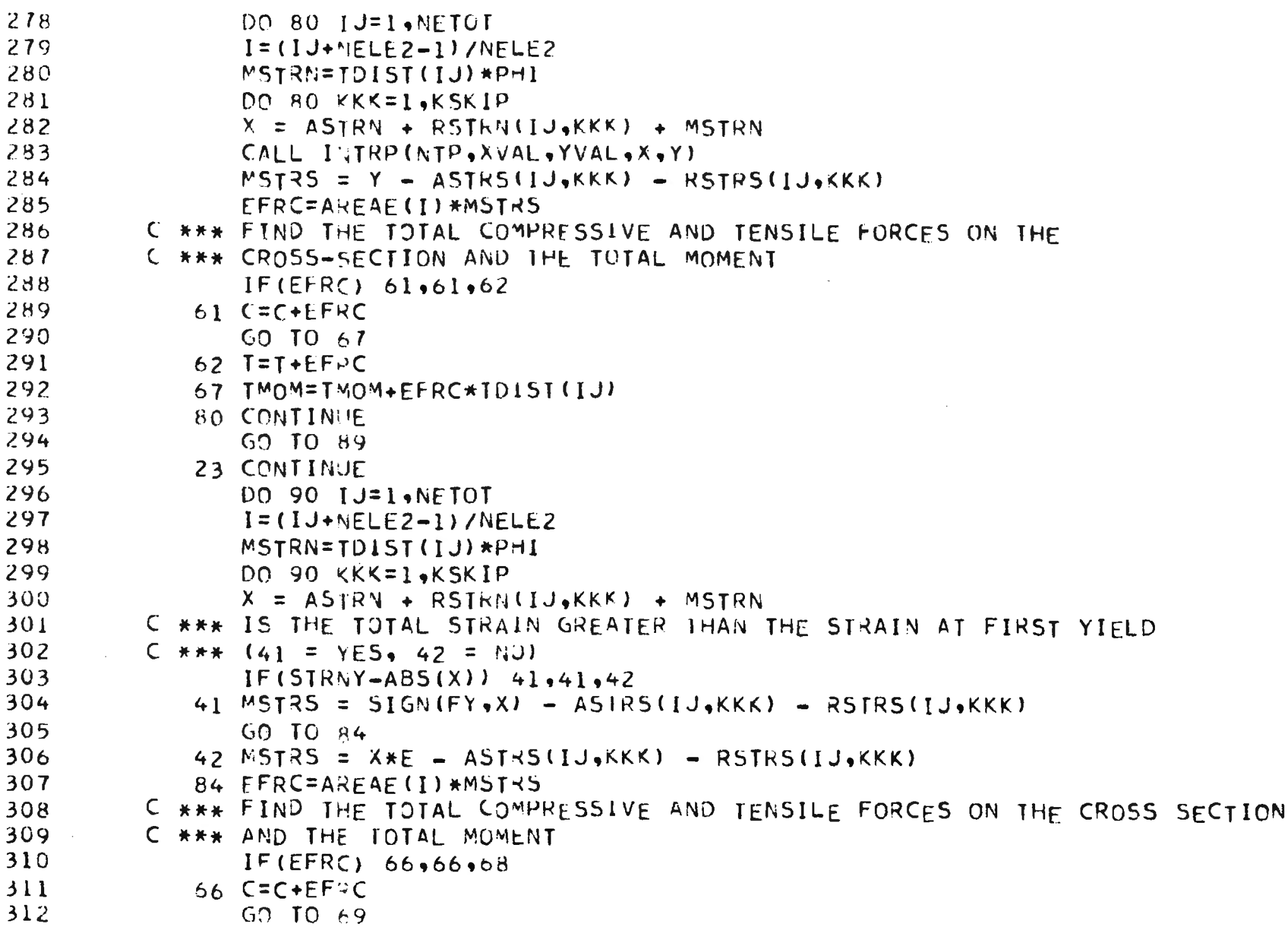




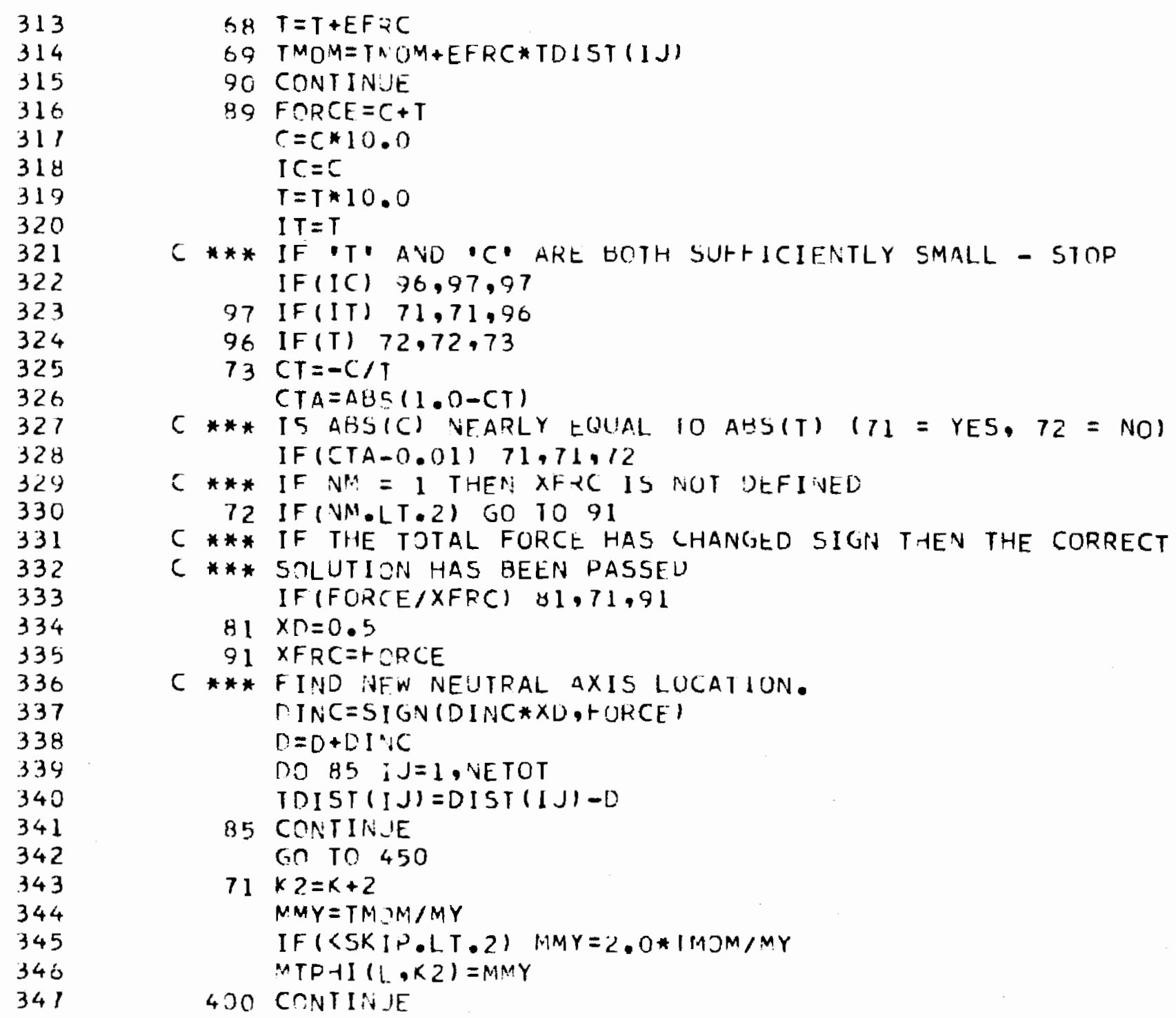




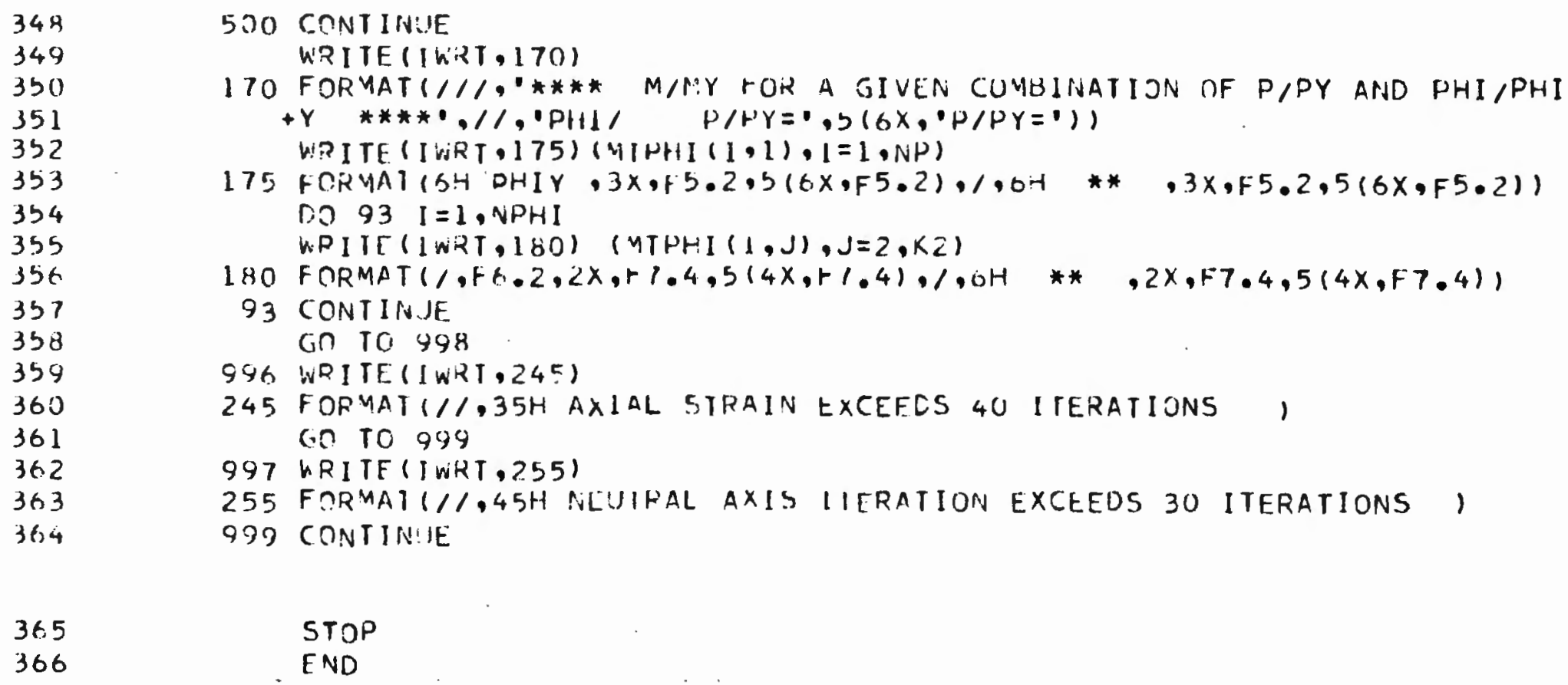


SLBRGUTIVE INTKH(VTH, XVAL, YVAL, X,Y)

$C * * *$ (IVEN a STRAIN VALUE $(X)$ r INU THE CORRESPONDING STRESS VALUE $(Y)$

$C * * *$ IISIVG \& SESDND URJER DIVIDEO DIFFERENCE INTERPOLATION

$C * * *$ IT IS ASSUN.ED THAI $(0,0)$ IS IHE FIRST PJINT ON THE CURVE AND

C *** THAT THE PROPERIIES IN IENSIUN ANO COMPRESSIJN ARE IDENTICAL LIMENSION XVAL (20), YVAL $(20)$ IF $(X) \quad 6,1,62,63$

$62 Y=0 . C$ (n) 10994

$61 \operatorname{SrN}=-1.0$

$x=-x$

$\begin{array}{llll}10 & 10 & 10\end{array}$

$6356 \mathrm{~N}=1 \cdot 3$

70 CONTINJE

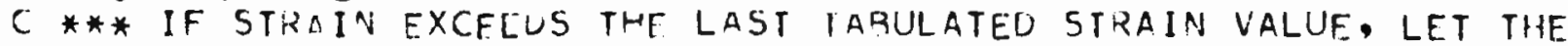

$C$ *** STRESS EOUAL THL LAST TABJLAIED STRESS VALUE. I $F(X-X V A L(N T P)) \quad 66,67,6$ (

$67 Y=Y V A L(N T P) * S G N$ GO TO $¥ 99$

66 CONTINUE

C *** FIND THE INTERVAL CONTALNIPH *X* U) $10 \mathrm{~J}=$ ? NTP IF $(X V A L(J)-X) \quad 21,23,23$

21 CONTIHUE

10 CORTITIVUE

23 IT $A B=J-1$ $I T A B I=1 T A B+1$

C*** HAKE AOJUSTMENTS IF P'ECESSARY. IF $(X-0.5 * X V A L(I T A D)-0.5 * X V A L(I T A B I)) 31,32,32$

31 ITAB $=1 T A B-1$

32 CONTINSE IF (ITA3) $42,42,43$

4? ITAU $=1 T A 3+1$ $C$ C TC $\rightarrow 5$

$431 X=1 T A \div+2$ 


\begin{tabular}{|c|c|c|}
\hline $\begin{array}{l}36 \\
37\end{array}$ & 46 & $\begin{array}{l}\text { IF }(N T P-I X) \quad 46,45,45 \\
\text { IX }=N 7 P-I X\end{array}$ \\
\hline $\begin{array}{l}38 \\
39\end{array}$ & 45 & $\begin{array}{l}\text { ITABI ITAB+IX } \\
\text { CONTINLE }\end{array}$ \\
\hline 40 & $C * * *$ & CALCULATE DIVIDED DIFFERENCES. \\
\hline 41 & & ITASI $=1 \Gamma A B+1$ \\
\hline 42 & & $1 T A 32=1 T A B+2$ \\
\hline 4.3 & & $D D_{11}=(Y \vee A L(I T A B 1)-Y V A L(I T A B))$ \\
\hline 44 & & $+/(X \vee A L(I T A B I)-X \vee A L(I T A B))$ \\
\hline 45 & & $D \cap_{12}=(Y V A L(I T A B 2)-Y V A L(1 T A B 1))$ \\
\hline $\begin{array}{l}46 \\
41\end{array}$ & & 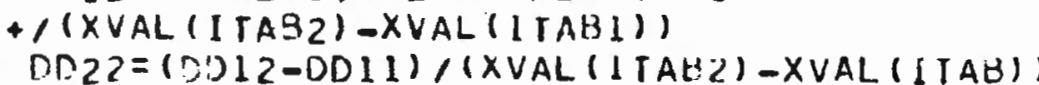 \\
\hline 48 & $C * * *$ & FIND $Y \cdot$. \\
\hline 49 & & $Y=Y V A L([T A B)+(X-X V A L(I T A B)) * U D 11$ \\
\hline 30 & & $++(X-X \vee A L(I T A B)) *(X-X \vee A L(I T A H I)) * D D 22$ \\
\hline 51 & & $Y=Y^{*} S G^{*} !$ \\
\hline 32 & 990 & PET JRIN \\
\hline 53 & & END \\
\hline
\end{tabular}


RESIDUAL STRESS PROGRAM

DATA INPUT

Note: Numbers at left indicate card columns,

A. Cross Section and Materlal Properties

FORMAT $(2 \mathrm{I} 5,4 \mathrm{E} 15.5)$

1-5 Number of layers of elements.

(Max. = 5)

6-10 number of elements in $1 / 4$ circle of one layer.

(The product of the above two numbers must not exceed 50.)

11-25 Outs1de diameter (1n.)

26-40 Wall thickness (1n.)

41-55 Modulus of elast1c1ty (ks1).

56-70 Yleld stress (ks1).

B. Date and Time of Run

FORMAT (4I5)

1-5 Month

6-10 Day

11-15 Year

16-20 Time (001-2400)

C. Inttial Stress Values

FORMAT (3E10.3)

1-10 T1 - Tens1le stress value (ks1).

11-20 C - Compresstve stress value (ksi).

21-30 T2 - Tens1le stress value (ks1).

(The program does not allow the restdual stress at any element to exceed the yleld stress.) 
D. Stress-Strain Option

FORMAT (2I5)

1-5 Number of tabulated points on stress-strain curve. (Enter 0 if prevlous response was -1)

Note: Data 18 now complete if the actual stress-atrain data is not used.

E. Stress-Strain Data

For each tabulated point on the stress-gtrain curve:

FORMAT (2E 15.5)

1-15 Stress value (ks1).

16-30 Strain value 
RESIDUAL STRESS PROGRAM

FLOW DIAGRAM
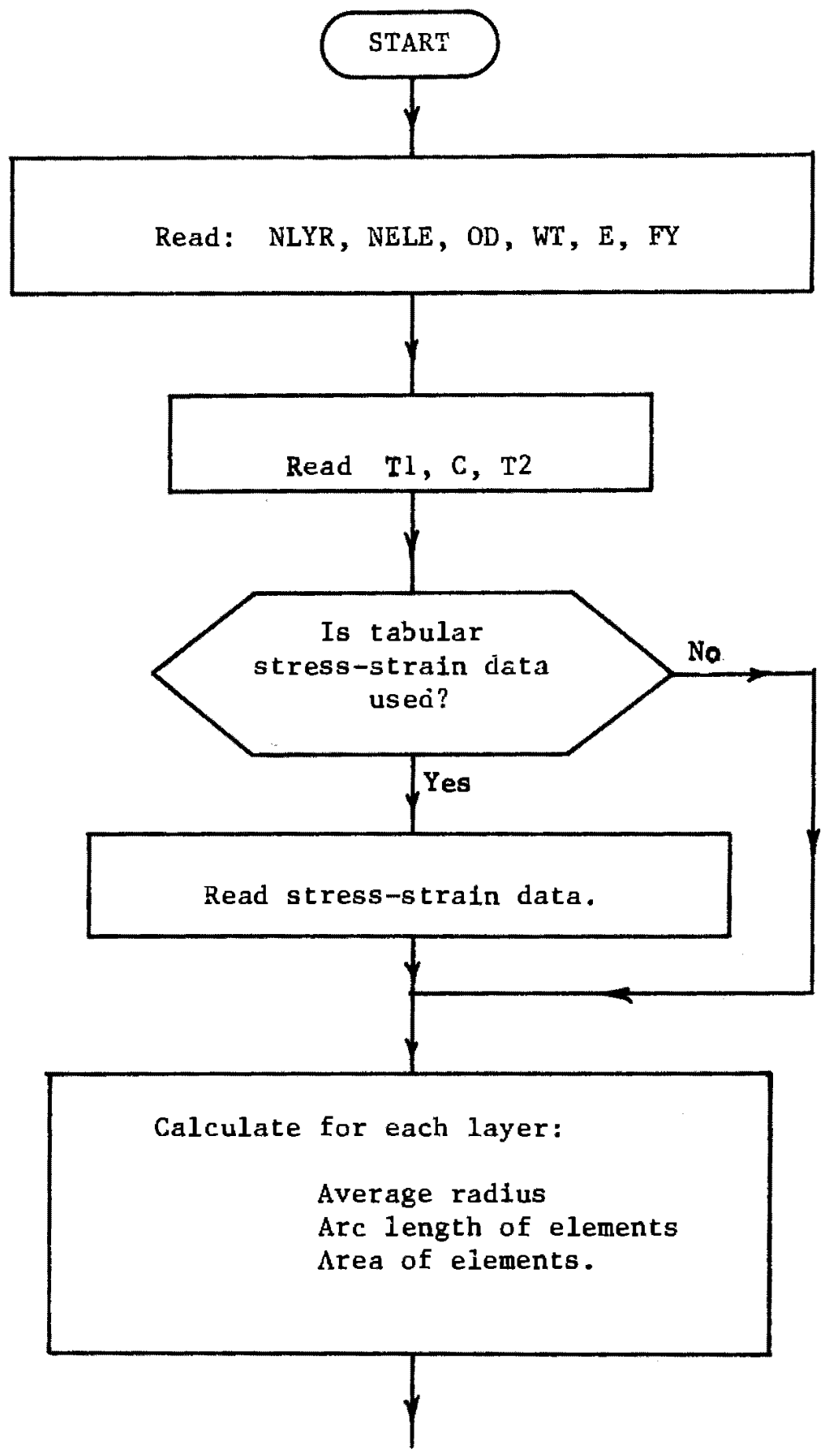


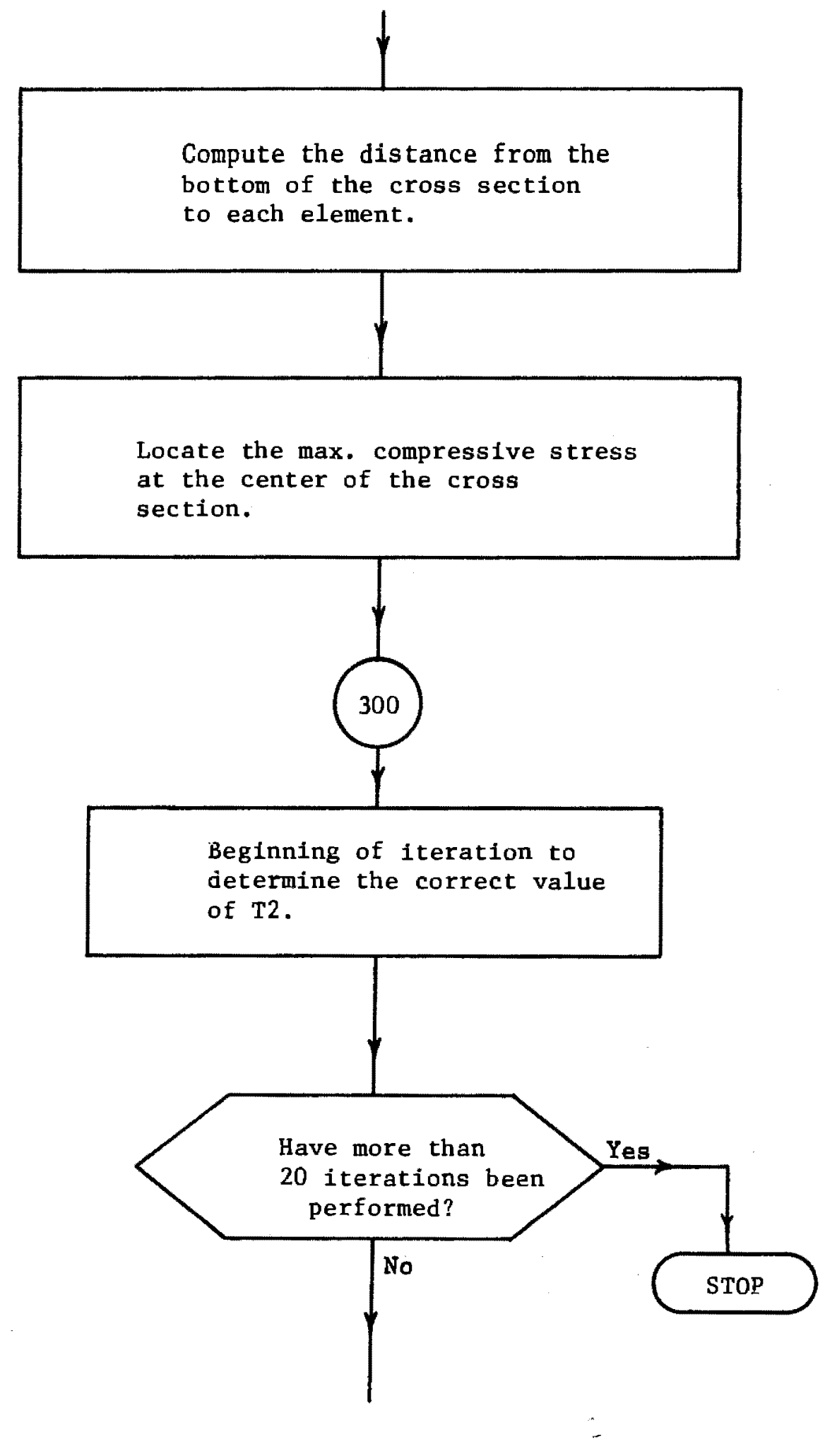




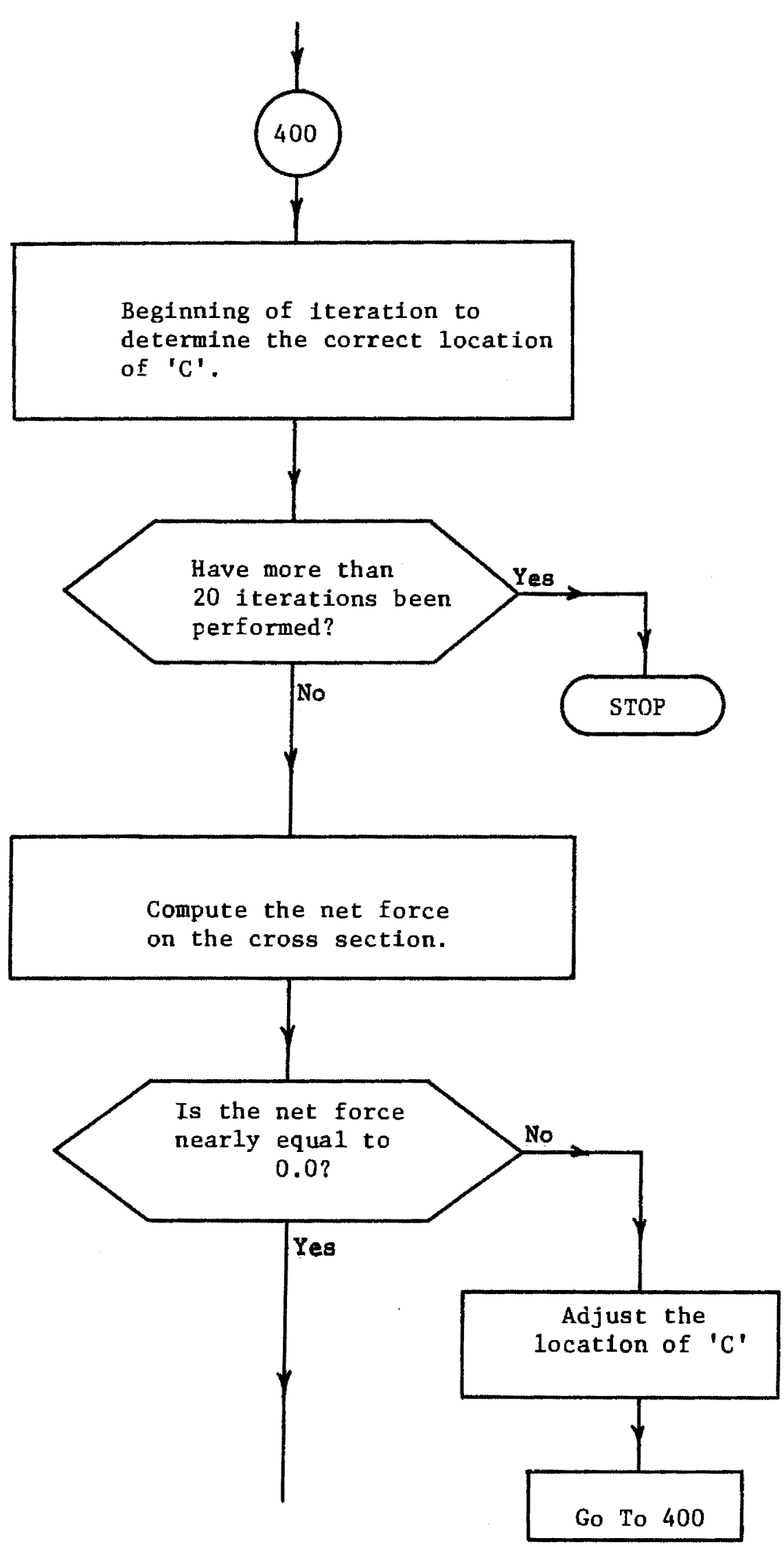




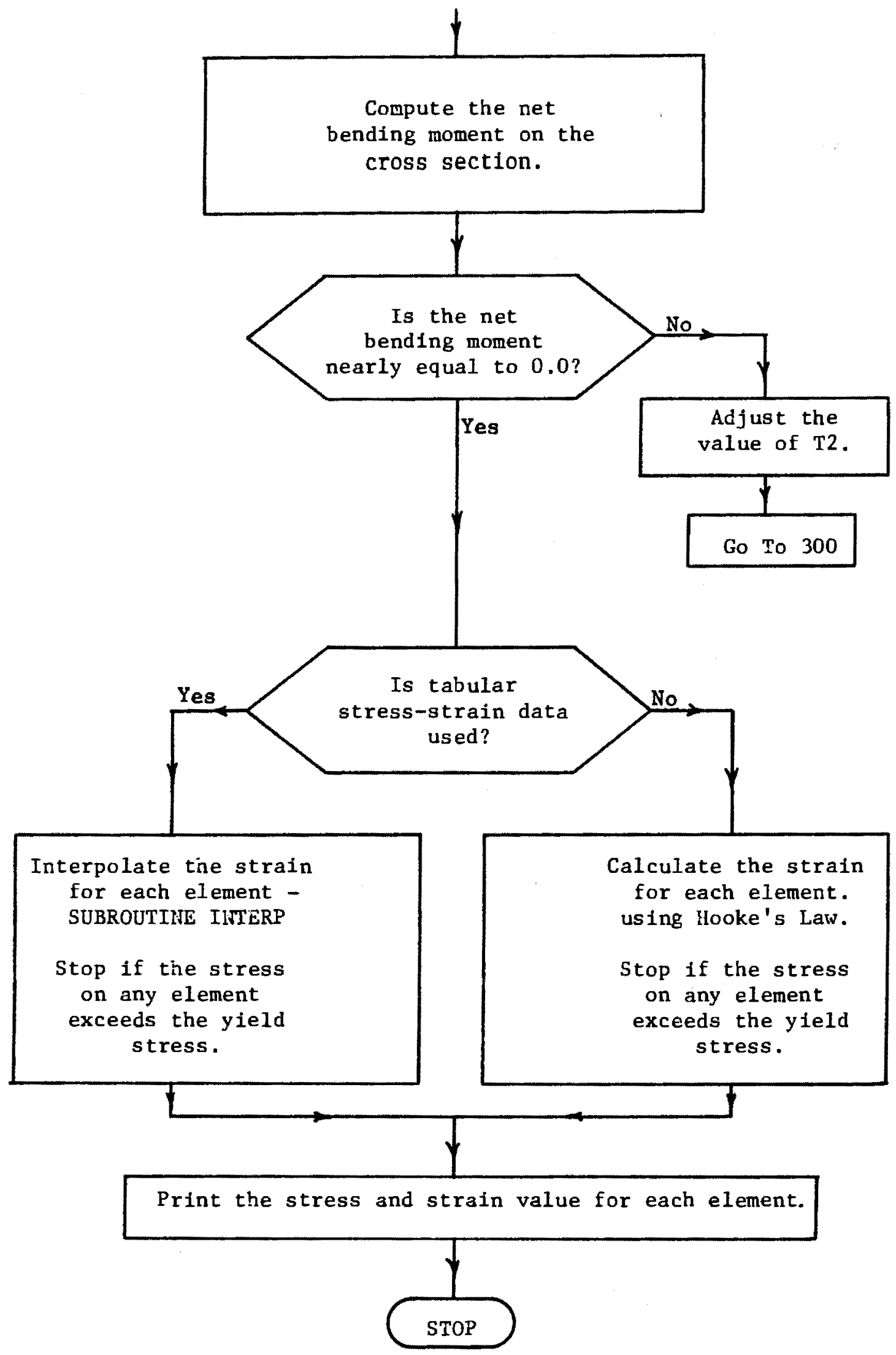




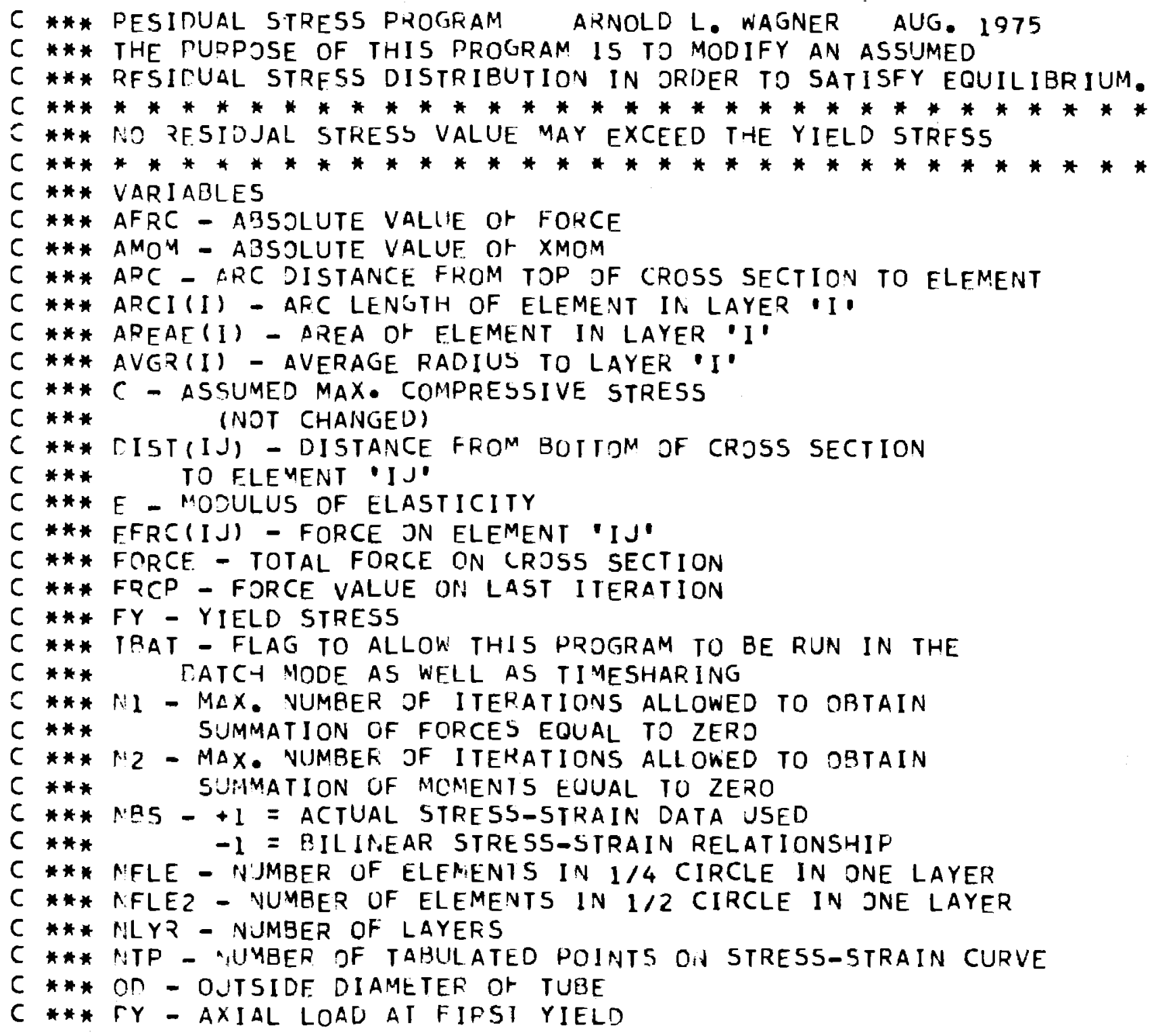




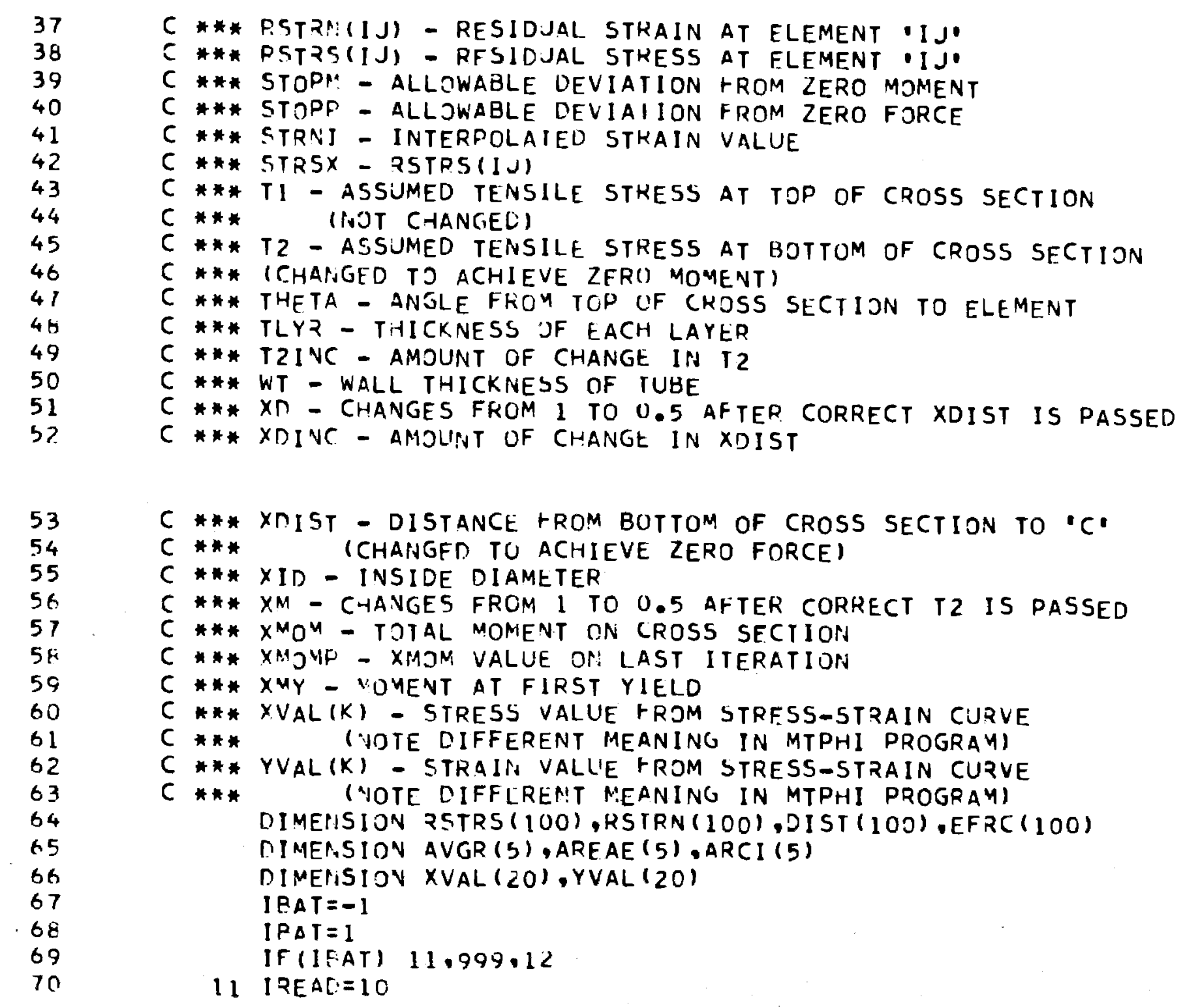




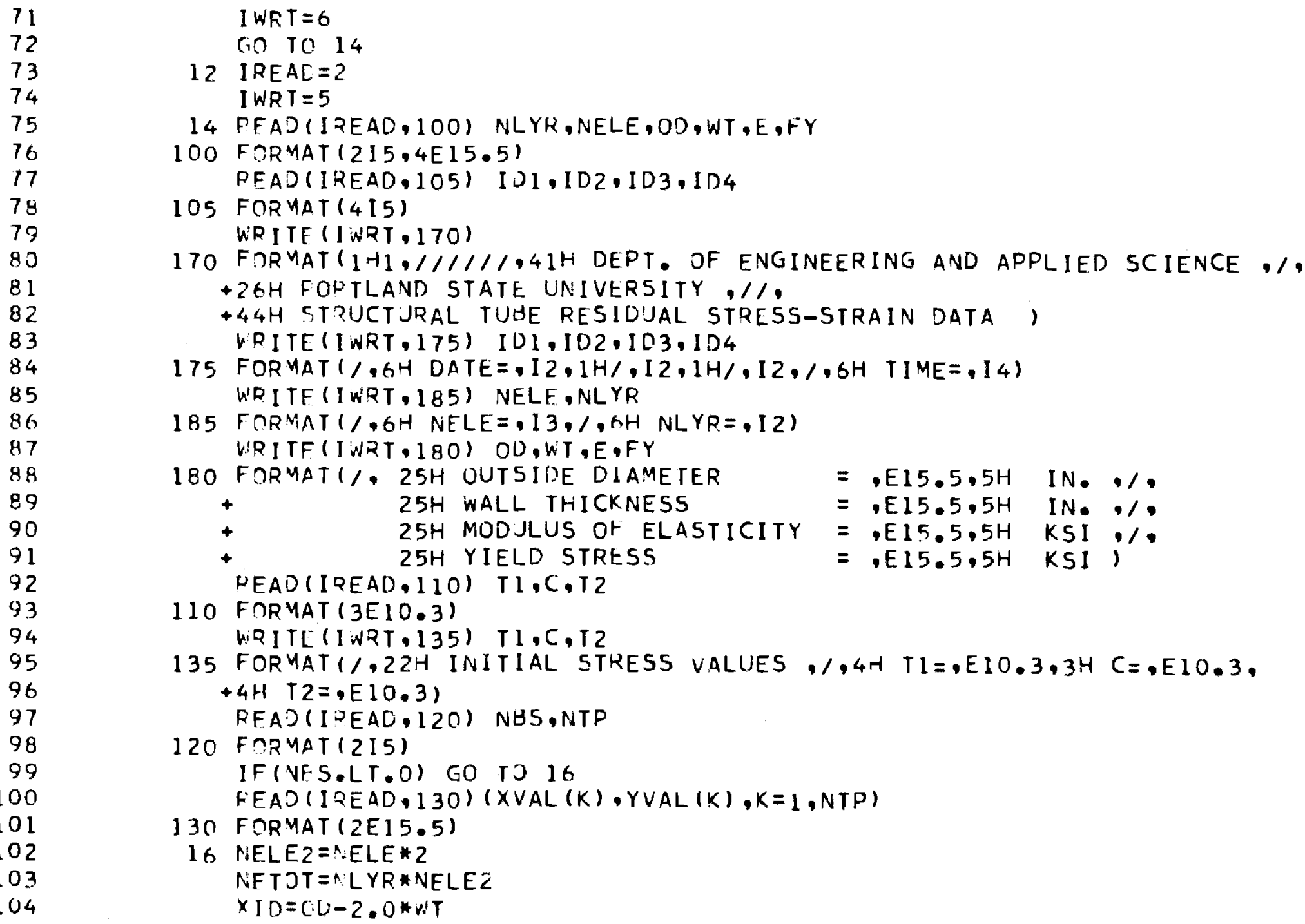




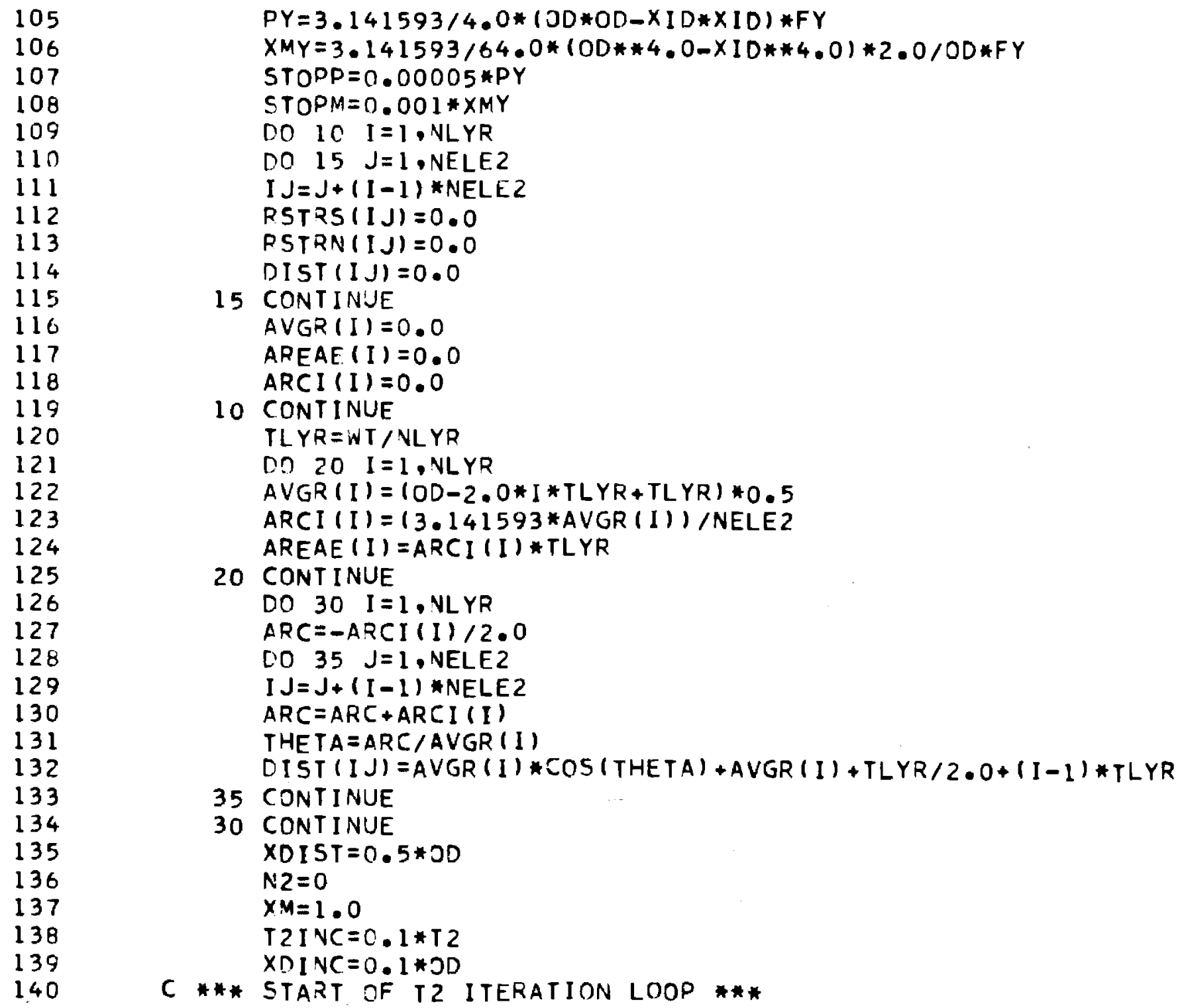




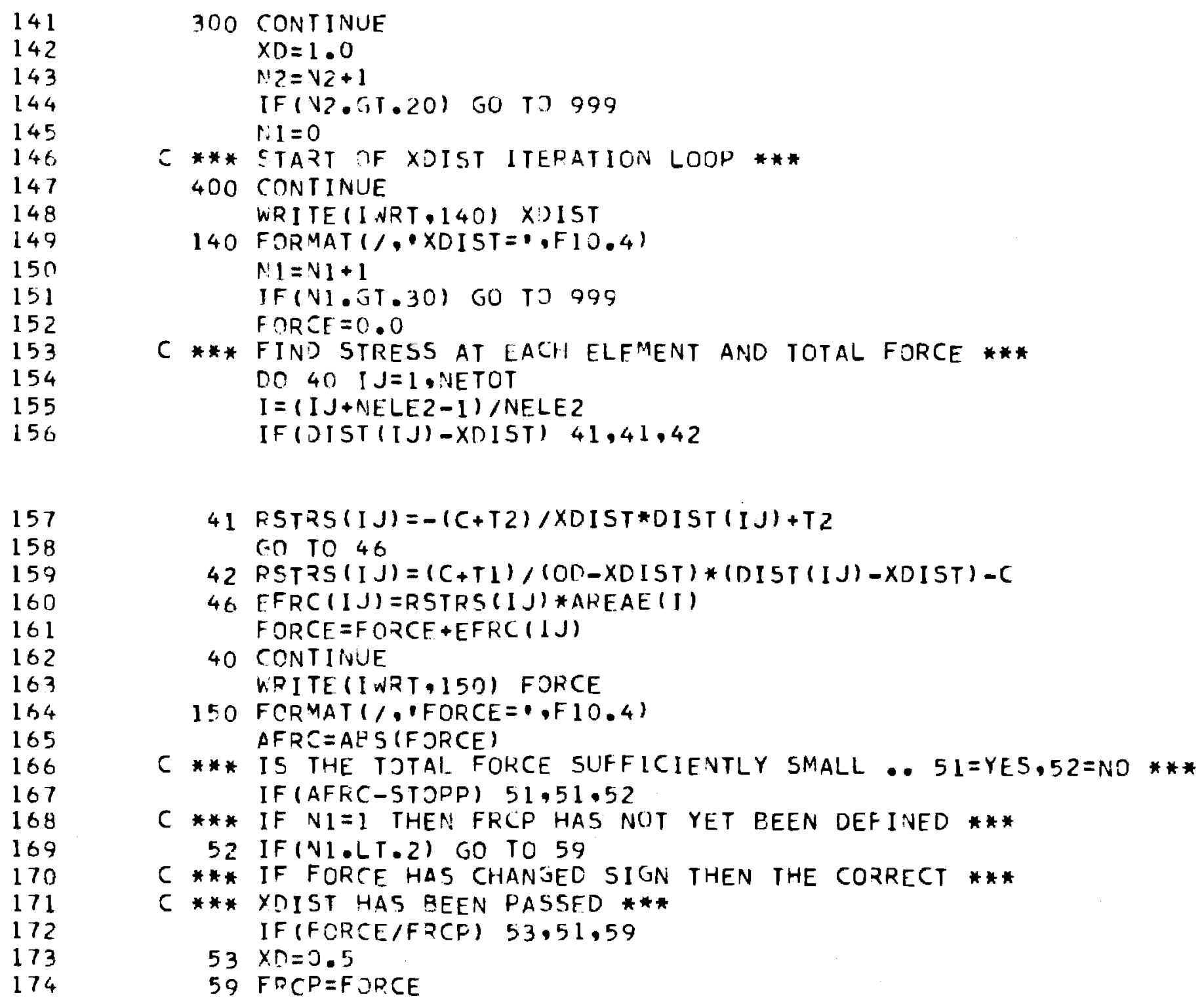




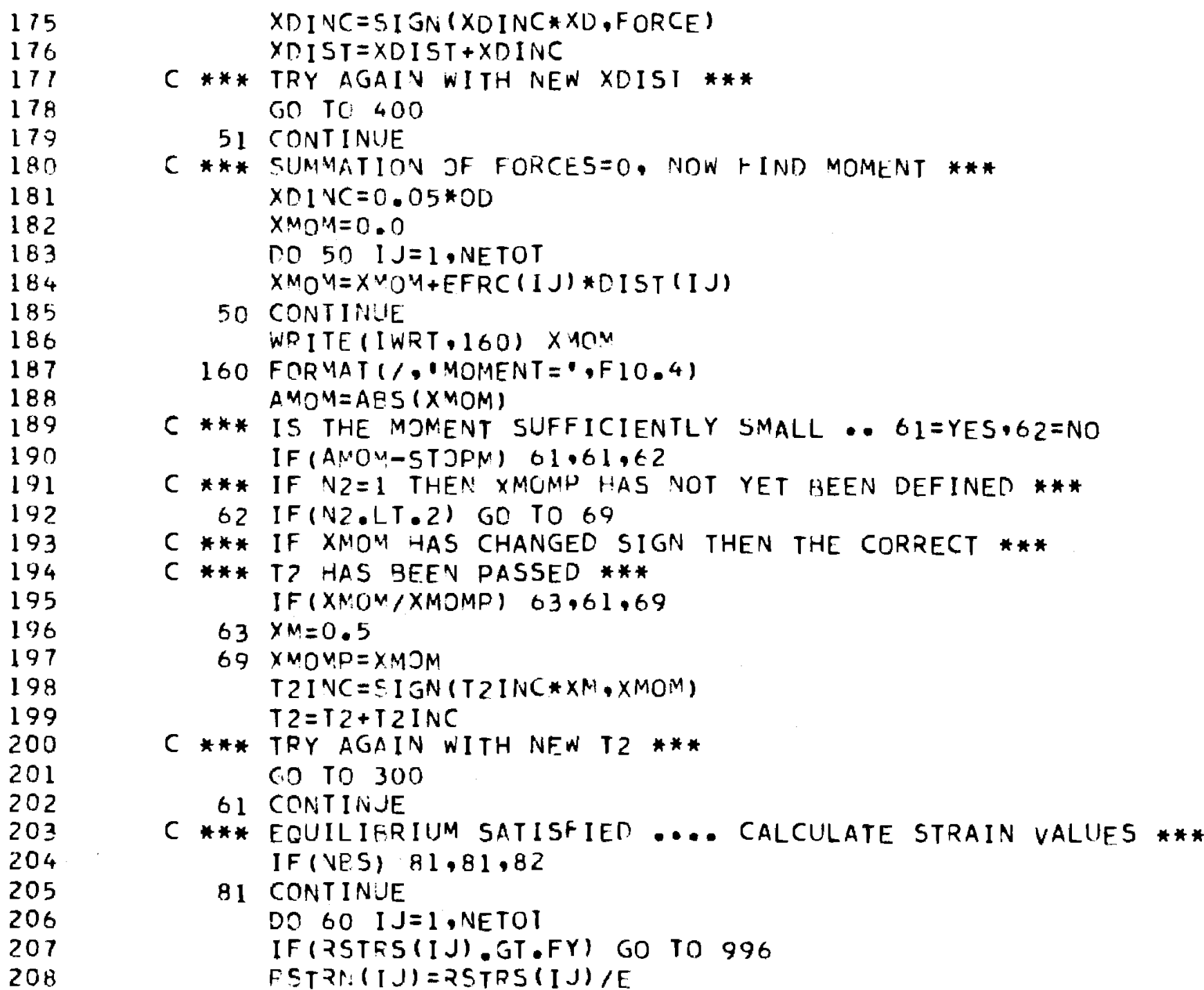


60 CONTINUE 60 TO 86

82 CONTINUE

TO 70 I J $=1$, NETOT

JF(RSTRS(IJ).GT.FY) GO TO 996

$x=R S T R S(I J)$

CALL INTRP (NTP,XVAL, YVAL,X,Y)

FSTRN I J) $=Y$

70 CONTINUE

86 WDITE (INRT,200)

200 FORMAT $1 / 1,28 H$ RESIDUAL STRESS-STRAIN DATA $\%$

$+35 H$ ELEM. NO.

STRESS

STRAIN )

WRITE (IWRT, 210$)(I J, R S T R S(I J), R S T R N(I J), I J=1, N E T O T)$

210 FORMAT(" , I5.3X,2E15.5)

GO TO 999

996 WRITE(INRT, 250$)$

250 FORMAT $(1,43$ H RESIJUAL STRESS VALUE EXCEEDS YIELD STRESS)

999 CONTINUE

STOP

END 


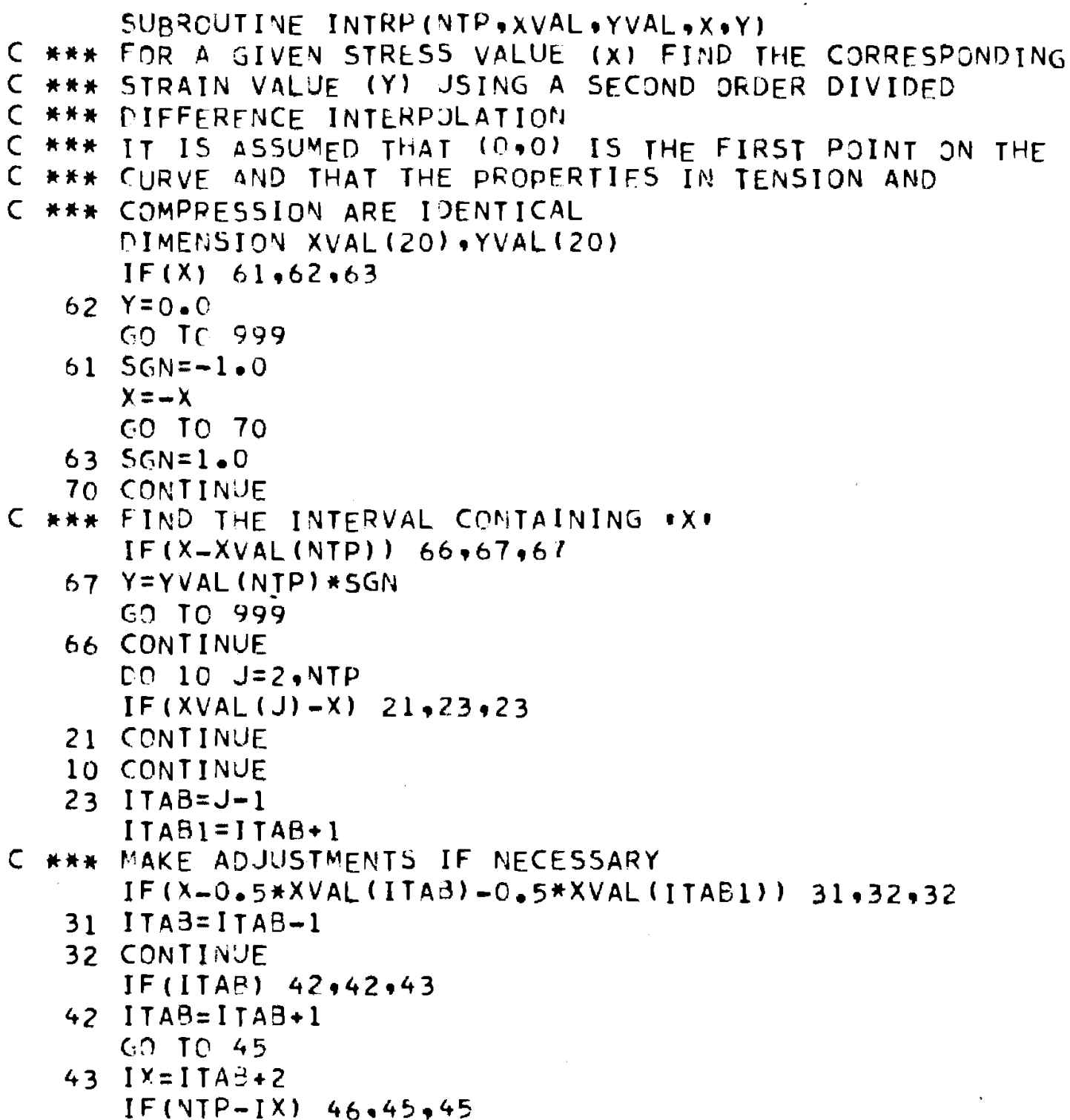


$46 \quad I X=N T P-I X$

I TAB $=$ I TAB + IX

45 CONTINUE

C *** Calcllate divided differencies

ITABI $=$ I TAB + I

$I T A B 2=I T A B+2$

DO $11=(Y V A L(I T \Delta B I)-Y V A L(I T A B))$

$+/(X V A L(I T A B I)-X V A L(I T A B))$

CDI2 = (YVAL (ITAEZ) -YVAL (ITABI))

+ ( (XVAL (ITAE2) -XVAL (ITABI)

Dr22 $=(D D 12-D D 11) /(X V A L(1 T A B 2)-X V A L(I T A B))$

C.*** FIND 'Y'

$Y=Y \vee A L(I T A B)+(X-X \vee A L(I T A B)) * D D 11$

$++(X-X \vee A L(I T A B)) *(X-X \vee A L(I T A B 1)) * D D 22$

$Y=Y * S G N$

999 PETIRN

FND 
Arnold L. Wagner was born on March 9,1951 in Portland, Oregon, the son of Mr. and Mrs. Walter Wagner.

He received his primary education at Mt. Pleasant Grade School and Thora B. Gardiner Junior High School in Oregon Clty, Oregon. He graduated from Oregon City Sentor High School in June 1969.

In September 1969 he entered Portland State University and graduated in June 1973 with a B.S. Degree in Applied Sclence. In September 1973 he began work towards a Master of Science Degree in Applied Science at Portland State University.

He is a member of the Structural Engineer's Association of Oregon. 